Environmental Security Technology Certification Program and Dredging Operations and Environmental Research Program

\title{
Dredging in Sediments Containing Munitions and Explosives of Concern (MEC)
}

ESTCP Project No. 200321

Timothy Welp, George Follett, Michelle Crull, August 2008 and Cheryl Pollock 


\section{Dredging in Sediments Containing Munitions and Explosives of Concern (MEC)}

ESTCP Project No. 200321
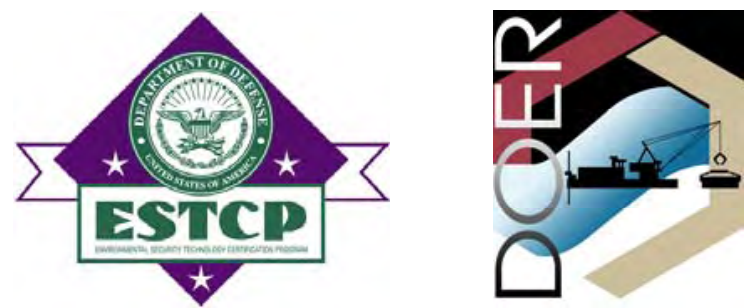

Timothy Welp and Cheryl Pollock

Coastal and Hydraulics Laboratory

U.S. Army Engineer Research and Development Center

3909 Halls Ferry Road

Vicksburg, MS 39180-6199

George Follett

U.S. Army Engineer District, Baltimore

City Crescent Building

10 South Howard Street, Room 11000

Baltimore, MD 21201-2555

Michelle Crull

U.S. Army Engineering Support Center, Huntsville

4820 University Square

Huntsville, AL 35807-4301

Final Report

Approved for public release; distribution is unlimited.

Prepared for Environmental Security Technology Certification Program 901 North Stuart Street, Suite 303

Arlington, VA 22203 


\begin{abstract}
This document provides guidance to personnel (e.g., planners, cost estimators, specification writers, engineers, managers, and dredging contractors) involved in dredging projects with sediment containing Munitions and Explosives of Concern (MEC). The guidance is primarily in the form of compiled information gained from experiences on past dredging projects involving MEC and was compiled from a variety of sources. This report describes the different types of dredges and dredging projects that can encounter MEC, describes how these dredges' operational methodologies can be impacted by MEC, and summarizes past project methodology modifications that have been used to deal with MEC. Technical aspects of past MEC/ dredging projects are presented with regard to engineering controls to mitigate detonation hazards, underwater MEC detection and discrimination technologies, contracting, public awareness, safety requirements, and MEC separation techniques and (where available) subsequent impacts on production rates and costs.
\end{abstract}




\section{Contents}

Figures and Tables...........................................................................................................................

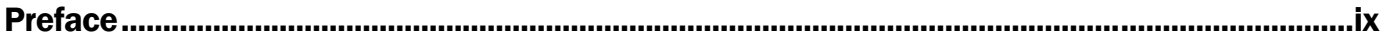

Unit Conversion Factors...........................................................................................................................

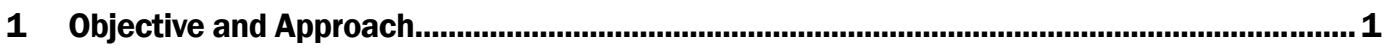

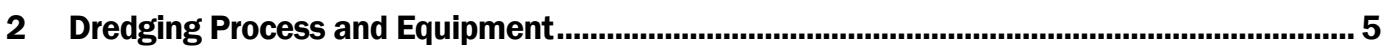

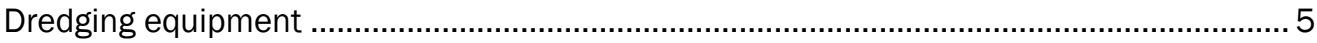

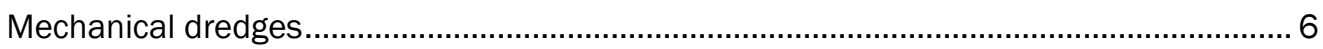

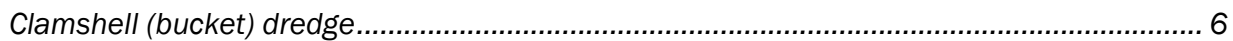

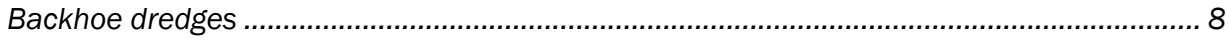

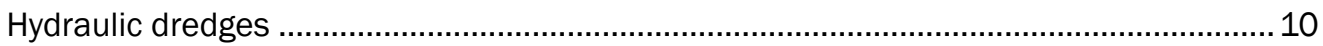

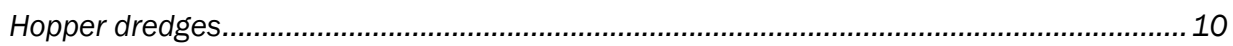

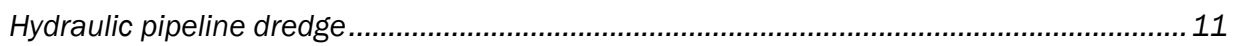

Special purpose dredges ...................................................................................... 14

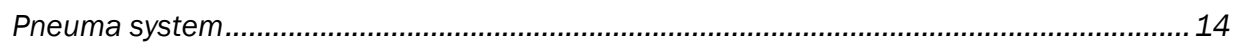

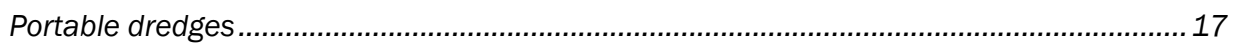

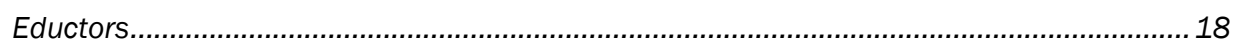

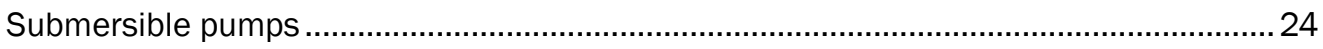

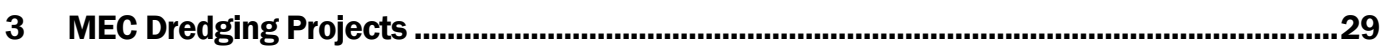

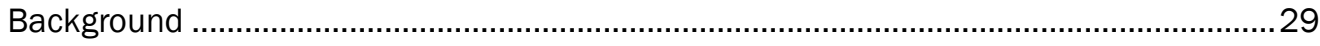

General planning approaches to MEC dredging projects ................................................. 31

What to do if MEC is encountered unexpectedly onboard a dredge..................................... 33

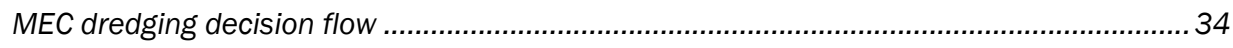

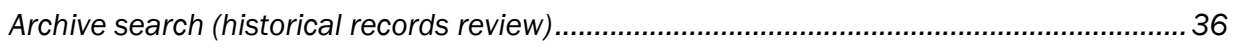

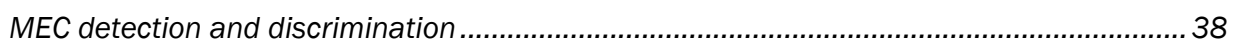

Classification and mapping of underwater UXO (ESTCP MM-9527)..................................... 46

UXO detection and characterization in the marine environment (ESTCP MM-0324) ............ 47

Marine Gradiometer Array (MGA) system .......................................................................... 54

Current ESTCP underwater MEC detection and discrimination technology

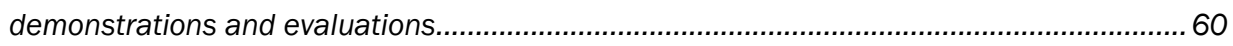

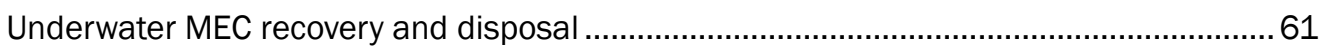

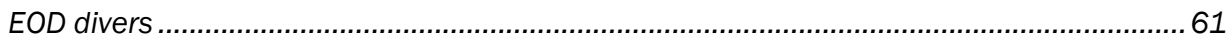

Current ESTCP underwater MEC recovery technology demonstrations and

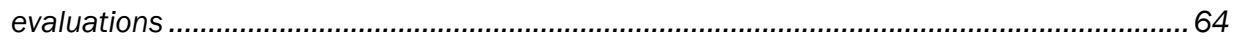

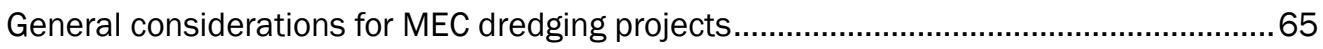

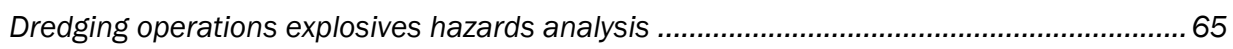

Removal of MEC versus leaving MEC underwater ...............................................................6

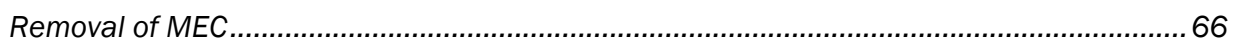

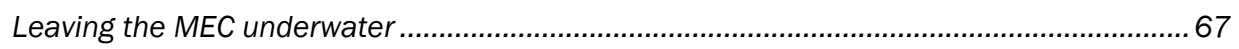




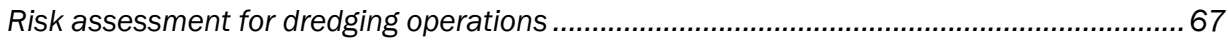

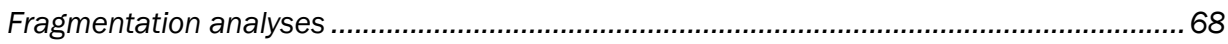

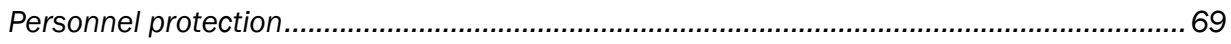

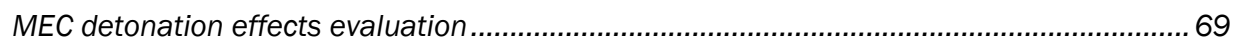

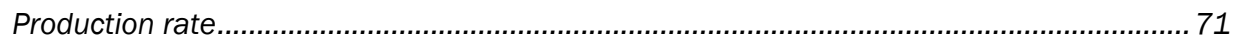

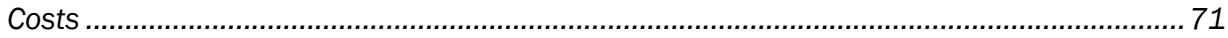

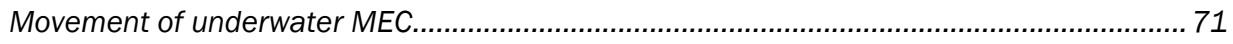

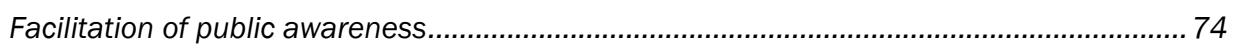

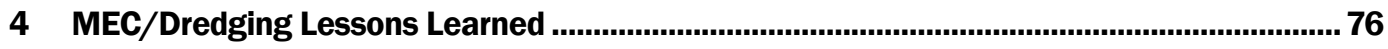

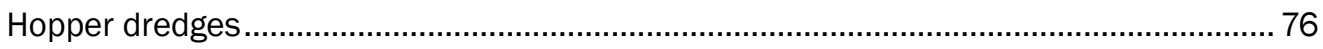

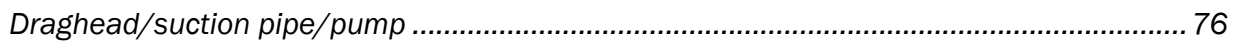

Pump discharge into hopper ...................................................................................... 101

Pumpout to beach ................................................................................................................. 103

Cutterhead dredges ................................................................................................ 114

Cutterhead/suction mouth/suction pipe side of pump ...................................................118

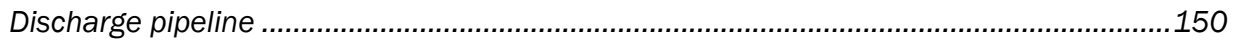

Mechanical dredges............................................................................................ 156

Kokkola Channel Project, Kokkola, Finland ....................................................................156

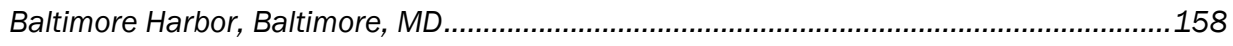

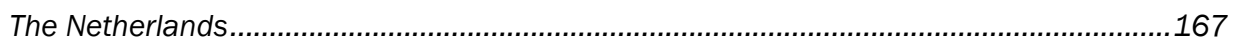

Toussaint River dredging project................................................................................. 171

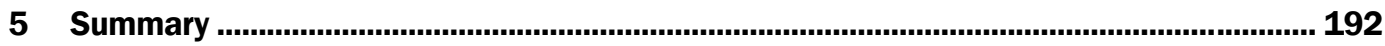

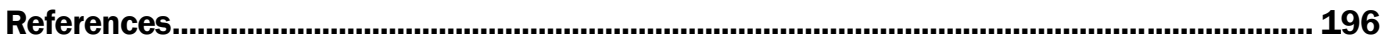

Appendix A: Munitions Response Terminology .......................................................................... 200

Appendix B: MEC/Dredging Project Planning Flow Chart .................................................... 211

Appendix C: Guide for Commercial Maritime Industries..................................................... 215

Appendix D: List of Acronyms............................................................................................. 228

\section{Report Documentation Page}




\section{Figures and Tables}

\section{Figures}

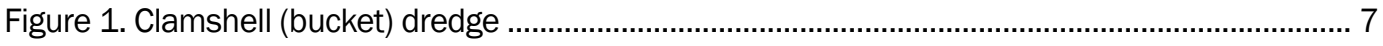

Figure 2. Backhoe dredge New York …………………............................................................. 9

Figure 3. Self-propelled hopper dredge .................................................................................. 10

Figure 4. Hydraulic pipeline cutterhead dredge …………….................................................... 12

Figure 5. Hydraulic pipeline dustpan dredge........................................................................... 13

Figure 6. Stages 1 through 3 of Pneuma Pump System pumping principles ................................. 14

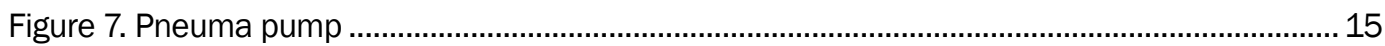

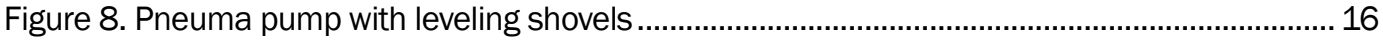

Figure 9. Pneuma pump with inlet pipes ………………….................................................. 16

Figure 10. Eductor (jet pump) hydraulic circuit................................................................................. 19

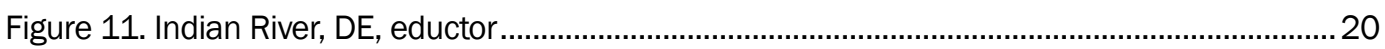

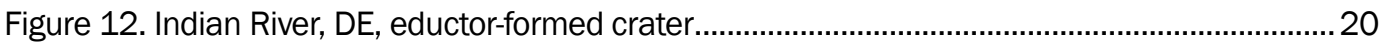

Figure 13. Standard Gravel Company (Genflo) eductor used in MEC trial ....................................... 21

Figure 14. Example $20 \mathrm{~mm}$ drogues.............................................................................................. 22

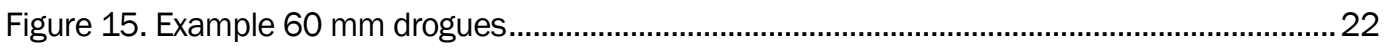

Figure 16. Screening tower with $10 \mathrm{~mm}$ (3/8 in.) apertures at pipeline discharge ......................... 23

Figure 17. Eductor-formed excavation crater ................................................................................23

Figure 18. One of three $20 \mathrm{~mm}$ drogues recovered during eductor experiment.............................. 24

Figure 19. Submersible pump with jetting ring ..........................................................................2

Figure 20. Toyo submersible pump with $250 \mathrm{~mm}$ (10 in.) discharge .............................................2 26

Figure 21. Submersible pump agitator and suction screen............................................................ 27

Figure 22. Submersible pump with MEC-exclusion screen..........................................................2 28

Figure 23. Backhoe-mounted submersible pump with MEC-exclusion screen and

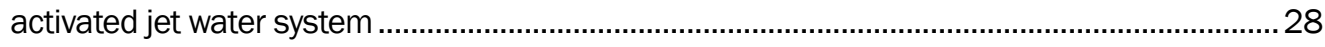

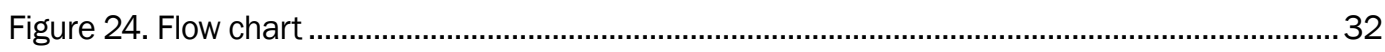

Figure 25. Cesium vapor magnetic gradiometer........................................................................ 45

Figure 26. Assembled marine sensor platform ............................................................................. 49

Figure 27. Schematic drawing of marine sensor platform .............................................................50

Figure 28. Marine sensor platform with hatch covers removed....................................................50

Figure 29. Screen clip showing target analysis windows from MTADS DAS................................... 51

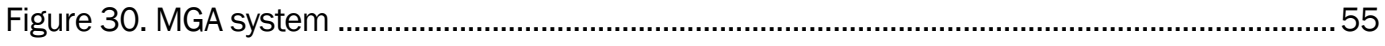

Figure 31. U.S. Navy test bed and calibration targets ............................................................... 57

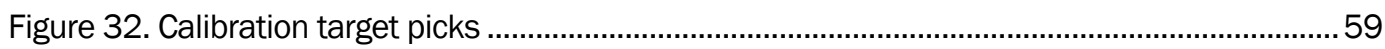

Figure 33. Study SMEC, 16 of 24 SMEC without radio transmitters installed .................................. 73 
Figure 34. Location map of Sea Bright borrow area relative to Fort Hancock ..................................78

Figure 35. MEC exclusion screen installed over draghead ........................................................... 91

Figure 36. General relationship between production and grid size at suction head........................ 97

Figure 37. Draghead screen on hopper dredge R.N. Weeks at Bethany Beach, DE .........................99

Figure 38. Beach screening basket in operation at Bethany Beach, DE......................................106

Figure 39. UXO Specialist inspection of beach screening basket at Bethany Beach, DE............... 107

Figure $40.37 \mathrm{~mm}$ armor piercing projectile captured in beach screening basket at

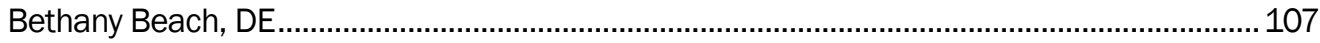

Figure 41. Angled screen plan view.....................................................................................110

Figure 42. Angled screen side view....................................................................................110

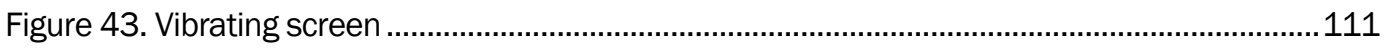

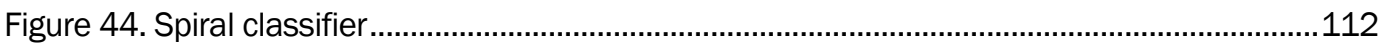

Figure 45. Trommel screen .............................................................................................112

Figure 46. Hydraulic cutterhead pipeline dredge encounter with UXO excerpt from Rock Island District's publication The Safe Channel, September 1939 ..........................................115

Figure 47. Explosion-torn pontoon pipe of dredge Rock Island ...................................................115

Figure 48. Pontoon pipe seam opened by explosion .................................................................116

Figure 49. Sediment and rock excavated by barge-mounted dragline .........................................117

Figure 50. Artillery shell excavated by barge-mounted dragline..................................................... 117

Figure 51. Basket type cutterhead with rods between blades to limit size of opening ...................121

Figure 52. Proposed cutterhead/waterjet configuration ............................................................123

Figure 53. Proposed hydraulic separator configuration .................................................................125

Figure 54. Proposed hydraulic separator screen .......................................................................126

Figure 55. Proposed remote flushing device for hydraulic separator ............................................127

Figure 56. Schematic of Gatling Gun ...................................................................................135

Figure 57. Gatling Gun suction screen .............................................................................136

Figure 58. Gatling Gun suction screen installed on cutterhead .................................................136

Figure 59. Closeup view of Gatling Gun suction screen ...........................................................137

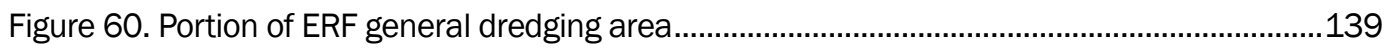

Figure 61. The PITHOG electric remote control lagoon pumper ..................................................140

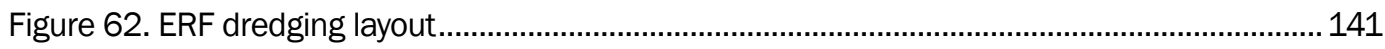

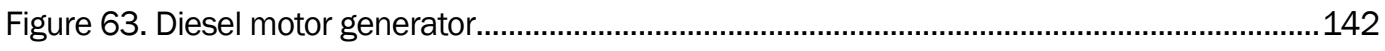

Figure 64. Flexible discharge hose and power cable on mobile spools .......................................143

Figure 65. Remote operator protective enclosure .....................................................................143

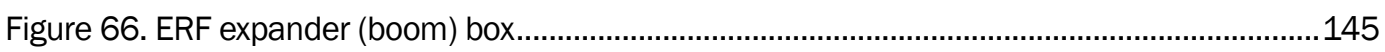

Figure 67. Screen over auger-head suction mouth ......................................................................146

Figure 68. Extracted debris (note aluminum illumination round fragment).................................... 147

Figure 69. Front view of augerhead suction mouth screen/cutter device .....................................148

Figure 70. Side view of augerhead suction mouth screen/cutter device.......................................148

Figure 71. Screen over barge alternative ................................................................................152

Figure 72. Screen operation on a spider barge ........................................................................153 
Figure 73. Discharge basket screens at Buckroe Beach ............................................................154

Figure 74. Two discharge basket screens on a bifurcated discharge line ....................................154

Figure 75. Trap door removed from discharge basket screen.....................................................155

Figure 76. Discharge basket screen ready for next filling cycle ...................................................155

Figure 77. Barge ready to be hydraulically unloaded at $\mathrm{HMI}$...................................................159

Figure 78. Hydraulically unloading dredged material at HMI ...................................................159

Figure 79. Accumulated dredging debris in a debris barge ...........................................................160

Figure 80. A 5 in. brass training round; first DMM discovered in Baltimore Harbor

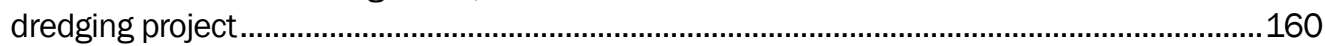

Figure 81. HMI waterway restricted zone and inland safety zone ................................................162

Figure 82. Unloading debris from barge bottom with clamshell bucket.........................................163

Figure 83. Inspecting debris in barge for DMM....................................................................163

Figure 84. DMM identified and recovered from barge ..............................................................164

Figure 85. Front-end loader placing debris on HMI static separation screen .................................164

Figure 86. Static screen with approximately 1 in. square apertures used at HMI ..........................165

Figure 87. Application of water jet on HMI static screen ..............................................................165

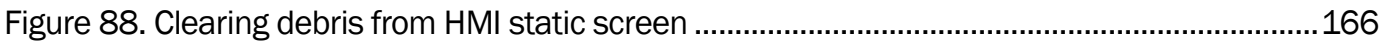

Figure 89. Several cannonballs recovered from debris at HMI ..................................................167

Figure 90. Armored backhoe dredge placing dredged material into separation hopper.................168

Figure 91. Closeup of bucket placing MEC-contaminated material into separation hopper .........169

Figure 92. Illustration of HUXOS separation process.................................................................169

Figure 93. Waterjet applied to MEC-contaminated sediment.......................................................... 170

Figure 94. MEC separated from dredged material .................................................................... 170

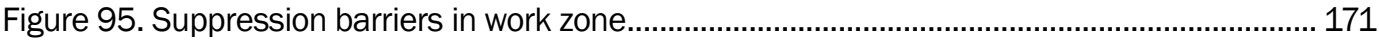

Figure 96. Location of Toussaint Dredging Demonstration and Erie Army Depot and Camp

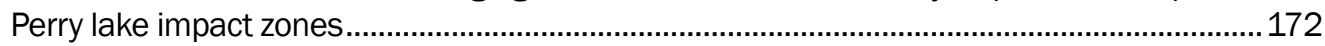

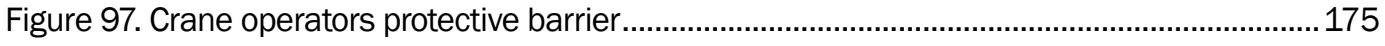

Figure 98. Deck layout and MEC dredging system ...................................................................... 176

Figure 99. Scow and separation screen ........................................................................... 177

Figure 100. Fluidization valve-control system ...................................................................... 178

Figure 101. Water cannon operator's station ....................................................................... 178

Figure 102. 10X zoom lens with remote-controlled pan and tilt .................................................179

Figure 103. Closed-circuit television control station inside observation trailer .............................180

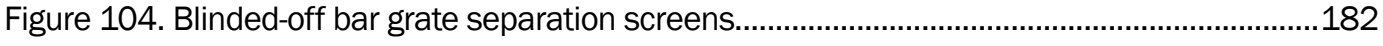

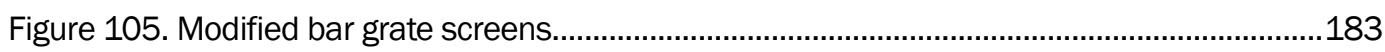

Figure 106. Space cloth separation screen ……………..............................................................184

Figure 107. MEC prepared for disposal detonation ....................................................................185

Figure 108. A 106 mm projectile on separation screen.............................................................186

Figure 109. Several examples of recovered ordnance fragments ................................................187

Figure 110. 1999 dredging layout....................................................................................................189

Figure 111. Crane operator's protective barrier ...........................................................................189 
Figure 112. Crew's protective barrier (underneath life jacket) ……............................................190

Figure 113. Scow release operator's protective barrier

\section{Tables}

Table 1. Dredge excavation, removal, transport, and placement processes 8

Table 2. Fort Hancock, Sandy Hook, NJ, battery statistics. 80

Table 3. Cost estimates for MEC exclusion dredge alterations. 88

Table 4. Estimated quantity of oversized dredged material collected per load for given screen size 102

Table 5. Beach pumpout operation facts..

Table 6. Total recovered items 186 


\section{Preface}

This effort was supported by the Environmental Security Technology Certification Program (ESTCP) and Headquarters, U.S. Army Corps of Engineers (HQUSACE), through the Dredging Operations Environmental Research (DOER) Program.

The ESTCP Director is Dr. J effrey Marqusee, and Program Manager for Munitions Management is Dr. Anne Andrews. The DOER Program is managed at the U.S. Army Engineer Research and Development Center (ERDC) by Dr. Todd Bridges, Environmental Laboratory (EL), and Edmond Russo, Coastal Hydraulics Laboratory (CHL).

The study was performed by personnel from U.S. Army Engineer Research and Development Center (ERDC), U.S. Army Corps of Engineer District, Baltimore, and the U.S. Army Engineering and Support Center, Huntsville, AL. The authors wish to thank the various personnel from the U.S. Navy Naval Ordnance Safety and Security Activity; Headquarters, U.S. Army Corps of Engineers, Washington, DC; U.S. Army Engineering and Support Center, Huntsville, AL; U.S. Army Engineer District, New York; U.S. Army Engineer District, Baltimore; and the U.S. Army Engineer District, Norfolk, who reviewed this report.

This report was prepared by Timothy Welp, Coastal Engineering Branch/ Dredging Group, CHL, ERDC, who was responsible for the overall technical direction for the study; George Follett, U.S. Army Engineer District, Baltimore, Military Munitions Design Center; Dr. Michelle Crull, Advanced Technology Branch, U.S. Army Engineering and Support Center, Huntsville; and Cheryl Pollock, Coastal Engineering Branch/ Dredging Group, CHL, ERDC. Successful completion of the study was facilitated by Bill Wild, Space and Naval Warfare Systems Center, San Diego. J . Holley Messing, Coastal Engineering Branch, Navigation Division, CHL, formatted and edited the draft report.

COL Richard B. J enkins was Commander and Executive Director of ERDC. Dr. J ames R. Houston was Director. 


\section{Unit Conversion Factors}

\begin{tabular}{|l|c|l|}
\hline Multiply & By & To Obtain \\
\hline acre & $4,046.873$ & square meters \\
\hline cubic yards & 0.7645549 & cubic meters \\
\hline feet & 0.3048 & meters \\
\hline inches & 25.4 & millimeters \\
\hline gallons per minute & 0.06308 & liters per second \\
\hline hectares & $1.0 \mathrm{E}+04$ & square meters \\
\hline miles (U.S. statute) & $1,609.347$ & meters \\
\hline pounds & 0.45359237 & kilograms \\
\hline pounds (force) per square inch & 6.894757 & kilopascals \\
\hline tons (2000 pounds); mass & 907.1847 & kilograms \\
\hline
\end{tabular}




\section{Objective and Approach}

This document's objective is to provide guidance to personnel (e.g., planners, cost estimators, specification writers, engineers, managers, and dredging contractors) involved in dredging projects with sediment contaminated by the presence of Munitions and Explosives of Concern (MEC). MEC "distinguishes specific categories of military munitions that may pose unique explosives safety risks, means: (1) unexploded ordnance (UXO); (2) discarded military munitions (DMM); or (3) munitions constituents (e.g., TNT, RDX) present in high enough concentrations to pose an explosive hazard." In the context of this document, military munitions-related terms and definitions will be used as defined by the Department of the Army in the Military Munitions Response Program (Appendix A).

Military munitions (Department of Defense [DoD] 2003) are:

all ammunition products and components produced for or used by the armed forces for national defense and security, including ammunition products or components under the control of the Department of Defense, the Coast Guard, the Department of Energy, and the National Guard. The term includes confined gaseous, liquid, and solid propellants, explosives, pyrotechnics, chemical and riot control agents, chemical munitions, rockets, guided and ballistic missiles, bombs, warheads, mortar rounds, artillery ammunition, small arms ammunition, grenades, mines, torpedoes, depth charges, cluster munitions and dispensers, demolition charges, and devices and components thereof. The term does not include wholly inert items, improvised explosive devices, and nuclear weapons, nuclear devices, and nuclear components, other than non-nuclear components of nuclear devices that are managed under the nuclear weapons program of the Department of Energy after all required sanitization operations under the Atomic Energy Act of 1954 (42 U.S.C. 2011 et seq.) have been completed. (10 U.S.C. 101 (e)(4). 
Unexploded ordnance(40 CFR 260 et seq.) are:

military munitions that have been primed, fuzed, armed, or otherwise prepared for action, and have been fired, dropped, launched, projected, or placed in such a manner as to constitute a hazard to operations, installation, personnel, or material and that remain unexploded either by malfunction, design, or any other cause.

Projectiles smaller than $20 \mathrm{~mm}$ do not have explosive charges and are not considered UXO.

Discarded Military Munitions (DoD 2003) are:

military munitions that have been abandoned without proper disposal or removed from storage in a military magazine or other storage area for the purpose of disposal. The term does not include unexploded ordnance, military munitions that are being held for future use or planned disposal, or military munitions that have been properly disposed of consistent with applicable environmental laws and regulations.

Munitions debris (MD), while not specifically included under the MEC definition, is another munitions term (40 CFR 260 et seq.) that is defined as:

remnants of munitions (e.g., fragments, penetrators, projectiles, shell casings, links, fins) remaining after munitions use, demilitarization, or disposal.

MD includes inert ordnance used for training purposes that, to the untrained eye, may appear and weigh the same as its actual functioning counterpart. Correct usage of the terms MD and UXO can critically influence the relative severity of subsequent impacts that these items can have on a dredging project.

Material Potentially Presenting an Explosive Hazard (MPPEH) is another definition that includes MD and is defined (40 CFR 260 et seq.) as: 
Material potentially containing explosives or munitions (e.g., munitions containers and packaging material, munitions debris remaining after munitions use, demilitarization, or disposal; and range-related debris); or material potentially containing a high enough concentration of explosives such that the material presents and explosive hazard (e.g., equipment, drainage systems, holding tanks, piping, or ventilation ducts, that were associated with munitions production, demilitarization, or disposal operations). Excluded from MPPEH are military munitions within the Department of Defenses established munitions management system and other hazardous items that may present explosion hazards (e.g., gasoline cans, compressed gas cylinders) that are not munitions and are not intended for use as munitions.

Past dredging projects have encountered MEC and MD. Items have been discovered intact on the dredges (i.e., in dragheads, cutterheads, pump casings, or turtle screens) and at the dredged material placement site (i.e., on renourished public beaches or in confined disposal facilities [CDFs]) (Halkola et al. 2006). Detonations have also occurred that have either damaged the dredge plant (U.S. Army Engineer District, Rock Island, hereafter Rock Island District), or, in more severe cases, even sunk the dredge (U.S. Department of the Army 1972).

The guidance presented herein is primarily in the form of compiled information gained from experiences on past dredging projects involving UXO and $\mathrm{MD}$. In the context of this document, this type of dredging project will be subsequently referred to as a MEC/ dredging project. This information has been compiled and summarized to inform the reader about what has been done in the past to deal with the risk inherent in a potentially dangerous situation where dredge and crew or the public (i.e., in a beach nourishment or renourishment project) can be exposed to MEC.

This document has been prepared to address the dearth of documentation commonly available on MEC/ dredging projects (Welp et al. 1994). The information contained herein has been gathered from a variety of sources that include a survey and literature search conducted during a previous Environmental Security Technology Certification Program (ESTCP) effort 
entitled "Dredging Equipment Modifications for Detection and Removal of Ordnance" (Halkola et al. 2006). Additional investigation and analyses were performed under this ESTCP effort in conjunction with supplemental funding provided by the Headquarters (HQ), U.S. Army Corps of Engineers (USACE) Dredging Operations and Environmental Research program's Operations Technologies Focus Area.

This report describes the different types of dredges and dredging projects that can encounter MEC, describes how these dredges' operational methodologies can be impacted by MEC, and summarizes past project methodology modifications that have been used to deal with MEC.

Where possible, the authors use current terminology stated above (e.g., MEC, UXO, DMM) to distinguish between specific categories of military munitions. In the context of this document, terms (e.g., ordnance, munitions, bombs, and explosives) used in the original quotations of cited references (as opposed to current correct terms, e.g., MEC, UXO, DMM) have been retained. To avoid confusion and ensure consistency with other DoD safety and logistics documents, the authors encourage the reader to remember that this convention is applied throughout this document.

Technical aspects of past MEC/ dredging projects are presented with regard to engineering controls to mitigate detonation hazards, underwater MEC detection and discrimination technologies, contracting, public awareness, safety requirements, and MEC separation techniques and (where available) subsequent impacts on production rates and costs. 


\section{Dredging Process and Equipment}

Dredging can be defined as the process of excavating sediments and other materials from underwater locations, and transporting and placing this material for purposes i.e., constructing new waterways, maintaining existing waterway dimensions, obtaining fill for land reclamation, beach nourishment, dike and levee construction, creating wetlands and marshes, obtaining materials from borrow areas, or other beneficial uses. A wide variety of dredge plants (the dredge and auxiliary equipment) excavate, transport, and dispose of sediment in many different ways to accomplish the numerous tasks stated in the definition above.

In essence, dredging is the act of excavating submerged or saturated sediment from one location and transporting it to another. During extraction, energy is applied to the sediment by mechanical and/ or hydraulic means to alter sediment physical characteristics. Mechanical dredges generally use some type of bucket for digging the sediment, then hoist or boom the load to the surface. Most common hydraulic methods use a centrifugal pump in converting kinetic energy into a pressure gradient to create a water flow that erodes and entrains sediment into a slurry (water and sediment mixture).

The sediment is transported from the dredge site to placement area by hydraulic or mechanical methods. In hydraulic applications, the centrifugal pump discharge can either be collected in a temporary storage container (usually a barge or scow) for later transportation to the placement area, or it can be conveyed directly into the placement area via the discharge pipeline. Mechanical dredges dump the bucket load within swing radius directly into the placement area, or into a transportation unit (i.e., barge, truck, conveyor belt, etc.) for haulage to the placement area.

\section{Dredging equipment}

General dredge classification is based on the way that the dredge extracts the submerged sediment (hydraulic or mechanical). There are other varieties of specialized dredges that use different combinations of physical mechanisms to perform dredging (e.g., pneumatic), but they are much less common. Overviews of different types of dredges are presented below. For 
detailed information on particular types of dredges, the reader is directed to HQUSACE 2007a; Bray et al. 1997; and Herbich 2000.

\section{Mechanical dredges}

Most mechanical dredges scoop sediment into a bucket-shaped container and bring it to the surface where it is dumped into a placement area or transportation unit. These dredges usually consist of an excavator (i.e., clamshell bucket, dragline, power shovel, or backhoe) mounted on the deck of a non-self-propelled barge. Some versions use conventional track or rubber-wheel-mounted excavators (used on land) that are driven onto barges for temporary use, while others have the excavator's turntable (horizontal swivel point) directly mounted to the barge deck. When mobilizing to and from a project site, the dredge is usually pulled or pushed by tug. In operation, the dredge holds its position by taking tension on anchors deployed around the barge, and/ or by dropping spuds (verticallyoriented large-diameter steel pipe) into the bottom sediment. The anchors are set by onboard cranes or auxiliary work vessels (tenders). Once the dredge has excavated all the sediment it can reach to the required depth at one station, it is repositioned to a new location to begin digging again. This relocation can be accomplished in a variety of ways (i.e., an anchor/ winch system, tug, movable spud system, or even by using the bucket itself as an anchor point).

\section{Clamshell (bucket) dredge}

A clamshell dredge lowers the opened clamshell bucket from the end of a crane boom into the sediment (as shown in Figure 1). After penetrating the sediment, the bucket jaws are closed in order to "grab" a load of sediment.

The loaded bucket is hoisted to the surface and side dumped into a transportation unit, or into the disposal site. Transportation units are usually barges (scows) that are towed or pushed by tugs. Barges dispose of dredged material in a variety of methods: dumping through doors mounted in the hull bottom or having the hull split open, pumping out the material in slurry form (direct-pumpout), or unloading by other bucket, auger, or conveyor machinery. 


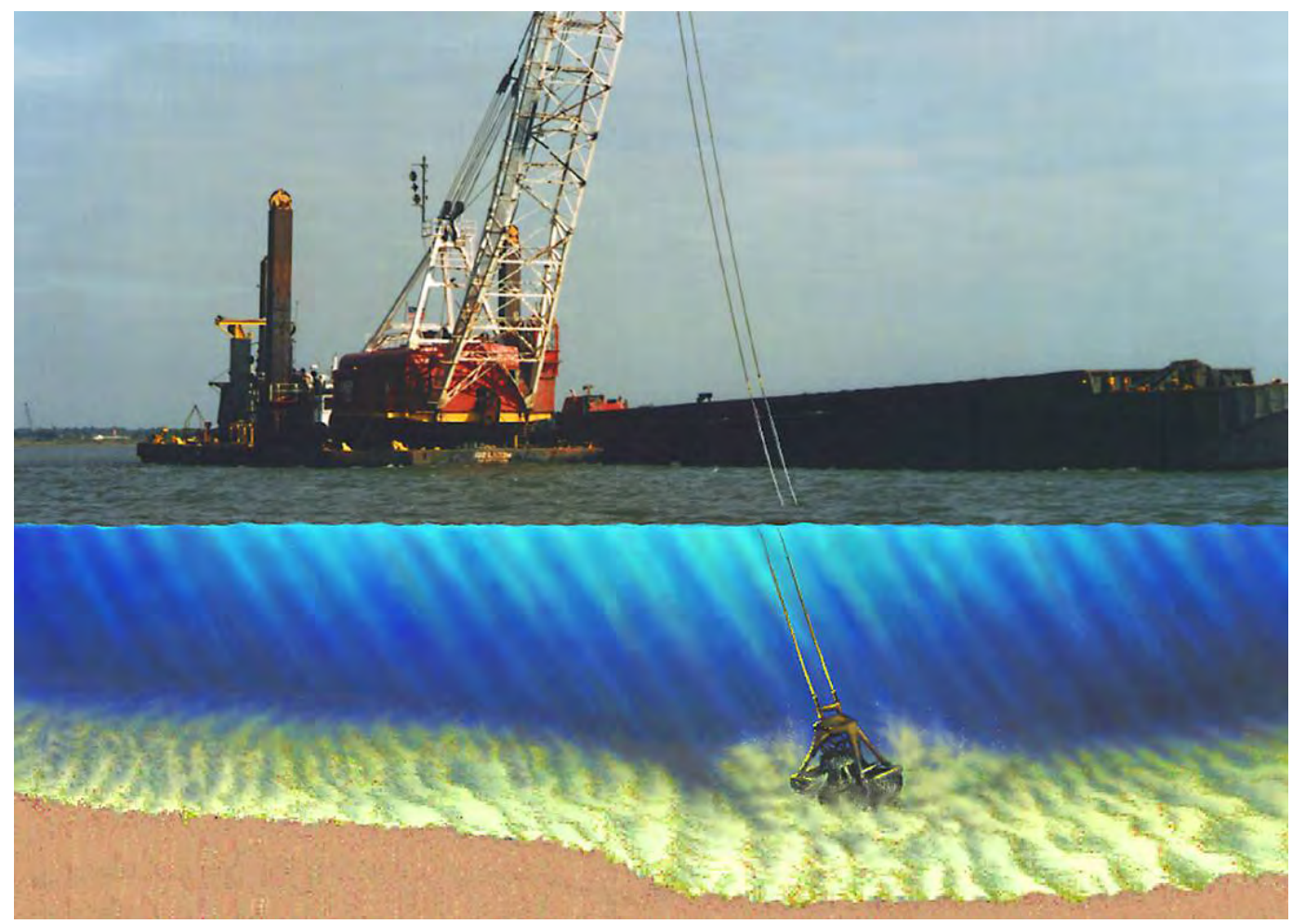

Figure 1. Clamshell (bucket) dredge.

Various bucket configurations with different digging characteristics (i.e., toothed vs. smooth-edged jaws) are used to optimize production rates for site-specific conditions. Where compatible, these different types of buckets can be changed out in the field relatively quickly to increase production. Because the clamshell is mounted on a flexible wire rope, its weight heavily influences the maximum digging force that can be applied to the sediment. Except for the most cohesive consolidated sediments, coral, and rock, clamshell bucket dredges can excavate most types of material.

The production rates of all types of dredges depend on the interaction between dredge-specific and site-specific parameters. Production rate will be defined as the in-situ volume of material removed from the dredging area and transported to the placement or treatment area per unit time. Dredge-specific parameters include dredge type, size, power, and operating methodology. Site-specific parameters include sediment characteristics, hydrodynamic conditions (depth, current, waves), and distance between dredge site and placement area. While a clamshell dredge's maximum operating depth is limited by the length of wire rope on the hoist drum, its maximum effective working depth is about $30 \mathrm{~m} \mathrm{(100} \mathrm{ft).}$ Clamshell dredges use a variety of bucket sizes ranging from $0.6 \mathrm{cu} \mathrm{m}$ ( $0.75 \mathrm{cu} \mathrm{yd}$ ) to $38 \mathrm{cu} \mathrm{m}$ (50 cu yd). A production rate of 30 to 60 bucket 
loads (or dredging cycles) per hour is typical, but these numbers can significantly vary as a function of dredging depth and sediment characteristics.

The density of sediment excavated can be about equal to its in-situ density. Clamshell dredges can operate efficiently in natural and manmade debris. This type of dredge can also operate close to structures (piers, jetties, etc.) because of the amount of control provided to the operator. But the clamshell's operating cycle produces a relatively uneven bottom surface, and its production rate is usually less than that of a hydraulic dredge. Table 1 summarizes the excavation, removal, transport, and placement processes for the most commonly used dredges.

Table 1. Dredge excavation, removal, transport, and placement processes.

\begin{tabular}{|c|c|c|c|c|}
\hline Dredge Type & Excavation Method & Removal Method & Transport Method & Placement Method \\
\hline \multicolumn{5}{|c|}{ Hydraulic Dredges } \\
\hline $\begin{array}{l}\text { Hopper } \\
\text { Dredge }\end{array}$ & $\begin{array}{l}\text { Hydraulic suction, } \\
\text { Hydraulic erosion, } \\
\text { Mechanical dislodge- } \\
\text { ment using knives or } \\
\text { blades }\end{array}$ & $\begin{array}{l}\text { From bottom to dredge } \\
\text { vessel in hydraulic } \\
\text { pipeline as a sediment- } \\
\text { water slurry }\end{array}$ & $\begin{array}{l}\text { Sediment settles in } \\
\text { hopper; vessel } \\
\text { moves to placement } \\
\text { site }\end{array}$ & $\begin{array}{l}\text { Bottom discharge or } \\
\text { pumpout }\end{array}$ \\
\hline $\begin{array}{l}\text { Cutterhead } \\
\text { Dredge }\end{array}$ & $\begin{array}{l}\text { Mechanical dislodge- } \\
\text { ment using rotary } \\
\text { cutter, } \\
\text { Hydraulic suction, } \\
\text { Hydraulic erosion }\end{array}$ & \multirow[t]{2}{*}{$\begin{array}{l}\text { From bottom to dredge } \\
\text { vessel in hydraulic } \\
\text { pipeline as a sediment- } \\
\text { water slurry }\end{array}$} & \multirow[t]{2}{*}{$\begin{array}{l}\text { From dredge vessel } \\
\text { to placement site in } \\
\text { pipeline as a } \\
\text { sediment-water } \\
\text { slurry }^{1}\end{array}$} & \multirow[t]{2}{*}{$\begin{array}{l}\text { Direct discharge on } \\
\text { land, water, or } \\
\text { beneficial use site }\end{array}$} \\
\hline $\begin{array}{l}\text { Dustpan } \\
\text { Dredge }\end{array}$ & $\begin{array}{l}\text { Direction suction, } \\
\text { Impingment scour } \\
\text { using water }\end{array}$ & & & \\
\hline \multicolumn{5}{|c|}{ Mechanical Dredges } \\
\hline $\begin{array}{l}\text { Bucket } \\
\text { Dredge }\end{array}$ & $\begin{array}{l}\text { Mechanical dislodge- } \\
\text { ment, scooping with } \\
\text { bucket }\end{array}$ & $\begin{array}{l}\text { Wire rope with } \\
\text { clamshell or dragline }\end{array}$ & \multirow{2}{*}{$\begin{array}{l}\text { Barge, land-based } \\
\text { conveyor belt, } \\
\text { trucks; material may } \\
\text { be sidecasted }\end{array}$} & \multirow{2}{*}{$\begin{array}{l}\text { Bottom discharge, } \\
\text { pumpout, or } \\
\text { mechanically to } \\
\text { unload; } \\
\text { Direct discharge from } \\
\text { belt, truck, or bucket }\end{array}$} \\
\hline $\begin{array}{l}\text { Backhoe } \\
\text { Dredge }\end{array}$ & $\begin{array}{l}\text { Mechanical dislodge- } \\
\text { ment, scooping with } \\
\text { backhoe bucket }\end{array}$ & $\begin{array}{l}\text { Rigid structural } \\
\text { members with backhoe } \\
\text { bucket }\end{array}$ & & \\
\hline
\end{tabular}

\section{Backhoe dredges}

Backhoe dredges are basically land excavators that have been modified for use on water. A mobile (tracked or wheel-mounted) backhoe excavator can be temporarily secured to a barge deck (like the clamshell dredge), or the 
more permanent versions have the excavator's turntable welded to the deck. The bucket is usually hydraulically activated on a boom/ stick configuration as shown in Figure 2. While working, the barge is usually held in place by spuds to provide reaction forces to the digging-induced forces. The maximum bucket size that can be used for a specific project will depend on the excavator's rated capacity, sediment characteristics, and water depth. Average bucket sizes generally range from $0.6 \mathrm{cu} \mathrm{m}$ (0.75 cu yd) to $4 \mathrm{cu} \mathrm{m} \mathrm{(5} \mathrm{cu} \mathrm{yd).}$

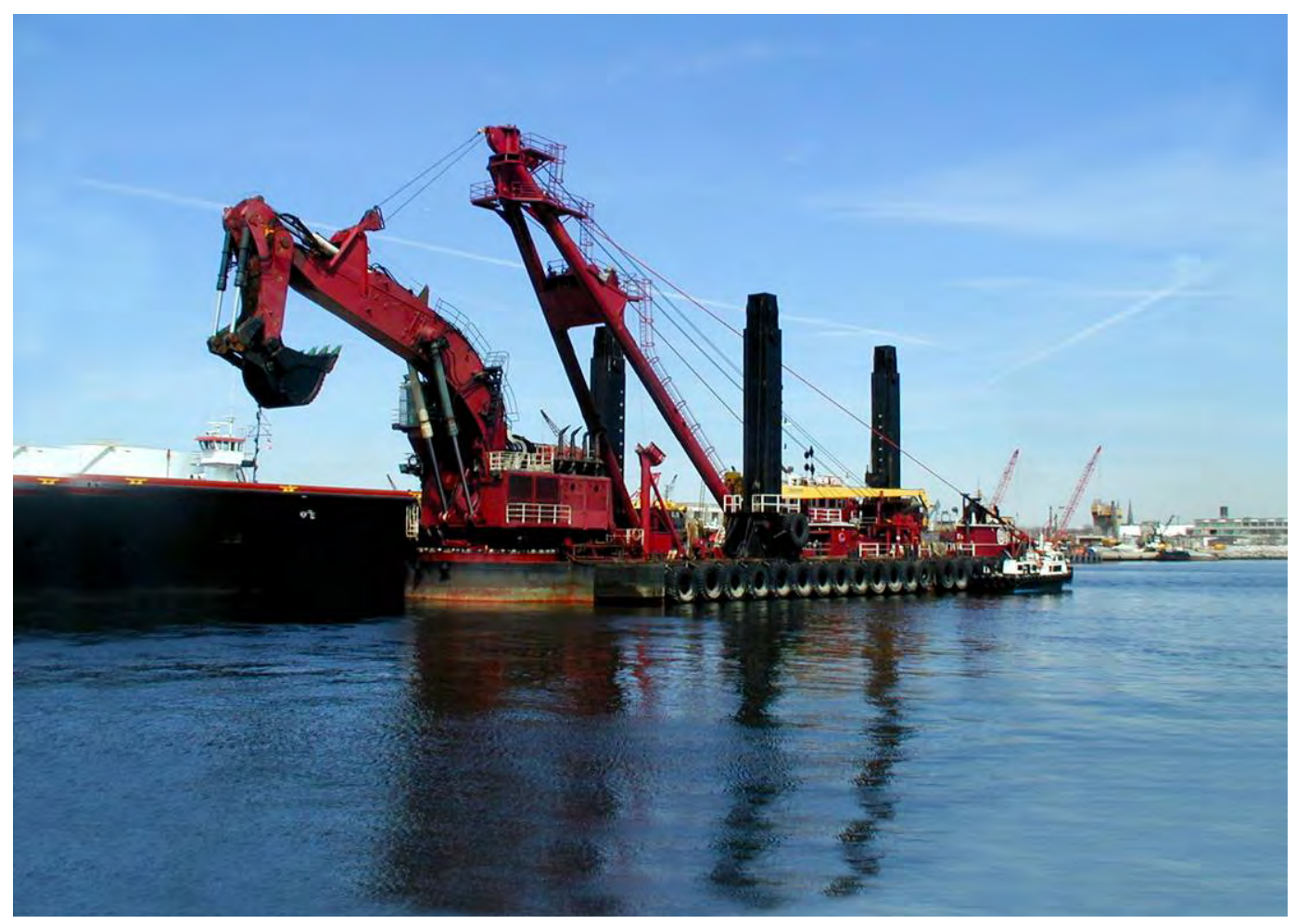

Figure 2. Backhoe dredge New York (courtesy of Great Lakes Dredge and Dock Company).

Larger backhoes have a bucket capacity of approximately $19 \mathrm{cu}$ m ( $25 \mathrm{cu}$ yd) and can excavate to a maximum depth of approximately $25 \mathrm{~m}$ (80 ft). Because a backhoe's bucket is connected by rigid structural members, more force can be applied to it, allowing these types of dredges to work in "harder" materials than cable-connected buckets (relatively cohesive consolidated materials, weak rock, and debris). Backhoes have operational characteristics that provide relatively high excavation accuracy and they can work closely around structures. The density of sediment excavated can about equal its in-situ density, but, like other conventional mechanical dredges, it generates a relatively large amount of sediment resuspension at the dredge site. 


\section{Hydraulic dredges}

The hydraulic dredge generally uses a centrifugal pump to excavate the dredged material in the form of a slurry (water and sediment mixture). The most common types of hydraulic dredges used, hopper and pipeline, are classified by their respective means of transporting material to the disposal site.

\section{Hopper dredges}

Hopper dredges (Figure 3) are self-propelled vessels that pump slurry into onboard hoppers for transportation to the disposal site. While excavating, the dredge uses centrifugal pumps to generate low head/ high volume water flow rates into specially designed suction mouths, or dragheads, that slide along the bottom entraining sediments. These dragheads determine the hydrodynamic flow field (and resultant slurry intake) going into the suction pipe. Because of their impact on production rates, a variety of draghead types have been designed for different sediments by incorporating mechanical and/ or hydraulic agitators. Normal configuration has two dragarms, one on each side of the ship. A dragarm is a pipe suspended over the side of the vessel with a suction opening called a draghead.

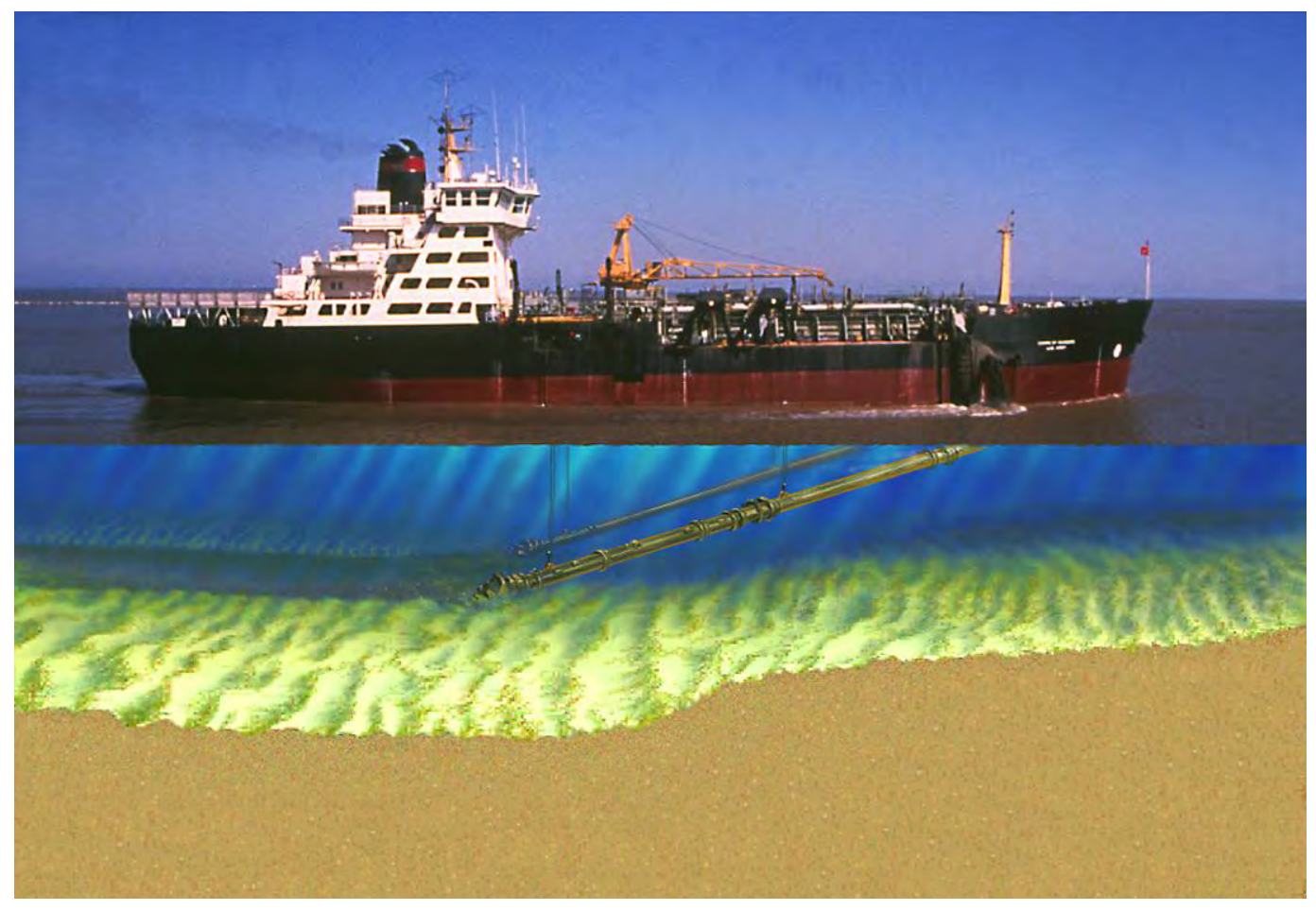

Figure 3. Self-propelled hopper dredge. 
The dragarm is connected to a dredge pump, usually located inside the hull. In some cases, the dredge pump is located on the dragarm to increase its hydraulic efficiency. The draghead is moved along the channel bottom as the vessel moves forward. The dredged material is entrained into the draghead, up the dragpipe, and deposited and stored in the hoppers of the vessel. Discharge of the centrifugal pumps is conveyed into the hoppers via a distribution system.

\section{Hydraulic pipeline dredge}

The hydraulic pipeline dredge also uses a centrifugal pump to entrain the sediment into a slurry, but instead of using a hopper for transporting dredged material to the placement site, it conveys the material through a pipeline connected to the pump discharge.

This type of dredge typically comprises a hull, main pump and engine, ladder, suction pipe, spuds, and hoisting and hauling equipment. During operation, a floating (or submerged) discharge pipeline transports the slurry to the placement site. If the pumping distance is longer than the dredge pump(s) can efficiently pump, then booster pump stations are added in the pipeline as needed. Most hydraulic pipeline dredges are barge-mounted without propulsion and require dredge tenders for mobilization to the dredge site. The conventional method of dredge advancement is controlled primarily by a system of winding gear, anchors, and spuds. When positioned on station, the port and starboard swing anchors (connected to the winches by wire rope) are set out a distance from the bow by the dredge's own anchor booms or payed out by derrick barges. The dredge is equipped with two stern spuds that can be raised or lowered (one at a time) into the bottom to function as pivot points. During dredging, one of the spuds is set in the bottom as a pivot point and the leverman moves the cutterhead across the channel in a circular arc by taking in one swing anchor cable while slacking off the other. The dredge advances, or steps, forward in the channel by alternating spud sets (e.g., swing to starboard on the starboard spud, then swing to port on the port spud). This sequence of swinging and spud setting (stabbing) in the channel has many variations, including traveling spud carriages that physically push the dredge forward, but the technique is fundamentally the same for the majority of hydraulic pipeline dredges.

The dredge size, described by the diameter of the discharge pipe, for Corps projects ranges from $203 \mathrm{~mm}$ (8 in.) to $860 \mathrm{~mm}$ (34 in.). Usually a diesel 
engine drives the dredge pump (or pumps), but other prime movers can include direct or alternating electric motors, gasoline engines, reciprocating steam engines, steam turbines, or gas turbines (Turner 1984). Some dredges use submerged pumps, sometimes called ladder pumps, to increase production rates at deeper depths. There are hydraulic dredges built in the 1930s that are still operating today with basically the same production instrumentation (i.e., vacuum and pressure gage) as used on their maiden voyages. These facts illustrate the wide range of age, size, and level of instrumentation that exists in the hydraulic dredge fleet today.

Sub-classes of pipeline dredges are defined by the mechanical and/ or hydraulic attachments used to loosen and convey bottom material into the suction mouth. Plain suction dredges have no attachments on the suction mouth, while dustpan dredges use a relatively wide-flared dredging head supplemented with water jets. Cutterhead dredges use a rotating mechanical array of cutters over the suction mouth as shown in Figure 4 . The rotational speed of the cutterhead usually varies between 0 and $35 \mathrm{rpm}$ with generally the larger the diameter of cutterhead, the slower the rotational speed (Huston 1986).

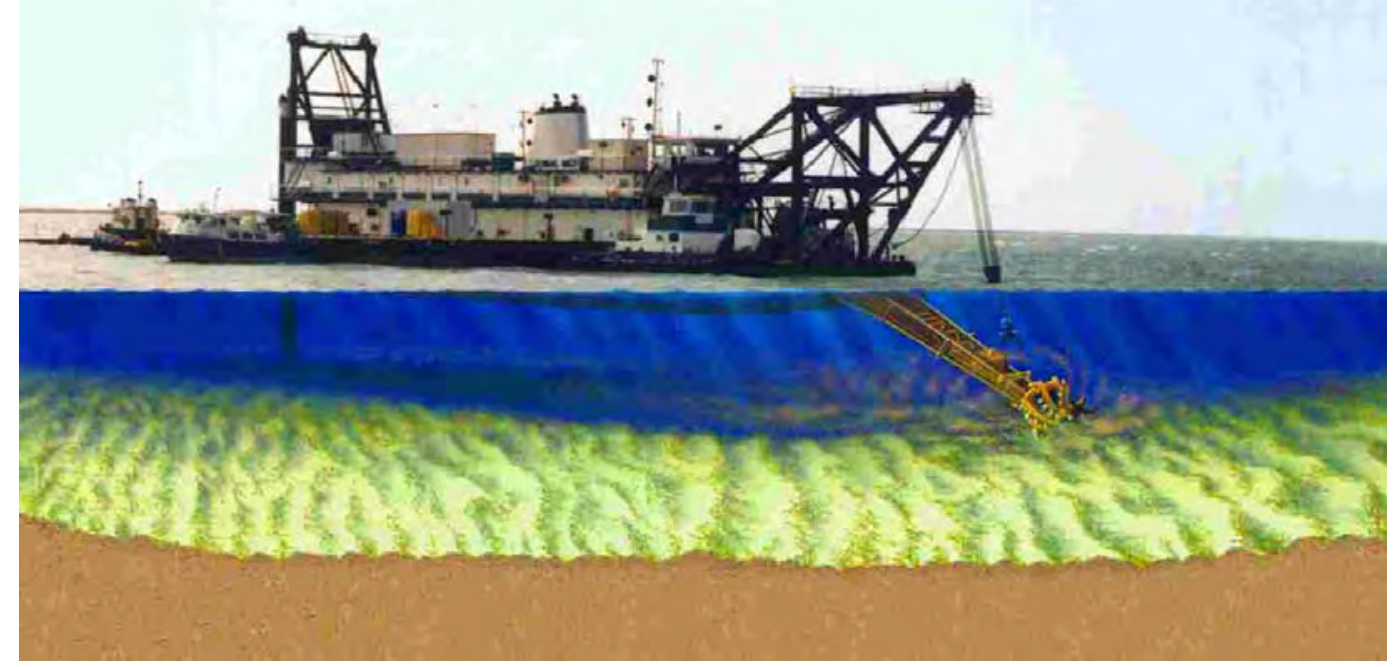

Figure 4. Hydraulic pipeline cutterhead dredge. 
The plain suction dredges can be used in free flowing sediments, but as the material's shear strength increases, the production rates decrease. The dustpan dredge's flared suction head with water jets enhances its production by directing the water jets downward into the sediment to loosen (fluidize) the soil prior to its entrainment into the suction mouth (Figure 5). A cutterhead dredge's mechanical cutting action allows these dredges to operate in sediments with higher shear strengths, even certain types of rocks. Hydraulic dredge production can be more sensitive to debris-related impacts than mechanical dredges because of their susceptibility to clogging.

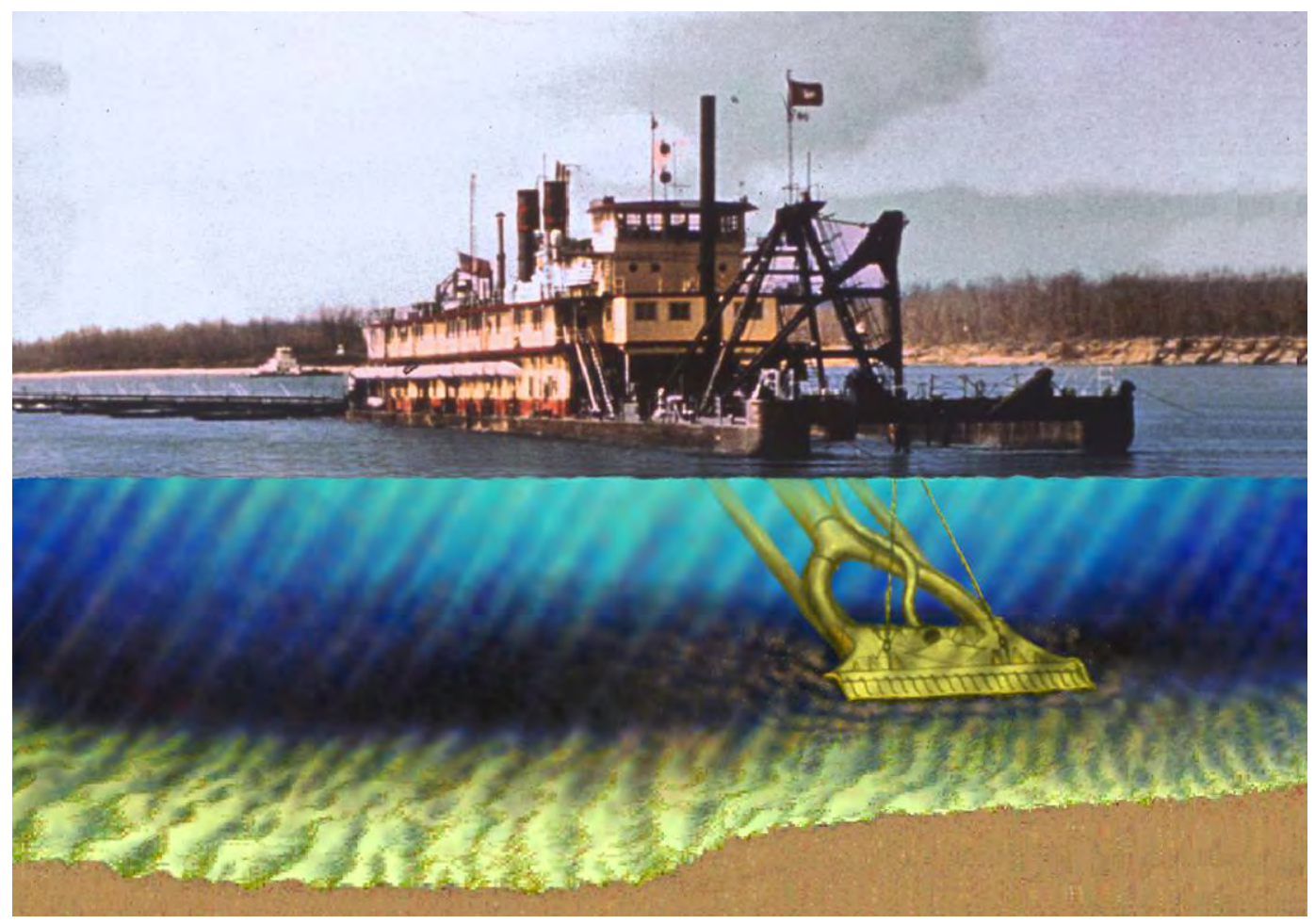

Figure 5. Hydraulic pipeline dustpan dredge.

Cutterhead dredges are by far the most common type of dredge, with hundreds of cutterheads available in the United States (though most are smaller than $600 \mathrm{~mm}$ (24 in.). Additional pumps, called booster pumps, can be installed in the discharge pipeline to increase the pumping distance. Because water is used to entrain the sediment into a slurry like a hopper dredge, the percent solids (by weight) of this slurry typically ranges between 10 and 20 percent. Table 1 summarizes these types of hydraulic dredges' operating characteristics. Because the suction mouth is enclosed by the cutterhead, no debris larger than the space between individual cutters will be introduced to the suction mouth. 


\section{Special purpose dredges}

The previously mentioned types of dredges move the majority of total sediment volumes in the world today, but in the last few decades specialized dredges have been developed to optimize particular operating characteristics for application in specific dredging situations. Some different types of dredge technologies that exhibit potential application for use on MEC dredging projects are described next.

\section{Pneuma system}

One such dredging technology is the Pneuma system. This system uses static water head and compressed air instead of centrifugal motion to pump slurry through a pipeline. The pump body generally consists of three cylinders without any internal rotating mechanisms besides rubber inlet valves and delivery valves (Pneuma 2006).

Once the pump body is lowered to the sediment, an alternating process of filling the chambers with sediment or water and then forcing compressed air into the chamber to evacuate the sediment out through exhaust pipes dredges sediment from shallow waters as well as great depths. This process is shown in Figure 6. In Stage 1, hydrostatic water pressure (or a vacuum system in shallow water) creates suction in the cylinder and causes the chamber to fill with sediment. In Stage 2, the inlet valve on the

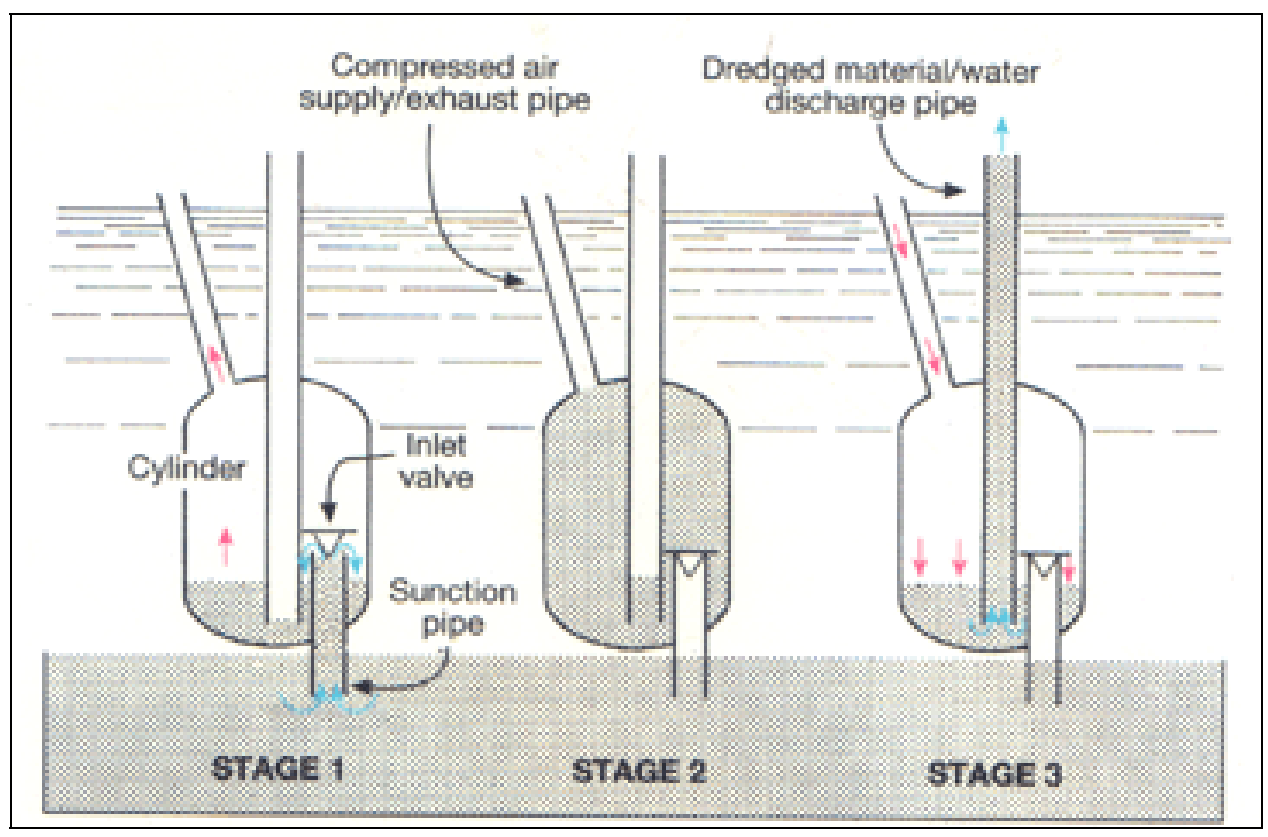

Figure 6. Stages 1 through 3 of Pneuma Pump System pumping principles (source: Pneuma 2006). 
bottom of the cylinder automatically closes when the chambers are filled. In Stage 3, compressed air is supplied through the valve (or exhaust pipe) at the top of the cylinder. The air performs as a positive displacement piston to force the material up and out through the discharge pipe. When the cylinder is nearly empty of sediment, the distributor discharges the air, releasing the internal pressure, and the cycle begins again (Pneuma 2006). Depending on the site-specific conditions, the pump (an example of one model is shown in Figure 7) can be deployed with leveling shovels and be pulled along the bottom (Figure 8) or be dropped vertically (without leveling shovels) with inlet pipes (Figure 9).

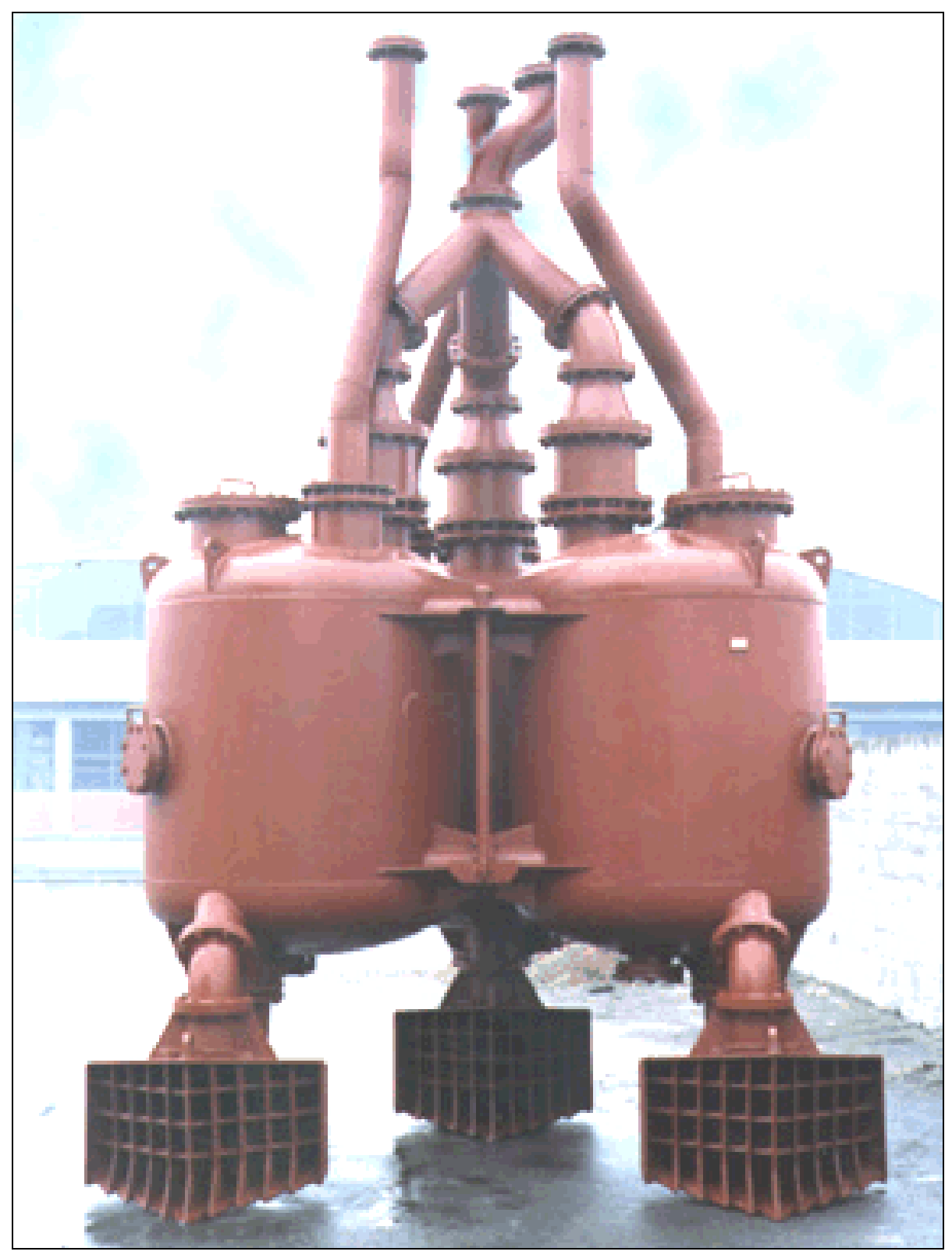

Figure 7. Pneuma pump (source: Pneuma 2006). 


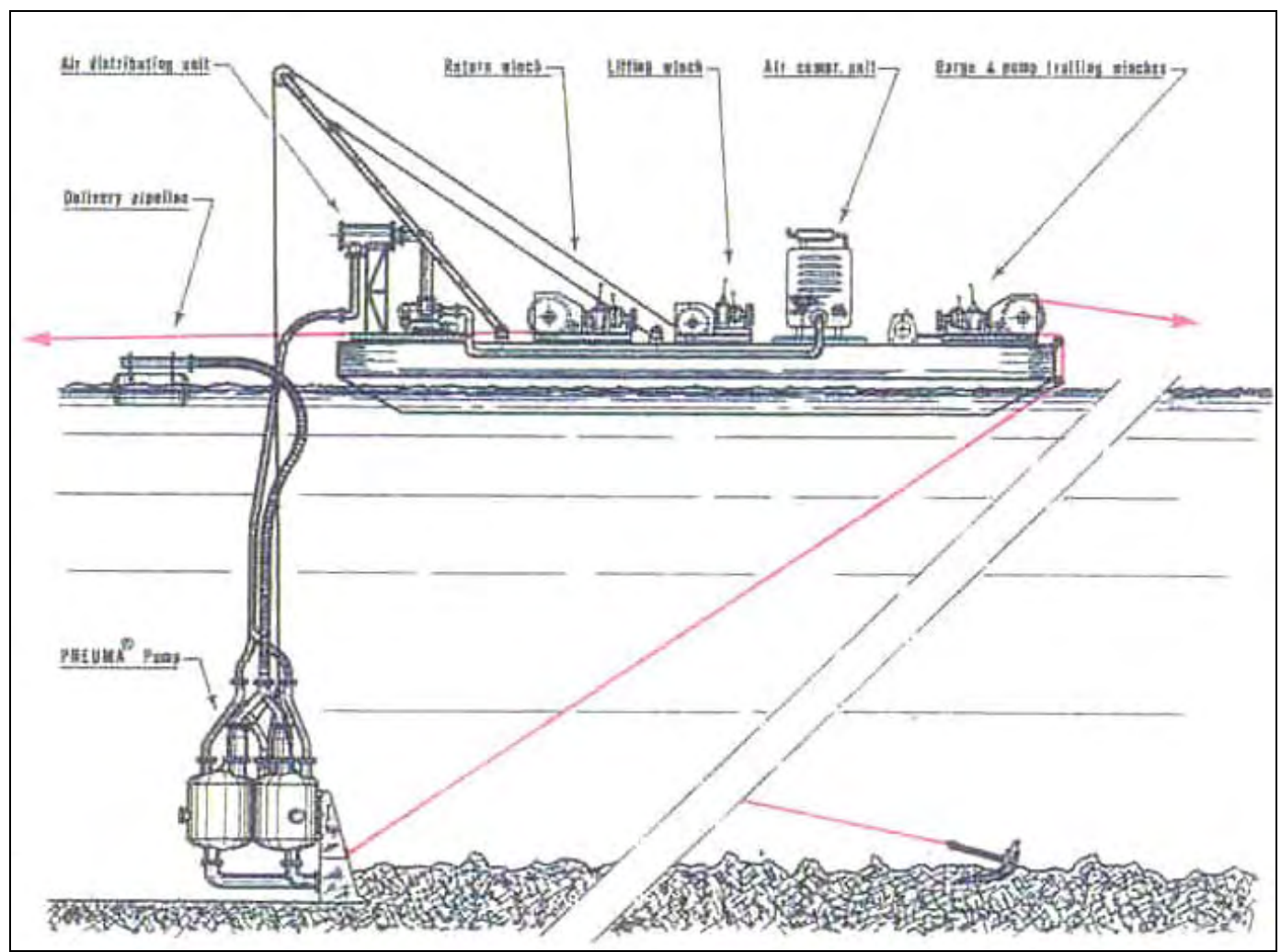

Figure 8. Pneuma pump with leveling shovels (source: Pneuma 2006).

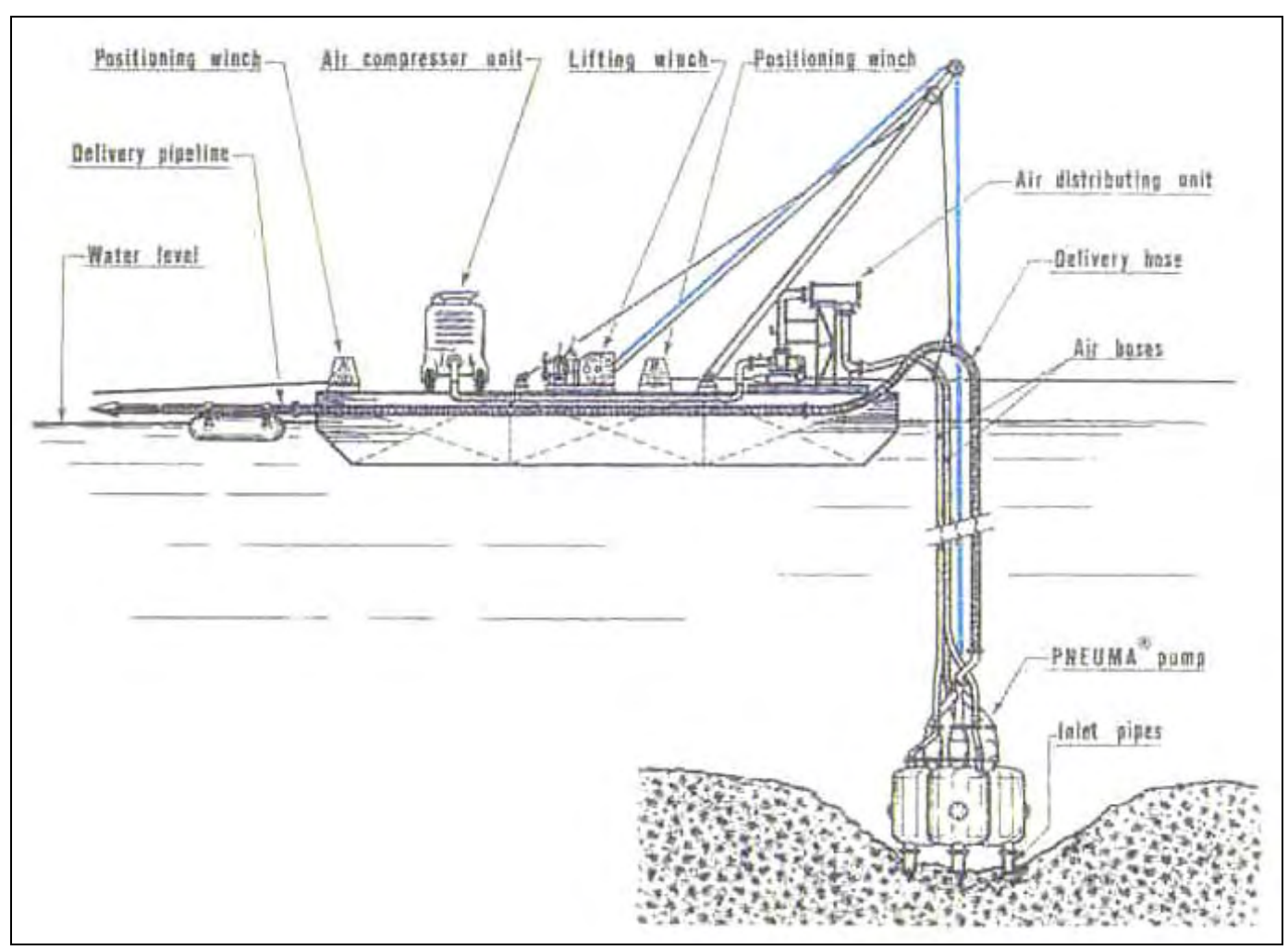

Figure 9. Pneuma pump with inlet pipes (source: Pneuma 2006). 
The manufacturer reports that the Pneuma trailing system is generally used for compacted cohesive bottom materials (clay and compacted silts) and is available in a variety of model sizes. Pneuma S.R.L. (http://www.pneuma.it/) lists output ranges from $40 \mathrm{cu} \mathrm{m} / \mathrm{hr}$ to $1,800 \mathrm{cu} \mathrm{m} / \mathrm{hr}$ (52 cu yd/hr to 2,354 cu yd/hr) and offers solid concentrations of up to 90 percent solids. Field tests on a Pneuma model 600/100 conducted by USACE found that material could be dredged at almost in-situ density in loosely compacted silty clay, typical of many estuarine sediments, but that the pump was not able to dredge sand at in-situ density and that efficiency of the dredge was consistently below 20 percent (Cullinane et al. 1986). Pneuma S.R.L. ${ }^{1}$ reports that, during a contaminated sediment removal (environmental) dredging project in Collingwood Harbour, Ontario, Canada, for the Ministry of Environment and Environment Canada, Toronto, the dredge removed 4,330 cu m (5,664 cu yd) of silty clay in 1992, and 3,000 cu m (3,924 cu yd) in 1993. The dredge reportedly averaged 30 percent solids by volume in the presence of debris, and 70 percent solids (by volume) in areas free of debris.

Information supplied by Pneuma s.r.l. ${ }^{1}$ identified a dredging site in which the system had been used in an area containing munitions, but the details of the sites were limited. In 1965 the Italian Governmental Oil Group, LA Spezia Bay, Italy, was constructing a gas pipeline terminal jetty at the entrance of the harbor of Portovenere. Dredging began with a cutter dredge working in approximately 10-m- (33-ft-) deep water when a bomb exploded inside the dredge and destroyed the pump room. The crew was not injured because they were not in the pump room, but were above deck smoking at the time of the explosion. A Pneuma pump with a reported output rate of $200 \mathrm{cu} \mathrm{m} / \mathrm{hr}$ ( $261 \mathrm{cu} \mathrm{yd} / \mathrm{hr}$ ) replaced the cutterhead dredge and completed the project without incident because of the shape of the shovels and the low trawling speeds. The origin of the military munitions was thought to be dumping of munitions by the Italian Fleet, present in the harbor at the end of World War II (WWII).

\section{Portable dredges}

Smaller, "portable" dredges, both hydraulic and mechanical, have been developed to minimize the mobilization and demobilization effort of inland projects. Clark (1983) defines a portable dredge as one that "can be moved easily from one jobsite to the next over existing roadways. If a

\footnotetext{
1 Personal communication with Chuck Tempus, Pneuma S.R.L. 2003.
} 
dredge must be dismantled for transport, it should be constructed for that purpose so dismantling and reassembling can be done easily and quickly." Logistically, these relatively smaller dredges can be transported to and from the project site more easily. Modes of transportation depend on hull dimensions and construction. The entire dredge might be transported on a flatbed truck, or towed on a trailer to the dredge site. At the dredge site, these small dredges can be put into the water by off loading equipment (i.e., crane or forklift) or slid off of the trailer. Other dredges arrive in standardized modules that have to be assembled at the worksite.

Some of these portable dredges are amphibious, designed for work on land, water, or swampy terrain. A large variety of mechanical and hydraulic attachments have been developed to increase production rates of these dredges. These attachments include augers, disks, cutterheads, chain cutters, bucket wheels, wide horizontal cutters, twin rotating vertical cutters, and jet pumps. Other attachments (i.e., choppers) have been designed to remove biomass (cattails, grasses, etc.) from ponds, lakes, and rivers. In addition to manual operation, some portable dredges can be remotely controlled from a shore station, or even programmed for automatic (unmanned) operation. Information on a remote-controlled dredge that was demonstrated on a Fort Richardson firing range (Eagle River Flats, AK) is provided in Chapter 6.

\section{Eductors}

Eductors (also known as jets pumps) are hydraulic pumps with no moving parts. They operate by using a supply (motive) water pump to provide high pressure flow at the eductor nozzle. As the jet contacts the surrounding fluid, momentum is exchanged in the mixer as the jet slows while it accelerates the surrounding fluid, entraining additional fluid into the jet Figure 10). As the surrounding fluid is entrained by the jet, it pulls in additional fluid from outside the eductor. Placing an operating eductor in saturated sand allows it to bypass a sand/ water slurry (eductors do not perform well in consistent fine-grained materials, i.e., compacted clays). Often some of the supply water is diverted to fluidizing nozzles to increase the flow of sand to the eductor. In the diffuser, the excess jet velocity is converted back into sufficient fluid pressure to allow operation with appropriate hydraulic conditions (Clausner et al. 1994). A booster pump may be required in the discharge line to increase hydraulic head to efficiently pump the required distance. 


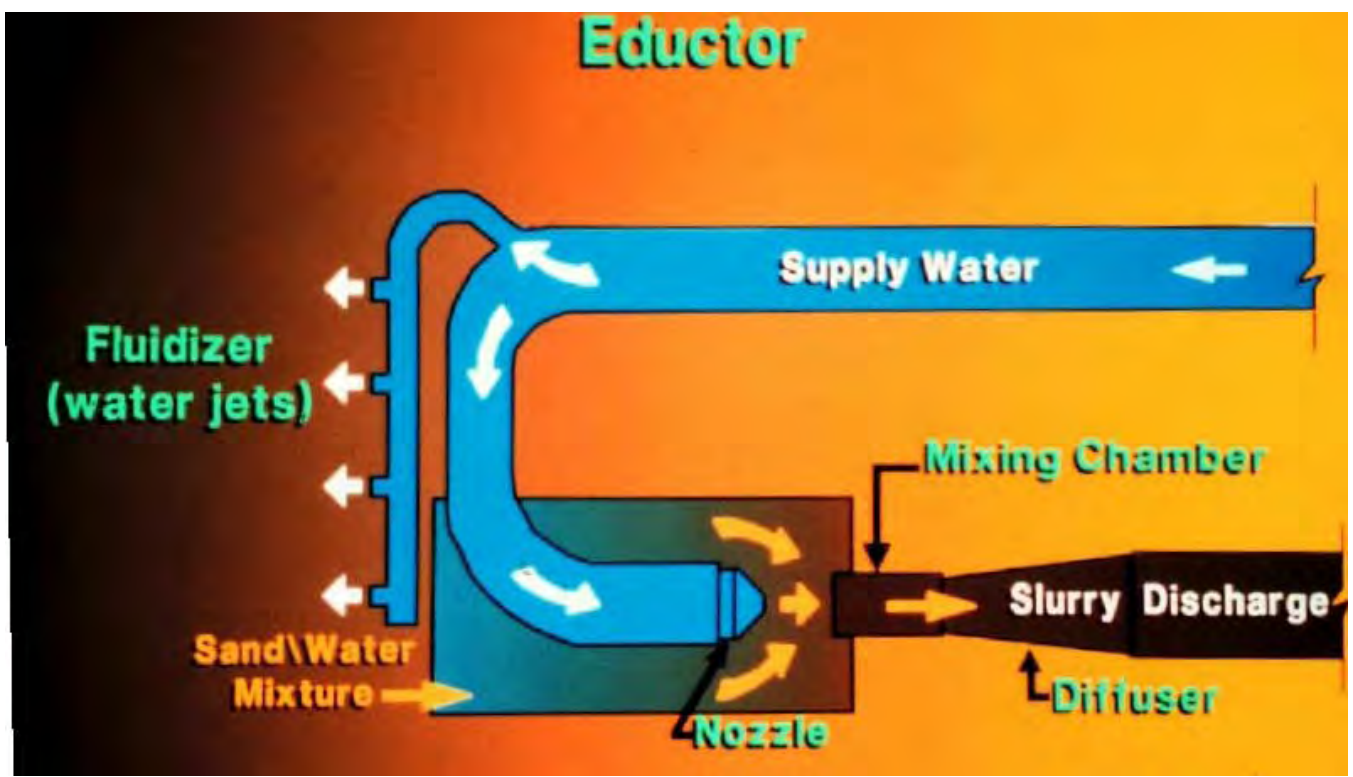

Figure 10. Eductor (jet pump) hydraulic circuit made as a slide (overhead) at ERDC.

Figure 11 shows an eductor (with and without shroud) installed at Indian River Inlet, DE, sand bypassing plant in 1990. This bypassing plant uses a single eductor deployed from a 135-ton crawler crane with a 37-m (120-ft) boom to mine the up-drift fillet in the surf zone (Figure 12). Between February 1990 and August 1991, this plant bypassed more than $153,000 \mathrm{cu} \mathrm{m}(200,000 \mathrm{cu}$ yd) of sand and successfully performed its mission. The supply (motive) water was fed by a $340 \mathrm{hp}$ pump providing

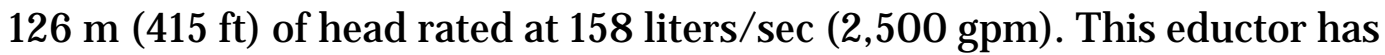
a $6.3 \mathrm{~cm}$ ( $2.5 \mathrm{in}$.) nozzle with $15 \mathrm{~cm}$ (6 in.) mixing chamber and averaged $153 \mathrm{cu} \mathrm{m} / \mathrm{hr}$ (200 cu yd/hr) discharged through an $280 \mathrm{~mm}$ (11 in.) pipe.

One advantage of eductors over conventional centrifugal pumps is that they are essentially immune from blockages in the discharge line. A brief explanation is that as the discharge line starts to clog, the pressure against which the eductor is working increases. This reduces the amount of material the eductor is entraining, thus reducing the potential for clogging the pipe. Disadvantages of the eductor are that it requires a separate motive water pump and water supply, and that the eductor can be susceptible to debris, particularly sticks and logs. 


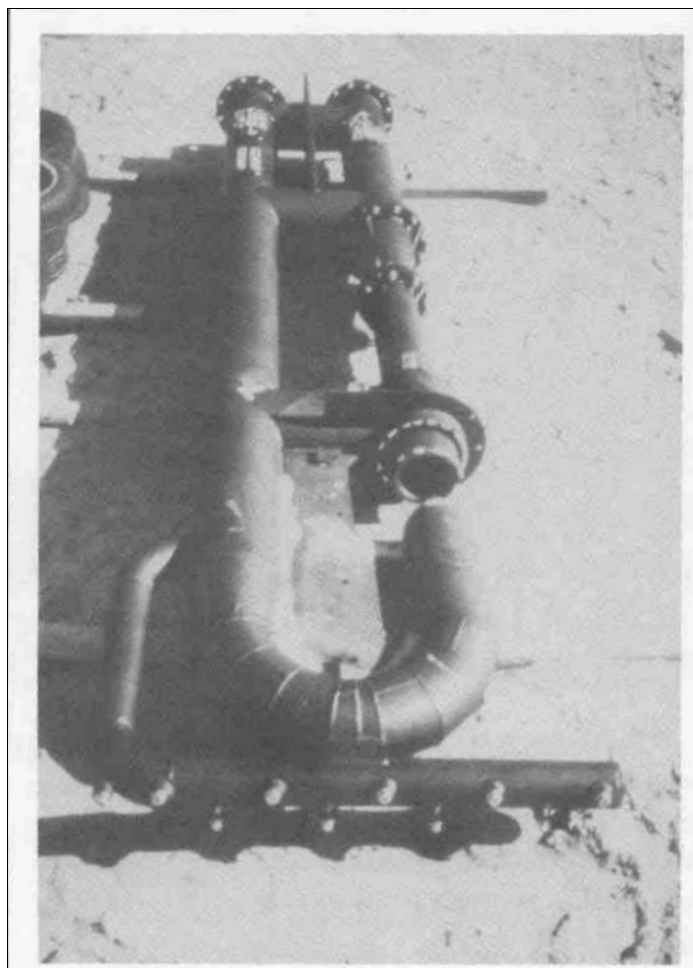

a. Without shroud

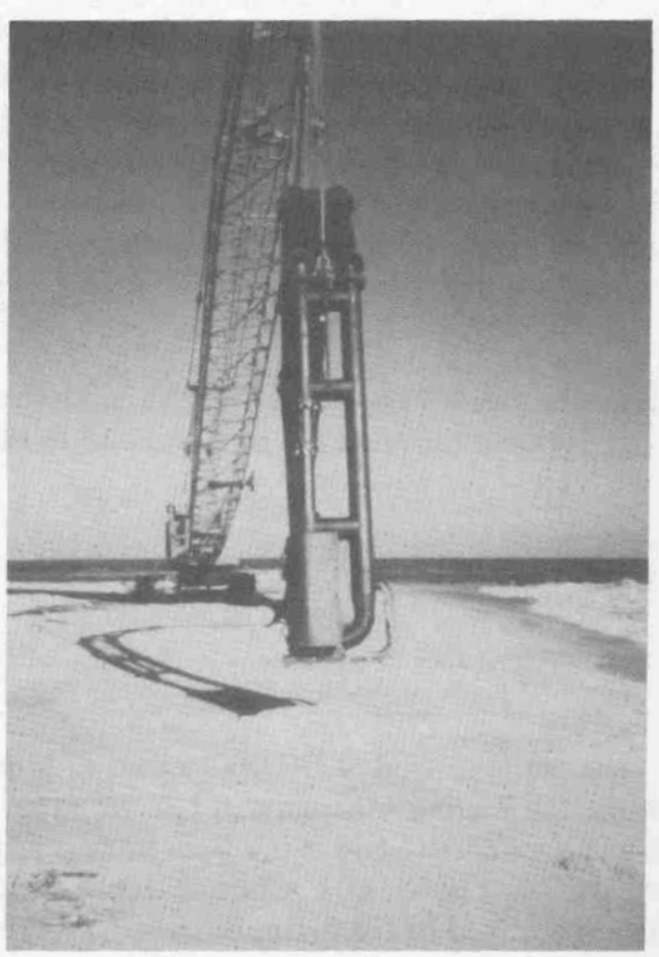

b. With shroud

Figure 11. Indian River, DE, eductor (source: Clausner et al. 1992).

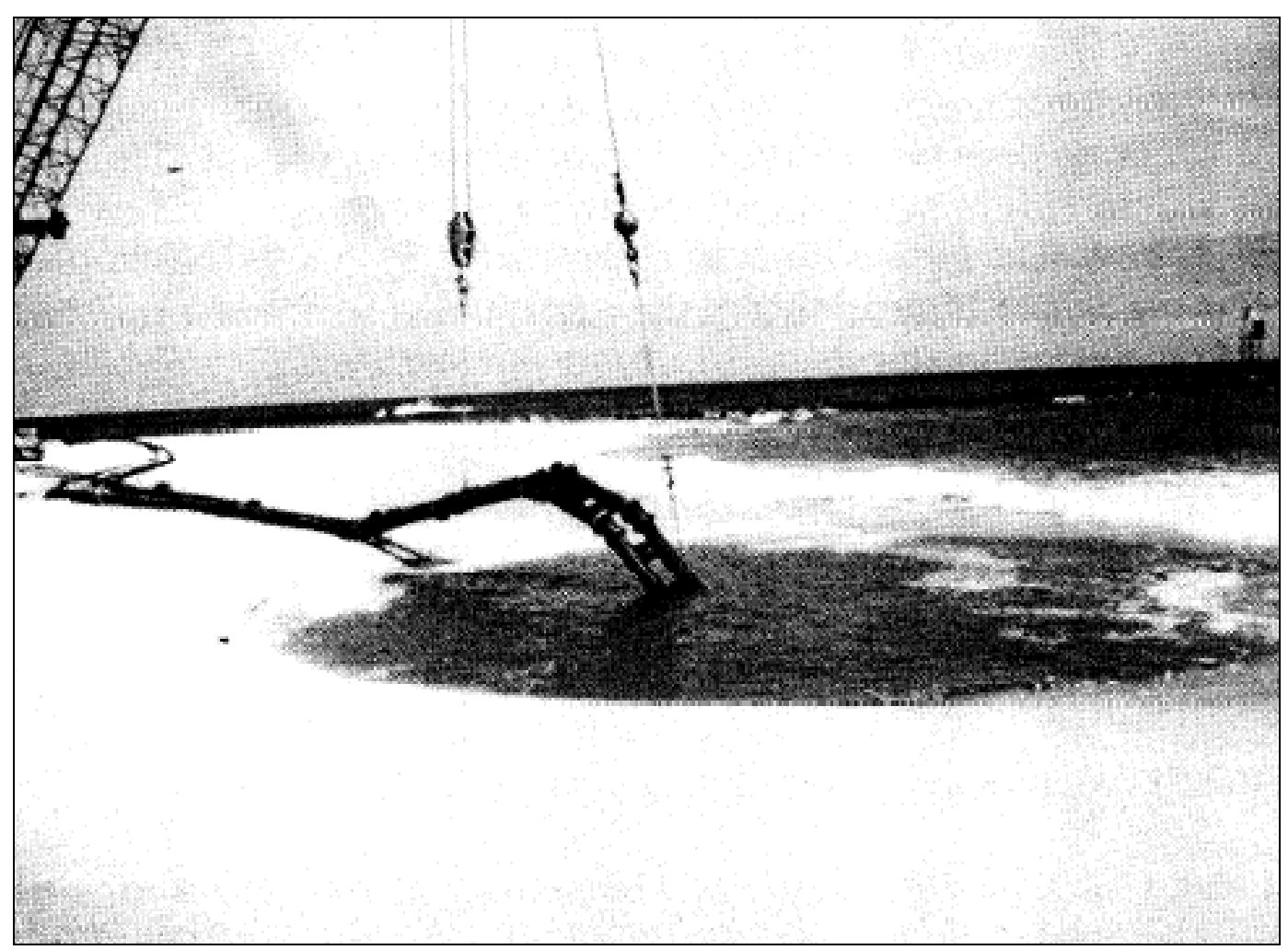

Figure 12. Indian River, DE, eductor-formed crater (source: Clausner 1990). 
Even though this type of pump has not, to the authors' knowledge, been used in a MEC dredging project, it exhibits application potential in sand projects due to its lack of moving parts and the (safety) separation distance provided by its deployment from a crane. The authors have conducted limited tests to investigate what effect the downward fluidization jets (Figure 13), coupled with the slurry momentum exchange mechanism, have on entraining MEC. It was speculated that the sand is suspended up into the water column by the water jets and entrained into the mixing chamber, while denser objects (i.e., MEC) would sink to the bottom and away from pump entrainment.

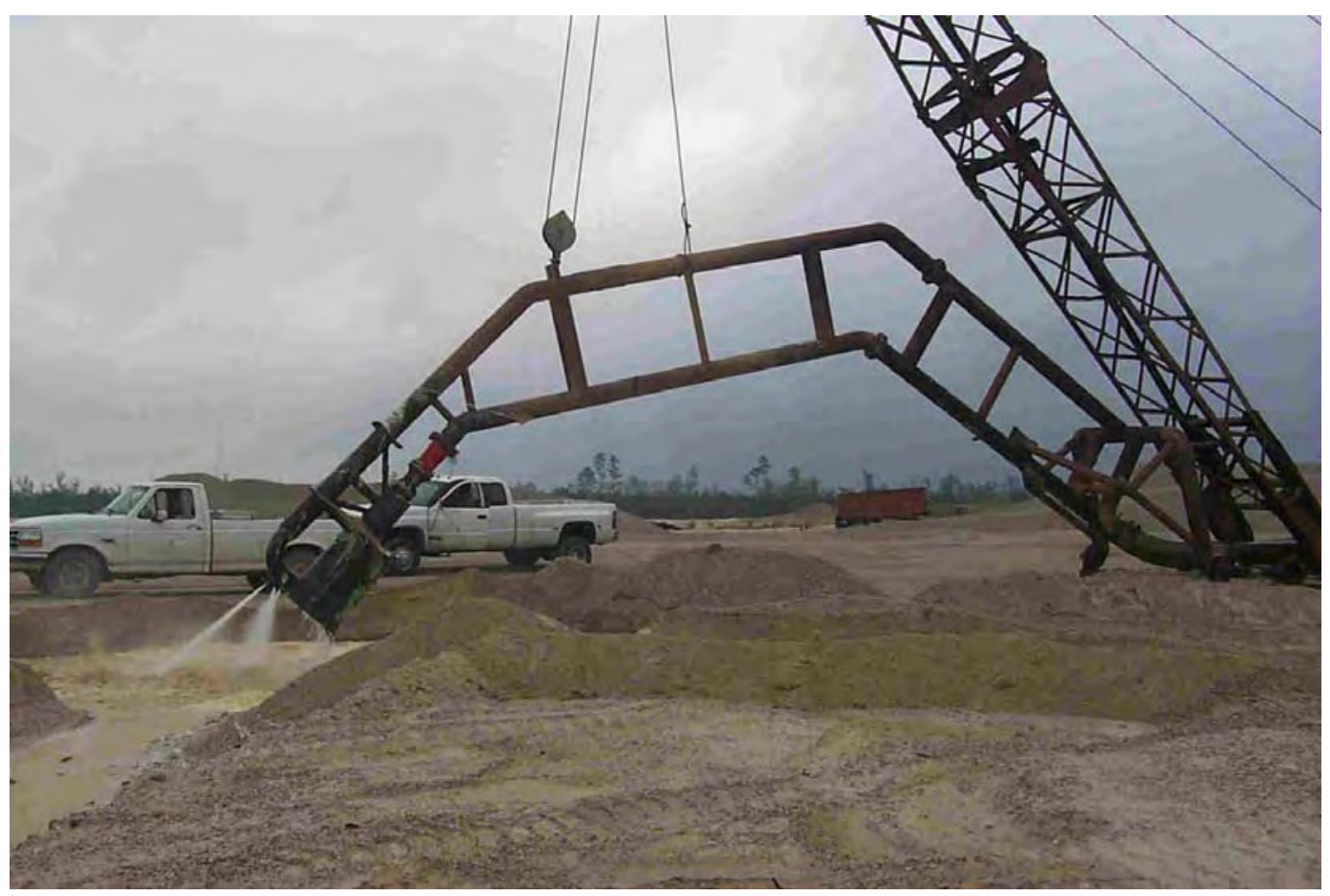

Figure 13. Standard Gravel Company (Genflo) eductor used in MEC trial.

These experiments were executed with equipment and personnel provided by the Standard Gravel Company of Franklinton, LA, the American representative of Genflo J et Pumps. Pieces of different diameter metal pipe, cut to various lengths to roughly approximate MEC ranging in caliber from 20mm (Figure 14) to $60 \mathrm{~mm}$ (Figure 15), were thrown into an eductor excavation crater as close to the mixing chamber as possible to see what the eductor would entrain. An eductor with a $15 \mathrm{~cm}$ (6 in.) diameter mixing chamber was used in these trials (Figure 13). This eductor typically pumps $100 \mathrm{cu} \mathrm{m} / \mathrm{hr}$ (130 cu yd/hr). At the eductor pump's discharge, a gravity screen separation tower with $10 \mathrm{~mm}$ (3/8 in.) apertures 


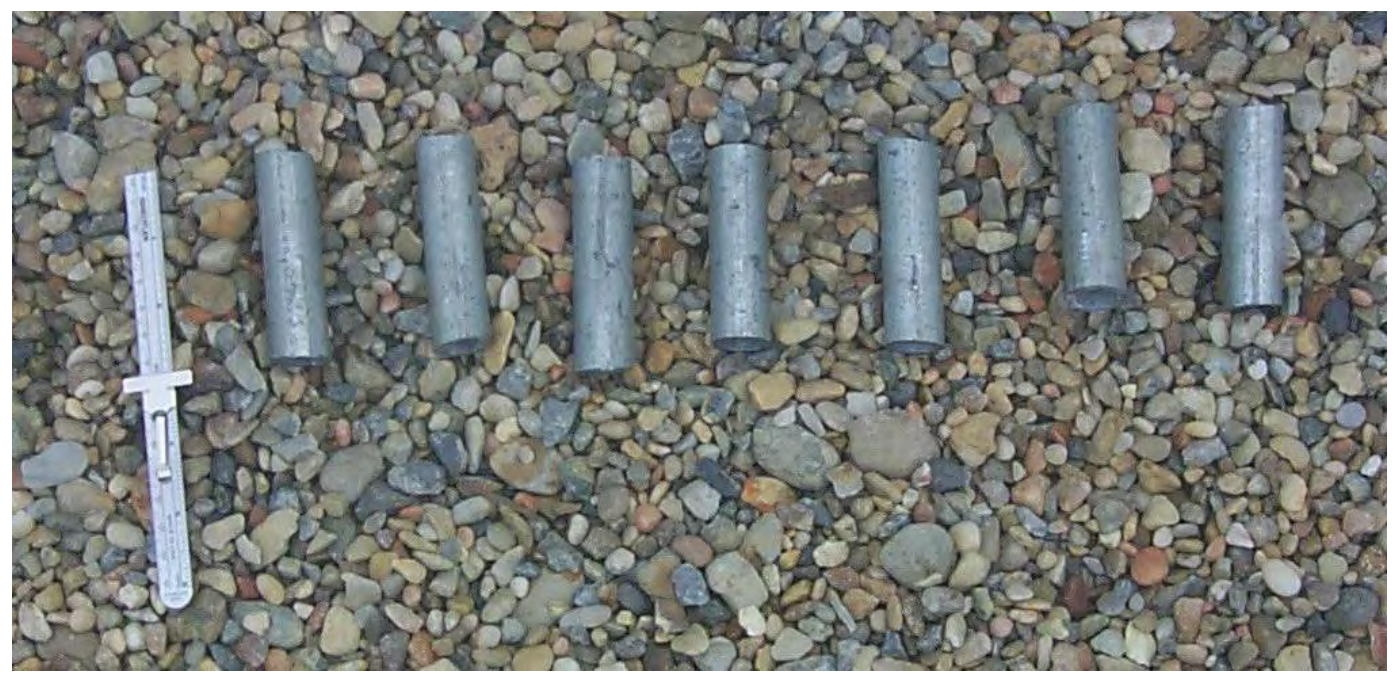

Figure 14. Example $20 \mathrm{~mm}$ drogues.

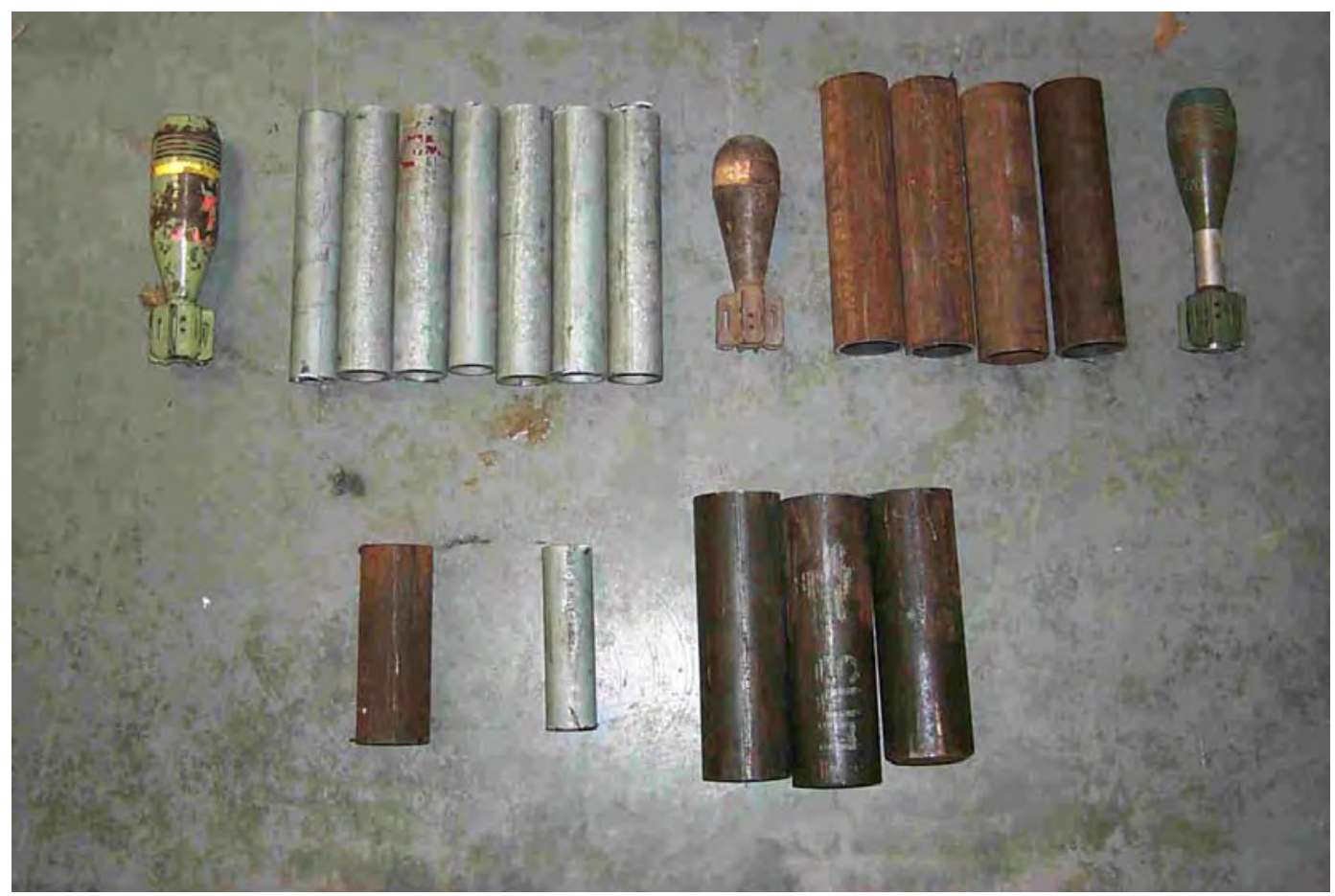

Figure 15. Example $60 \mathrm{~mm}$ drogues.

(Figure 16), used to separate gravel from sand, was also used to recover any drogues entrained by the eductor. A total of 24 drogues (ten $20 \mathrm{~mm}$ and fourteen $60 \mathrm{~mm}$ ) were thrown into the excavation crater (Figure 17) as close to the mixing chamber as was practical. From these 24 drogues, only three $20 \mathrm{~mm}$ drogues (one shown in Figure 18) and no $60 \mathrm{~mm}$ were recovered. 


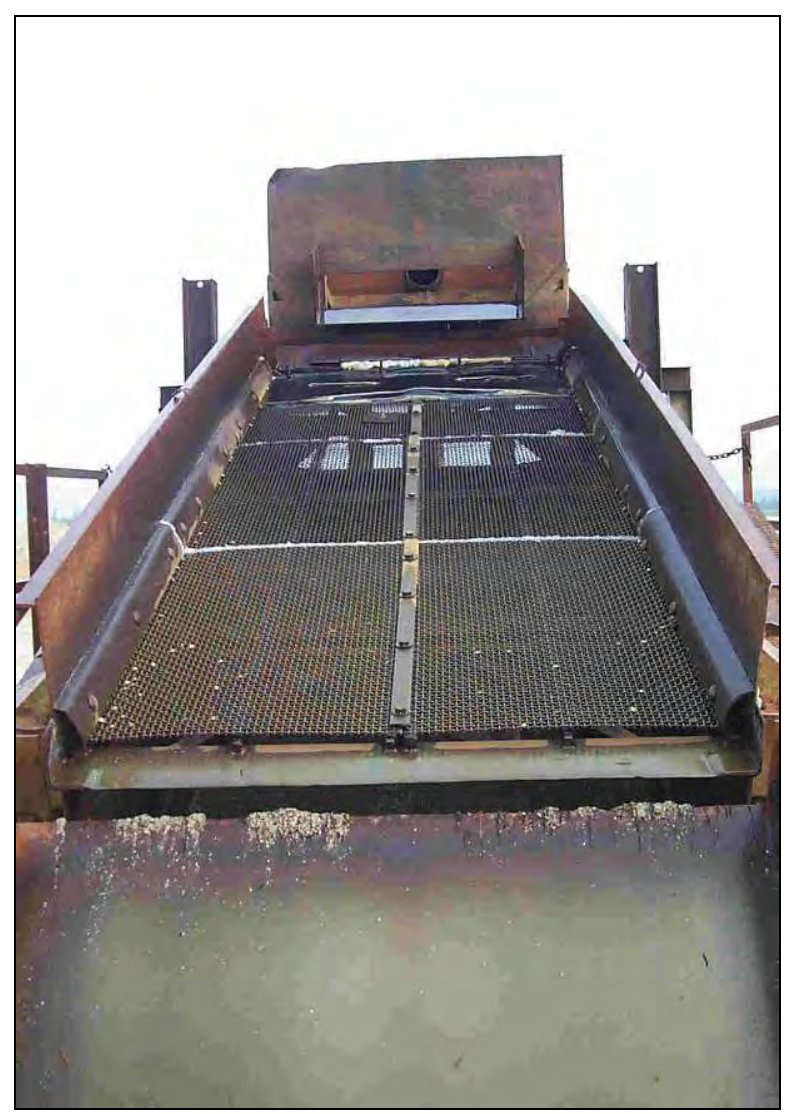

Figure 16. Screening tower with $10 \mathrm{~mm}$ (3/8 in.) apertures at pipeline discharge.

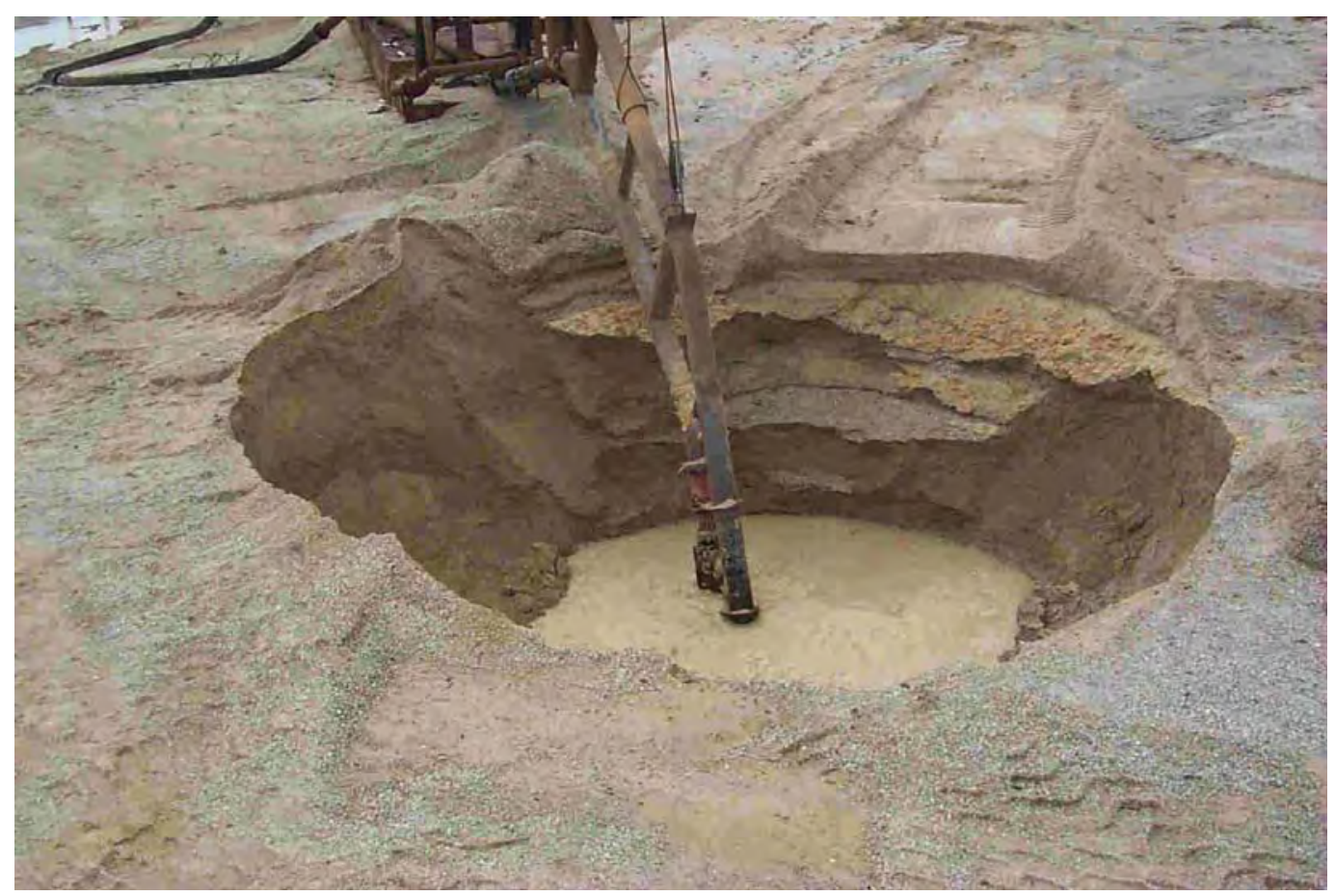

Figure 17. Eductor-formed excavation crater. 


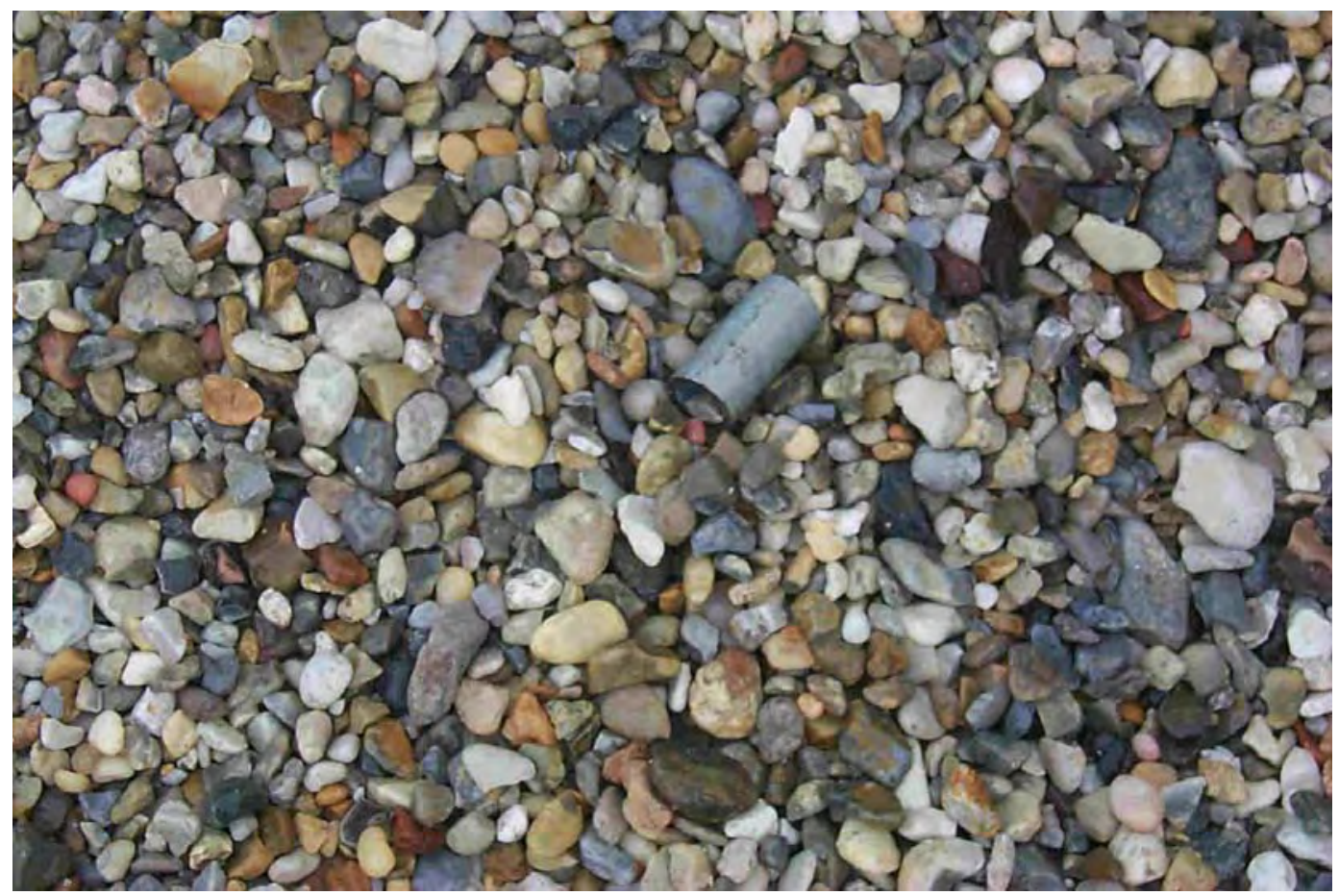

Figure 18. One of three $20 \mathrm{~mm}$ drogues recovered during eductor experiment.

\section{Submersible pumps}

Submersible centrifugal pumps are typically single-stage vertical pumps with discharge diameters that range from 100 to $300 \mathrm{~mm}$ (4 to $12 \mathrm{in}$.) (Figure 19). Pump sizes are usually based on discharge-line diameters. Submersible pumps differ from conventional dredges in that the submersible pump is placed directly in the material to be removed. Submersible pumps are powered by hydraulic or electrical motors, usually requiring a diesel power source for the hydraulic pump or a generator. The power requirements for most of the submersible pumps used in dredging applications are in the 50 to $190 \mathrm{kw}$ ( 70 to $250 \mathrm{hp}$ ) range. The pumps

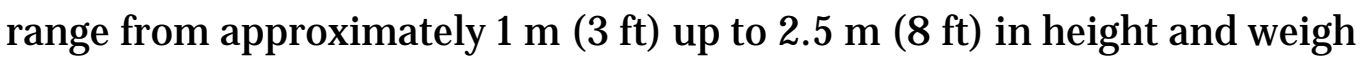
from under $227 \mathrm{~kg}$ ( $500 \mathrm{lb}$ ) to over 3,628 $\mathrm{kg}$ ( 4 tons). They can be deployed from various platforms such as at the end of a crane or the boom of a backhoe. Obviously, the smaller and lighter the submersible pump, the greater the number of deployment options. Submersible pumps (depending on the deployment method) can be easily maneuvered into areas of limited access. Some submersible pumps have an external agitator on the end of the impeller shaft that assists the material flow into the pump. In addition, an option to add a jetting ring or small cutterhead to improve material flow to the impeller is available on a number of submersible pumps. 


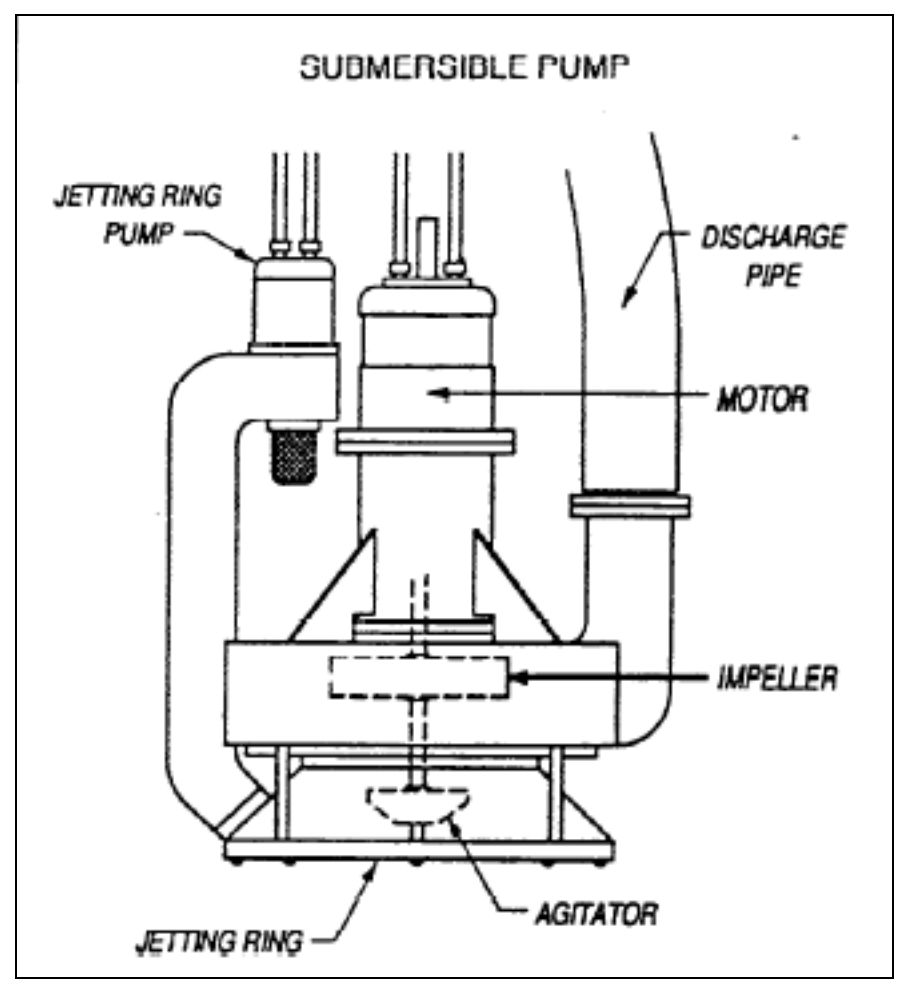

Figure 19. Submersible pump with jetting ring (source: Clausner et al. 1994).

A primary advantage of submersible pumps over eductors is that they do not require a clean water source. In coastal inlet sand-bypassing operations, eductors are often combined with booster pumps to optimize production and efficiency and to allow the discharge to be pumped from one to several thousands of feet down drift. Submersible pumps typically used for bypassing operations often have higher discharge pressures than eductors and therefore may not require booster pumps, depending on the distance the material must be pumped.

One disadvantage of submersible pumps is that they tend to dig verticalsided holes. This operating characteristic can be a particular problem in cohesive material because it makes the pump susceptible to collapse of the hole, which can bury and choke the pump and may result in the loss of the unit. Most submersible pumps are not designed for burial and selfstarting, unlike an eductor, for which the water supplied under pressure provides sufficient energy and dilution. Clean fine sand is the optimum material that submersible pumps can transport.

Tests were conducted by the U.S. Army Engineer Research and Development Center (ERDC) with different types of submersible pumps to 


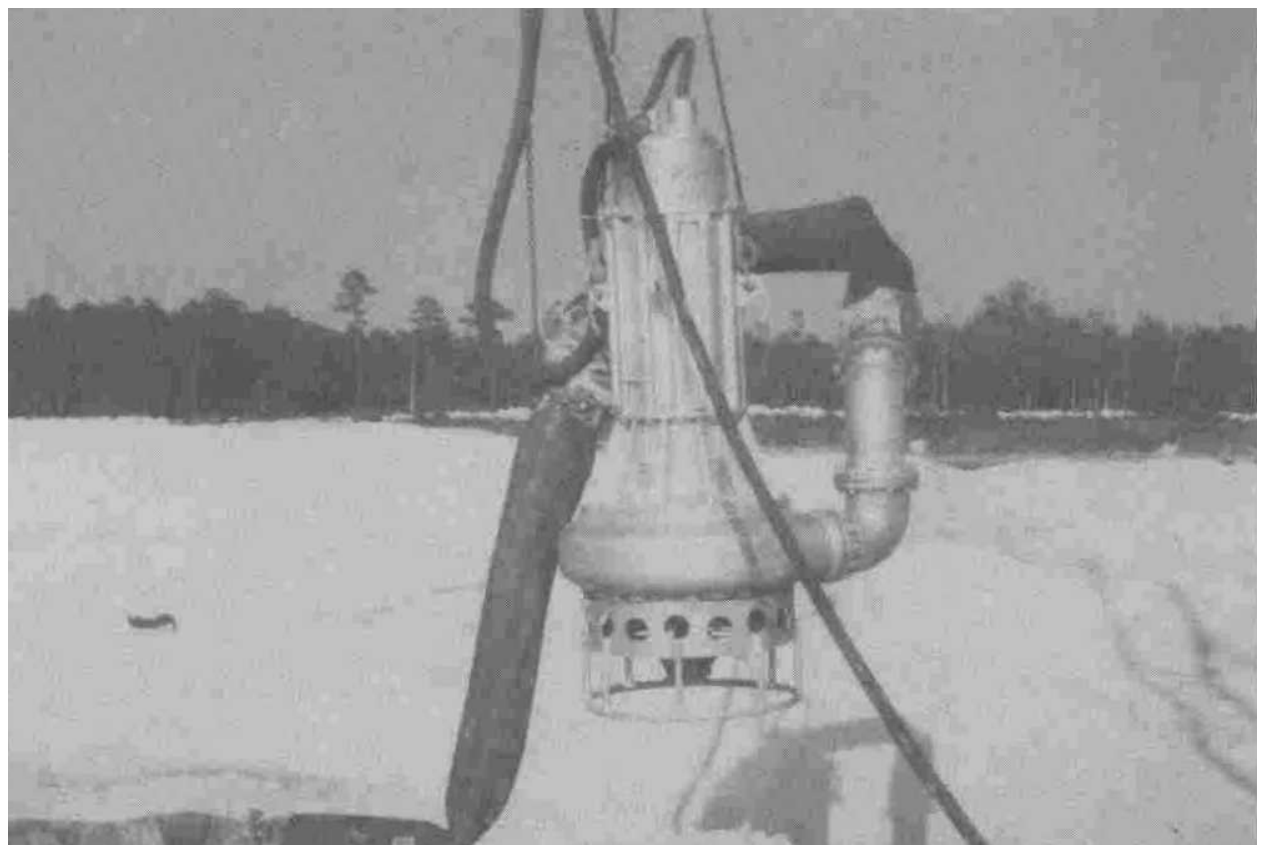

Figure 20. Toyo submersible pump with $250 \mathrm{~mm}$ (10 in.) discharge (source: Clausner et al. 1994).

investigate production in various types of debris (Clausner et al. 1994). One of the pumps, a $255 \mathrm{~mm}$ (10 in.) Toyo submersible pump (shown in Figure 20) achieved average production rates of $335 \mathrm{cu} \mathrm{m} / \mathrm{hr}$ (440 cu yd/ hr) in clean sand, and $215 \mathrm{cu} \mathrm{m} / \mathrm{hr}(285 \mathrm{cu} \mathrm{yd} / \mathrm{hr}$ ) in sand with wood debris.

This type of equipment has application potential in dredging projects due to its capacity to provide a (safety) separation distance by its deployment from a crane. Some submersible pumps also use a screen over the suction to prevent over-sized material from entering into the pump casing (Figure 21). The screen would also prevent larger-sized MEC from entering as well.

To the authors' knowledge, the only submersible pump used in MEC dredging projects is the Damen Dredging Equipment's DOP ${ }^{\circledR}$ submersible pump. A channel-deepening project was being conducted by the dredging contractor Martens en van Oord in an inland shipping channel at Twentekanaal, The Netherlands, when WWII MEC were encountered. All backhoe and excavator dredging operations were stopped due to the requirement that no MEC be brought to the surface (Damen Dredging Equipment 2007). The MEC was identified as WWII vintage that had been dumped in the canals around piers and bridges after the war. 


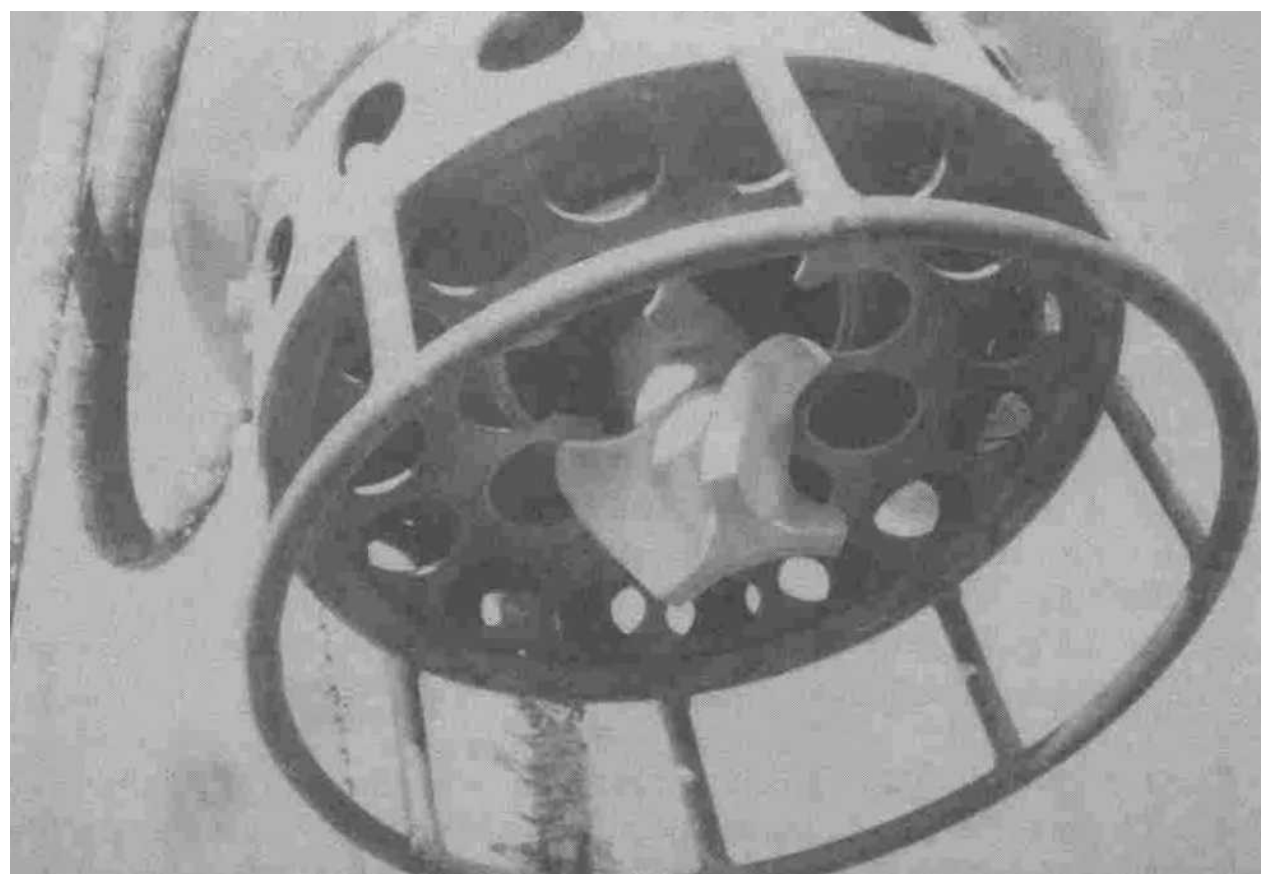

Figure 21. Submersible pump agitator and suction screen (source: Clausner et al. 1994).

A separation screen and jet-water system was designed and installed on a DOP submersible dredge pump (Figure 22). The screen was sized to exclude MEC from the hydraulic circuit and allow it to remain on the canal bottom. The jet water system was designed to reduce screen blinding. The submersible pump was connected to a backhoe stick (Figure 23) and pumped slurry to a "heavy-duty funnel-shaped barge loader" designed to capture any MEC that passed through the exclusion screen (this system has been patented by Martens en van Oord). 


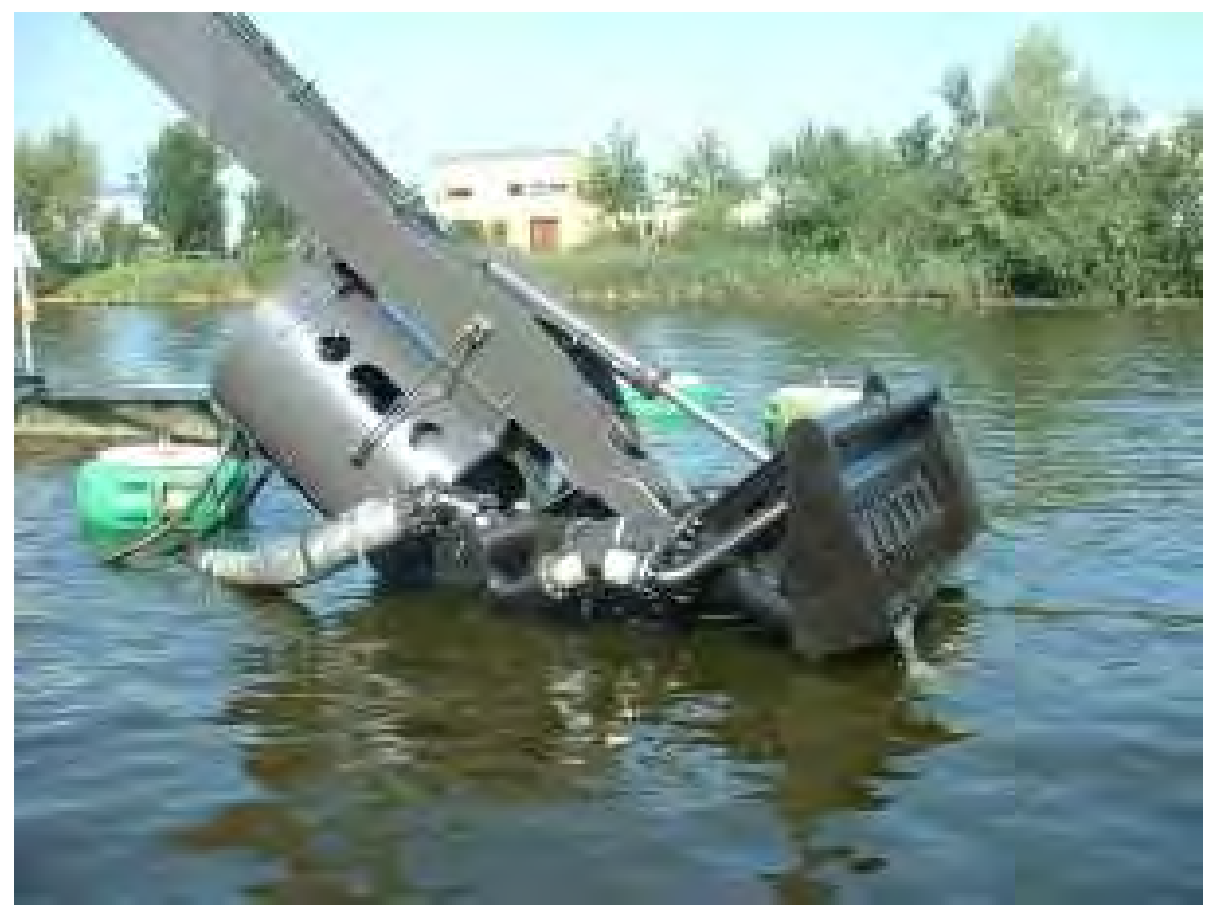

Figure 22. Submersible pump with MEC-exclusion screen (courtesy of Damen Dredging Equipment, The Netherlands).

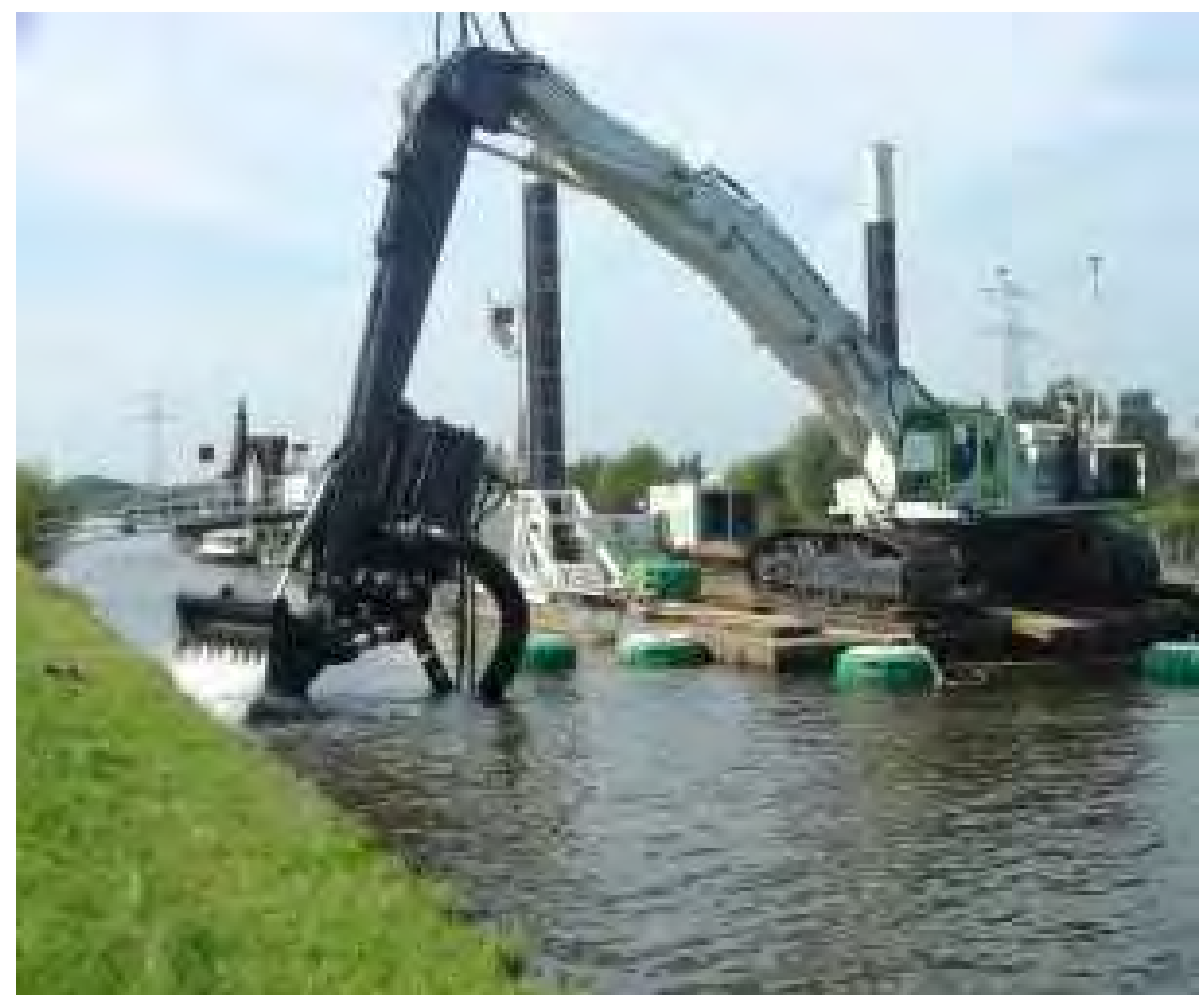

Figure 23. Backhoe-mounted submersible pump with MEC-exclusion screen and activated jet water system (courtesy of Damen Dredging Equipment, The Netherlands). 


\section{MEC Dredging Projects}

\section{Background}

The reasons that dredging is necessary are varied. They include, but are not limited to, activities such as construction of new waterways, maintenance of existing waterway dimensions, obtaining fill for land reclamation, beach nourishment, dike and levee construction, creating wetlands and marshes, or obtaining materials from borrow areas for other types of beneficial uses.

The following factors influence selection of dredging equipment and method(s) used to perform the dredging:

1. Physical characteristics of material to be dredged.

2. Quantities and physical layout of material to be dredged (i.e., thickness of dredged material layer).

3. Dredging depth.

4. Location of both the dredging and placement sites and distance between them.

5. Physical environment of and between the dredging and disposal placement areas.

6. Contamination level of sediments.

7. Method of placement.

8. Production required.

9. Type of dredges available.

10. Presence of MEC.

MEC can have a critical impact on project circumstances due to the potential hazard posed by that MEC to the dredge crew, the public, and dredging equipment.

A primary reason MEC exists in these underwater sites is from military activity in existing and formerly used military training and test firing ranges, disposal in documented and undocumented locations (Maddrell 2001), and from military conflicts (Welp et al. 1994; Maddrell 2001). Underwater MEC sites exist in ponds, lakes, marshes, streams, rivers, estuaries, harbors, canals, seas, and oceans. Some sites have existed for decades and are well-known, while MEC at other sites are discovered 
during dredging operations. This MEC unexpectedly appears somewhere in the dredging system (such as lodged in a cutterhead, rattling in the stone box, or lying on a disposal site) or it explodes. The type(s) and number of UXO, DMM, and/ or MD encountered on a dredging project can vary dramatically as illustrated by the MEC/ dredging projects described in the following chapter.

Certain types of MEC can remain potentially dangerous for very long periods of time. For example, several American Civil War era (1861- 1865) artillery shells equipped with percussion and "uncut" time fuses (both generally equipped with watertight seals) have been recovered that can be classified as UXO (Kerksis and Dickey 1968). An explosive ordnance disposal (EOD) guidance document was prepared by the U.S. Navy because of the continuing need for guidance in safe and proper inerting of explosive Civil War MEC (U.S. Naval School EOD 1972). Not all apparent MEC items contain energetic material. Only a qualified EOD or UXO technician can determine which items are considered UXO or DMM and dealt with accordingly. In some cases, it may not be possible to visually determine what the item is due to corrosion or encrustation.

While documentation of past projects that have encountered MEC is sparse, it appears that it is more often encountered in new work projects as opposed to maintenance dredging projects (Welp et al. 1994; Halkola et al. 2006). New-work dredging is conducted in areas that have not previously been dredged, while maintenance dredging is the cyclic dredging of a constructed project over a period of time to remove recurring sediment (shoal buildup) to allow unobstructed ship and barge traffic.

The majority of documented MEC/ dredging projects include those involved with navigation and beach renourishment, along with a couple specialized projects involving environmental dredging (dredging to remove contaminated sediments) and trenching. Examples of MEC encountered in new work have been described by Welp et al. (1994), Maddrell (2001), and Halkola et al. (2006). Summary information on these projects is presented by Halkola et al. (2006). This technical report will discuss these projects in greater detail (where possible) to provide information to those involved in $\mathrm{MEC} /$ dredging projects in a more categorical manner (by project type, dredge class, etc). 


\section{General planning approaches to MEC dredging projects}

The relative magnitude of some of the effects that MEC can have on dredging projects depends on factors such as (modified after Welp et al. 1994):

1. MEC presence (how many, what type, what caliber?).

2. Timing of the determination that MEC exists at the site (when was MEC discovered?).

3. Type of dredging project being conducted (navigation, beach renourishment, remediation).

4. Relative size of dredging project.

5. Feasible alternatives to obtain original dredging goals.

6. Contractual issues (i.e., scheduling, payment basis, risk allotment).

7. Type(s) of dredges used.

8. Potential environmental impacts.

9. Social and political considerations.

10. Dredging location in relation to people, structures, resources, etc.

A decision flowchart was originally developed by Halkola et al. (2006) to assist in the development of a plan for safely executing dredging in MECcontaminated sediments. Figure 24 is a modified version of that original flowchart. This report presents information regarding those aspects (components) when information was available (from previous MEC dredging projects) to draw upon. These experiences are presented in a "current practices" guidance format for the purpose of assisting the reader in dealing with MEC in their own respective dredging project. This flowchart begins in the preliminary planning stages of the dredging project, but, as illustrated by some of the experiences described in the following sections, more than one project has unexpectedly encountered MEC after digging has started. Appendix B contains an enlarged version of this flowchart.

Due to the relatively high financial costs of post-beach renourishment removal of MEC, the presence of MEC in an offshore borrow area should be assumed until proven otherwise. As an example, the Coastal Storm Damage Reduction Project (CSDRP) in Surf City, NJ (2007), cost about $\$ 6 \mathrm{M}$ to place approximately 880,000 cu yd of sand. The estimated total cost of removal of MEC inadvertently placed with the sand is approximately $\$ 20 \mathrm{M}$. The MEC appears to originate from an uncharted "disposal 


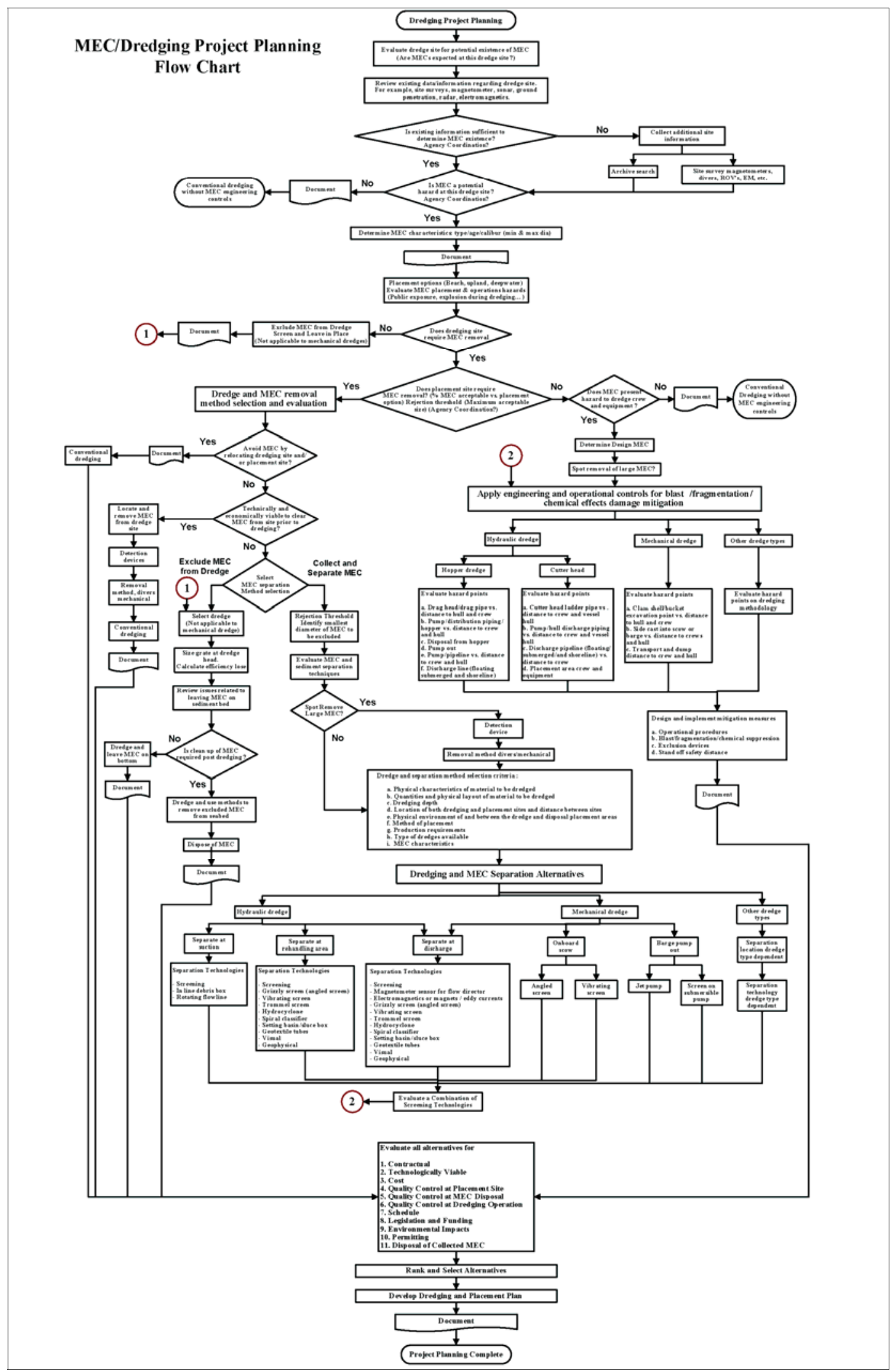

Figure 24. Flow chart. 
at sea" dump site that coincided with the selected borrow area. These uncharted dump areas can occur anywhere offshore. The cost of preventing the introduction of MEC with placed material is far less than postdredging removal. A recent (2007-2008) dredging project in Bethany Beach, DE, implemented MEC prevention techniques. The actual costs of preventing MEC from entering the dredging stream by the dredging contractor on this 3.2 million cu yd project was approximately $\$ 100,000$. The cost incurred by the government while providing UXO Safety Specialist oversight was about $\$ 200,000$.

\section{What to do if MEC is encountered unexpectedly onboard a dredge}

If MEC is encountered unexpectedly on a dredging project onboard the dredge, the subsequent actions of the crew will depend on the circumstances. Some general tips on how to respond if you suspect that you have encountered munitions are the 3Rs presented in the document "Munitions at Sea, A Guide for Commercial Maritime Industries" by the Defense Ammunition Center, U.S. Army Technical Center for Explosives Safety. This document is available at https://www.denix.osd.mil/denix/Public/Library/ Explosives/UXOSafety/ESG/MunitionsAtSeaREAD.pdf and is provided in Appendix C of this report.

The 3Rs consist of:

RECOGNIZE: Recognize when you may have encountered a munition.

RETREAT: If you know or suspect you have encountered a munition, jettison it or secure it and keep the crew out of the immediate area.

REPORT: Immediately notify the U.S. Coast Guard of the vessel's or munition's location and provide a description of the munition.

Emergency contacts:

- In port: Call 911.

- At sea: Use channel 16 (156.800 MHz).

A document that presents information on MEC basic safety concepts and considerations is USACE Engineer Pamphlet (EP) 385-1-95a "Basic Safety Concepts and Considerations for Munitions and Explosives of Concern 
(MEC) Response Action Operations" (HQUSACE 2004)

(http://www.usace.army.mil/publications/eng-pamphlets/ep385-1-95a/entire.pdf).

\section{MEC dredging decision flow}

The flowchart (Figure 24) begins with a historical review to evaluate the likelihood that MEC will be encountered during the dredging operation. Results of this evaluation define whether conventional dredging is viable or whether special dredging procedures must be used. The characteristics, if known, of the MEC (type/ caliber/ age) would also be determined and documented during this phase.

In the flow of this process, the dredging project employer (entity requiring the dredging) is required to coordinate with their respective MEC safety organization (i.e., Baltimore District Military Munitions Design Center, http://www.nab.usace.army.mil/MilitaryMunitions/mmdc.htm) for USACE projects, and the Naval Ordnance Safety and Security Activity (NOSSA) (http://www.nossa .navsea.navy.mi//) for U.S. Navy projects. While safety in MEC-related activities is a primary mission of these centers, they differ somewhat in their respective submittal, review, and approval procedures used to achieve that safety objective (e.g., health and safety plans, explosive safety plans, explosive safety submittal, etc.). A detailed discussion of specific regulations and required submittal, review, and approval documents/ processes of these different organizations in relationship to the Department of Defense Explosives Safety Board (DDESB) ${ }^{1}$ is beyond the scope of this document.

Personnel performing munitions response to Army MEC projects are responsible for safely executing these operations in accordance with the approved Safety Program including the Site Safety and Health Plan, Accident Prevention Plan, approved Work Plan, and all applicable laws, regulations, and policies. A detailed discussion of USACE organizational responsibilities for Military Munitions Response Program (MMRP) projects is presented in Engineer Regulation (ER) 1110-1-8153 (HQUSACE 2006). Safety and health requirements, responsibilities, and procedures for MEC operations are defined in ER 385-1-95 (HQUSACE 2007b) and Engineer Manual EM 385-1-1(HQUSACE 2003).

\footnotetext{
1 The DDESB mission is to provide objective advice to the Secretary of Defense and Service Secretaries on matters concerning explosives safety and to prevent hazardous conditions to life and property on and off DoD installations from the explosives and environmental effects of DoD titled munitions (http://www.ddesb.pentagon.mil/).
} 
For applicable U.S. Navy projects, an Explosive Safety Submission (ESS) must be made in accordance with Naval Ordnance Safety and Security Activity Instruction 8020.15, Military Munition Response Program Oversight (U.S. Navy 2003).

Once it is determined that MEC issues need to be addressed during the dredging operation, four general paths evolve in the decision flowchart. These paths are based on whether the objective is to remove MEC from: (1) the dredge site, (2) the dredged material placement site, (3) neither site, or (4) both. All paths address the safety of personnel and dredge/ placement equipment. In cases 2 and 3, where MEC are not required to be removed from the dredge site, the dredging operation is simplified by excluding the MEC from the dredge and leaving it on the seabed (for hydraulic dredges only). For case 4, the dredge site and the dredge material placement site require MEC removal, separation, and disposal. Specifically, when the dredge site and the placement site require MEC removal before dredging or transportation through the dredge followed by the separation of the MEC, then the focus of the MEC handling needs to be on the safety of the personnel and equipment. This case 4 path includes four sub-paths that address the following:

1. Selecting new sites, if possible, to avoid MEC issues.

2. Clearing MEC from the dredge site before dredging.

3. Excluding MEC during dredging and using post-dredging cleanup of the munitions on the seabed.

4. Separating MEC from the dredge material and collecting them during the dredging and/ or placement process.

Where MEC separation from the dredge material and its collection during the dredging and placement operation is required, a "rejection threshold" is identified as the diameter of MEC that will be excluded from the dredging operation at the suction end of a hydraulic dredge. Any MEClarger than this size would be left on the seafloor. Multiple criteria are suggested to select dredge types and separation methods. Additionally, a variety of separation methods are identified in the decision flowchart for application at various locations in the dredging process for different dredge types.

At the final phase of the decision flowchart, all alternative paths are evaluated on multiple criteria. The alternatives are reviewed and the optimum 
alternative is selected. The decision flowchart also recommends that dredging and placement plans need to be well documented.

This flowchart with its various components is intended only as a general framework to assist in the development of a plan for safely executing dredging in MEC-contaminated sediments. It was formulated with an emphasis on illustrating different considerations that would have to be evaluated for modifying dredging equipment. Project-specific conditions stated above will dictate how the various flowchart components will interact with each other and how they are prioritized (aspects [i.e., type of dredging project], different stakeholder involvement [states and other federal government agencies, non-governmental organizations, etc.], explosives safety submittals, engineer regulations, required approvals, etc.).

No absolutely safe procedures exist for dealing with MEC, merely procedures considered to be least dangerous. It is essential that a planned and systematic approach to dealing with such items be established. Plans should be developed to expose the least number of people to the minimum amount of MEC for the shortest amount of time. Past projects have proven that it is safer and usually more cost effective to address the presence of MEC from the very outset of the dredging project (i.e., in planning), as opposed to dealing with it later after the actual dredging has started.

\section{Archive search (historical records review)}

One of the first steps in evaluating the likelihood that MEC might be encountered on a dredging project is to conduct an archive search (historical review). Different "levels of effort" can be exerted in performing a search to determine if the dredging site falls within a range fan, impact area, or an identified or unidentified MEC disposal site (i.e., a sea dumping area and ammunition depot pier, respectively). Often the information available may be slightly inaccurate. If the dredging site is close to one of these areas, it may be prudent to err on the side of safety. A number of sources of information can be consulted to ascertain probability of MEC including:

1. USACE Archive Search Districts.

2. U.S. National Archives, College Park, MD; Regional Offices, St. Louis, MO.

3. Library of Congress. 
4. U.S. Environmental Protection Agency Environmental Protection Indicators for California Files.

5. Defense Environmental Network and Information Exchange (DENIX), Defense Technical Information Center, Army Environmental Center, Corps' Project Information and Retrieval System, Munitions Items Disposition Action System, DDESB, U.S. Army Soldier and Biological Chemical Command, and Naval Ordnance Safety and Security Activity (NOSSA).

6. Service Military History Centers and Safety Centers.

7. Other Federal Agencies, i.e., Department of Interior, Bureau of Land Management, U.S. Coast Guard, and General Services Administration.

8. LEXIS/NEXIS and other web searches.

9. State and county government archives.

10. State and local historical organizations.

11. City and county clerks offices.

12. Local libraries and newspapers.

13. EOD reports.

14. Local police reports.

Investigation of these sources may help to determine if historical evidence exists that indicates channels, anchorages, mooring areas, piers, or wharves once or currently being used by Navy, Army, or Coast Guard vessels for loading, unloading, or transferring munitions. Efforts should investigate the entire known history for the site. It is a documented fact that cannonballs from the earliest days of our country's history can still detonate given the right circumstances.

One source of MEC contamination in borrow areas (offshore locations where sand is dredged for beach nourishment and renourishment projects) is that these areas have fallen within the impact areas of coastal defense artillery batteries, or anti-aircraft batteries. Artillery shells can be fired a considerable distance (i.e., a $120 \mathrm{~mm}$ (4.7 in.) projectile firing range can be approximately $8.05 \mathrm{~km}$ ( $5 \mathrm{mi}), 406 \mathrm{~mm}$ ( $16 \mathrm{in}$.) projectile firing range can be over $32.2 \mathrm{~km}$ ( $20 \mathrm{mi})$, and anti-aircraft batteries in WWI and WWII normally fired projectiles up to a $90 \mathrm{~mm}$ diameter with approximate ranges up to $6.44 \mathrm{~km}$ (4 mi).

Additional references for historical record reviews include Interstate Technology and Regulatory Council Response Historical Records Review (http://www.itrcweb.org/teampublic_UX0.asp), USACE EP 1110-1-18, Ordnance and 
Explosives Response, Chapter 7, 24 April 2000 (http://www.usace.army.mil// publications/eng-pamphlets/ ep1110-1-18/c-7.pdf), and USACE Engineer Manual (EM) 1110-1-1200, Conceptual Site Models for ordnance and explosives (OE) and hazardous, toxic and radioactive waste (HTRW), 3 February 2003 (http://www.usace.army.mil/inet/usace-docs/eng-manuals/em1110-1-1200/toc.htm).

\section{MEC detection and discrimination}

Various technologies have been used to detect and/ or discriminate underwater MEC in the past in relatively shallow waters ( $<20 \mathrm{~m}[<65 \mathrm{ft}])$. Current research is being conducted to improve these capabilities. The following sections give examples of such technologies.

Sea Bright project

Underwater detection technologies were investigated during the Ordnance Reconnaissance Study for the Sandy Hook to Barnegat Inlet, New J ersey, Beach Erosion Control Project (Parsons et al. 1999) to investigate the feasibility of identifying clean areas (areas not contaminated with MEC) within the Sea Bright sand borrow area that did contain MEC. These technologies included:

1. Synthetic Aperture SONAR.

2. Magnetometers and electromagnetic induction sensors.

3. Magnetometer/SONAR.

4. Differential Magnetometer.

5. Mobile Underwater Debris Survey System.

The feasibility of site characterization of the borrow area (approximately $7.77 \mathrm{sq} \mathrm{km}$ [3 sq mi]) was investigated to see if screening requirements during dredging operations (screens on dragheads) could be relaxed to improve production. Geophysical detection of the 37-mm projectile was the lowest threshold target as this is the smallest known UXO to have been discovered in the borrow area. It was reported that the small mass of this target presented a unique challenge to site characterization because the most advanced geophysical instruments (in 1994) could detect an anomaly of such a small mass and density only to a maximum of $2 \mathrm{ft}$ below the bottom surface. Hand-held geophysical instruments had a detectable range for the 37-mm projectile of only $2 \mathrm{ft}$ (Parsons et al. 1999). 
This project's site characterization methodology for having the dredge avoid MEC was described by Parsons et al. (1999) as follows:

In general, the larger the ordnance and the closer it is to the surface of the seabed, the greater the accuracy of the detection method. Current methods of ordnance detection are generally limited to 2 to $4 \mathrm{ft}$ below the seabed for detection of the smallest ordnance. Larger ordnance may be detected at greater depths depending on the ordnance size and method of detection. However, to consider elimination of exclusion screens, dredging operations would be limited to the practical detection depth for the smallest ordnance. This means that multiple survey passes are required over a given area to utilize the full depth of the borrow material layer. In-water site characterization to the $15 \mathrm{ft}$ dredging depth will require the coordinated efforts of the geophysical data collection team and dredge operators. The borrow area should be divided into a number of smaller sections such that dredging and characterization procedures can alternate between areas without significant dredge downtime. The geophysical data collection team would begin by characterizing the area. At the completion of characterization to a depth of $4 \mathrm{ft}$, maps showing the location of suspected UXO would be provided to the dredge operator. The known areas would be avoided, and those areas showing no ordnance to $4 \mathrm{ft}$ would be dredged to a safe depth of $2 \mathrm{ft}$. Note, dredging in $2-\mathrm{ft}$ intervals is assumed to compensate for lack of accuracy of both detection and dredging equipment and to provide an additional factor of safety.

The geophysical data collection team would then return to conduct a second pass over the area to detect anomalies to another $4 \mathrm{ft}$ bringing the total area characterized to a depth of $6 \mathrm{ft}$ within the area.

This process will be repeated until the entire borrow area has been dredged to a depth of $15 \mathrm{ft}$. Data 
collection and dredging activities may be performed concurrently provided the safe separation distance, established by the Corps of Engineers, is strictly maintained.

Site characterization technology capable of detecting small ordnance in the marine environment (was) is still in the development stage. At the time, the accuracy of ordnance detection technology was between 2 and $4 \mathrm{ft}$ below the sea bottom, practical dredging tolerances are plus/minus $6 \mathrm{in}$. to $1 \mathrm{ft}$ in the vertical direction and more than twice that in the horizontal direction. Therefore, complete avoidance of ordnance would be extremely difficult and inefficient. Dredging production losses of 10 to 20 percent are estimated to account for the multiple passes, avoidance of ordnance contaminated areas, loss of borrow source material and coordination/ downtime between the surveys and dredging operations. In addition, for quality control purposes, on-beach ordnance surveys are required to supplement the offshore surveys, if ordnance exclusion screens are eliminated.

Parsons et al. (1999) concluded, because of the high potential costs and continued risks associated with this avoidance alternative, that it not be recommended for further study.

Former Erie Army Depot

Pope et al. (1996a) field-tested and used magnetics (Proton 3 magnetometer), electromagnetics (EM61), ground penetrating radar, high frequency side scan sonar, and an underwater video camera system on a remotely operated vehicle (ROV) to investigate Lake Erie MEC densities at the former Erie Army Depot near the Toussaint River in Port Clinton, OH. They report that:

Electromagnetics. The electromagnetic study at the Toussaint River spit test site of buried inert ordnance documented the capabilities of the EM61 system in detecting and locating buried ordnance both on land and under water. Furthermore, the calculated depths 
of buried inert ordnance placed in the Toussaint River spit area was in general agreement with the placed depths. With a controlled survey grid, the EM61 has the potential to be used to map approximate depth of burial and the gross size of ferromagnetic objects (Authors' note: The EM61 is not limited, as magnetometers are, to the detection of just ferromagnetic objects). However, the EM61 antenna and electronics need further ruggedization and a more automated deployment procedure to improve waterborne survey coverage and efficiency. In particular, a deployment technique which allowed for running offshore perpendicular lines would allow better correlation of the bathymetry with ordnance concentration.

Waterborne measurements using the EM61 system confirmed suitability of the electromagnetic method for underwater studies and its suitability in the detection and delineation of ordnance and explosive waste (OEW) concentrations. Waterborne electromagnetic survey carried out in the East Zone area defined two very localized areas of higher concentrations of OEW presence on the lake bottom. This type of information was necessary to understand the physical processes which are moving and concentrating the ordnance.

Magnetics. Waterborne total field magnetics proved satisfactory for gross mapping of ordnance concentration zones over a broad area. The marine total field magnetic investigation defined the zone of ordnance density in Lake Erie off of the shoreline of the former Erie Army Depot and defined the general boundaries of this ordnance field. Within this region, two higher density ordnance fields which lie close to the beach were resolved. The results of the transient electromagnetic survey conducted in the Central Zone and East Zone corroborated well with the nearshore portions of the waterborne total field magnetic data. In some areas ferromagnetic target density exceeded detection frequency of the magnetometer, limiting the 
applicability of this system for pinpoint mapping and classification of complex ferromagnetic target fields. Further improvements in survey quality would be realized by developing a swath-like deployment technique.

Ground penetrating radar (GPR). GPR showed promise in locating bottom OEW in fresh water. Data collected during this study suggest that GPR might be used to detect the orientation of a target, particularly if the antenna polarization was deployed perpendicular rather than parallel. This should provide much more favorable results. Further improvement in the GPR deployment procedure to allow stable towing above the bottom is needed due to safety concerns in ordnance-contaminated areas.

Side-scan sonar (SSS) and remotely-operated vehicle (ROV). Shallow-water towing of the $200 \mathrm{KHz}$ SSS required a relatively calm sea state to optimize sonograph quality. During this study SSS did detect suspected ordnance concentration field and various bottom texture patterns. Larger features including stone fields, cables, linear drag-marks, and containers were readily detectable. However, the real value of the SSS was in providing an image of the bottom sediment reflectivity which, with proper ground truthing (obtained via sampling and ROV imagery), can provide information suitable for mapping bottom type.

Underwater video is extremely helpful in defining bottom types and for inspecting underwater target objects. However, the murky waters and silty bottom at this site limited the visibility and effectiveness of an ROV. Results would have improved with a low light camera and/ or less turbidity. Even with this limitation, the ROV and underwater video did provide information on bottom type and the stability of objects in deeper water. 
Oresund Link project

Maddrell (2001) reports that for this European dredging project to excavate a $120 \mathrm{~m}$ (393 ft) wide trench for a tunnel in sediment contaminated with MEC (50 kg [110 lb] bombs) that an eight channel magnetometer system, operated by Heinrich Hirdes $\mathrm{GmbH}$, was used. The objective was to detect bombs or other MEC, ferromagnetic, or military equipment, up to $2 \mathrm{~m}$ below the seabed. A pontoon deployment configuration was initially tried to survey from the sea surface that provided a detection distance of $12.5 \mathrm{~m}$, but this detection depth was not sufficient to reach all the planned area. A heavier, more stable pontoon configuration capable of being lowered to $12 \mathrm{~m}$ below the water level was subsequently used.

A deferential global positioning system (DGPS) was used to reference the magnetometer information in a multi-channel data logger, and charts were produced daily for an "Object Classification Survey." The object classification survey was carried out with divers onboard duo-spud equipped vessels with diving baskets installed to enable precise mooring and positioning of the diver (Maddrell 2001).

A total of 15 bombs were recovered and disarmed by the Royal Danish Navy EOD Service during the project. In addition to these items, several ferromagnetic items, anchors, wires, chains, etc., were also located and recovered. Between J uly and December 1996, ten bombs were recovered out of a total of 724 targets (ferromagnetic objects or gabbroic boulders with high ferromagnetic content), resulting in a ratio of bombs to targets of 1 in 72. Between April and J une 1997, two bombs were recovered from a total of 378 targets encountered. Maddrell (2001) reported that the magnetometer survey was able to clear the areas with no delays to dredging, and that the overall survey cost was at some $\$ 5$ million, or about 1 percent of the final total dredging project contract cost of \$450 million in 1997 prices.

Sea Bright beach nourishment

Pope et al. (1996b) also field-tested and used underwater video cameras, side scan sonar, a sweep frequency subbottom profilers X-star, and a cesium vapor magnetic gradiometer for investigating the MEC contamination in a sand borrow site (used for beach nourishment) off the coast of NewJ ersey. The X-star had limited use in determining if there are hard object targets (could be MEC, stones, or even wood) buried in the 
sediments. X-star did not add any substantial additional data capability. The side-scan sonar could and should be used to provide a reconnaissance-level assessment of obstructions/large objects and bottom texture.

In this project (Pope et al. 1996b), the gradiometer was used:

...to accurately and rapidly detect the magnetic field variations produced by ordnance, a much more precise magnetic sensor is used than commonly employed in terrestrial and marine surveys. The instruments used for the Sandy Hook investigation were state-of-the-art cesium vapor marine magnetic sensors produced by Geometrics of Sunnyvale, CA.

These were fabricated and configured expressly for this project in a development effort [Figure 25]. The normal precision of a standard marine magnetometer is about \pm 4 nanoTeslas (nT). (As a reference, the Earth's magnetic field intensity is about 55,000 nT at this site.) For marine use, this sensitivity level has been satisfactory in the location of larger objects such as hulls, wrecks, etc. To pinpoint smaller items such as ordnance, it is necessary to use cesium-vapor magnetic sensors or some other extremely precise instrument which have a sensitivity of $\pm 0.02 \mathrm{nT}$. This aids the discovery effort in two ways: (1) a much smaller object can be detected, and (2) it is possible to measure the local field using two or more closely spaced sensors and achieving the gradient of the anomalous magnetic field. This measurement can be used to effectively vector toward the object. From several locations, the target location can be established by triangulation. In addition, by using the magnetic gradient to detect the ordnance, a much more accurate and straightforward procedure is achieved. In this investigation, two cesium vapor magnetometers were towed about $50 \mathrm{~m}$ behind a fiberglass-hulled research vessel at a height of 1 to $2 \mathrm{~m}$ off the ocean 
bottom [Figure 25]. These instruments were mounted $2 \mathrm{~m}$ apart, transverse to the towed direction. The following data were collected every 2 sec: (1) time, (2) ship's position, (3) instrument setback, (4) instrument altitude from the sea bottom, (5) course over ground (COG), and (6) speed over ground (SAG). The following were recorded every $0.1 \mathrm{sec}$ : (1) the magnetic field at both sensors, and (2) the horizontal magnetic field gradient. As a consequence of measuring the magnetic gradient, it was possible to immediately determine if an ordnance type signature originated from the port or starboard side of the track line.

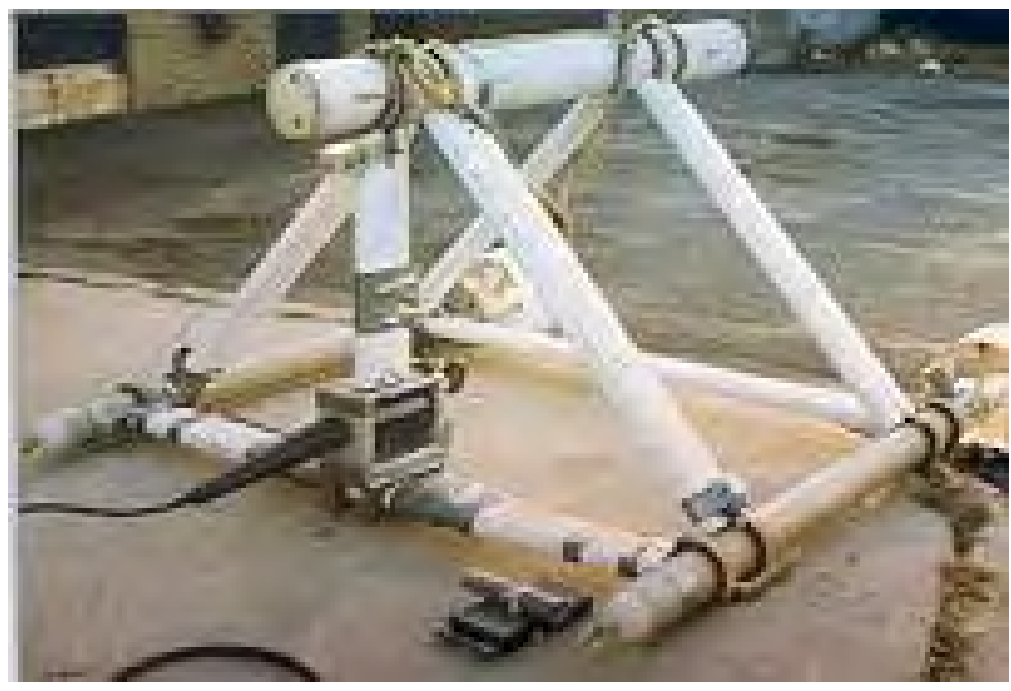

Figure 25. Cesium vapor magnetic gradiometer.

Arete Engineering Technologies Corporation (AETC) of Arlington, VA, examined and conducted additional post-processing of about 60 percent of the magnetometer data from Sea Bright. AETC used a target characterization procedure based on matching measured magnetic anomalies to magnetic dipole fields using Maximum Likelihood Estimation techniques.

In summary, the AETC sensitivity analyses indicate that, out to a range of 3 or $4 \mathrm{~m}$ from the survey track, a large piece of ordnance (e.g., greater than a 4-in. caliber shell) can be located within $10-20 \mathrm{~cm}$ accuracy 
$(\mathrm{x}, \mathrm{y}$, and $\mathrm{z})$ relative to the array using the survey data. Using a statistical sample of 100 magnetic anomalies from the surveys, the distribution of apparent dipole orientations indicates that the magnetic moments are largely induced and that the objects tend to be lying flat, parallel to the bottom, rather than upright. Most objects appear to be on the bottom or at fairly shallow depths.

\section{Classification and mapping of underwater UXO (ESTCP MM-9527)}

An ESTCP project "Classification and Mapping of Underwater UXO" conducted by the Naval Facilities Engineering Service Center in 1997, demonstrated tools and techniques originally designed for quantitatively mapping seabed mineral deposits (developed by the Hawaii Marine Mineral Technology Center [MMTC]) for detecting and discriminating underwater MEC. Technologies demonstrated included:

1. MMTC Side-Scan SONAR.

2. Reson, Inc., SeaBat 9001 Multibeam Bathymetric SONAR.

3. MMTC Phased-Array Sub-Bottom Acoustic Profiler.

4. Sea Engineering, Inc., Chirp Sub-Bottom Profiler.

5. Geometrics, Inc., Model G-882A Cesium Magnetometer.

6. J.W. Fishers Mfg., Inc., Pulse 12 Time-Domain Electromagnetic Detector.

7. SETS Technology, Inc., Advanced Airborne Hyperspectral Imaging System.

These tools were demonstrated for mapping and classifying underwater UXO on a test range. The test range was designed and installed offshore of the Pacific Missile Range Facility in Barking Sands, Kauai, Hawaii. Inert ordnance and man-made targets were placed on and under the seafloor to demonstrate these technologies.

The results of the ordnance mapping and classification demonstration were inconclusive due to system failures, navigation problems with the location of towed sensors relative to the survey vessel, and movement of the targets in the underwater environment during the course of testing. The question of whether 
side-scan sonar and seismic systems used for mineral exploration are acceptable for detecting underwater UXO cannot be confirmed or denied with the data gathered. The performance of magnetic and electromagnetic techniques for detecting underwater UXO in the high magnetic background environment could not be evaluated since the team was unable to operate the sensors on the test range. (http://www.estcp.org/projects/ uxo/UX-9527v.cfm)

The final report from this project (MM-9527) is available at http://www.estcp.org/Technology/MM-Underwater.cfm.

\section{UXO detection and characterization in the marine environment (ESTCP MM-0324)}

The objectives of this ESTCP project was to acquire the components to build an underwater UXO search system, test and integrate the components, complete the full system integration and shakedown testing, and conduct two UXO demonstration surveys in shallow water (http://www.estcp.org/projects/uxo/UX-03240.cfm).

The expected benefit of this underwater search system research was to:

Enable the Department of Defense (DoD) to conduct comprehensive MEC surveys in shallow water environments that are typical of most MEC contamination problems associated with Closed, Transferred, and Transferring ranges and the harbors used by the military and in the manufacture and shipping of munitions. The combined sensor approach emphasizes both detection and discrimination. The goal for detection limits of single isolated UXO targets is $60-\mathrm{mm}$ mortars (or their equivalents) if they are buried shallow in the bottom sediments. The ultimate payoff will be the system's transition to a commercial services vendor to provide UXO search and clearance operations for the DoD in shallow water.

(http://www.estcp.org/projects/uxo/UX-03240.cfm) 
Much of the modeling and engineering design work used in the ESTCP MM-0324 project had been completed through an earlier Strategic Environmental Research and Development Program (SERDP) project, Technology Needs for Underwater UXO Search and Discrimination (UX-1322). The primary objective of the SERDP project was to:

...develop techniques for the deployment of extended arrays of magnetometer and EMI sensors and dynamic control of their depth and orientation at a fixed distance above the bottom sediments in 0 to $15 \mathrm{ft}$ of water while surveying at a vessel speed of several knots. Secondarily, new EMI sensor designs must (were to) be developed that have the required detection sensitivity at a standoff distance of 1 to $2 \mathrm{~m}$ to detect even small UXO targets while maintaining the time resolution to extract object shape information that can be used for target classification. Finally, highfrequency sonar imaging technology must (were to) be adapted for use in bottom mapping, depth profiling (in real time), and providing shape information for targets proud (or partially proud) of the bottom. (http://www.serdp.org/research/UX/UX-1322.pdf).

A significant number of system components developed for the Airborne Multi-Sensor Towed Array Detection System (MTADS) were directly adapted for the Marine MTADS platforms. These components included the data acquisition and pilot guidance systems, the magnetometer sensors, the navigation control and attitude sensors, the data analysis algorithms and software Graphical User Interface (GUI), and the output graphics, interfaces, and remediation support documentation (http://www.serdp.org/research/UX.UX-1322.pdf).

The Marine MTADS (Figure 26) was used to conduct a MEC survey of Currituck Sound west of the former Duck Naval Target Facility, NC, between 9-19 May 2005. The controllable surface wing-shaped fiberglass structure contains a depth sounder, actuators/ stern planes, Geonics EM68 units, and magnetometers (preliminary design schematic shown in Figure 27 and photograph in Figure 28). 


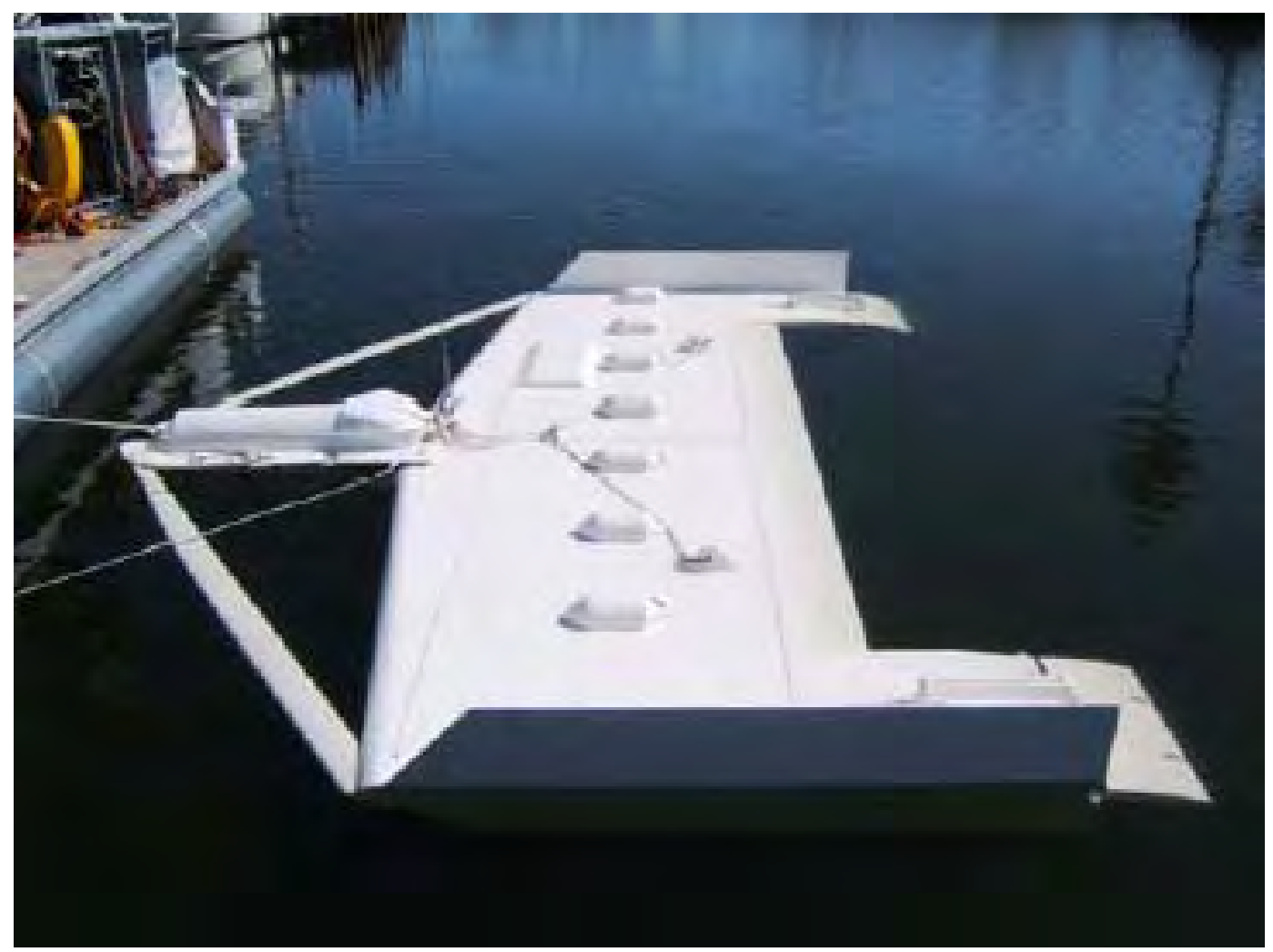

Figure 26. Assembled marine sensor platform (source: AETC Inc. 2005).

To control platform depth, three primary operational control algorithms were developed for the sensor platform GUI. The first mode allows platform operation at an operator-specified depth below the surface. The second mode is designed to control the sensor platform at a specified height above the bottom. The third mode is referred to as the Emergency Rise mode that can either be called from the keyboard or automatically invoked by pressing the Emergency Rise button on the electronics rack console panel. This mode is intended for use if a bottom obstruction is observed that is likely to cause an impact with the sensor platform (AETC Inc. 2005). An example screen clip showing the electromagnetic survey and magnetometry target analysis windows from the MTADS Data Analysis System is shown in Figure 29. 


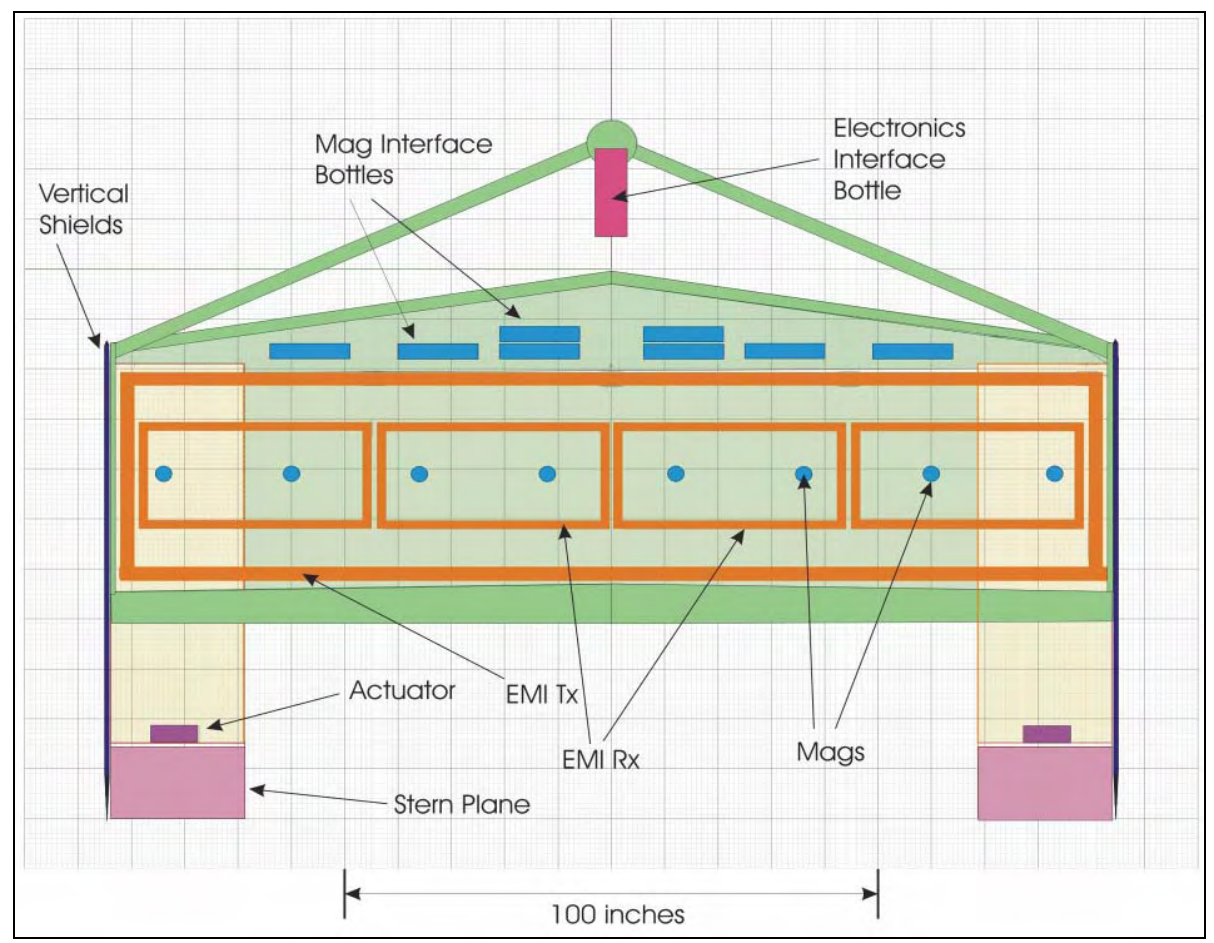

Figure 27. Schematic drawing of marine sensor platform (source: AETC Inc. 2005).

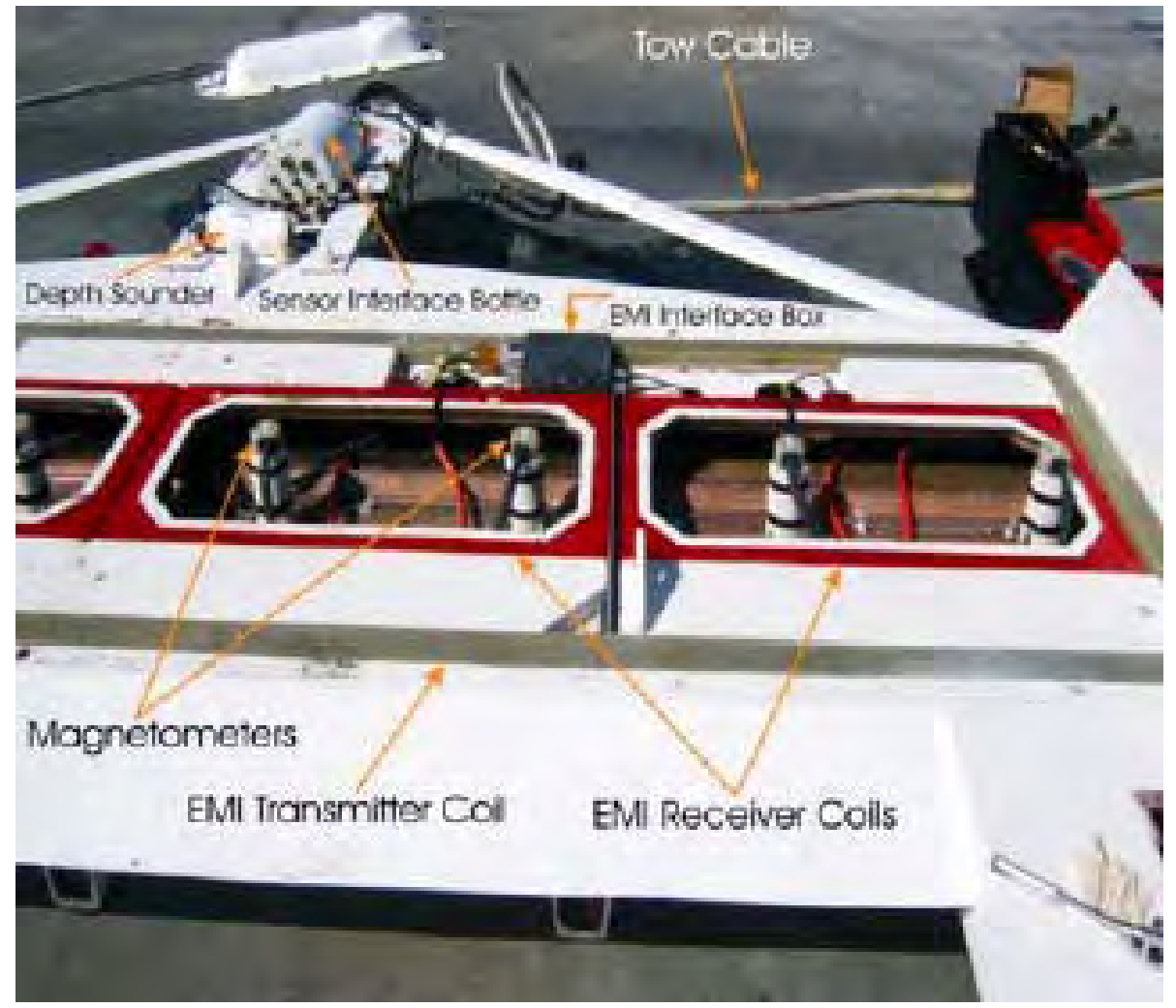

Figure 28. Marine sensor platform with hatch covers removed (source: AETC Inc. 2005). 


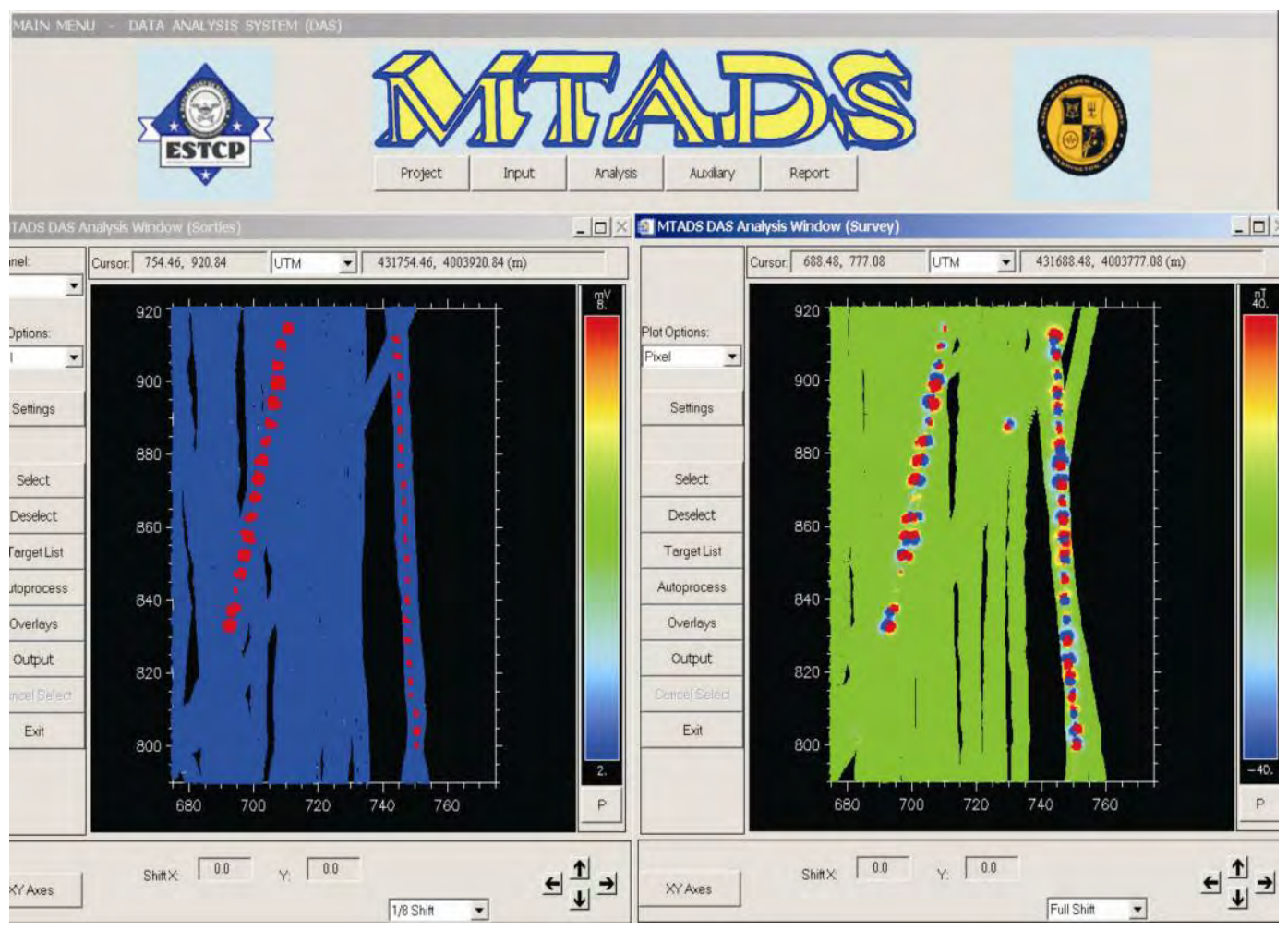

Figure 29. Screen clip showing target analysis windows from MTADS DAS. Image on left is from EM survey showing pipe signatures on left and rebar signatures on right. Same targets are shown on right from magnetometry survey (source: AETC Inc. 2005).

The following abstract from AETC Inc. (2005) summarizes the MEC survey conducted at the former Duck Naval Target Facility.

Between May 9 and May 19, 2005, the Marine Towed Array conducted a UXO survey of the Currituck Sound west of the former Duck Naval Target Facility. The Range (700 X 1,000 m) stretched from the Sound shore to the Ocean shore. It was used for 25 years (1941-1965) as an air-to-ground rocket and bombing range. In 1972, more than 2,000,000 lb of ordnance was removed from the Range before it was transferred to the Army for development of a research station, the Army Corps of Engineers Field Research Facility. In the mid 1990s, further EE/CA studies documented the continued presence of buried UXO on and near this facility. It was a goal of this demonstration to determine the presence of and map out the distribution of UXO in the Currituck Sound, which resulted from undershoots of the Range by approaching aircraft. 
AETC conducted UXO surveys using both the magnetometer and EM arrays in the Sound from the shallow water limit to a distance of $\sim 700 \mathrm{~m}$ offshore (more than $1.5 \mathrm{~km}$ west of the original target bull's eye). The effective shallow water survey limit for the Towed Array is $\sim 1.25 \mathrm{~m}$ ( $4 \mathrm{ft}$ ). After a slow start because of equipment malfunctions, survey rates of $35 \mathrm{acres} /$ day were achieved on the final three full days of survey. This is slightly short of the projected goal of 40 survey acres per day. The most important effects in determining survey production rates are the ferry distances to and from the dock each day, the length of the survey lanes (and the turn arounds), and the water depth. The most important of these for this demonstration was the amount of survey work that was done in very shallow water. Working in very shallow water requires that survey speeds be reduced by $\sim 50$ percent, and that turns be made very carefully (to keep the survey platform from impacting the bottom). About half of the survey lines were $>1 \mathrm{~km}$ long, the remainder were $600 \mathrm{~m}$ long. After the first 3 survey days, we moored the boat and survey platform near the southern end of the survey area, thus requiring only a few minutes of ferry time to and from the survey area.

A series of UXO surrogates (seventeen sections of steel pipe) and twenty-four $46 \mathrm{~cm}$ long sections of rebar were installed by divers in a relatively uncluttered area. Their positions were carefully measured by the divers using GPS from a boat. These positions were compared to the positions that resulted from the target-fitting algorithms using the MTADS DAS to analyze the survey data. The data files for analysis were prepared as mapped target files using Oasis Montaj ${ }^{\odot}$ for preliminary data processing to "clean up" the data set. The known target positions were reproduced in the target files to approximate the predicted level of accuracy, $25 \mathrm{~cm}$ in the horizontal plane for magnetometry data and $35 \mathrm{~cm}$ for the EM data. Although the $\mathrm{S} / \mathrm{N}$ ratio was poorer than expected for 
the EM array, all of the pipe and rebar targets were easily detectable with each array.

Target analysis of the magnetometry and EM data led to selection of $\sim 500$ potential UXO targets. These data were used to prepare the master dig list. Targets predicted to lie deeper than $0.6 \mathrm{~m}$ in the sediment were excluded from the list, as were targets predicted to be larger than a $5 \mathrm{in}$. Zuni rocket. A list of 150 targets was prepared, with the intention of 100 of them being dug. A priority was placed on targets analyzed in shallow water, because there was a prior agreement that we would attempt to split the dig list with about 50 percent of the targets in shallow water and 50 percent in deeper water. Only 20 targets in shallow water qualified for the dig list. The next 80 targets in water deeper than $2.5 \mathrm{~m}$ accentuated (but not exclusively) larger targets (with predicted sizes in the range of Mk76s to $5 \mathrm{in}$. rockets.

Recovery operations were carried out by two threeman dive teams. They worked between 20 May and $3 \mathrm{~J}$ une. First they were trained in the use of the AETC GPS equipment to reacquire and flag the targets from the dig list. They used classical EOD/ UXO diver techniques to recover the targets. First, the diver using a fluxgate magnetometer attempted to verify the existence of a target adjacent to the flag. If it was not readily apparent, he began a spiraling search pattern to locate the signal. If it was not found within $2 \mathrm{~m}$ of the flag, the flagged position was to be declared a "dry hole." In all 100 cases the target was located $<1 \mathrm{~m}$ from the flag.

Only two of the first 100 targets were not recovered. In one instance, although the target was demonstrated to be present using the magnetometer, it was deeper than predicted. The diver using a small hand shovel could not uncover the target because the walls of the hole kept falling in. In other cases where the targets were deeper than predicted, the diver was able 
to sufficiently uncover the targets so that a rope could be attached and the targets were pulled out of the mud using a small winch on the dive boat. The other target that was not recovered was too large to lift with the available winch. Two additional targets were dug to replace these targets. We discovered after $\sim 20$ targets were dug (including seven crab traps) that the signatures of crab traps could be identified in the magnetometry data. This was verified by digging three more predicted crab pots. At that point 13 more predicted crab pots were removed from the dig list and replaced with the next 13 targets on the list. Overall, almost exactly 50 percent of the recovered targets were ordnance or ordnance components. These included eight Mk23s, 22 SCAR and 2.75-in. rockets, five Mk76s, one 100-lb bomb, one 75-mm rocket W.H., and one Zuni W.H.

All recovered targets were removed to a secure area at the Field Research Facility and photographed for documentation. Ordnance items were challenged using explosive shaped charges (jet perforators). The ordnance scrap was certified as explosives clean and shipped for disposal.

All major goals and objectives of this demonstration were achieved.

The MTADS was also deployed at the former Erie Army Depot to survey in the impact area in Lake Erie and in deeper portions of the Toussaint River. The results from this effort are reported by McDonald (2007) and available at http://www.estcp.org/Technology/upload/MM-0324-LakeErie.pdf.

\section{Marine Gradiometer Array (MGA) system}

Funk et al. (2007) reported on a MGA system that was evaluated during a trial sponsored by the U.S. Naval Facilities Engineering Command Northwest. The trial included an evaluation of the MGA system's (Figure 30) ability detect large ( $81 \mathrm{~mm}$ mortar) and small $(20 \mathrm{~mm})$ underwater UXO items. (Authors' note: The previously described MTADS was evaluated at this site as well). 


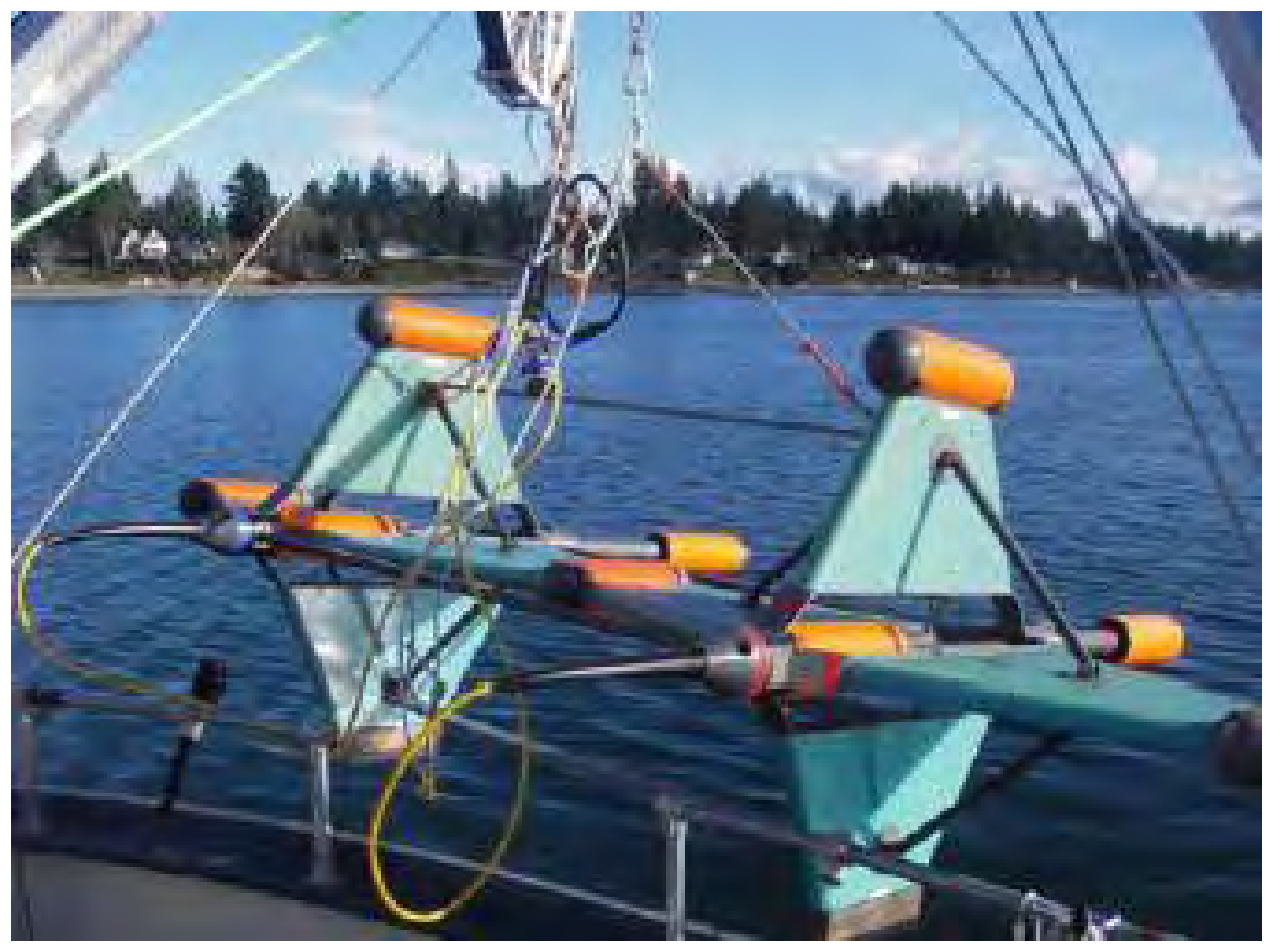

Figure 30. MGA system (source: Funk et al. 2007).

As per Funk et al. (2007):

The Marine Magnetics system consists of three Overhauser magnetometers arranged on a 1.5-m-wide nonmagnetic platform that was developed for hydrodynamic stability in marine and freshwater environments. Marine Magnetic's system was used as a starting point for merging hardware and software to create the MGA system. The baseline MGA sensor array is comprised of seven Overhauser magnetic sensors arranged on a non-magnetic platform in a 3-m-wide array. The geometry of the magnetic sensors for system testing and evaluation was three fixed sensors spaced $1.5 \mathrm{~m}$ apart and two sensors $0.5 \mathrm{~m}$ above and centered between the lower sensors ( $0.75 \mathrm{~m}$ horizontal separation between all sensors) and two rear sensors centered between the lower sensors and $1.1 \mathrm{~m}$ aft. This sensor array is designed to be scalable (i.e., increasing the sensor array width) by adding basic modules. The wider array allows for increased detection and survey efficiencies. The unique acquisition platform design and the geometric 
arrangement of the magnetic sensors optimize data collection, and processing and interpretation due to the system's measurement capabilities, which include recording the total magnetic field measurement for each sensor, as well as several magnetic gradients and the true 3-D analytic signal. Gradient measurements and 3-D analytic signal delineate complex magnetic anomalies into their individual constituents more readily than total field measurements and are not influenced by the naturally occurring diurnal changes in the earth's magnetic field. The hydrodynamic design of the towfish allows for dynamic flight of the sensor array, at 1 to $1.5 \mathrm{~m}$ above the bottom. This is achieved by paying out and in the tow cable with a winch. Maintaining a relatively constant low altitude makes it possible to reliably detect small individual UXO items, while eliminating a majority of the risks associated with snagging and/ or impacting the bottom, which can be a problem if sensors are installed on a sled and dragged on the bottom. However, the MGA is configurable as a bottom drag sled, if a requirement exists to detect small and/ or deeply buried items and if site conditions permit.

To evaluate the capability of commercially available systems which have the ability to find UXO in nearshore waters, the Navy installed a test bed in Ostrich Bay, near Bremerton, WA, and issued a request for proposals for companies interested in demonstrating the ability to detect and map the location of the simulated and/ or inert UXO items. The Navy also selected an independent contractor to be responsible for monitoring participant's activities during the demonstration and evaluating the results. [The test bed area and the location of a calibration line, a string of simulated and inert UXO items (i.e., seed items) that were installed west of the test bed area are shown in Figure 31.] Each company that selected to participate in the demonstration was provided the locations ( $\mathrm{x}$, y), burial depth, and descriptions of each of the calibration line targets. Selected participants were 


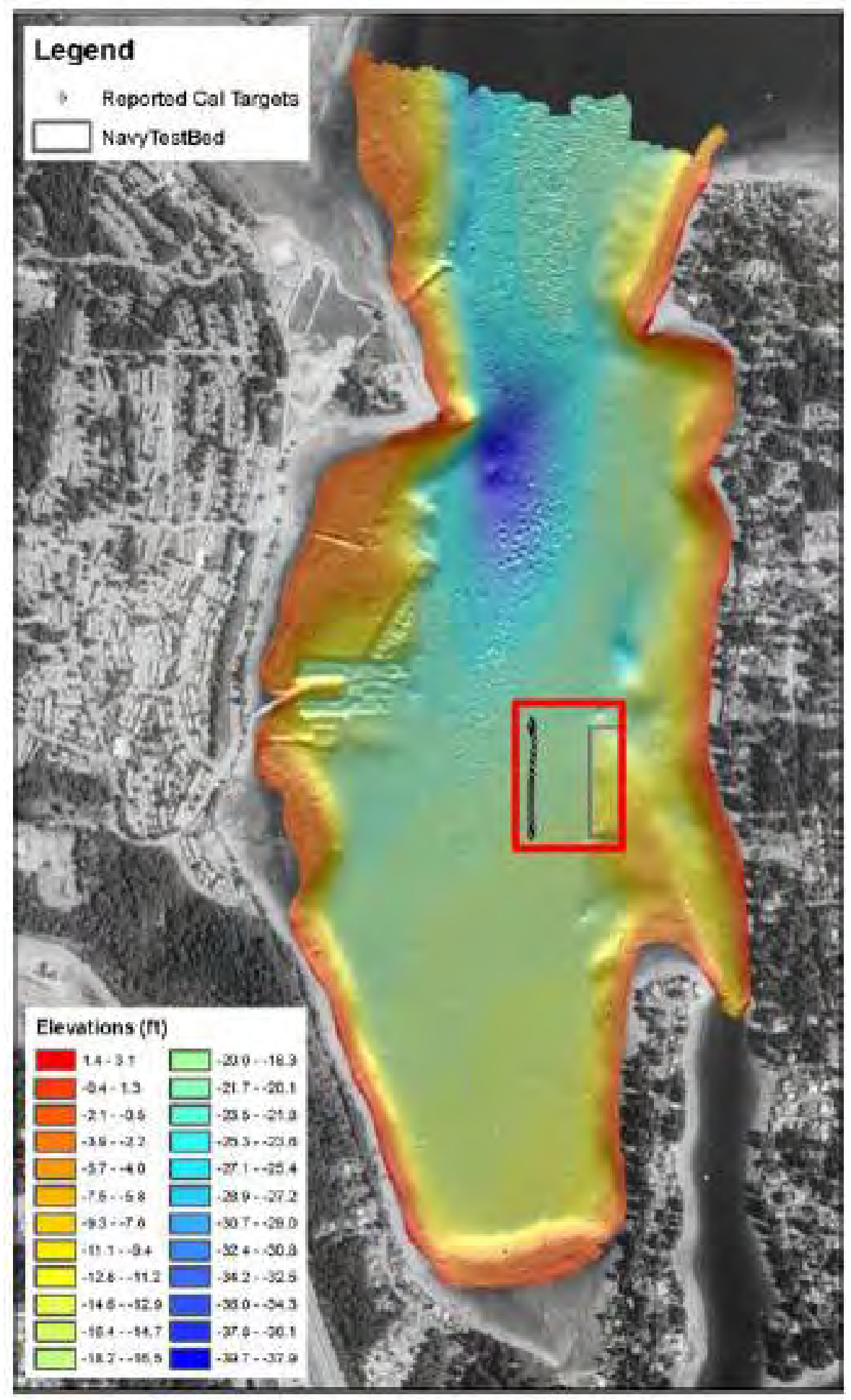

Figure 31. U.S. Navy test bed and calibration targets (source: Funk et al. 2007).

allocated 1 week between August and October 2006 during which they were required to mobilize to the site, calibrate their systems, and survey the test bed. 
Final results were required to be reported within 2 weeks of completion of the company's survey. The independent contractor compared the reported locations of detected anomalies with the positions reported by the Navy divers who placed the seed items in the test bed, and generated a performance report and score for each participant. At this time, the Navy has not authorized publication of participant's test bed survey results, as they anticipate that further testing may occur at the site. Data collected at the calibration line area provide a good measure of the effectiveness of the MGA system for detection and location of targets of various sizes (i.e., large, medium, and small ferrous targets).

These targets ranged in size from a hand grenade and fuse, to an 8 in. projectile and multiple Mk81 bombs. In J une 2006, the Navy reported that the Mk81 bombs in the calibration line were proud of the sediment and the remainder of the targets were buried up to 12 in. deep. During a subsequent check by Navy divers, some items were found to have settled into the soft sediments and/ or sediment deposition had occurred by as much as $40 \mathrm{~cm}$. The Navy's subsequent check also included a QC check on the positions $(\mathrm{x}, \mathrm{y})$ of three of the calibration line targets. The offsets were found to range from 17 to $48 \mathrm{~cm}$, with an average of $31 \mathrm{~cm}$. The MGA did not detect two of the smallest targets in the calibration line, the grenade and the fuse. This is believed to be due to their small size/ magnetic signature and burial depth, which increases the range from the sensors to the target, decreasing the observable total field and 3D analytic signal. The $20 \mathrm{~mm}$ cluster, another very small target, was seen, but with a very small signal. The rest of the targets were clearly visible in the total field and/ or 3D analytic signal data. The average distance between the reported and detected positions was $1.16 \mathrm{~m}$, but this reflects the uncertainties in both the placement of the items and the errors in the MGA survey system positioning. 
Figure 32 shows the results as reported by Funk et al. (2007) of the comparisons between the individual target positions reported by the Navy and the detection results from the MGA survey system.

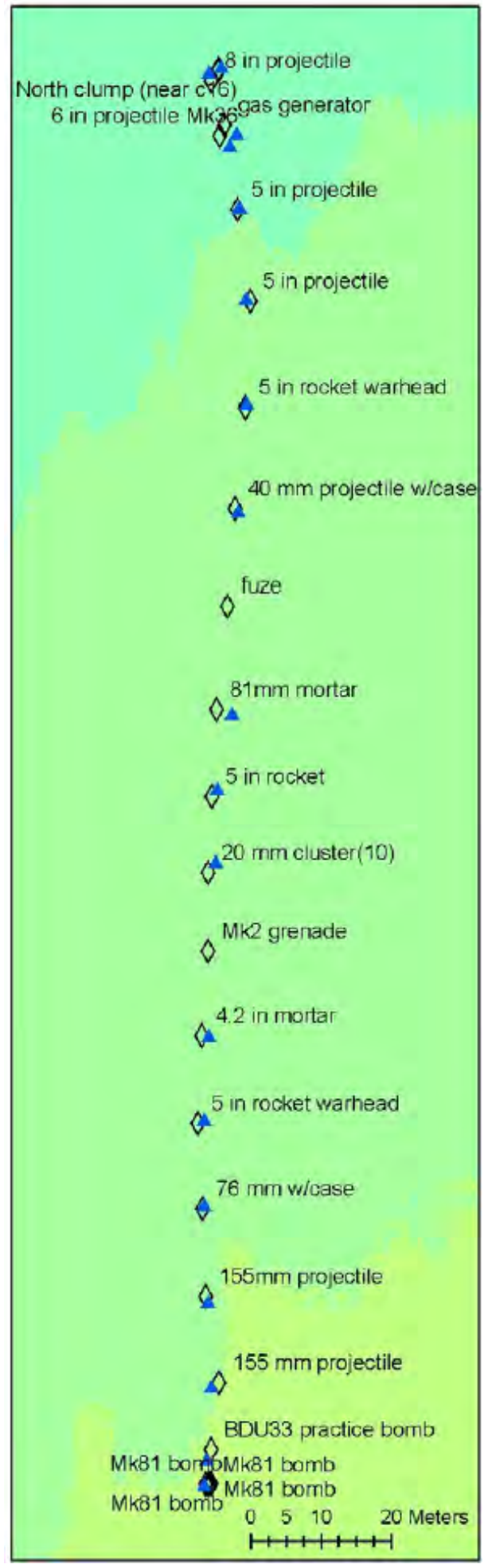

Figure 32. Calibration target picks (source: Funk et al. 2007). 


\section{Current ESTCP underwater MEC detection and discrimination technology demonstrations and evaluations}

ESTCP is currently funding various technological demonstrations and evaluations on underwater MEC detection and discrimination survey systems. Several examples of these efforts (cited from ESTCP's website http://www.estcp.org/technology/MM-Underwater.cfm) are listed along with a brief description of their respective objectives.

1. Underwater Simultaneous Electromagnetic Induction and Magnetometer System (MM-0733).

The objective of this project is to demonstrate and validate the Underwater Simultaneous Electromagnetic Induction Magnetometer System (USEMS), which employs concurrent magnetometers and EM61 sensors through the interleaving process. Using a small, low-drag sensor pod that is towed by a kinematically constrained structure behind a small boat, USEMS will provide the UXO community a low-cost, highly maneuverable alternative for geophysical mapping in shallow water environments.

2. Underwater Acoustic Positioning Systems for MEC Detection and Reacquisition Operations (MM-0734).

There have been few advances in commercially available, high-precision underwater positioning systems to support munitions and explosives of concern (MEC) detection needs. Though the basic technologies for detecting underwater unexploded ordnance (UXO) are the same as those on land, the underwater environment poses a distinct challenge to positioning geophysical measurements, particularly when the need exists to compensate for current, wave action, and wind when calculating accurate sensor positions. The objective of this project is to modify two long baseline (LBL) positioning systems, AquaMap Seafloor and RangeNav, for use in high-precision underwater MEC detection and reacquisition operations. 
Both are acoustic positioning systems manufactured by Desert Star Systems, LLC.

3. Deep Water Munitions Detection System (MM-0739).

Modern unexploded ordnance (UXO) search technologies that can comprehensively digitally map magnetic or electromagnetic anomalies associated with individual ordnance items have not been effectively demonstrated for application to wetlands or marine areas deeper than $30 \mathrm{ft}$. The objective of this project is to demonstrate an integrated deep-water sensor platform suitable for munitions detection in water depths up to $100 \mathrm{ft}$. The system will be capable of detecting medium and large ordnance with adequate horizontal positioning for routine reacquisition by explosive ordnance disposal (EOD) divers.

\section{Underwater MEC recovery and disposal}

\section{EOD divers}

EOD divers can not only be used, in proper site conditions, to detect and discriminate MEC, but they can also dispose of it. Diver detection methods include visual identification (visibility permitting), handheld magnetometers, or acoustic imaging sonar. MEC determined acceptable to move can be brought to the surface and disposed, or those items determined to be too unsafe to move are blown-in-place. The major cost elements for underwater UXO remediation revolve primarily around planning, diver operations, explosive operations, and environmental and safety surveillance (Pederson et al. 2002).

Pederson et al. (2002) describe some requirements and associated costs for using EOD divers.

Planning. An approved Explosive Safety Submission (ESS) that describes how demolition and explosive materials will be handled and controlled needs to be approved by the NOSSA and the Department of Defense Explosive Safety Board. Other regulatory environmental compliance issues, impact statements, 
etc. may also have to be addressed. [Authors' note: NOSSA only reviews and approves ESSs for work done for or by the U.S. Navy. Any work done at other dredging sites by other Services would be subject to the review and approval of that Service's explosives safety organization.]

Dive Operations. Federal OSHA regulations (29 CFR 1910, Subpart T) mandate safe practices for commercial diving companies. Each state has an administrative code that may impose additional regulations.

Commercial EOD diving companies typically base their operating procedures on the U.S. Navy Dive manual. Consequently, a minimal dive team is composed of four divers. The dive team will require diving equipment and dive support equipment (boat charter and decompression chamber support). Federal regulations, 29 CFR Part 5, Subpart A - Davis Bacon and Related Acts and Procedures, govern the labor costs of divers. Cost per diver in wages and fringe benefits is \$72/hour; G\&A and overhead would double the cost to $\$ 144$ / hour. Labor rates will increase 25 percent for depths greater than $50 \mathrm{fsw}$ [feet of seawater] and increase another 25 percent for depths greater than 100 fsw. Water currents and temperatures will place limits on dive operations and will be cost drivers by limiting productivity. Divers will require a dive boat with crew of sufficient size to carry all their equipment and to shelter them from the environment. If the expected depth/ duration of a dive is expected to require decompression, then a decompression chamber must be provided on-site (if not otherwise accessible) with qualified personnel, at an estimated cost of $\$ 1,200 /$ day (Global Divers, LA). The cost to conduct one day of dive operations (4 divers) over an 8-hour day is estimated as follows:

Dive suit/ scuba rental $\$ 600$

Air for scuba $\$ 50$ 
Labor $\$ 4,600$

Boat Charter $\$ 500$

Decompression Chamber \$1,200

Total \$6,750/day

Environmental/Safety Surveillance and Issues.

Explosive operations may require a Medivac helicopter on standby, at an estimated expense of $\$ 1,000 /$ hour. Explosive operations may require range safety boat(s) to keep pleasure craft away from the operating area, at $\$ 400 /$ day. Helicopter surveillance may be necessary to ensure endangered species are clear of the area (e.g., gray whales, green sea turtles, etc.). The rental cost for a Hughes 500 helicopter is estimated at \$650/ flying hour.

Mobilization and Operational Requirements. The Department of Defense Explosive Safety Board (see DoD directive 6055.9-STD “DoD Ammunition and Explosives Safety Standards," J uly 1999) will require an explosive safety submission via the NOSSA with the goal of ensuring that the operation is conducted safely. Federal regulations (29 CFR 1910.109 and 1926.912) govern safe practices for the storage of explosives and underwater blasting. Divers will require a portable magazine (ready service locker) to store HL-21s and other explosive material. Explosivequalified divers will require detonation and support equipments including lines, augers, detonators, galvanometer, and blast machine.

Federal OSHA regulations (29 CFR 1910, Subpart T) mandate safe practices for commercial diving operations. U.S. Coast Guard regulations (46 CFR Ch. 1, 10-1-89 Edition, Subchapter V - Marine Occupational Safety and Health Standards) apply if the operation is off the continental coast. Each state has an administrative code that may impose additional regulations. The dive team will require diving equipment (suitable 
to the expected temperatures) and dive support equip-

ment (boats and decompression chamber support).

The low-order operation may require environmental surveillance both before and after the low-order operation. Boats and/ or aircraft may be necessary to ensure marine mammals are not in the area before the low-order shot is attempted. Divers may be required to search in the affected area and assess damage to fish and other biota after the shot."

\section{Current ESTCP underwater MEC recovery technology demonstrations and evaluations}

ESTCP is currently funding various technological demonstrations and evaluations on underwater MEC recovery systems. An example of these efforts (cited from ESTCP's website http://www.estcp.org/technology/MMUnderwater.cfm) is described.

Efficient shallow underwater UXO retrieval project ESTCP MM-0606.

This project will develop and demonstrate a UXO retrieval system that will allow UXO buried in bottom sediments in shallow water to be uncovered, inspected, and recovered without diver intervention. Implementation of this technology will allow UXO recovery operations to be conducted from the deck of a boat without hands-on diver intervention in most circumstances. Following a UXO survey, data analysis, and preparation of a prioritized dig list, designated targets will be reacquired and flagged for investigation. Operating from a recovery boat secured beside the flagged target, a shroud structure will be lowered over the target initially to provide some protection from unintended detonations and to prevent the bottom sediments from sloughing into the target area as the target is excavated. A vacuum dredge will be used to remove overlying sediments to expose the target so that it can be visualized using lights and remotely operated cameras. Following identification and a safety evaluation, the target will be recovered using either an 
electromagnet system or a mechanical grapple operated from the deck. UXO deemed to be too dangerous for this recovery approach will be flagged for later recovery or demolition by UXO-qualified dive teams.

\section{General considerations for MEC dredging projects}

The presence of MEC may not necessarily make dredging impossible if the proper safety precautions are taken. As previously stated, there are no absolutely safe procedures for dealing with MEC, merely procedures considered to be least dangerous. With forethought and planning, the use of appropriate engineering controls and standard operating procedures can maximize the safety of MEC dredging operations. The following section describes various components of the $\mathrm{MEC} /$ dredging project planning flowchart (Figure 24) that consist of general considerations. It also includes discussion of hazards analysis specific to dredging operations involving MEC and MEC engineering controls that may be used to mitigate the hazards from MEC. The following chapter will expand upon these considerations for specific dredge types.

\section{Dredging operations explosives hazards analysis}

Project planning for dredging operations in an area containing or suspected to contain MEC requires consideration of protection of dredging personnel, the public, and equipment from the effects of an unintentional detonation in addition to all of the usual planning considerations affecting the selection of the dredge type. The explosives hazards analysis must be specific for the type(s) of dredging equipment to be used and types of MEC expected to be encountered. In addition, the project team should consider:

- Removal of the MEC versus leaving the MEC underwater.

- Risk assessment for the dredging operations (risks to people and equipment).

- Production rate.

- Equipment cost.

Additional information on safety analyses of equipment for MEC removal from sediment (distribution authorized to U.S. Government agencies only) is presented in Concurrent Technologies Corporation (2006). 


\section{Removal of MEC versus leaving MEC underwater}

When dredging in areas containing or suspected to contain MEC, the project team has two options with regard to the disposition of the MEC. The regulators and stakeholders involved with the project will have a great impact on the decision whether to remove the MEC and dispose of it elsewhere or to leave the MEC underwater. However, both options have hazards to be considered. In some areas where maintenance or repetitive dredging is required, leaving the MEC on the bottom and not collecting it and disposing of it will leave the same problems for the next dredging cycle. It may be more cost effective in the long run to take the time, effort, and funding to remove MEC and have a clean dredge or borrow area, but this approach requires serious consideration of the respective confidence interval of removing all MEC the first time, and the risk of subsequent encounter of MEC missed in that removal action.

\section{Removal of MEC}

Designing a dredging operation to include the removal of MEC involves consideration of the hazards from an unintentional detonation of the MEC. The explosion effects including fragmentation and blast overpressure are a function of the size (i.e., munition case geometry and net explosive weight) of the MEC. The likelihood of an unintentional detonation is related to the sensitivity of the MEC and the interaction of the dredging operations with it.

Some other aspects of the dredging operation design are the method(s) used to separate the MEC from the dredged material, the MEC disposal method(s) and location, and the reliability of the dredging method with respect to MEC removal. The nature of dredging operations involving MEC can make disposition by blow-in-place (BIP) of the MEC a very undesirable necessity.

During dredging, the MEC are moved from the original place underwater along with the dredged material. Ideally, the design of the dredging operation should include an efficient and effective means of separating the MEC from the dredged material. In some past MEC dredging projects, everything was removed from the dredge area (sediment, MEC, debris, etc.) and was placed on land, and this area required a military munitions response action to remove the MEC. While this can be an effective means of 
separating the MEC from the dredged material, it may not be the most efficient from a cost and schedule standpoint.

Once the MEC have been located and identified, they must be disposed of. While DMM and MPPEH may be recovered and transported for off-site disposal, the preferred method of disposal for UXO is in-situ disposal or BIP. Depending on the location of the UXO, a BIP may not be possible, or it may require the use of engineering controls to mitigate the effects of blast overpressure and fragmentation, or it may require disposal in a contained detonation chamber.

\section{Leaving the MEC underwater}

Designing a hydraulic dredging operation to leave the MEC underwater requires consideration of the method(s) used to ensure that it is separated from the dredged material underwater (no known exclusion technologies exist for mechanical dredges to exclude MEC from the bucket and leave it on the bottom). The size of the MEC involved will affect the design. Depending on specific project conditions (MEC size(s), sediment type, etc.), it may be feasible to place screens over the dragheads or cutterhead suction mouth to exclude all the MEC or maybe just screen the larger sized MEC, and design engineering controls and safety operating procedures to deal with the smaller sized MEC that are allowed into the hydraulic circuit. The addition of screens on the suction side can reduce production by adding additional resistance that reduces the hydraulic efficiency. This condition can be exacerbated by debris blinding (clogging) the screen apertures (openings) and further increasing the hydraulic resistance. Plans for clearing clogged screens must consider the explosive hazards of the MEC.

\section{Risk assessment for dredging operations}

There are two primary questions regarding MEC hazards to be considered in the risk assessment for dredging operations involving MEC:

1. What points in the dredging process are most likely to cause the MEC to detonate?

2. What are the potential consequences of a detonation at each of these points?

Potential consequences can range from loss of life to damage of equipment. A detonation in a pump might cause the dredge to sink with the 
potential for loss of life. A detonation at any point in the process may cause personnel injury or fatality due to explosion effects (fragmentation, overpressure, fire, etc). A detonation may cause equipment damage or loss or adversely impact the environment.

Once potential consequences have been identified, the project team needs to decide whether or not these consequences present an acceptable risk.

\section{Fragmentation analyses}

This section presents information relative to the fragmentation analysis blocks in the MEC/ dredging project planning flow chart (Figure 24).

The methodology for calculating the fragment characteristics of a munition item in an unconfined detonation (munition not constrained by slurry, pipeline wall, or pump casing) is detailed in DDESB (2007) Technical Paper TP 16, "Methodologies for Calculating Primary Fragment Characteristics." This paper is available on the DDESB secure site at http://www.ddesb.pentagon.mil. The secure site requires a password and the application for this password is available on the site. Included with TP 16 is a database that includes the following information for a wide variety of munitions:

- Munition diameter, explosive weight, and explosive type.

- Maximum fragment weight and velocity.

- Various overpressure distances.

- Maximum horizontal and vertical fragment ranges.

- Hazardous fragment range.

- Information on engineering controls for intentional detonations.

- Required thicknesses of various materials to prevent fragment perforation.

The information in this database can be used to determine the munition with the greatest fragment distance (MGFD), the required minimum separation distances to protect the public, and the required minimum separation distances and/ or material thicknesses to protect equipment operators. This methodology applies to naturally fragmenting munitions (as opposed to munitions with pre-formed fragments) that are generally cylindrical in shape and that are filled with explosives (i.e., the explosives are in contact with the case). 


\section{Personnel protection}

When determining the minimum separation distance, personnel are divided into two categories: essential and non-essential personnel. The public are considered non-essential. The minimum separation distance is different for each category as described below.

\section{Essential personnel}

Essential personnel are those personnel essential to the operations being performed. For example, dredge operators would be essential personnel while administrative personnel would not be essential personnel. Dredging operations are considered to be mechanized operations from an explosives safety standpoint.

Therefore, essential personnel must be provided protection from fragmentation. While fragmentation protection may be provided by distance, such distances are generally too large to be practical from an operational standpoint. The material thicknesses provided in the TP 16 database are the thicknesses required to prevent perforation from the design fragment from the munition. These thicknesses are suitable for use for an unintentional detonation but may not be used for engineering controls for an intentional detonation (demolition).

Non-essential personnel

Anyone not considered essential personnel must be provided with "inhabited building distance" protection. In some situations the MEC or the operations may be present, such hazards that the public must be provided with a minimum separation distance of the MGFD rather than the hazardous fragment distance. Generally, if a single MEC is UXO and/ or the operations have the potential to apply sufficient force to the MEC, the MGFD is required. This consideration should be part of the explosives hazard analysis.

\section{MEC detonation effects evaluation}

The following section is a technical approach (modified from Halkola et al. 2006) to evaluate the trade-offs between shielding personnel and critical equipment and/ or screening MEC from the dredge. 
To minimize the potential overpressure and fragmentation effects that could result from MEC detonation by or within the dredge, a technical approach is required. This approach would use an iterative process to evaluate the trade-offs between shielding personnel and critical equipment and/ or screening MEC from the dredge. This issue is complex because explosion damage within the dredge is a function of many variables that include the over pressure and fragmentation patterns and forces, the density of the surrounding medium, the containment volume and wall strength, the location of the explosion by or within the dredge, as well as the proximity of the MEC to the wall of a pipe/ pump/ hull.

Initially a list of MEC that may be found within the dredging area should be developed if prior knowledge is available. A sequence of this evaluation might include the following steps.

1. Evaluation of the dredge's hydraulic circuit (aspects, i.e., suction mouth geometry, suction and discharge pipeline diameters, etc.) and determination of the dimensions of the largest size of MEC that could physically be passed into the dredged system. All MEC on the initial list that exceed the physical limits of the pipe will be eliminated from the list of munitions to be evaluated in the iterative investigation of detonations within the dredge (detonations caused by the dredge contacting and initiating MEC on the bottom will require a different analyses approach). The MEC remaining on the list are now the design MEC for this investigation.

2. The design MEC are then correlated with the actual physical dimensions of each MEC item and the potential over pressure and fragmentation effects associated with their explosion in water, slurry, and air. The iterative evaluation begins here.

3. From the design MEC list, the selection of the MEC with the highest over pressure and fragmentation effects would be necessary, followed by an evaluation of the potential damage that an explosion of this most conservative estimate would impart on the dredge crew.

4. Additionally it would be necessary to determine the engineering controls for safety and damage suppression as well as cost for the engineering controls and damage repair.

5. In parallel, determination would be made of the minimum aperture for screening on the intake with spacing that will exclude the oversize design MEC from entering the dredge. Dredge production rate losses associated with the reduced screen aperture would be evaluated and then the best option between screening and engineering controls would be selected. 
6. If a smaller screen aperture is selected, then another cycle of this iterative process would be evaluated, selecting the design MEC associated with the next most powerful over pressure and fragmentation effects and proceeding with theiterative evaluation until an acceptable level of safety and engineering controls is achieved.

\section{Production rate}

In general, production rates will decrease when dredging in an area containing or suspected to contain MEC. The magnitude of this impact on production and resultant cost increase depends on the factors previously listed in this chapter. The design of dredging operations should include plans for delays and/ or stoppages due to MEC-related incidents such as jammed or clogged equipment, replacement or repair of damaged equipment, and disposal of MEC. Chapter 4 will present more detailed information of these MEC-induced effects on specific types of dredges.

\section{Costs}

The costs of dredging operations in an area containing or suspected to contain MEC will be affected by lower production rates, the requirement for EOD personnel, possible equipment repair or replacement, possible public evacuation, and MEC disposal. Chapter 4 will present more detailed information of these MEC-induced effects on specific types of dredges.

\section{Movement of underwater MEC}

The potential for movement of underwater MEC by hydrodynamic (waves or currents) or ice-induced forces could possibly impact a MEC dredging project regarding situations such as:

1. MEC that might be located in areas adjacent to a navigation channel could be, after the channel has been previously dredged, transported into the channel and be encountered by subsequent dredging operations.

2. If a portion of a borrow site has been cleared of MEC prior to dredging, MEC adjacent to that section could be transported into that previously cleared area and subsequently be encountered by a dredge.

3. If a MEC clearance operation is being undertaken at a particular underwater site where the MEC targets have been previously geo-referenced ( $\mathrm{x}$, $\mathrm{y}$, and z coordinates) by an underwater MEC detection and location survey system, any subsequent MEC movement (i.e., from a big storm occurring 
while the clearance is being conducted) could introduce reacquirement errors that impact clearance efficiency.

Welp et al. (2004) conducted a study at the former Erie Army Depot impact range in Lake Erie to determine if MEC that might be located in areas adjacent to a navigation channel (that had been previously dredged with MEC separated from the dredged material) could be transported into the channel and subsequently be encountered by future dredging operations. Twenty-four pieces of simulated MEC (sMEC) were deployed in several nearshore areas in the vicinity of the Toussaint River in depths less than $6 \mathrm{ft}$ (several sMEC are shown in Figure 33). These sMEC were deployed on both sides of the Toussaint River navigation channel where they could potentially be moved into the channel, and alongshore southeast of the Toussaint River in documented impact areas, where they could potentially be transported toward the river. These locations were chosen to provide information on movement as it relates to the potential of encountering MEC during future dredging operations. Surveys to relocate and map the sMEC positions were conducted over an approximate 2-year period, during which the sMEC were exposed to a range of lake wave, current, water level, and ice conditions.

Approximate tracking of the sMEC was accomplished with the use of two different types of positioning methodologies, radio and acoustic, while precise positioning was accomplished with the use of a Real Time Kinematic (RTK) DGPS. Radio transmitters were installed in sMEC placed in shallow water (approximately less than or equal to $2 \mathrm{ft}$ of water), while acoustic transponders were installed in sMEC placed in deep water (less than $6 \mathrm{ft}$ deep).

Pope et al. (1996a) concluded that: "The mechanisms of ordnance transport appear to be a result of several factors (i.e., waves, ice, and human dragging of fish nets toward shore)." Over the study duration, with its respective wave, current, water level, and ice effects on the sMEC, the results of this study indicated that the net transport of MEC is largely due to ice. It is not known how it occurs, however, and to what extent waves and water levels may play a role. In total, the study indicated that MEC in Lake Erie is migrating in the vicinity of the Toussaint River Navigation Channel and has the potential to migrate into the navigation channel. 


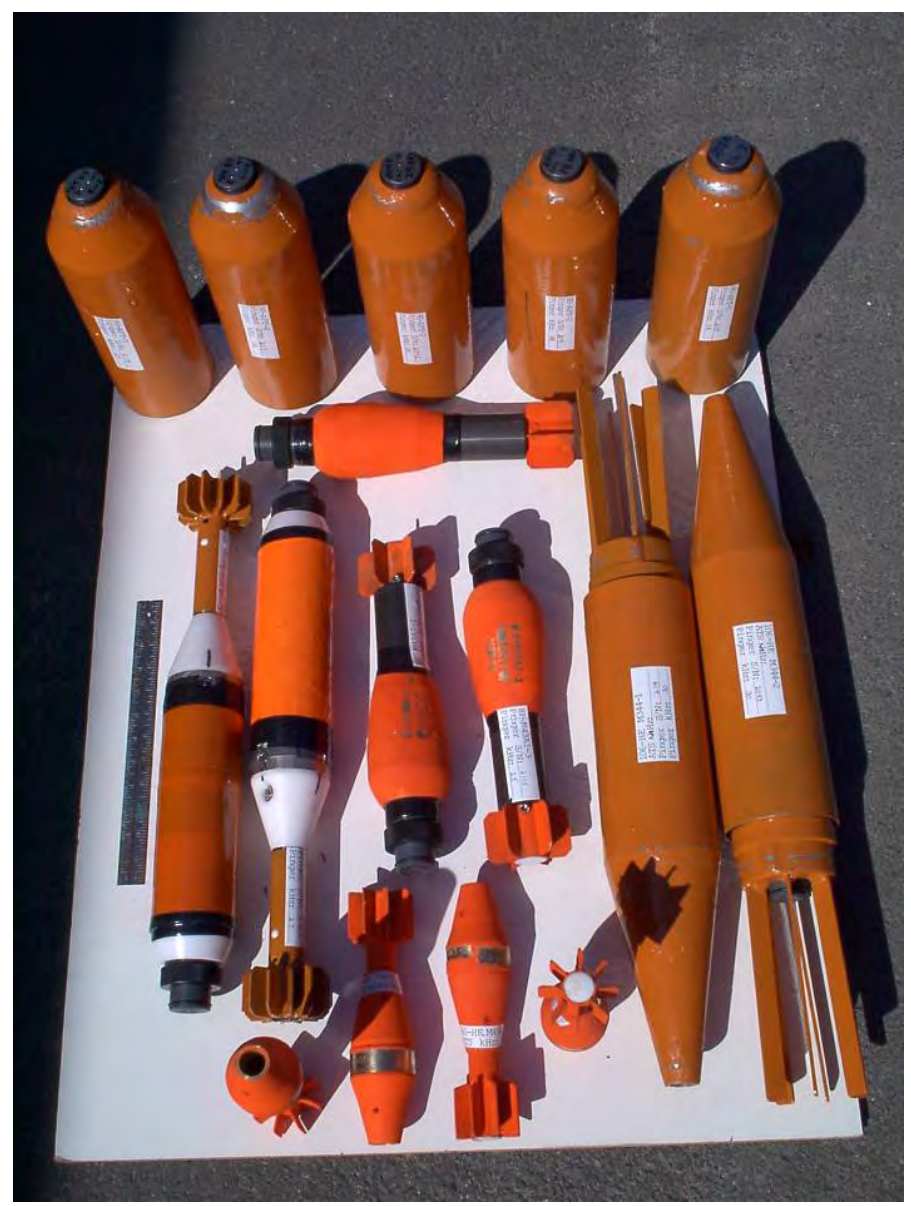

Figure 33. Study sMEC, 16 of 24 sMEC without radio transmitters installed (source: Welp et al. 2004).

There is currently an ESTCP demonstration and evaluation of the use of a numerical model to predict the mobility and burial of underwater MEC (http://www.estcp.org/Technology/MM-0417-FS.cfm).

The objective of this project is to support risk assessment analyses for the Department of Defense (DoD) in making informed decisions regarding the movement of unexploded ordnance (UXO) underwater. The VORTEX model, developed to track mine mobility, has been modified to predict UXO mobility and burial in the underwater environment. Using this modified model, the fate of UXO over the broad range of coastal diversity can be resolved. Mobility information also can be used to prepare a risk assessment by identifying the areas and entombment depths likely to contain UXO, thus reducing costs associated with 
fieldwork directed at physically locating or clearing UXO items. The ultimate goal is to incorporate UXO mobility and burial modules into a risk assessment model similar to the Army Risk Assessment Modeling System (ARAMS).

The ESTCP UXO Mobility Model project also comprises two field demonstrations. The basic approach of these demonstrations is to place a series of sMEC at known locations off the coast and track their movement using acoustic pingers and diver tracking systems, while also recording the local current and wave conditions. The observed movement is then compared to the Model predictions, and the Model is thereby first calibrated and then validated. A report (Wilson et al. 2006) documenting interim field results from the field demonstration currently being conducted at the U.S. Army ERDC Field Research Facility, Duck, NC, is available at http://www.estcp.org/Technology/upload/MM-0417-IR.pdf.

\section{Facilitation of public awareness}

Safety is the number one priority. In the event that the public could potentially be exposed to MEC resulting from a dredging operation, i.e., in a beach renourishment project where sand is (and MEC could possibly be) placed upon a public beach, an awareness program is necessary to inform the public and educate them on the potential hazards of MEC. Cooperation between the various stakeholders (public, and city, state, and federal agencies) facilitates this education process. An example of a public awareness effort conducted at Buckroe Beach by the U.S. Army Engineer District, Norfolk (hereafter Norfolk District) is presented at: http://www.nao.usace.army.mil/Projects/Environmental_Projects/Buckroe_beach/homepage.asp.

One aspect of this public awareness is a series of documents known as talking points that the Norfolk District issued to inform the public on a variety of issues concerning the inadvertent placement of MEC with beach renourishment sand and its subsequent clean up. Aspects addressed in these talking points included:

1. What (MEC) was found at Buckroe?

2. How did it (MEC) get there? When?

3. How dangerous is it (MEC)?

4. When will the (cleanup) work begin?

5. What will be done to solve the problem? 
6. What other agencies are involved in restoration?

7. What are the present restrictions for beach goers? Will restrictions remain indefinitely?

8. What do you mean when you say no digging on the beach? Can a child dig with a pail and shovel?

9. What should you do if you find something suspicious on the beach? 


\section{MEC/Dredging Lessons Learned}

The following sections present lessons learned from experiences gained on past MEC/ dredging projects involving hopper, cutterhead, and mechanical dredges.

\section{Hopper dredges}

From the available literature, it appears that hopper dredges have predominately encountered MEC on beach nourishment and maintenance dredging projects. This section presents information from experiences gained from MEC dredging projects involving hopper dredges.

As presented in Chapter 3, a risk assessment should ask the two primary questions regarding $\mathrm{MEC}$ hazards:

1. What points in the dredging process are most likely to cause the MEC to detonate?

2. What are the potential consequences of a detonation at each of these points?

The hydraulic circuit of a hopper dredge will be divided into two segments to review available documentation on previous MEC-related projects. The first hydraulic segment will consist of the draghead, up through the suction (drag) pipe and into the pump. The second hydraulic segment will consist of the pump discharge pipeline system into the hopper and pumpout involving discharging material via a hydraulic system to the beach, barge, etc. These segments cover applicable portions of the hopper dredge and dredging MEC separation alternatives in the MEC/ dredging project planning flow chart (Figure 24).

\section{Draghead/suction pipe/pump}

Sea Bright beach nourishment project

The U.S. Army Engineer District, New York (hereafter New York District), and the state of NewJ ersey are constructing the largest beach restoration project ever undertaken in the United States, known as the "Atlantic Coast of NewJ ersey, Sandy Hook to Barnegat Inlet, Section I, Sea Bright to Ocean Township." Its purpose is to protect $19 \mathrm{~km} \mathrm{(12} \mathrm{mi)} \mathrm{of} \mathrm{heavily} \mathrm{eroded}$ 
and highly developed northern NewJ ersey shore from coastal storm damages. The total initial project cost is estimated at $\$ 140$ million (federal and non-federal costs). The primary source for the beach quality sediment is a $7.8 \mathrm{sq} \mathrm{km} \mathrm{(} 3 \mathrm{sq} \mathrm{mi}$ ) area located 1.6 to $5 \mathrm{~km}$ ( 1 to $3 \mathrm{mi}$ ) offshore of the southern end of Sandy Hook (Figure 34). Hopper and hydraulic pipeline dredges excavate sediment from the authorized borrow area (initial project construction total of 14.1 million cu m or 18.5 million cu yd) and transport the sediment onto the beach via nearshore pumpout facilities or discharge pipeline. The project is scheduled to be constructed in four phases as individual contracts are awarded per section of beach and designated area within the borrow area (i.e., contracts $1 \mathrm{~A}, 1 \mathrm{~B}, 2$, and 3). Fifty years of beach nourishment are programmed into this project (Pope et al. 1996b).

Dredging started on 31 May 1994 with the award of contract 1A. On the first day of dredging, a 3 in. shell was picked up by the Weeks Marine hopper dredge R.N. Weeks, and 2 weeks later a $5 \mathrm{in}$. shell was found on the beach. The U.S. Army Engineering and Support Center, Huntsville (CEHNC) and U.S. Navy personnel were consulted to set up "a procedure for future ordnance discoveries" and by $24 \mathrm{~J}$ une 1994, 33 shells of various sizes had been encountered and dredging operations were halted by the New York District until further notice. An EOD contractor "swept" the beach and other shells of various sizes, grenades, and cannon balls were recovered and disposed (Parsons et al. 1999).

It was determined that this MEC was being excavated along with the sand from the borrow area, although there had been no pre-project data suggesting the presence of this contamination. A clamming troller (clam dredge) was deployed in the borrow area to investigate the presence of MEC and subsequently identified the presence of MEC ranging in size from 76.2 to $406 \mathrm{~mm}$ (3 to 16 in.) shells.

From a pilot study on MEC characterization within the borrow site, Pope et al. (1996b) reports that coastal fortifications and military posts have been located at the northern end of Sandy Hook, NJ , since the mid-1700s (Figure 34). This strategic location guards the major navigation routes into New York Harbor. Construction of Fort Hancock began in 1857, and by 1874 Sandy Hook was designated as the Army's first proving grounds for munition and weapon testing. Consequently, various generations of large 


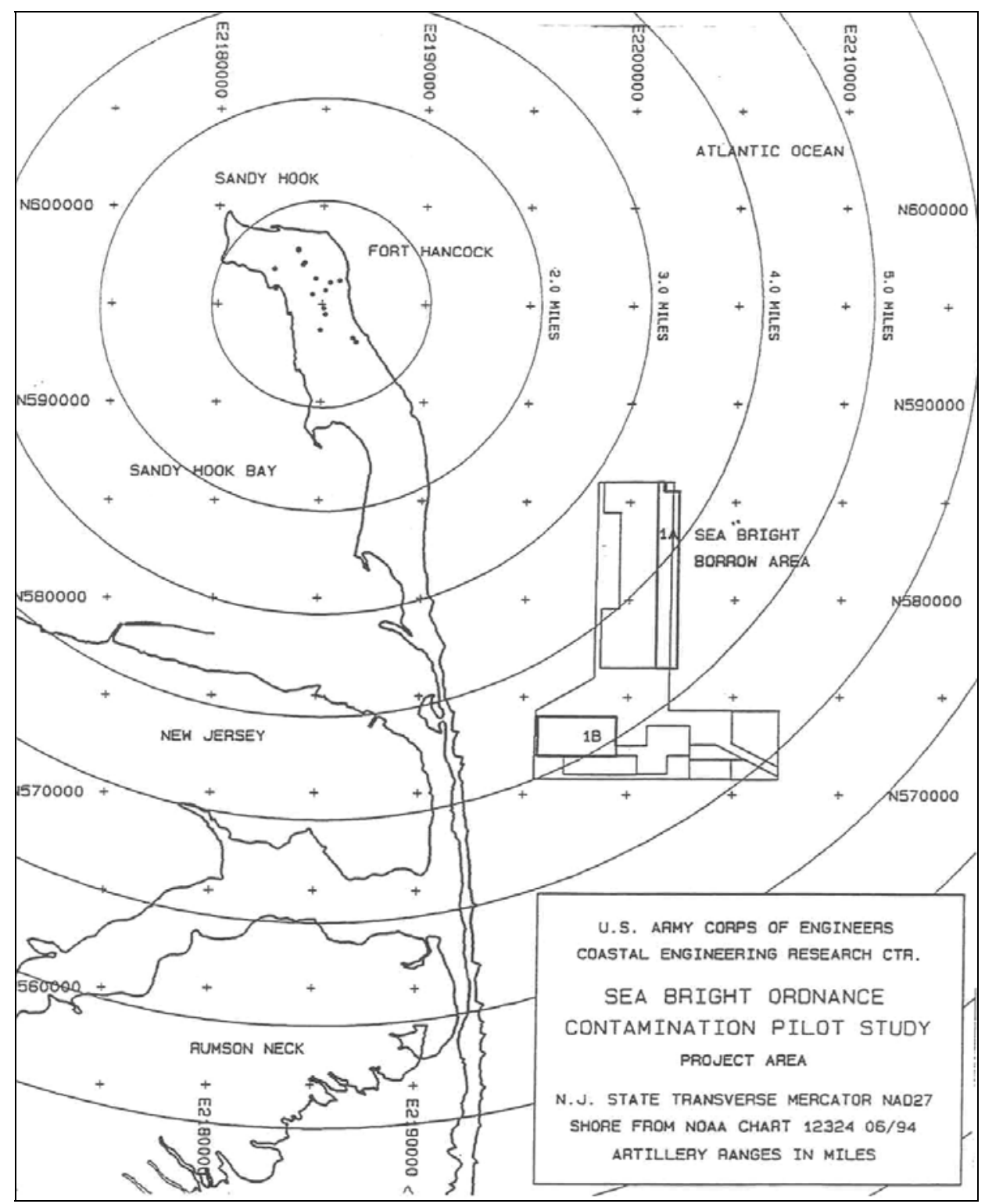

Figure 34. Location map of Sea Bright borrow area relative to Fort Hancock (source: Pope et al. 1996b).

shore-based artillery and mortar batteries were built at Fort Hancock at the north end of this sand spit. Remnants of the fortifications constructed from the 1890s until the 1940s are still in place at this formerly used defense site (FUDS) and maintained by the National Park Service.

From 1874 until World War I, a $6.44 \mathrm{~km}$ (4 mi) stretch of beach and coastal dunes extending to the south and the offshore in several directions were used as target areas for the nation's primary artillery proving ground. Various naval and army artillery and experimental rounds were tested along with proof firing of barrels for government acceptance. This 
long-term use of Sandy Hook for military training and artillery proofing has resulted in MEC contamination of large sections of Sandy Hook proper and the nearshore (St. Louis District 1993). A wide variety of MEC (light artillery to $381 \mathrm{~mm}$ [15 in.] cannonballs), dating from the Civil War through WWII, have been and are currently being recovered from Sandy Hook and adjacent areas (Pope et al. 1996b).

During the pilot study, each remnant battery and proving station at Fort Hancock was located and its position determined using a hand-held GPS receiver. These positions were entered into the project Geographic Information System database and are plotted in Figure 34. This mapping analysis was conducted to locate the Sea Bright borrow relative to Fort Hancock and its documented firing ranges to ascertain the potential for Fort Hancock to be the source of the observed MEC contamination. In addition, a historical summary of the various batteries (caliber, range, firing zones) was developed based on information available through Fort Hancock National Park (Table 2). It is known that the coastal batteries trained on targets that were towed in the Atlantic. Firing fans tended to cover the hemisphere from the north through the eastern quadrants to the south-southeast (directly down the line of the spit) with ranges generally on the order of $11.25-14.5 \mathrm{~km}$ (7-9 mi) (maximum of $32 \mathrm{~km}$ [20 mi]). Figure 34 shows the borrow area in relation to battery positions. Note that the entire borrow area is within the quoted firing fans and range potential for most classes of artillery tested at Fort Hancock (Pope et al. 1996b).

Discussions with EOD team members at Fort Monmouth, NJ (Army) and Earle Naval Air Station, NJ , confirmed that the age and caliber of recovered MEC from the general vicinity suggest that Fort Hancock is a likely source for the bulk of this material. They referenced finding Civil War-era cannonballs, parrot rounds, and a common array of $3 \mathrm{in}$. hollow rounds and 10 in. rounds filled with ball bearings, which were known to have been tested at Fort Hancock from 1875-1919. However, they also pointed out that 90 percent of the WWII ordnance shipped to Europe left out of New York Harbor. Some of these vessels were sunk by German U-boats just outside the harbor. In addition, some ordnance cargo may have been lost or dumped off ships outside the harbor entrance. So a potentially more modern source of MEC contamination to the area exists, and more modern (circa WWII) pieces have been found in the offshore (Pope et al. 1996b). 
Table 2. Fort Hancock, Sandy Hook, NJ, battery statistics (source: Pope et al. 1996b).

\begin{tabular}{|c|c|c|c|c|c|c|c|}
\hline Battery & Active Period & $\begin{array}{l}\text { Number } \\
\text { Guns }\end{array}$ & $\begin{array}{l}\text { Armorment } \\
\text { (inches) }\end{array}$ & Weight & Range (miles) & Primary Direction of Fire & Comments \\
\hline Morris & 1903-1942 & 4 & 3 & $\begin{array}{l}15 \mathrm{lb} \text { for projectile + cartridge case } \\
\text { was about } 15 \text { more pounds, } 30 \mathrm{lb} \text { per } \\
\text { fixed round }\end{array}$ & $6-8$ & $\begin{array}{l}\text { North end of Sandy } \\
\text { Hook toward NYC }\end{array}$ & $\begin{array}{l}360 \text { deg field of fire guns mounted on } \\
\text { Barbette carriages }\end{array}$ \\
\hline Urmston & 1903-1942 & 6 & 3 & $\begin{array}{l}15 \mathrm{lb} \text { for projectile }+ \text { cartridge case } \\
\text { was about } 15 \text { more pounds, } 30 \mathrm{lb} \text { per } \\
\text { fixed round }\end{array}$ & $6-8$ & $\begin{array}{l}\text { Could fire } 360 \text { deg but } \\
\text { mainly north toward } \\
\text { NYC }\end{array}$ & 360 deg swivel Barbette carriages \\
\hline Engle & $1898-1918$ & 1 & 5 & $50-60 \mathrm{lb}$ & $7-9$ & $\begin{array}{l}\text { North end of Sandy } \\
\text { Hook toward NYC could } \\
\text { train to the east }\end{array}$ & $\begin{array}{l}\text { Constructed } 1898 \text {, disarmed } 1918 \text {, } \\
\text { fires north to east }\end{array}$ \\
\hline Peck & Constructed 1903 & 2 & 6 & $\begin{array}{l}108 \mathrm{lb} \\
18 \mathrm{in} . \text { long }\end{array}$ & 15 & $360 \mathrm{deg}$ & Barbette carriage 360 deg swivel \\
\hline $\begin{array}{l}\text { 9-Gun } \\
\text { battery }\end{array}$ & 1898-1902 & $\begin{array}{l}3 \\
6\end{array}$ & $\begin{array}{l}10 \\
12\end{array}$ & $700-1,080 \mathrm{lb}$ & $8-9$ & Northeast to southeast & $\begin{array}{l}\text { 2.5- to } 4 \text { - or } 5 \text {-ft-long "torpedo" shell } \\
\text { elevator platform guns }\end{array}$ \\
\hline Potter & $\begin{array}{l}\text { Completed 1894, first } \\
\text { fired } 1892\end{array}$ & 2 & 12 & $\begin{array}{l}700-1,000 \mathrm{lb} \\
700-1,080 \mathrm{lb}\end{array}$ & $7-8$ & 360 deg & $\begin{array}{l}\text { Mortar pits } 360 \text { deg swivel. Four } \\
\text { concrete firing pits, four mortars/pit }\end{array}$ \\
\hline Granger & $\begin{array}{l}\text { Built in } 1896 \text {, armed in } \\
1897-98 \text {, fired } 1898 \text { to } \\
1943\end{array}$ & 2 & 10 & $900-1,000 \mathrm{lb}$ & $8-9$ & & \\
\hline $\begin{array}{l}\text { Sandy } \\
\text { Hook } \\
\text { Mortar } \\
\text { Battery }\end{array}$ & 1894 & 16 & 12 & $700 \mathrm{lb}$ & $\begin{array}{l}\text { Maximum range } \\
\text { was up to } 9 \mathrm{mi} \text {, but } \\
\text { accurate up to } 6 \\
\mathrm{mi}\end{array}$ & & \\
\hline
\end{tabular}


While it was not the intent of Pope et al. (1996b) or this cursory review of potential MEC sources to conduct a complete historical assessment, the information presented here does indicate potential for a wide variety of MEC types and sizes to exist throughout the borrow area. A more in-depth archival review would be needed to better characterize the caliber, vintage, location, and volume of expected MEC contamination. ${ }^{1}$

The New York District, after consulting with the CEHNC (Huntsville Center's Ordnance and Explosives Center of Expertise), had the contractor install $38 \mathrm{~mm}$ (1.5 in.) spaced bars on the hopper dragheads to exclude any MEC larger than $38 \mathrm{~mm}$ (1.5 in.) in diameter from being entrained. On 2 J uly 1994, the dragheads of the R.N. Weeks were fitted with these $38 \mathrm{~mm}$ (1.5 in.) spaced bars known as "ordnance exclusion screens." After these screens were installed, dredge production dropped by an estimated 20 percent due to the reduced suction area of the dragheads.

The initial decrease in the R.N Weeks' production caused an increase in cost, which prompted the New York District to investigate possible alternatives to beachfill operations. The New York District contracted Parsons et al. (1999) to conduct a MEC reconnaissance study and investigate a wide range of alternatives to address MEC present in the borrow site. Four proposed alternatives for supplying sand for beach nourishment projects were investigated in this study and included:

1. Characterize the current borrow area by locating ordnance for the purpose of avoidance during dredging operations.

2. Remove ordnance from the present borrow site to a level of confidence where ordnance exclusion devices are no longer needed.

3. Improve dredging techniques while still preserving worker and public safety.

4. Identify an alternate borrow site free of ordnance that contains required quantities of sand meeting project specifications.

The results of this study (Parsons et al. 1999) were that:

The current draghead and cutterhead screening methods provide an adequate solution to the ordnance contamination in the Sea Bright borrow area.

\footnotetext{
${ }^{1}$ Personal communication, Thomas Hoffman, National Park Service, Fort Hancock, Sandy Hook, NJ.
} 
However, because dredging in areas which are known to contain ordnance poses risk, preliminary investigation of a new borrow area is (was) recommended.

Parsons et al. (1999) describe the hazards of MEC as:

The explosive and toxic hazards of unexploded ordnance do not deteriorate with age. This is clearly evidenced by a fatal accident in 1972 by a North Carolina resident who inadvertently exploded a Civil War era cannon ball while attempting to drill through it for the purpose of making a lamp base. Black powder, found in some ordnance, is a composition that does not deteriorate with age. While wet, black powder is very stable but when dry, it becomes violent when subjected to abusive disturbances.

Primary explosives, found in fuses from WWI to present, remain energetic in wet or dry environments. Because of their extreme sensitivity, bulk primary explosives are stored underwater to reduce their exposure to heat, shock, and friction. A rare number of explosives become more sensitive with age and form explosive crystals, such as Picric Acid. Secondary explosives (found in the main charge) are far less sensitive than primary explosives but remain energetic in wet or dry conditions and require a highenergy stimulus to detonate. Therefore, ordnance containing impact fusing mechanisms present the greatest threat. Modern U.S. ordnance fusing systems require an arming sequence, such as setback, centrifugal force, or electrical time delay to become armed. Accuracy of fuse condition indicators cannot be relied upon with ordnance that has failed to function as designed or where environmental conditions may have deteriorated internal safety features.

The largest ordnance item known to exist in the borrow area is the 16-in. projectile. Two versions of the 16-in. projectile exist; high capacity and armor 
piercing. The high capacity projectile contains 154 lbs of Composition-D pressed explosive where the armor piercing version carries an explosive payload of $41 \mathrm{lbs}$ (pressed Comp-D). The high capacity and armor piercing versions have a gross weight of 1,700 and 2,100 lbs, respectively. The exact version of the 16-in. projectile likely to be found in the borrow area could not be verified, thus the maximum credible event MCE [sic] for this project is established at $154 \mathrm{lbs}$ net explosive weight.

While a detonation of a 16-in.-high explosive projectile is the MCE [sic] for this operation, the actual probability of such a round detonating when contacted by the dredging arm is minimal. Such unknowns as the type of fusing, condition of the round and fuse, position of the round and the contact point of the arm with the projectile must be considered. Due to the corrosive nature of environment, and the time the projectiles have been in place, the projectiles will probably be in a non-movement sensitive condition. However, some types of fuse used with the 16-in. round were movement sensitive and, if intact and unaffected by conditions at the site, could be activated by contact with the dredging arm.

Possible effects associated with detonation of the 16-in. projectile are as follows:

The detonation of the 16-in. high-explosive projectile in $50 \mathrm{ft}$ of water will create a large gas bubble, which will more than double in size before it reaches the surface. The shock wave will travel through the water four times faster than it would through air, because water does not compress as does air. A vessel directly above the point of detonation will "fall" into the gas bubble created in the water by the detonation. The severity of the shock to the vessel resulting from this fall will depend on the displacement of the vessel, its age and condition, its construction, hull design, etc. 
Regardless of the condition of the vessel the resulting jolt to the vessel will cause great injury to the crew as they are thrown about. Probable effects to the dredging vessel of a detonation directly below, or just aft, may include:

- Keel is broken, cracked or bent.

- Hull plates are sprung.

- Equipment becomes unmounted.

- Running equipment is knocked off line.

- Shaft seals and packing glands spring leaks.

- Booms and davit arms under tension fail.

- Loaded cables and hydraulics fail.

- Bulkhead doors loose water tight seal, spring open, or wedge shut.

- Loose equipment, stores, and crew are thrown about.

- Fuel, oil, and water tanks leak.

The safe separation distance from an intended detonation is 1 nautical mile.

Parsons et al. (1999) concluded that, based on the (then) current dredging operations, there were two primary objectives to be achieved by screening the dredged material for MEC.

Safety of the dredge and crew. This suggests screening device(s) designed to keep larger ordnance from entering the dredge piping system. Some risk of damage to the underwater portion of dragarms or cutterheads is acceptable.

Safety of the public. This suggests devices designed to keep all ordnance from ending up in public use areas of the restored beach.

There are two alternative approaches to the screening. First, the screens can be sized to exclude the smallest ordnance expected to be found on the project, or $37 \mathrm{~mm}$ (The current 1.5-in. bar spacing requirement 
for the screens was designed for the exclusion of ordnance of this size). This approach has the advantage of offering a single solution. The screening will simply reject most ordnance although the possibility exists for ordnance to explode and damage the dragarm or be wedged in the dragarm thus requiring backflushing or physical removal.

The second approach is to exclude the ordnance deemed dangerous to the dredge or crew. It is assumed this is larger than $1.5 \mathrm{in}$. and could be designated by ordnance experts. With this approach, the openings in the screen would be larger allowing the small arms ammunition to move through the dredge pipe and pumping system. Under the second approach it is necessary to remove the remainder of the ordnance which was allowed to pass through the dragarm screening. Two methods with precedent in the dredging industry come to mind. The first is the installation of a purpose designed "rock box" someplace in the dragarm between the draghead and the pump. The concept of the rock box is that it constitutes an enlargement of the pipeline size leading to a drop in velocity over the box. Heavier objects will drop by gravity into the rock box. Design work will be required to size the box and pipeline to capture intended ordnance sizes. The potential problem with this approach includes encountering gravel or boulders filling the rock box instantly thus reducing its value to trap ordnance.

If the rock box is not practical for the materials to be dredged, another approach is to screen the dredge effluent as it enters the hopper at the point of pump discharge. An open screen sized to catch the smallest ordnance could be installed in the hopper and could, in theory, be equipped for automatic cleanout. Another possibility is to use the screening concept at the beach as a final quality control on ordnance recovery. The rock box, the hopper screen and the 
beach screen, and to a lesser extent the draghead screen, require procedures for recovering and disposing of the ordnance trapped by the installed system.

Another concept considered is to increase the overall opening areas on the draghead enough to drop the entry velocities below the critical velocity needed to lift the ordnance into the draghead. This concept would likely require physical modeling to define the critical velocities and test various opening sizes with ordnance. This approach has not been considered further due to the complexity of analysis.

In summary, four concepts are deemed worthy of further consideration. They are:

1. Screening the draghead to exclude larger ordnance.

2. Use of a rock box to segregate ondnance before it reaches the pump.

3. Screening material leaving the pump and entering the hopper.

4. Screening material in the pipeline between the dredge and point of discharge.

These concepts can be used individually or in combination to achieve the level of quality assurance and risk reduction desired.

Maximizing Dredging Efficiency. The production of a hopper dredge is highly dependent on the suction available at the draghead. The suction is applied by the dredge pump which may be located in the hull or mounted on the dragarm near the draghead. The screening method can be expected to reduce the suction available since the screens reduce the size of suction openings and create head losses as the water and slurry collide with the screens. 
There are two methods available to offset the losses described. The first, which has been successful on this project thus far, is to increase the overall size of the draghead so that the area of the suction openings, after installation of screens, is unchanged. This should provide the same entrance velocities, and ratio between suction pipe size and openings, as existed prior to installation of the screens. There probably will be some loss of efficiency due to the hydraulic losses at the screen bars but the evidence seems to be that overall loss in production was negligible after the modification. In some cases, production improved slightly with the net increase in suction area.

The second method would apply to hopper dredges without dragarm pumps. Installation of a dragarm pump can be expected to increase the available suction at the draghead thus potentially offsetting suction losses due to screening. If a dredge already has a dragarm pump, this method will not be applicable. However, the use of a dragarm pump assures adequate suction to accommodate the increased suction area and minor head losses associated with this solution.

Use of specifically designed rock box is not expected to reduce pump production in a hopper dredge which is adequately powered and has either a conventional or dragarm mounted pump. There may be a loss of pumping time and a cost associated with cleanout of the rock box although in general it should be possible to clean it out during non-pumping periods. As noted above, encountering gravel or boulders could lead to shutdown to clean the rock box of material which otherwise could have been expected to go through the system. 
The study produced preliminary cost estimates for these different MEC "capture" methods relative to the Sea Bright projects. Table 3 lists these costs in terms of estimated capital cost, operation and management and other costs, and a total cost in dollars per cubic yard assuming 45 million cu yd are dredged over the life of the project. The purpose of this table was to provide comparative cost figures and no allowance was made for profit or contingencies. From the comparisons of additional costs for hopper dredge modifications, the lowest cost option was the enlarged dragheads with MEC exclusion screens $1 \mathrm{~B}$. This was also considered the safest alternative because it removes MEC before entering into the hydraulic circuit, reducing detonation risk aboard the dredge or on the beach (Parsons et al. 1999).

Table 3. Cost estimates for MEC exclusion dredge alterations ${ }^{1}$ (source: Parsons et al. 1999).

\begin{tabular}{|c|c|c|c|c|}
\hline Cost Items & $\begin{array}{l}\text { Capital Cost (Over } \\
5.0 \mathrm{mil} / \mathrm{cy})\end{array}$ & $\begin{array}{l}\text { Additional } \\
\text { Operation \& } \\
\text { Maintenance }\end{array}$ & Other Costs & $\begin{array}{l}\text { Total Additional } \\
\text { Costs }^{2}\end{array}$ \\
\hline \multicolumn{5}{|c|}{ Hopper Dredge (\$ per cubic yard) } \\
\hline $\begin{array}{l}\text { Modified Dragheads² } \\
\text { Screens @ } 1.5 \text { in. openings }\end{array}$ & $\begin{array}{l}20,000 \\
0.004\end{array}$ & 0.020 & $\begin{array}{l}\text { Lost Production } \\
0.400\end{array}$ & $19,080,000$ \\
\hline $\begin{array}{l}\text { Enlarge Dragsheads }{ }^{2} \\
\text { Screens @ } 1.5 \text { in. openings }\end{array}$ & $\begin{array}{l}80,000 \\
0.016\end{array}$ & 0.018 & $\begin{array}{l}\text { Lost Production } \\
0.000\end{array}$ & $1,534,500$ \\
\hline Rock Box/Suction² & $\begin{array}{l}30,000 \\
0.006\end{array}$ & 0.100 & $\begin{array}{l}\text { Ord. Removal } \\
0.222\end{array}$ & $14,760,000$ \\
\hline $\begin{array}{l}\text { Screen @ Hopper/1.5 in. } \\
\text { openings }\end{array}$ & $\begin{array}{l}13,000 \\
0.003\end{array}$ & 0.200 & $\begin{array}{l}\text { Ord. Removal } \\
0.222\end{array}$ & $19,107,000$ \\
\hline Rock Box on Beach & $\begin{array}{l}20,000 \\
0.004\end{array}$ & 0.130 & $\begin{array}{l}\text { Ord. Removal } \\
0.222\end{array}$ & $16,020,000$ \\
\hline Screen w/Booster & $\begin{array}{l}600,000 \\
0,120\end{array}$ & 0.500 & $\begin{array}{l}\text { Booster Operation } \\
0.130\end{array}$ & $33,750,000$ \\
\hline \multicolumn{5}{|c|}{ Cutterhead Dredge (\$ per cubic yard) } \\
\hline $\begin{array}{l}\text { Install Bars in Cutter } \\
1.5 \text { in. openings }\end{array}$ & $\begin{array}{l}30,000 \\
0.006\end{array}$ & 0.200 & $\begin{array}{l}\text { Lost Production } \\
0.400\end{array}$ & $27,270,000$ \\
\hline $\begin{array}{l}\text { Bars on Suction } \\
2 \text { in. opening }\end{array}$ & $\begin{array}{l}10,000 \\
0.002\end{array}$ & 0.500 & $\begin{array}{l}\text { Lost Production } \\
0.400\end{array}$ & $40,590,000$ \\
\hline $\begin{array}{l}\text { Rings in Cutter } \\
2 \text { in. opening }\end{array}$ & $\begin{array}{l}20,000 \\
0.004\end{array}$ & 0.500 & $\begin{array}{l}\text { Ord. Removal } \\
0.222\end{array}$ & $32,670,000$ \\
\hline Rock Box on Suction & $\begin{array}{l}15,000 \\
0.003\end{array}$ & 0.500 & $\begin{array}{l}\text { Ord. Removal } \\
0.222\end{array}$ & $32,625,000$ \\
\hline Rock Box on Beach & $\begin{array}{l}20,000 \\
0.004\end{array}$ & 0.150 & $\begin{array}{l}\text { Ord. Removal } \\
0.222\end{array}$ & $16,920,000$ \\
\hline Screen w/Booster & $\begin{array}{l}600,000 \\
0.120\end{array}$ & 0.300 & $\begin{array}{l}\text { Booster Operation } \\
0.800\end{array}$ & $22,500,000$ \\
\hline
\end{tabular}


In discussion of these aspects, Parsons et al. (1999) state:

It is apparent that there are a number of methods available to handle the ordnance problem through dredge improvements. Generally, the methods available for hopper dredges and cutterhead dredges have been used for ordnance (primarily on this project) or have been used to exclude boulders or debris from the dredge intake.

Safety of the Dredge and Crew. The following outlines screening device(s) designed to keep larger ordnance from entering the dredge piping system thereby minimizing the threat to the dredge and crew. The approach accepts some risk of damage to the underwater portion of dragarms or cutterhead.

For the hopper dredge, the apparent best solution is to screen the draghead. The screen opening should exclude ordnance deemed to be dangerous to the dredge or crew if allowed into the pumping (suction and discharge) system. Screening can be compensated by increasing the size of the draghead in order to maintain the original suction area. However, if the openings become too small the potential for loss of production is increased. The source of the loss of production will be in hydraulic losses associated with the small openings as well as the tendency of the small openings to become blocked with debris.

For both the hopper and cutterhead dredge examples, potential loss of suction is of less concern if the dredges are equipped with dragarm and ladder pumps, respectively. The use of underwater pumps substantially increases the suction available such that minor suction losses due to screening would be of little significance. Dredges not equipped with underwater pumps may present more of a problem. 
Safety of the public. This suggests devices designed to keep ordnance from ending up in public use areas of the restored beach. For the hopper dredge, the most positive screening device will be a screen mounted at either the discharge into the hopper or along the discharge line. (The screening could be done on a barge between the dredge and the beach.) Each of these screening alternatives will have no impact on efficiency. Production losses can be minimized by timing the clean-out with other downtime parts of the dredging cycle. The choice between the two methods will be a matter of personal preference and safety considerations rather than dredge efficiency. In either case the dredging specification can be written to exclude all ordnance from getting on the beach."

This report also suggested further study requirements as follows:

The pumping characteristics of sand and gravel have been studied and prototype and theoretical studies can be used to approximate the pumping characteristics of these materials. The shape and density of ordnance suggests different behavior in dredged slurry which makes it difficult to anticipate how it will behave at the suction entrance, over a rock box or at the discharge end of the line. Use of a rock box or large box and screen on the beach, should be complemented by hydraulic studies. This would allow testing of various sizes and configurations of ordnance through a range of slurry velocities in the system. Establishment of a "test ring" allowing the pumping of slurry and ordnance would provide better definition of the effect of ordnance on the system and allow for testing or both rock rings and suction screening alternatives.

In conclusion, Parsons et al. (1999) determined that:

The best solution for the improvement of dredging techniques is the continuation of screening using the 
enlarged dragheads. This solution is the safest, least costly, and easiest to implement and maintain. Unlike other solutions discussed, draghead screening is the only technique that excludes ordnance before entering the piping system. Therefore, it is the safest because it provides the greatest separation between dredge personnel and the ordnance. This solution is also the least expensive to use and maintain. Enlarging the dragheads has regained the production loss initially encountered from the reduced suction area. This tried and proven method is therefore recommended over other dredge improvements.

The various contracts that were awarded after the initial Sea Bright dredging contract (1A) have included the use of: the same strategy used in contract 1A (single hopper dredge/ pumpout); several hopper dredges working in conjunction with a hydraulic pipeline dredge; and a hydraulic pipeline dredge working solo. All of these dredges were required to install $38 \mathrm{~mm}$ (1.5 in.) spaced bars on the suction intakes (Parsons et al. 1999). Figure 35 shows a MEC exclusion screen on a draghead used in one of these contracts.

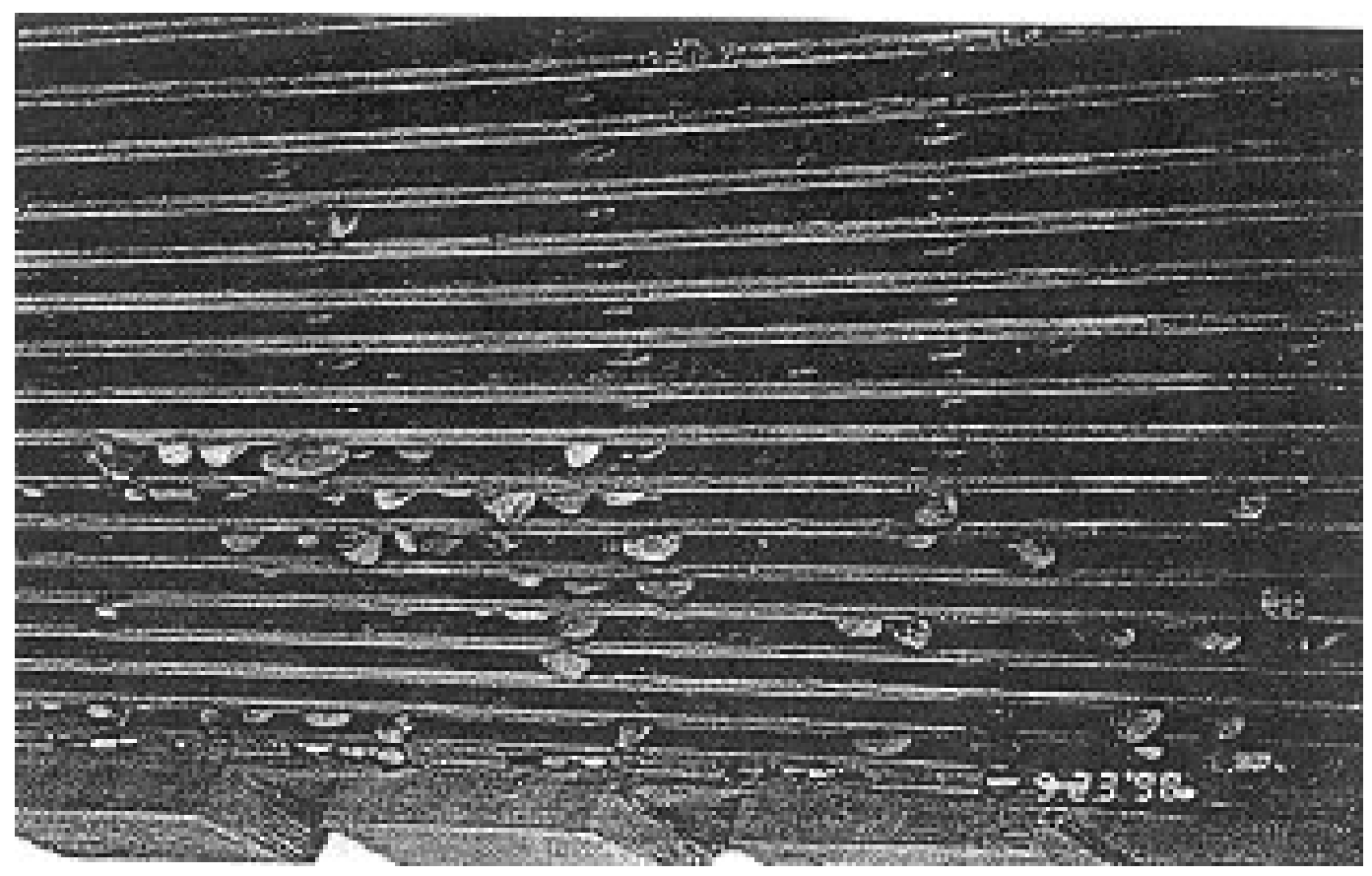

Figure 35. MEC exclusion screen installed over draghead (source: Halkola et al. 2006). 
Past New York District Sea Bright nourishment contract specifications (New York District 2001) have included requirement descriptions of the overall character of material. These descriptions include, in addition to the sand geotechnical characteristics, the following:

Character of Material

The character of materials within the borrow area is provided in Section 00903 of these specifications. Rock, rubble, ordnance or other debris may be encountered during the dredging operations; however, the required screens on the intake heads will preclude the passage of any material greater than one and one-half inches in diameter. If rock, rubble, ordnance or other debris larger than one and one-half (1-1/2) inches in diameter is excavated and placed on the beach from the borrow area, it will be removed by the Contractor, totally at his own cost. If the Contractor fails to remove the rock, rubble, ordnance or other debris, the completed fill section will not be accepted for payment. It is noted that ballast stone and ordnance were found in the borrow area being used for previous contracts. Paragraph 3.1.6 specifies the required action by the Contractor if rock, rubble, ordnance or other debris greater than one and onehalf (1-1/2) inches in diameter are discharged on the beach fill. Bidders are expected to examine the site of the work and boring samples and decide for themselves the character of the materials.

Documentation detailing the MEC exclusion devices are required before dredging starts (New York District 2001).

Hopper Dredge Basket or Screens

Drawings showing the design and method of fabrication of the basket or screen used for hopper dredging as specified in this section shall be submitted for approval prior to the commencement of dredging activities. 
Past contract specifications (New York District 2001) detailing requirements for the MEC exclusion devices were presented as follows:

Based on dredging and test dredging, unexploded ordnance consisting primarily of large caliber projectiles having diameters of three inches or larger, have been found in the adjacent borrow areas. Because of the danger presented by these objects, dredging equipment utilizing suction heads will have to be equipped with longitudinal bar screens which will have a maximum opening of one and one-half inches between adjacent bars.

The screens should be constructed of material which is very durable and wear resistant. The dimensions of the screen bars will be designed and constructed in a manner to maximize the total open area of the suction head through which borrow sediments can be dredged and maximize the hydraulic transport efficiency of the draghead. The screens should be constructed whereby the screen bars are in the same plane as the existing lower load bearing surfaces of commonly-used dragheads. This design allows for a self-cleaning type of screen which tends to increase efficiency. During the course of the dredging operation the suction heads and screens shall be inspected on a daily basis to assure that they are functional. If the Contractor proposes the use of dredge plant which utilizes a dredging methodology other than with suction heads, the Contractor will have to demonstrate to the satisfaction of the Contracting Officer, or his representative, that the proposed method will exclude picking up ordnance greater than the one and one-half inch diameter size and passing it through to the area of sand placement.

The New York District (2001) contract specifications included a reference copy of CEHNC's Safety Concepts and Basic Considerations for Unexploded Ordnance (UXO) Operations, Rev. 16, December 1992. 
San Diego Channel, San Diego, CA

The U.S. Navy was conducting a new works dredging project to deepen the San Diego Channel to Naval Air Station, North Island, San Diego, for the USS J ohn C. Stennis (CVN74), a Nimitz-class aircraft carrier. Dredging began August 1997 with a hopper dredge (Bean Stuyvesant LLC dredge Stuyvesant) with a hopper capacity of $8,460 \mathrm{cu} \mathrm{m}$ (11,065 cu yd) that was joined in early October 1997 by a cutterhead (Great Lakes Dredge and Dock's [GLDD's] Florida) with a 864 mm (34 in.) diameter discharge pipeline. The base bid volume for this project was approximately 5.5 million cu m ( 7 million cu yd) (Southwest Division, Naval Facilities Engineering Command [NAVFAC Southwest] 1998) with the dredged material either going to nearshore placement areas or upland for beach renourishment. From 21- 25 September, MEC items ranging in size from small arms shells to a live 81-mm mortar round were discovered in the South Oceanside beach fill. The beach renourishment operations were halted after 55,000 cu m (72,000 cu yd) had been deposited on the beach by the Stuyvesant. To avoid significant delay costs due to stopping the dredging operations, the U.S. Navy directed the Stuyvesant to place material offshore and directed the contractor to demobilize the Florida. Several other attempts to place channel material on the beaches were tried, but "small live ordnance and another $81 \mathrm{~mm}$ mortar were found during beach sweeps and by the public" (NAVFAC Southwest 1998).

Halkola et al. (2006) reported that:

While the ordnance was subsequently removed from the beach, the cost associated with the geotechnical surveys and reprogramming of the dredging effort and the negative public relations activities were significant and unforeseen. Dredge standby costs were up to $\$ 75,000$ per day while alternatives to the replenishment effort were explored.

In October 1997 NAVFAC Southwest authorized Fredric R. Harris to prepare a concept study to identify sand screening methods to remove MEC from sand extracted from the San Diego Channel. This concept study investigated available technologies to separate MEC from the sand before or during final placement either near shore or onshore near the beaches. Alternatives were identified and evaluated relative to the following issues: 
- Technological viability of screening MEC and ammunition from dredge material.

- Cost/quantity of sand placed.

- Schedule.

- Legislation/ funding.

- Environmental impacts.

- Permitting requirements.

- Contractual issues.

A requirement of this screening process was that it provide "reasonable assurance of removing all ordnance, including 50 caliber, M16, 20, 30, 40, and $50 \mathrm{~mm}$ rounds."

The report identified five categories of alternatives for evaluation:

1. Screening at the bottom.

2. Screening in the hopper/material barge.

3. Screening at or near the beach.

4. Removing MEC by other methods.

5. Do not screen dredged material.

"Removing MEC by other methods" considered methods other than screening, i.e., in-line debris box (modified rock box), and the "do not screen dredged material" category considered other alternatives for completing the project, i.e., dredge channel material and place offshore; then dredge "clean" sand from borrow pits for beach placement.

Over half of all the alternatives were eliminated from further investigation because they were not technologically feasible. The remaining alternatives had environmental and safety implications that required varying degrees of environmental impact analysis that could have affected the project schedule. Extensive delays for environmental documentation and permitting could have necessitated contract termination to avoid excessive standby costs. Alternatives for screening involved technologies that were untested and unproven for the quantities, flow rates, and material characteristics of the project. In short, no technologies or processes for sand screening were found to be practical within the schedule and funding constraints of this project (NAVFAC Southwest 1998). 
Halkola et al. (2006) report that:

The U.S. Navy decided to dispose the dredged materials offshore and incur the extra costs to dredge sand from a separate borrow area and place it on the beaches to meet the terms of agreement with the California Coastal Commission. A valuable resource, clean sand uncontaminated with ordnance, was lost. An additional cost of $\$ 9$ million, approximately 20 percent of the project cost, was incurred to replace the material that was subsequently disposed of in a deep-ocean location (Southwest Division Naval Engineering Command 1998).

The "screen at the bottom" alternative consisted of screening MEC at the draghead. For a given dredge and its respective pumping system, the report presented the primary controlling factors affecting the viability of this alternative as the size of the screen opening and the quantity of oversized material (material greater than the screen size). Larger sized screens are commonly used on dragheads to keep material larger than the maximum-sized solid that the pump can handle, but the concern was that screening for items, i.e., 50 caliber, M16, 20, 30, 40, and $50 \mathrm{~mm}$ rounds, would result in an excessive reduction in dredge production (therefore not viable) caused by reduced flow area at the draghead openings and increased hydraulic losses. "In order for the hydraulic pumping system to operate efficiently, a suction head opening in the order of 150 percent of the hydraulic pipe area is required" (NAVFAC Southwest 1998).

The addition of small screens on the draghead (suction head) reduces the draghead's flow area due to the physical dimensions of the screen and the oversized material that usually becomes lodged in between and over (or blinding) the screen's openings. Once this oversized material starts to blind the screen, then smaller material can accumulate on the screen and blinding is exacerbated. This blinding further reduces the flow area, increases the suction head losses, and reduces efficiency of the hydraulic suction system. NAVFAC Southwest (1998) presented a general relationship (Figure 36) between screen (grate) size and production and reported that: 


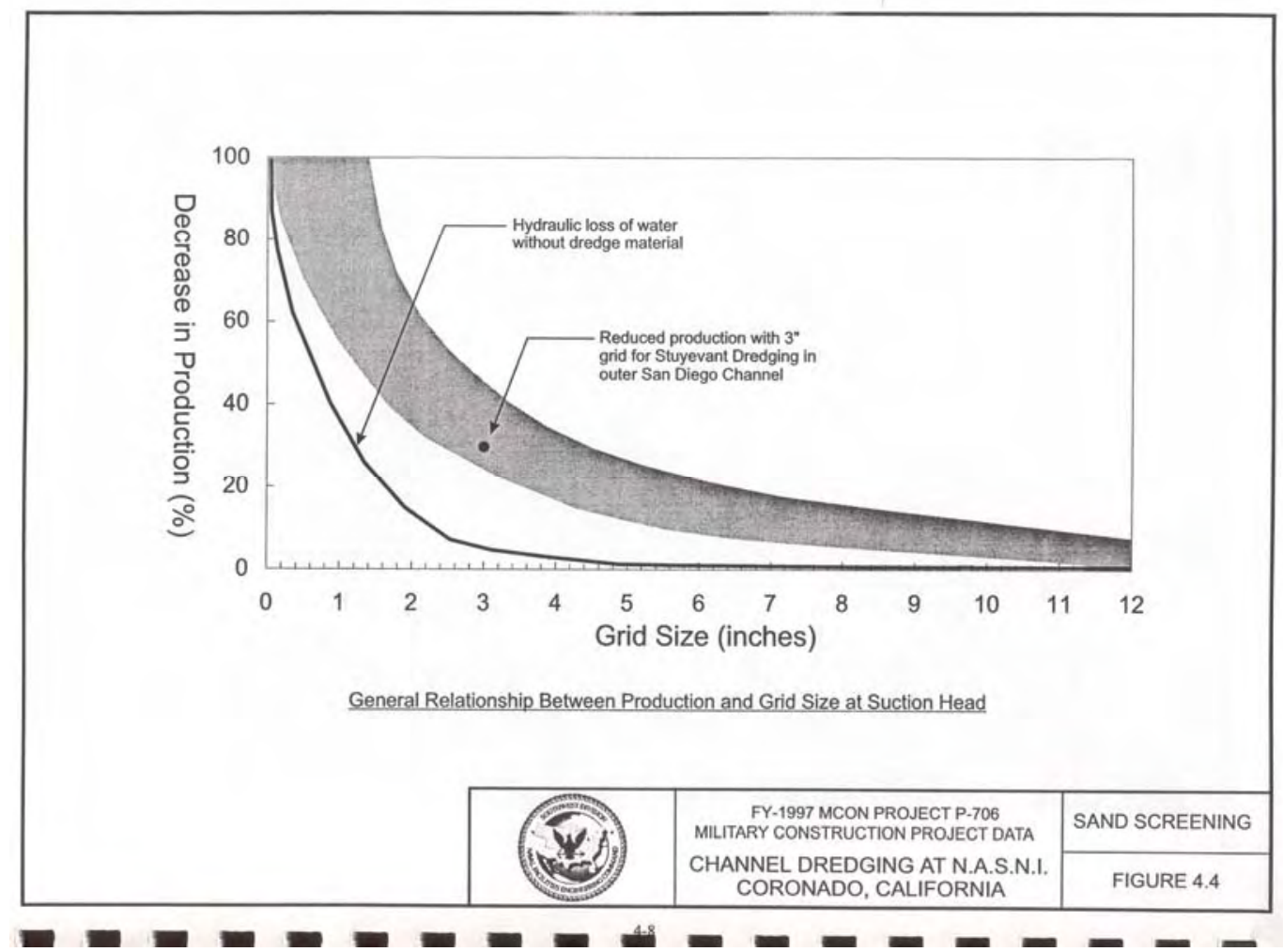

Figure 36. General relationship between production and grid size at suction head (source: NAVFAC Southwest 1998).

The lower line shows the hydraulic losses when pumping only water. The band shows a possible range of hydraulic losses when pumping hydraulic dredged material. Introduction of a very small screen at the suction head would essentially choke off the hydraulic suction of the dredge.

In the worst case, the drag head would rapidly clog, a water hammer could develop and result in a catastrophic failure of the pumping system. The more likely scenario would be for the suction head to progressively clog and starve the pump of water resulting in cavitation on the pump impellers and low production with eventual equipment burnout.

NAVFAC Southwest (1998) reported that the dredge Stuyvesant was required to install a 3 in. ( $76 \mathrm{~mm}$ ) screen while dredging on this project. The addition of this screen reduced production by approximately 30 percent, and the report attributed it: 
To increased suction head loss from the grate itself as well as clogging. It takes longer to load the hopper and dredging is intermittently stopped to unclog the drag heads. This is causing an increase in loading time of approximately 55 min (45 min due to decreased production and 10 min to intermittently unclog the suction head). It is anticipated that production will be further reduced as the cobbles and other oversized dredged material that are screened out, accumulate within the dredge cut, and contribute to an increased rate of grate clogging. Cohesive-clayey sediments, which also have a tendency to clog the grate on the suction head, have not been an issue for dredging in the outer channel since the material is essentially free of these materials. The inner channel has more cohesive material and more coarse material greater than $5 / 16$ in. which will likely have a greater effect using this method.

Bethany Beach/South Bethany Beach Storm Damage Reduction Project

The U.S. Army Corps of Engineers District, Philadelphia (hereafter Philadelphia District) is currently conducting the Bethany Beach/South Bethany Beach Storm Damage Reduction Project. The purpose of this project is to provide coastal storm damage reduction and shoreline protection along $4.5 \mathrm{~km}$ (2.8 mi) of ocean front in Bethany Beach and South Bethany Beach. Initial project construction cost is approximated at $\$ 22.5$ million and the estimated cost of periodic nourishment per cycle (approximately every 3 years) is $\$ 5.3$ million. Total estimated project cost per year for the beachfill and dune system is $\$ 3.624$ million over the 50 -year project life. This cost estimate includes initial construction costs, periodic nourishment, major rehabilitation, and project monitoring over 50 years. The average project benefits per year are $\$ 6.647$ million, which includes the major categories of storm damage reduction and recreation.

This project was planned to place 2.5 million cu m (3.2 million cu yd) of material over $4 \mathrm{~km}$ ( $2.5 \mathrm{mi}$ ) of shoreline and started in September 2004 with two hopper dredges. Prior dredging projects at this site, coupled with review of historical documents of the area, indicated a high probability of encountering UXO in the selected borrow area. Due to prior DoD activities in the entire area during WWI and WWII, no alternate borrow site deemed 
to be free of MEC was available in the vicinity. The Philadelphia District's project team, working with the USACE Baltimore Military Munitions Design Center (MMDC), required the contractor to screen out MEC at the dragheads and at the end of the beach discharge pipeline (pumpout). The screens on the dragheads were sized to $32 \times 292 \mathrm{~mm}(1.25 \times 11.5 \mathrm{in}$.) (Figure 37).

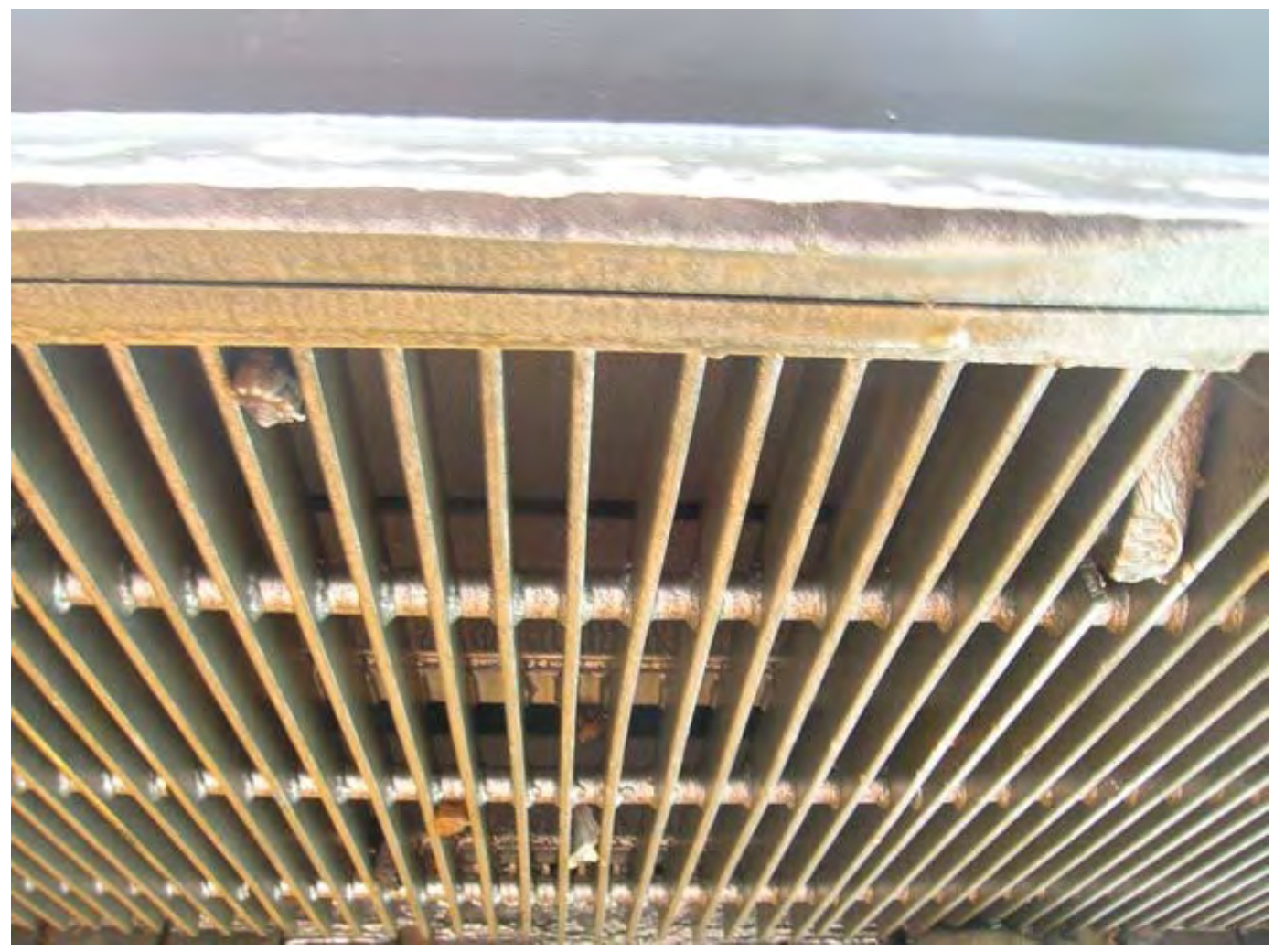

Figure 37. Draghead screen on hopper dredge R.N. Weeks at Bethany Beach, DE (2007). Apertures sized to $32 \mathrm{~mm} \times 292 \mathrm{~mm}$ (source: Weeks Marine Inc.).

To date, during the course of the project, nine MEC items were collected in the beach screening baskets (see the "Pumpout to beach" section, p 103, for more information on the beach screening baskets). These items were $37 \mathrm{~mm}$ (1.4 in.) and $40 \mathrm{~mm}$ (1.5 in.) projectiles. The draghead screens were damaged by rocks encountered during the course of dredging on several occasions. This allowed the MEC items to enter the dredging stream. All of the MEC items passing through the draghead screens were captured in the beach screening baskets. This was verified through magnetometer sweeps conducted on the placed dredged material.

As of early 8 J anuary 2008, 1,295 loads had been pumped ashore by the dredges (one of which had departed on 16 December 2007) for an 
estimated placed volume of approximately 3 million cu yd. Draghead screen repairs had resulted in downtime of approximately 6 days per dredge over this time period and the estimated cost of MEC avoidance screening to date is approximately $\$ 100,000$.

Some of the steps taken to ensure the safety of the dredge and beach crews were:

1. Initial MEC Safety and Recognition Training provided to all personnel (including grass planting teams and infrastructure construction teams). Follow-on training to all replacement personnel.

2. Standard Operating Procedures were established for the dredging crew and the beach crew in the event MEC are discovered.

3. Advance liaison with local law enforcement and U.S. Coast Guard MEC response elements.

4. UXO Safety Specialists on-site/ on-call 24/ 7 during the course of dredging.

\section{Medway Estuary, United Kingdom}

Maddrell (2001) reports that in 1989 a new-works dredging project involving the removal of 3 million cu m (3.9 million cu yd) of material was conducted in support of a new container port development project. The dredged material was placed in an open-water dredged material placement site. The area was known to contain MEC from previous dredging conducted in this area (with sediments predominantly fine-to-medium sands, and with some locations having gravel and "stiff London clay"). During a previous project conducted in 1971, over a 6- to 7-week maintenance dredging contract, approximately 50 different types of MEC were recovered. In 1985, 4 in. projectiles and $40 \mathrm{~mm}$ Bofor projectiles were also recovered from this same area while dredging 2,000 cu m (2,616 cu yd) of material (Maddrell 2001).

MEC exclusion screens were required on the three hopper dredges, Geopotes XV, Volvox Delta, and Alpha B, with hopper capacities ranging from $5,000 \mathrm{cu} \mathrm{m}$ to $8,000 \mathrm{cu} \mathrm{m}(6,540 \mathrm{cu}$ yd to $10,464 \mathrm{cu} \mathrm{yd})$, to exclude MEC from being deposited at the placement site. The MEC exclusion screens consisted of $25 \mathrm{~mm}$ ( $1 \mathrm{in}$.) bars installed on the dragheads to form aperture areas of approximately $150 \mathrm{sq} \mathrm{cm}$ (23 sq in.). This screen configuration successfully excluding major MEC items from entering the hydraulic circuit of the dredge, but significant amounts of MEC subsequently became jammed in the dragheads. Production was reduced due to 
rocks, clay, and debris that accumulated and blinded the screens because these dragheads had to be raised and cleaned every 20 to $40 \mathrm{~min}$. When the cleaning delays exceeded $30 \mathrm{~min}$, the contractor claimed downtime (Maddrell 2001).

Approximately 770 MECitems were recovered from this area from 1989 to 1990. The majority of these items were inert (cannon balls from the Dutch and Napoleonic wars and inert training rounds), but 32 military ordnance items required disposal by the Royal Navy's EOD personnel. These EOD personnel were required to be onboard the hopper dredges to handle the ordnance during the three dredging contracts. "While relatively expensive in terms of specialist staff and downtime, the cost of this operation was about 3 percent of the overall project cost of some 6 million pounds (\$10.7 million U.S. dollars)" (Maddrell 2001).

\section{Pump discharge into hopper}

San Diego Channel, San Diego, CA

NAVFAC Southwest (1998) investigated the viability of installing screens in the pump discharge piping system and determined that:

For a given dredge and hydraulic pumping system, the primary controlling factors affecting the viability of these alternatives are:

- Size of screen.

- Quantity of material greater than screen size; handling and disposal of that material.

- Physical constraints of hopper dredge.

- Location of placement site for oversized dredged material collected on the screen.

The quantity of oversized dredged material (everything larger than the screen aperture) to be screened was considered to be a very significant factor in this project. It was estimated, based on available sediment data, that the fraction of material greater than $8 \mathrm{~mm} \mathrm{(5/16} \mathrm{in.)} \mathrm{was} \mathrm{estimated} \mathrm{to}$ be on the order of 5 to 7 percent by volume. NAVFAC Southwest (1998) estimated the quantities of oversized material based on one hopper load of the Stuyvesant (volumes in Table 4) and noted that these volumes "are 
substantial and will hinder the screening, identification of small ordnance, and disposal of oversized material."

Table 4. Estimated quantity of oversized dredged material collected per load $(6,000 \mathrm{cu} \mathrm{m})$ for given screen size.

\begin{tabular}{|c|c|c|c|c|c|}
\hline \multirow{2}{*}{$\begin{array}{l}\text { Quality of } \\
\text { Material }\end{array}$} & \multicolumn{5}{|c|}{ Screen Size } \\
\hline & No Screen & $3 \mathrm{in.}$ & $2 \mathrm{in.}$ & $1 \mathrm{in.}$ & $5 / 16$ in. \\
\hline $\begin{array}{l}\text { Percent by } \\
\text { Volume }\end{array}$ & 0 & 1 to 2 percent & 2 to 3 percent & 3 to 4 percent & 5 to 7 percent \\
\hline Volume & 0 & $\begin{array}{l}60 \text { to } 120 \mathrm{cu} \mathrm{m} \\
\text { ( } 80 \text { to } 160 \mathrm{cu} \text { yd) }\end{array}$ & $\begin{array}{l}120 \text { to } 180 \text { cu m } \\
\text { (160 to } 240 \text { cu yd) }\end{array}$ & $\begin{array}{l}180 \text { to } 240 \mathrm{cu} \mathrm{m} \\
\text { ( } 240 \text { to } 320 \mathrm{cu} \mathrm{yd} \text { ) }\end{array}$ & $\begin{array}{l}300 \text { to } 420 \text { cu m } \\
\text { ( } 400 \text { to } 560 \text { cu yd) }\end{array}$ \\
\hline
\end{tabular}

(Source: NAVFAC Southwest 1998).

Four primary screen issues were identified:

1. Where is the sand screened?

2. How is the sand screened to $5 / 16$ in.?

3. After sand is screened, how does it get into the beach fill design section?

4. What is done with oversized dredged material greater than $5 / 16$ in.?

An analysis was performed in the context of a Stuyvesant pumpout operation to transfer sand from the hopper to the beach and to put this operation into perspective. NAVFAC Southwest (1998) presented the following description of volume and flow rate for this evolution.

Each load for pump out on the beach is approximately $6,000 \mathrm{cu} \mathrm{m}(7,800 \mathrm{cu}$ yd) or the equivalent of 600 dump truck loads at $10 \mathrm{cu} \mathrm{m}$ (13 cu yd) each. This load is discharged on the beach over a period of 1-1/2 hr or at a rate of approximately seven dump truck loads per minute, 400 truck loads per hour.

These values are calculated on the following Stuyvesant pumpout operation facts in Table 5.

Table 5. Beach pumpout operation facts.

\begin{tabular}{|l|l|}
\hline Pipe diameter & $0.9 \mathrm{~m}$ (35 in.) \\
\hline Flow rate & 6,300 liters $/ \mathrm{sec}(100,000 \mathrm{gpm})$ \\
\hline Velocity & $11 \mathrm{~m} / \mathrm{sec}(36 \mathrm{ft} / \mathrm{sec})$ \\
\hline Solids & 12,000 tons over $90 \mathrm{~min} ; 2.2$ tons $/ \mathrm{sec} ; 1.1 \mathrm{cu} \mathrm{m} / \mathrm{sec}$ \\
\hline Water & 28,000 tons over $90 \mathrm{~min} ; 5.3 \mathrm{tons} / \mathrm{sec} ; 4.7 \mathrm{cu} \mathrm{m} / \mathrm{sec}$ \\
\hline TOTALS & 40,000 tons over $90 \mathrm{~min} ; 7.5 \mathrm{tons} / \mathrm{sec} ; 5.8 \mathrm{cu} \mathrm{m} / \mathrm{sec}$ \\
\hline
\end{tabular}

(Source: NAVFAC Southwest 1998). 
In discussion with industry professionals, NAVFAC Southwest (1998) reports that the "screen in the hopper dredge" alternative indicated that this method had been used successfully in screening small rocks greater than $38 \mathrm{~mm}$ (1-1/2 in.) for a project in Florida with GLDD's hopper dredge Long Island. The sand/ water slurry was discharged through perforations in a pipe that crossed the hopper on an incline, while the rocks "rolled down to the end of the pipe and were caught in a rock basket."

Because of this experience, this alternative initially appeared promising, but it was determined that the Stuyvesant's hopper created a very constrained space and that this physical constraint would make it very difficult to handle the oversized dredged material. NAVFAC Southwest (1998) determined that "dumping of the oversized material after each load would increase dredge cycle time by approximately $1 \mathrm{hr}$ per load (assuming a dump site is 8 miles off shore) plus the time to discharge the load." Due to these estimates it was determined that screening dredged material to $8 \mathrm{~mm}$ (5/ $16 \mathrm{in}$.) on the Stuyvesant was not feasible, but the same alternative under a new contract onboard a different hopper with different physical constraints was determined to be technologically viable.

\section{Pumpout to beach}

Sea Bright beach nourishment project

Parsons et al. (1999) determined in the Sea Bright ordnance reconnaissance study that:

Screening the discharge at or near the beach may or may not introduce efficiency and cost considerations. One method of accomplishing the screening would be for the pipeline to discharge into a large box with an open screen and cleanout capability. A booster pump would be mounted drawing in the slurry after it has passed the screen. If the project required a booster anyway, the incremental cost of the clean-out system would be small. If a booster was not normally required, the additional cost of providing it would be a significant item. 
Past New York District Sea Bright nourishment contract specifications (New York District 2001) have included the following specifications regarding the beach pumpout operations:

Rock, rubble, ordnance or other debris may be encountered during the dredging operations; however, the required screens on the intake heads will preclude the passage of any material greater than one and one-half inches in diameter. If rock, rubble, ordnance or other debris larger than one and one-half (1-1/2) inches in diameter is excavated and placed on the beach from the borrow area, it will be removed by the Contractor, totally at his own cost. If the Contractor fails to remove the rock, rubble, ordnance or other debris, the completed fill section will not be accepted for payment. It is noted that ballast stone and ordnance were found in the borrow area being used for previous contracts. Paragraph 3.1.6 specifies the required action by the Contractor if rock, rubble, ordnance or other debris greater than one and one-half (1-1/2) inches in diameter are discharged on the beach fill. Bidders are expected to examine the site of the work and boring samples and decide for themselves the character of the materials.

During all pumping operations, the Contractor shall provide personnel to maintain visual control at the end of the discharge line. Radio contact shall also be provided by the Contractor to enable such personnel to halt dredging in case of emergency.

(9) The area where filling operations are in progress shall be floodlighted during the hours of darkness illumination shall be provided by using portable light equipment. A minimum of $3 \mathrm{ft}$ candles of illumination shall be maintained within a $50 \mathrm{ft}$ radius of the pipe discharge.

(10) If during the course of the fill placement, it is observed that any item greater than one and one-half 
inch diameter is discharged on the beach, the Contractor will immediately cease the pumping operation, notify the Contracting Officer representative, inspect the screens on his dredge equipment to determine if a break has occurred, and conduct a magnetometer survey on the beach area being filled, at the Contractor's own expense, to assure that no ordnance has been placed on the beach.

(11) The Contractor shall prepare and submit a site specific magnetometer work plan and a safety and health plan to the Government for approval prior to mobilization. The work plan shall contain an UXO operation plan detailing the Contractor's proposed methodology to complete the magnetometer search and ordnance removal procedures. All UXO related procedures shall comply with CEHNC Safety Concepts and Basic Considerations for UXO, 16 December 1992, U.S. Army Corps of Engineers, Huntsville, Technical Support Center, Mandatory Center of Expertise for Ordnance and Explosive Waste (Section 00905). The work plan shall describe the qualifications of the UXO personnel. The following are the minimum nonwaiverable qualifications for UXO personnel:

(i) UXO Team Leader (UXO Supervisor): a graduate of the Naval EOC School, Indian Head, MD, with at least 10 years combined active military EOC and contractor experience. (ii) UXO Team Member (UXO Specialist): shall have more than 3 years active duty military EOC experience. The work plan shall provide details of the magnetometer equipment which will be used in the beach survey. The work plan shall also describe the grid layout for any magnetometer surveys which may be necessary. The work plan shall propose an evacuation distance based on the largest piece of UXO expected to be found on the beach. The Contractor shall describe feasible alternatives for disposal, and shall recommend the safest and most cost 
effective method of treatment and disposal of any explosive ordnance and inert ordnance encountered. If on-site detonation is not acceptable, an alternate disposal method should be considered and proposed by the Contractor, and forwarded to the Contracting Officer for approval prior to mobilization.

\section{Bethany Beach/South Bethany Beach Storm Damage Reduction Project}

In addition to the draghead screens previously discussed, the Bethany Beach Storm Damage Reduction Project also required beach screening baskets with minimum screen openings to not exceed $32 \times 32 \mathrm{~mm}$ $(1.25 \times 1.25 \mathrm{in}$.). Figure 38 shows a beach basket in operation, and Figure 39 shows one being inspected during downtime. This inspection process was halted when UXO was discovered. Future inspections were conducted by UXO Specialists.

During the course of the project, nine MEC items were collected in the beach screening baskets. These items were $37 \mathrm{~mm}$ (1.4 in.) and $40 \mathrm{~mm}$ (1.5 in.) projectiles. Figure 40 shows a $37 \mathrm{~mm}$ armor piercing projectile

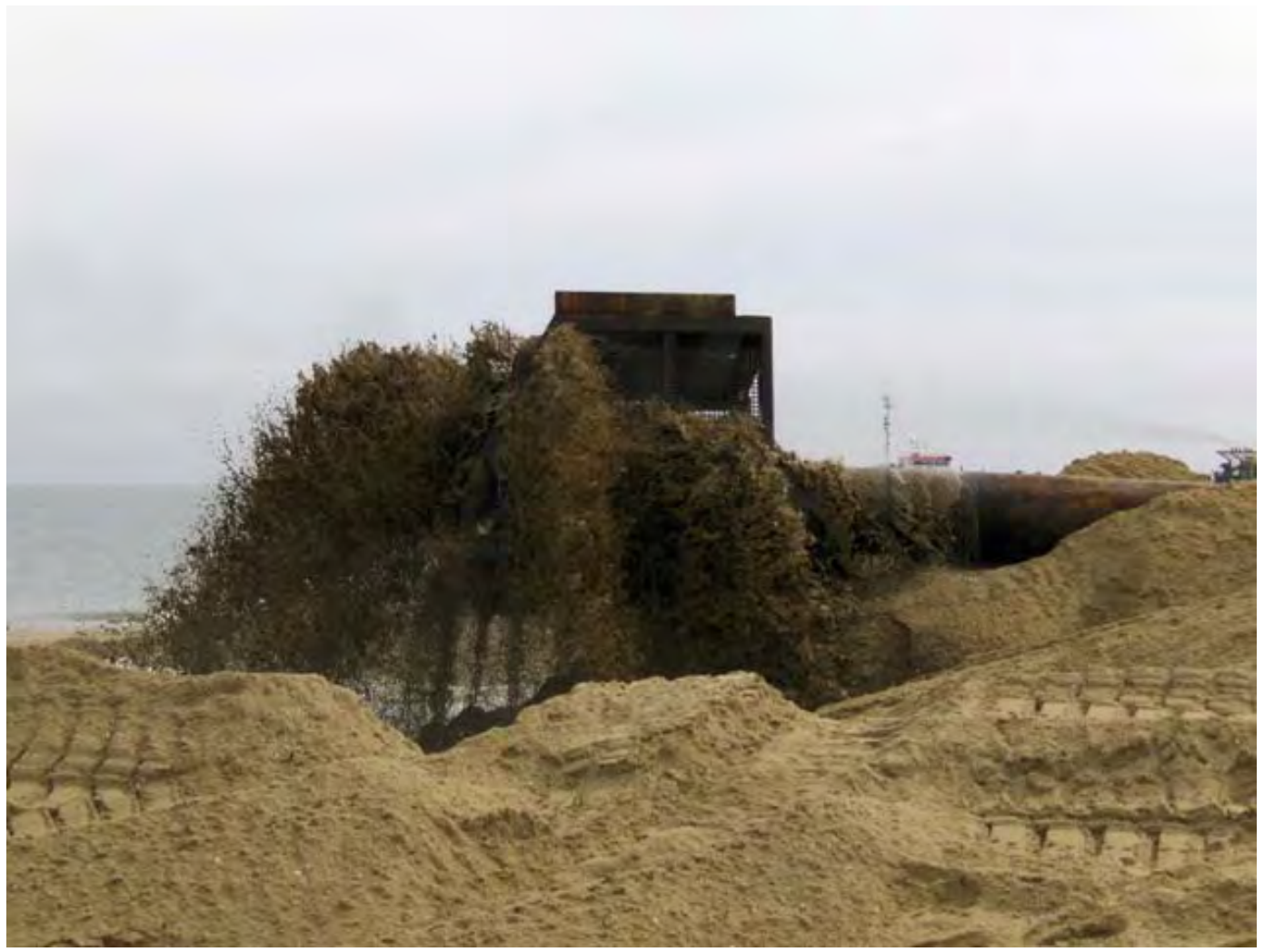

Figure 38. Beach screening basket in operation at Bethany Beach, DE (2007). 


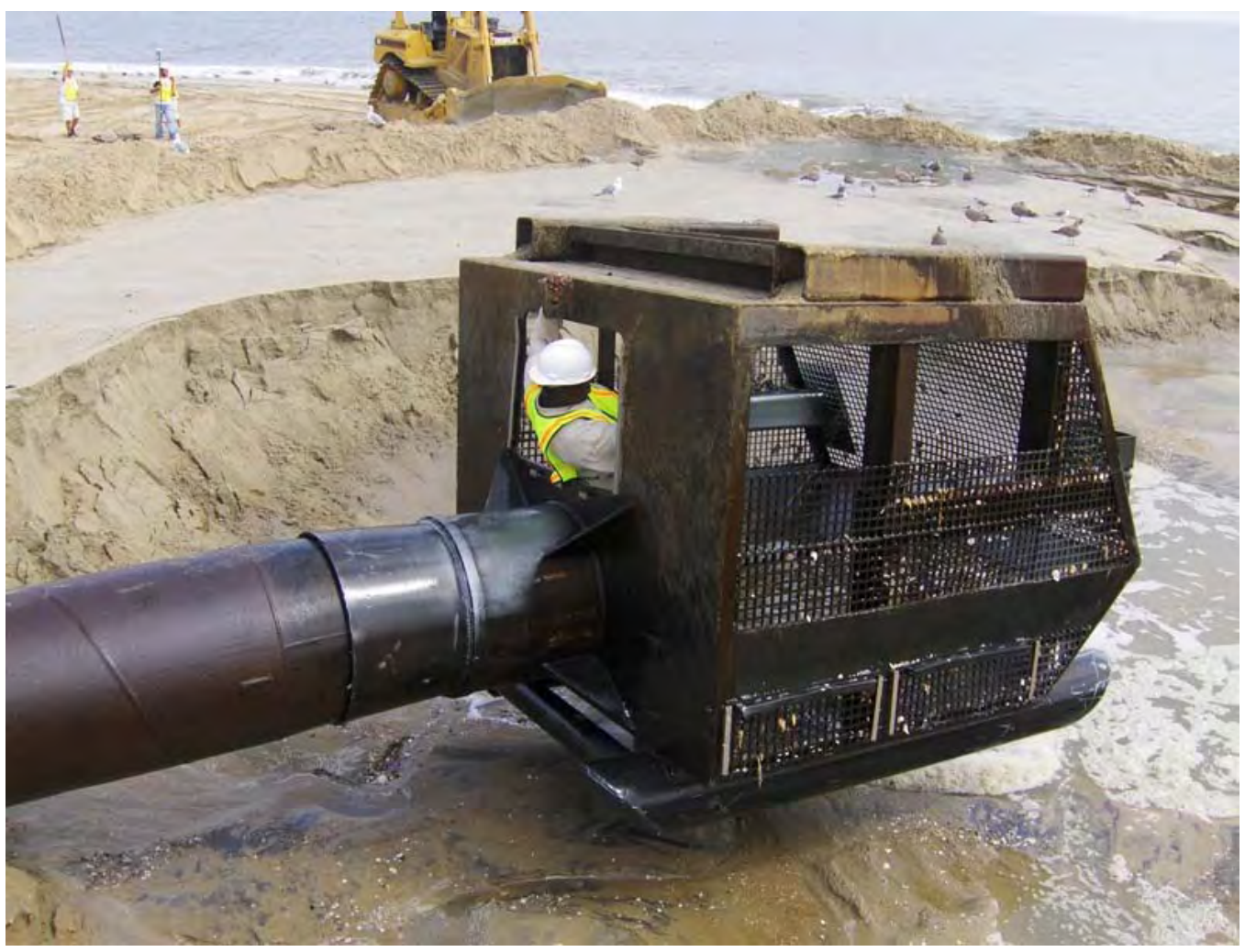

Figure 39. UXO Specialist inspection of beach screening basket at Bethany Beach, DE (2007).

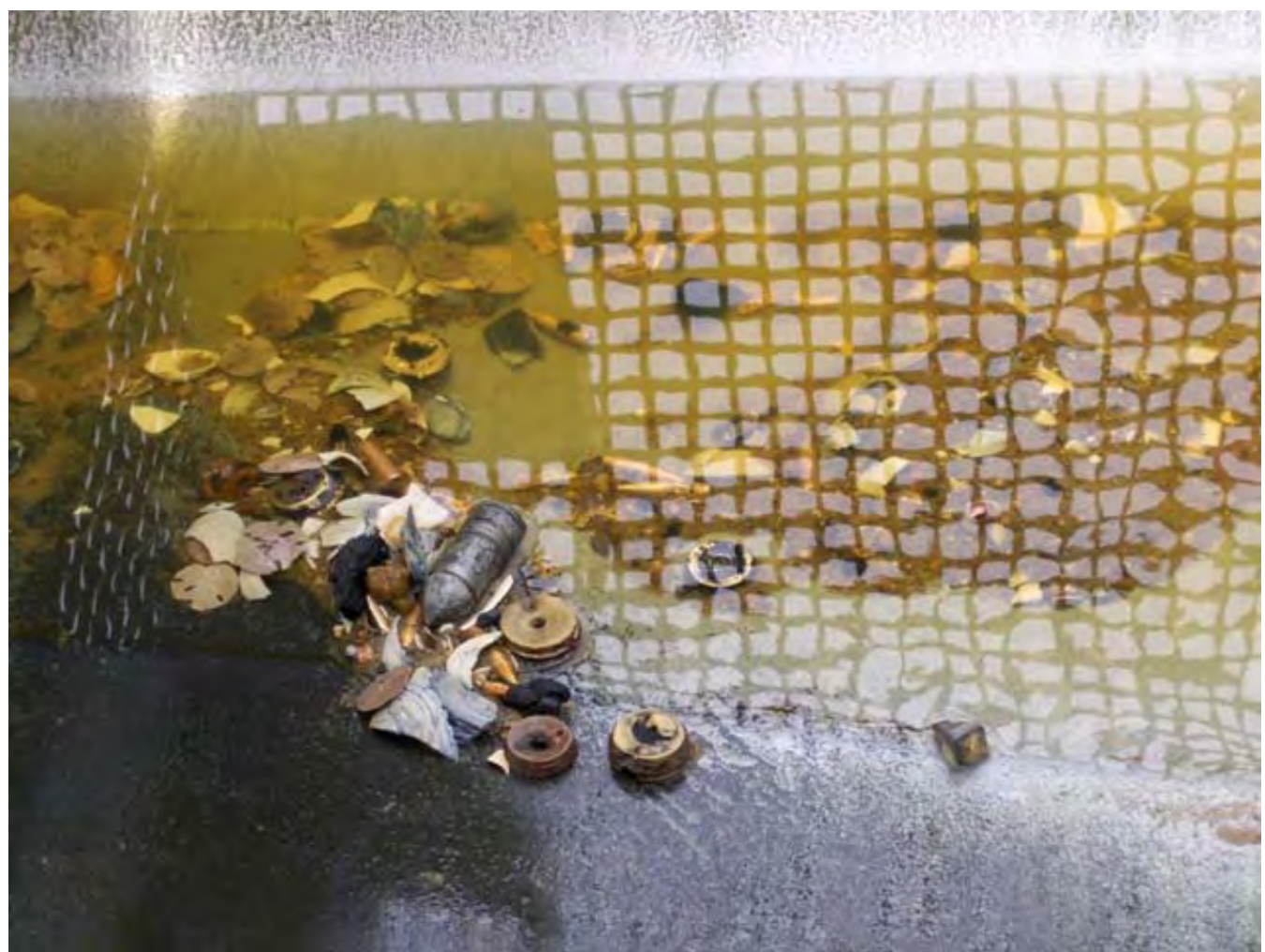

Figure $40.37 \mathrm{~mm}$ armor piercing projectile captured in beach screening basket at Bethany Beach, DE (2007). Note various fuze pieces and .50 caliber projectiles and casings. 
captured in a screening basket. The screens on the dragheads were sized to $32 \mathrm{~mm} \times 292 \mathrm{~mm}$ (1.25 in. $\times 11.5 \mathrm{in}$.). The draghead screens were damaged by rocks encountered during the course of dredging on several occasions. This allowed the MEC items to enter the dredge's hydraulic circuit. All of the MEC items passing through the draghead screens were captured in the beach screening baskets. This was verified through magnetometer sweeps conducted on the placed material, inspection of material dumped from beach screening boxes conducted by UXO Specialists, and removal of various munitions debris items from beach screening baskets and placement by UXO Specialists.

Some lessons learned during this project included:

1. The presence of MEC, rocks, and other debris in beach screening baskets larger than the apertures in the draghead screens is an indication that damage to the draghead screens has occurred.

2. Draghead screens must be inspected for MEC and damage after each inflow cycle.

3. Inspection of beach screening baskets should occur only from the outside of the basket (unless performed by UXO Specialist).

4. When beach screening baskets contain an amount of material (rocks and etc.) that render the basket unusable for screening (through volume or weight), the material in the basket must be dumped in the presence of a UXO Specialist. The dumped material must be inspected with the aid of a handheld metal detector. An exclusion zone must be established during this dumping and inspection procedure.

5. The cleaner a borrow site is with regard to rocks and MEC, the less damage the MEC screens will sustain over the course of dredging.

6. Be prepared for MEC response elements to conduct a BIP of found MEC on-site.

7. Spare beach screening baskets will reduce the periods of down-time when damage to an operational basket occurs.

8. Exclusion zones must be implemented during dredging and unloading of dredged material.

San Diego Channel, San Diego, CA

NAVFAC Southwest (1998) reports that the primary factors affecting the viability of screening on or near the beach for the San Diego Channel project were: 
- Size of screen.

- Quantity of material greater than screen size.

- Available staging area to handle, process, and stockpile sand.

- Location of oversized dredged material stockpile and disposal site.

The different methods of screening that were evaluated included:

- Angled screen.

- Vibrating screen.

- Spiral classifier.

- Trommel screen.

A brief description of these methods is included here; for more detailed information refer to NAVFAC Southwest (1998) and Halkola et al. (2006).

Angled screen. NAVFAC Southwest (1998) reported that angled screens are readily available from mining and aggregate industry equipment suppliers; but for the San Diego project conditions, the required size of screen would require special fabrication. Conceptual sketches of this report's version of angled screens are presented in Figures 41 and 42 . At an estimated design flow of 100,000 gpm with 2.2 tons/ sec of solids to be screened at $8 \mathrm{~mm}$ (5/16 in.), it was anticipated that the angled screen would clog intermittently and would be extremely large, on the order of $100 \mathrm{sq} \mathrm{m}$ (1,075 sq ft). This operation was anticipated to be labor intensive and costly, and as with all screening operations, crew safety would be a concern. This alternative appeared capable of achieving the necessary screening requirements; however, it "was not proven that the equipment will work for this application" NAVFAC Southwest (1998). The beach installation would be large, and details (i.e., placement, stability, and a system to get the screened sand to the beach fill section) remained to be worked out.

Vibrating screen. NAVFAC Southwest (1998) reported that vibrating screens are also available from a number of manufacturers (Figure 43) and are able to screen materials to $8 \mathrm{~mm}$ (5/ $16 \mathrm{in}$.). It was estimated, based on discussions with manufacturers, that six to eight units would be required with screens approximately $7.5 \mathrm{~m}$ long $\times 3 \mathrm{~m}$ wide $(24 \mathrm{ft}$ long $\times 10 \mathrm{ft}$ wide). 


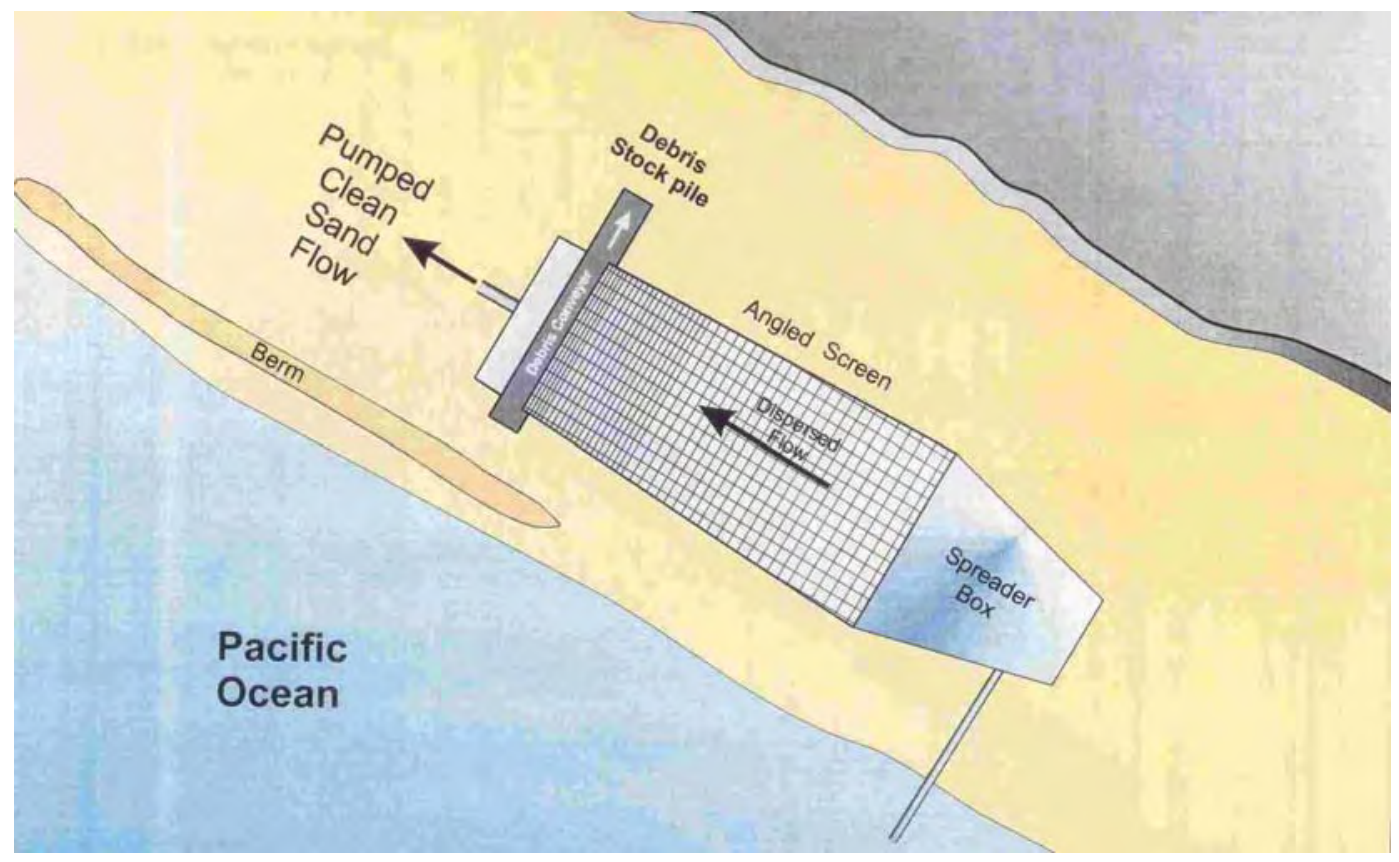

Figure 41. Angled screen plan view (source: NAVFAC Southwest 1998).

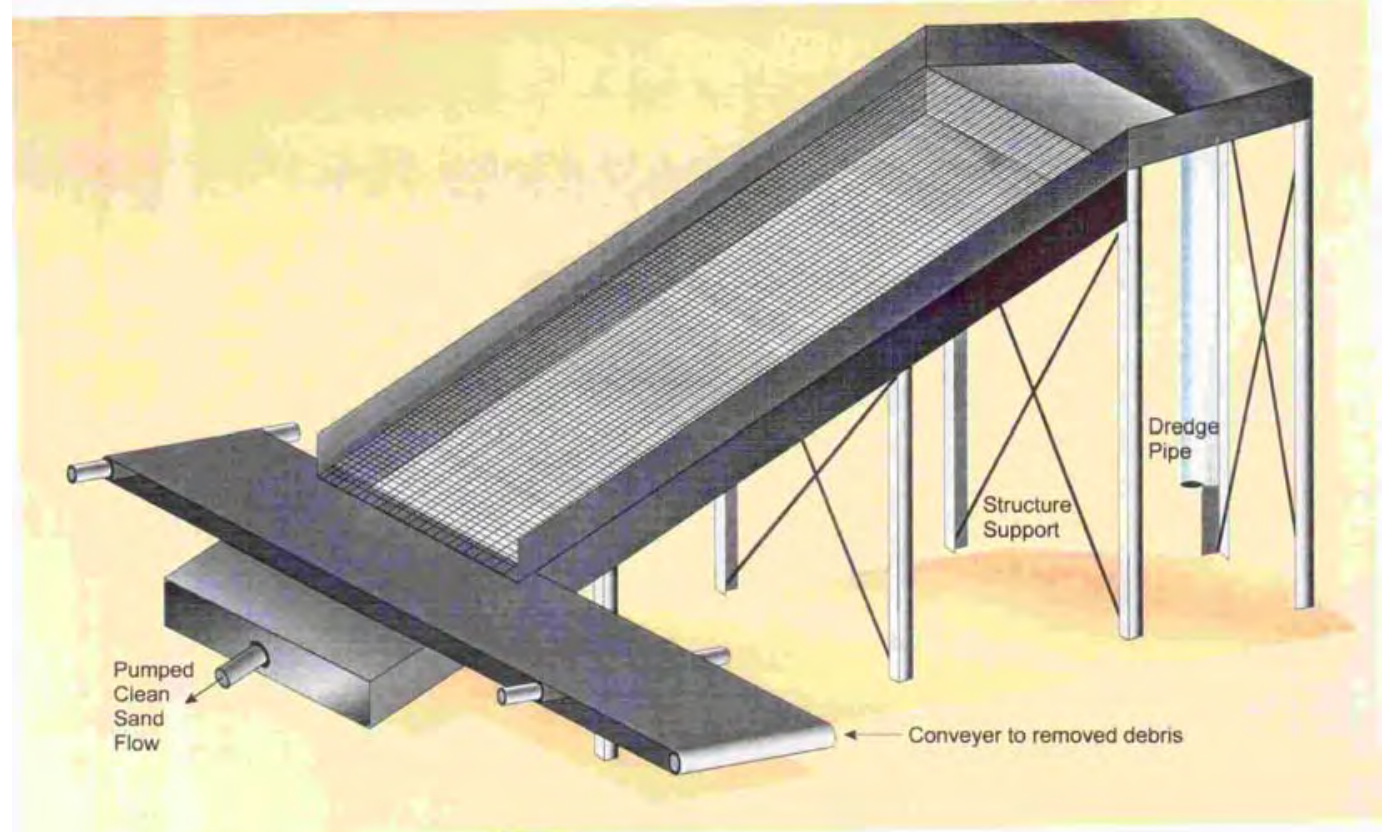

Figure 42. Angled screen side view (source: NAVFAC Southwest 1998). 


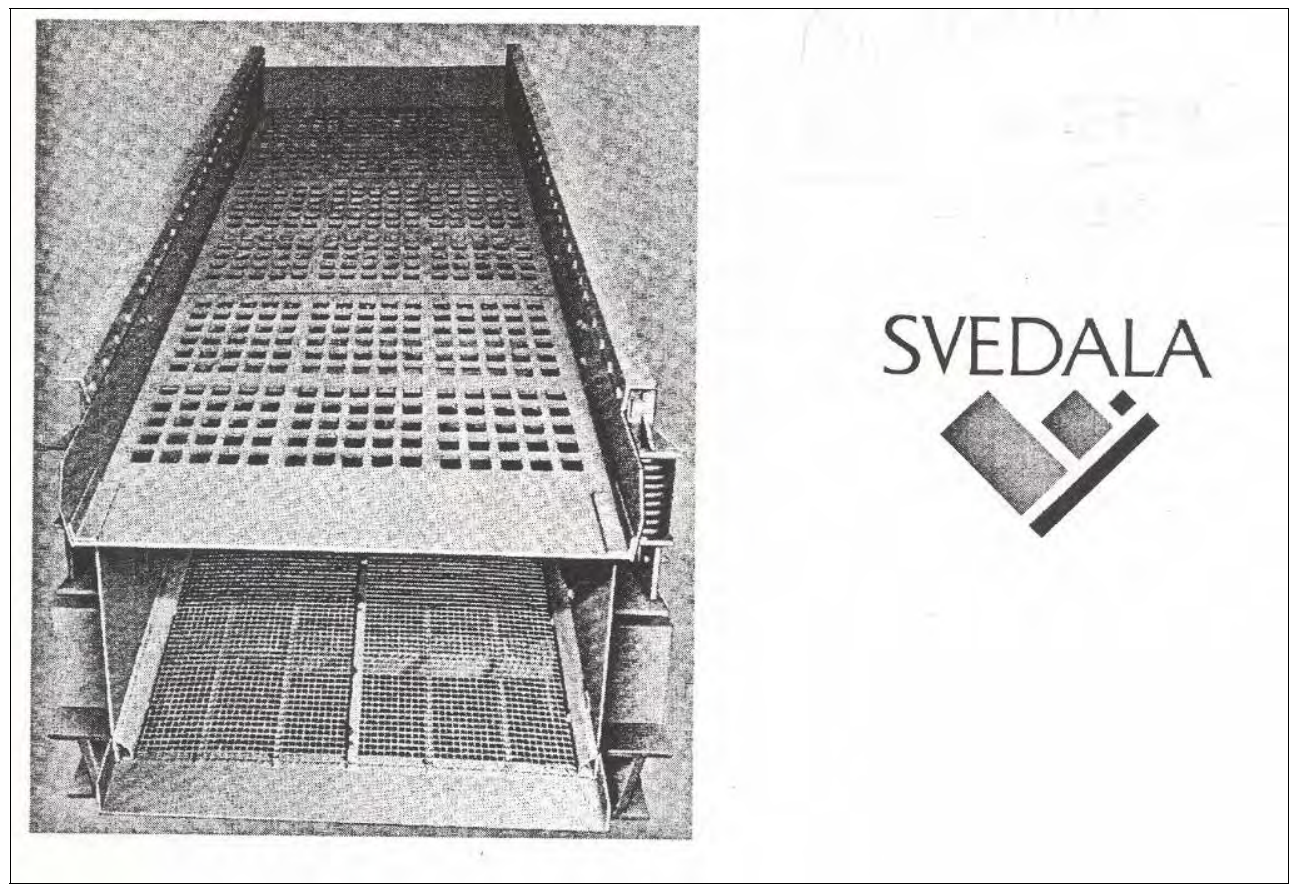

Figure 43. Vibrating screen (source: NAVFAC Southwest 1998).

This alternative appeared "capable of the necessary screening, however, it is not proven that the equipment will work for this application." The vibrating screen plant is large, noisy, requires additional power, and is expensive" (NAVFAC Southwest 1998), and it will have the same issues as the angled screens. As noted by Halkola et al. (2006), any perceived concern of MEC being subjected to the high-frequency vibration was not addressed in the report.

Spiral classifier. NAVFAC Southwest (1998) reported that spiral classifiers (Figure 44) are available, used for operations (e.g., washing pea gravel), and should be able to screen out MEC and other oversized material greater than $8 \mathrm{~mm}$ (5/ $16 \mathrm{in}$.). In discussions with a manufacturer, it was concluded that twin $200 \mathrm{~cm}$ (78-in.) classifiers could perform the task. This alternative appeared capable of achieving the necessary screening; however, it "has not been proven that the equipment will work for this application," and it will have the same issues as the vibrating screen concept. 


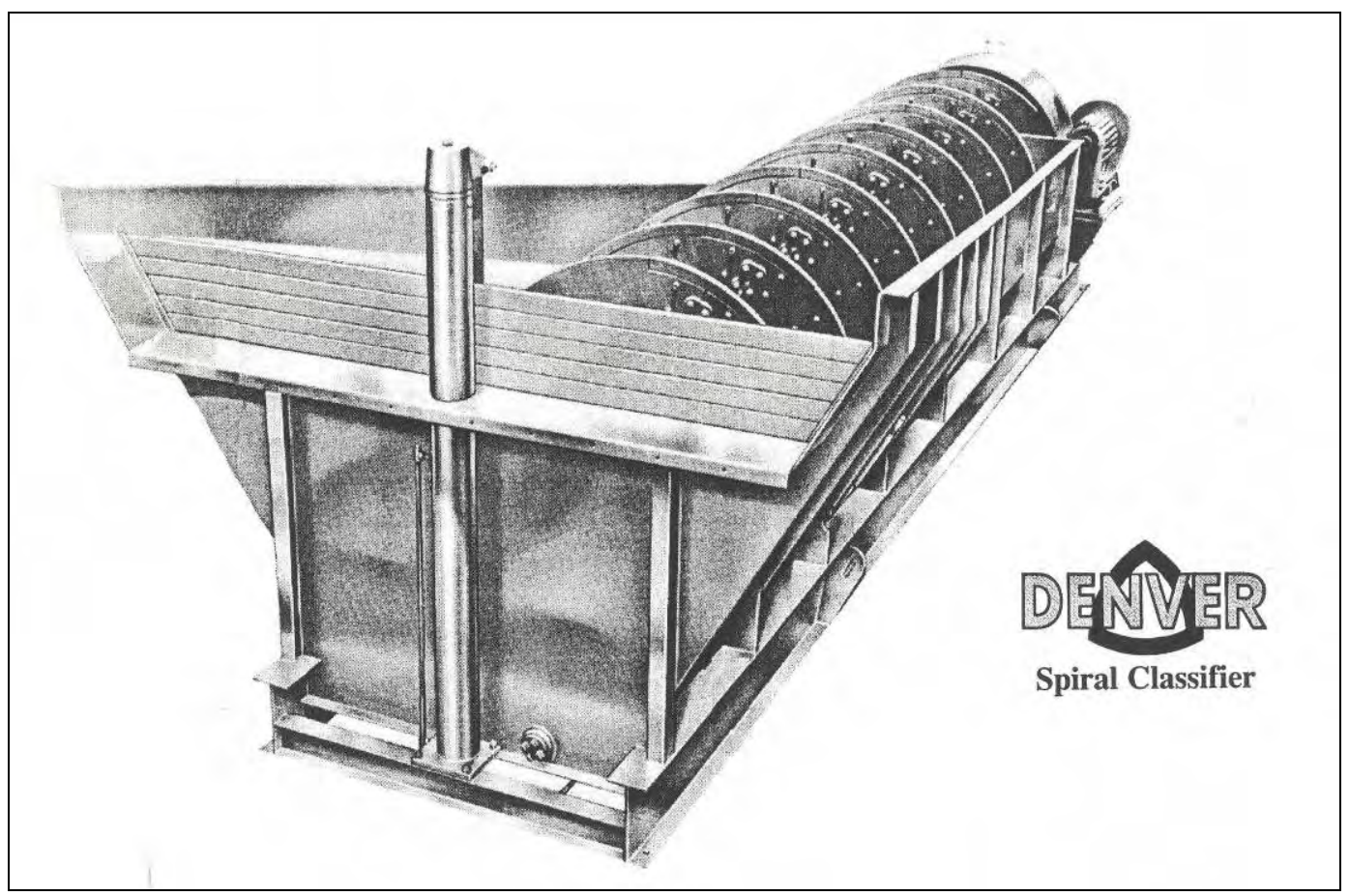

Figure 44. Spiral classifier (source: NAVFAC Southwest 1998).

Trommel screen. NAVFAC Southwest (1998) reported that the trommel screen (Figure 45) was also a technologically viable alternative for beach operations. Trommel (or revolving) screens are usually used to separate items from approximately 1 to $10 \mathrm{~cm}$ ( 0.4 to $4 \mathrm{in}$.) in diameter (Halkola et al. 2006).

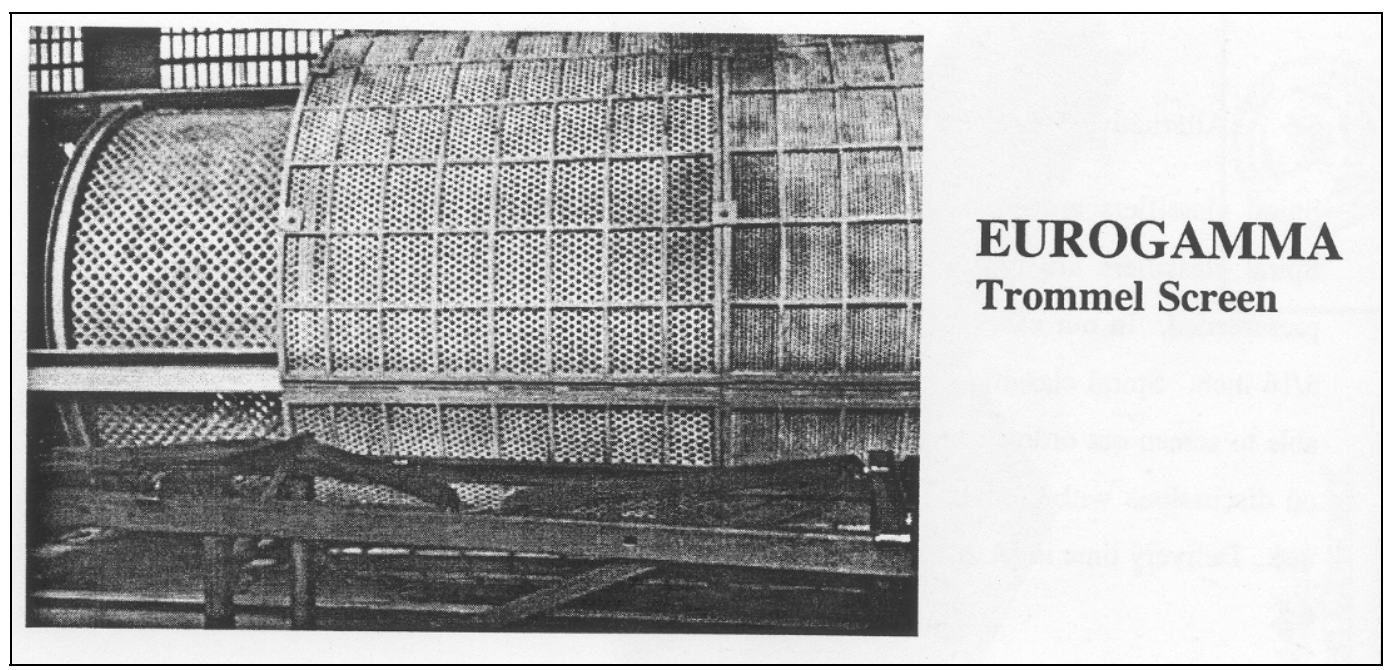

Figure 45. Trommel screen (source: NAVFAC Southwest 1998). 
Quality Assurance Report for P-326 sediment screening, San Diego, CA

As summarized by Halkola et al. 2006:

The Naval Station (NAVSTA) San Diego has had a history of mothballing inactive ships, repairing naval vessels, and providing logistical support to locally based units. Since the 1900s, ordnance-handling activities such as loading and unloading have been practiced on and near the piers. In 1999, a dredging project discovered ordnance near the piers and the effort was discontinued. As it became more evident that ordnance was being encountered in portions of San Diego Bay, two issues were considered: worker safety during dredging operations and limited disposal options for ordnance containing dredged sediments. The P-326 Report was initiated to conduct field tests using various processes and technologies regarding post-processing of sediment to separate ordnance. It assessed the potential efficacy of these technologies by computing cost, processing rates, physical properties of sediments, implementation ability, and effectiveness in finding ordnance in dredged sediments. Screening tests were conducted at the mole pier on NAVSTA San Diego property, on approximately 2 acres surrounded with a continuous berm. A single batch size of dried dredged sediment was considered to be $20 \mathrm{cu}$ yd for this project into which inert 20-mm rounds were placed. Various types of separation techniques were used to quantify the effectiveness of detection and removal. The types of techniques included visual, geophysical, and mechanical. Visual screening included inspection of the oversize materials discharged from the mechanical process. The geophysical technologies included a gradiometer and a pulse-induction metal detector. The mechanical processes included various types of rotating, vibrating, and inclined screens, specifically square mesh, harpwire, and trommel screens. The mechanical screens were variously combined with visual and geophysical screening methods. 
The final result showed that a visual inspection as a stand-alone process was the least costly, whereas the 2.54-cm (1-in.) rotating (trammel) combination (visual) process was the most costly. The visual inspection took the least time, and the rotating trommel took the longest time. The visual process only captured 10 percent of the ordnance test units (OTUs), while the trommel captured 76 percent. The 2.54-cm (1-in.) mechanical, vibrating screen yielded a 100-percent capture rate, which was the only test completed in the project that retrieved all OTUs.

\section{Cutterhead dredges}

Cutterhead hydraulic pipeline dredges (described in Chapter 2) are the most commonly used type of dredge in the United States. This chapter discusses various aspects of its operation in past MEC-contaminated projects.

A documented cutterhead dredge dramatic encounter with "ordnance" was the U.S. Navy 70-cm (27-in.) cutterhead dredge Sandpumper in Vietnam in 1969 (U.S. Department of the Army 1972). This dredge "sucked up live ordnance from the bottom of the My Tho River and sank following a detonation of the explosives. For a period of 4 months, attempts were made to raise her, but, as in the case of the Thu Bon I, a cost survey revealed that salvage and repair were not economically feasible." It is not known if the explosive item(s) encountered by the Sandpumper were MEC or intentionally placed by the enemy.

One of the earliest documented cutterhead dredge encounters (consisting of some text and pictures) in the United States is described by the following excerpt in Figure 46 taken from the Rock Island District (1939) publication The Safe Channel dated September 1939 (courtesy of the Rock Island District).

The Rock Island was a 20 in. cutterhead dredge. Figure 47 shows another picture of the "ripped open" section of discharge pipe mentioned in the excerpt, and Figure 48 shows the seam that was opened up farther down the line. The cause of the explosion was not immediately known as is evident by the question in the article ("Are mines being sowed in our 'Old Mississippi'?"). The records are not clear at this point, but it is thought 


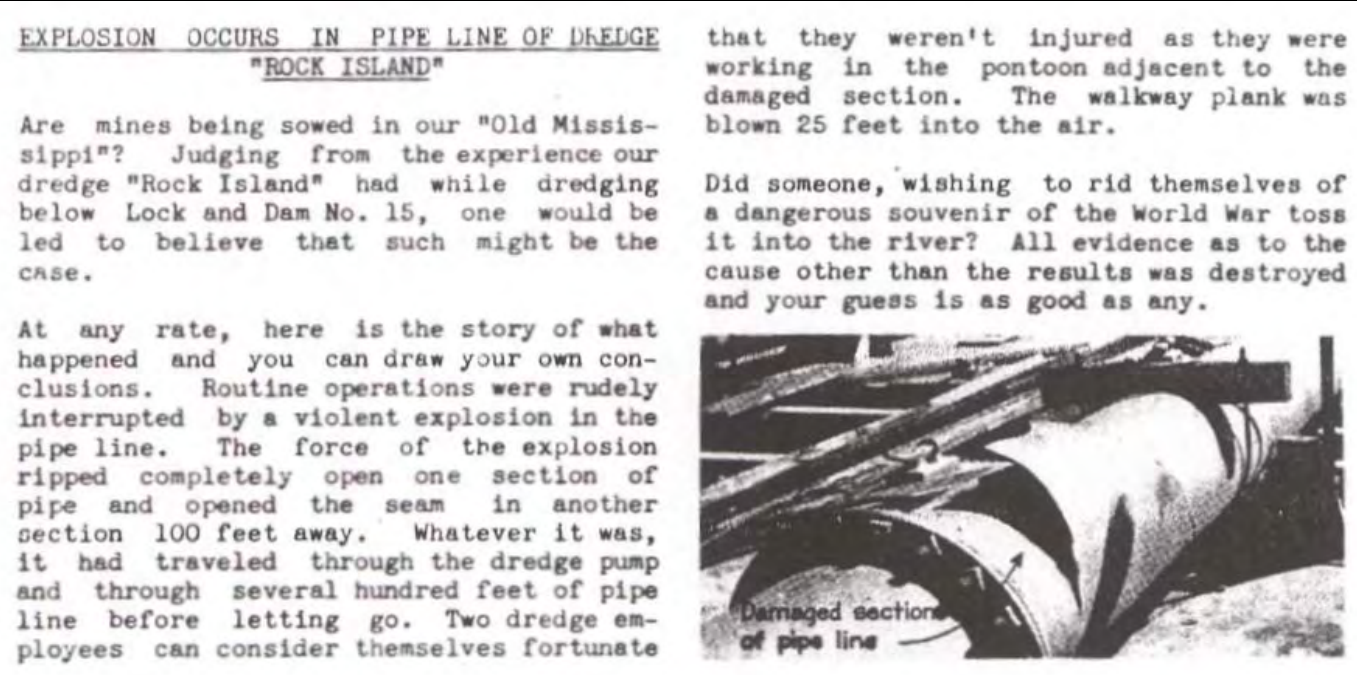

Figure 46. Hydraulic cutterhead pipeline dredge encounter with UXO excerpt from Rock Island District's publication The Safe Channel, September 1939 (courtesy of Rock Island District).

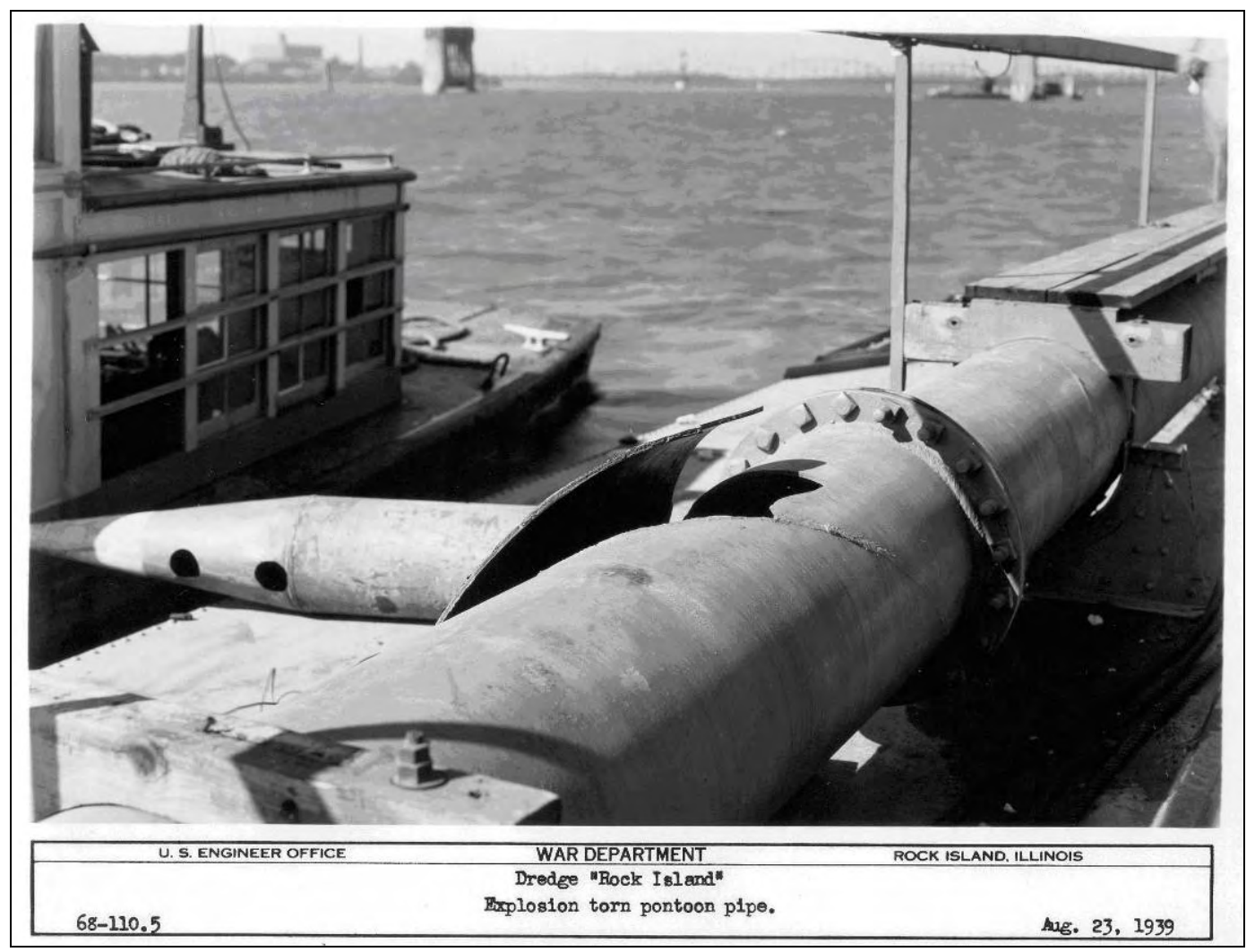

Figure 47. Explosion-torn pontoon pipe of dredge Rock Island (courtesy of Rock Island District). 


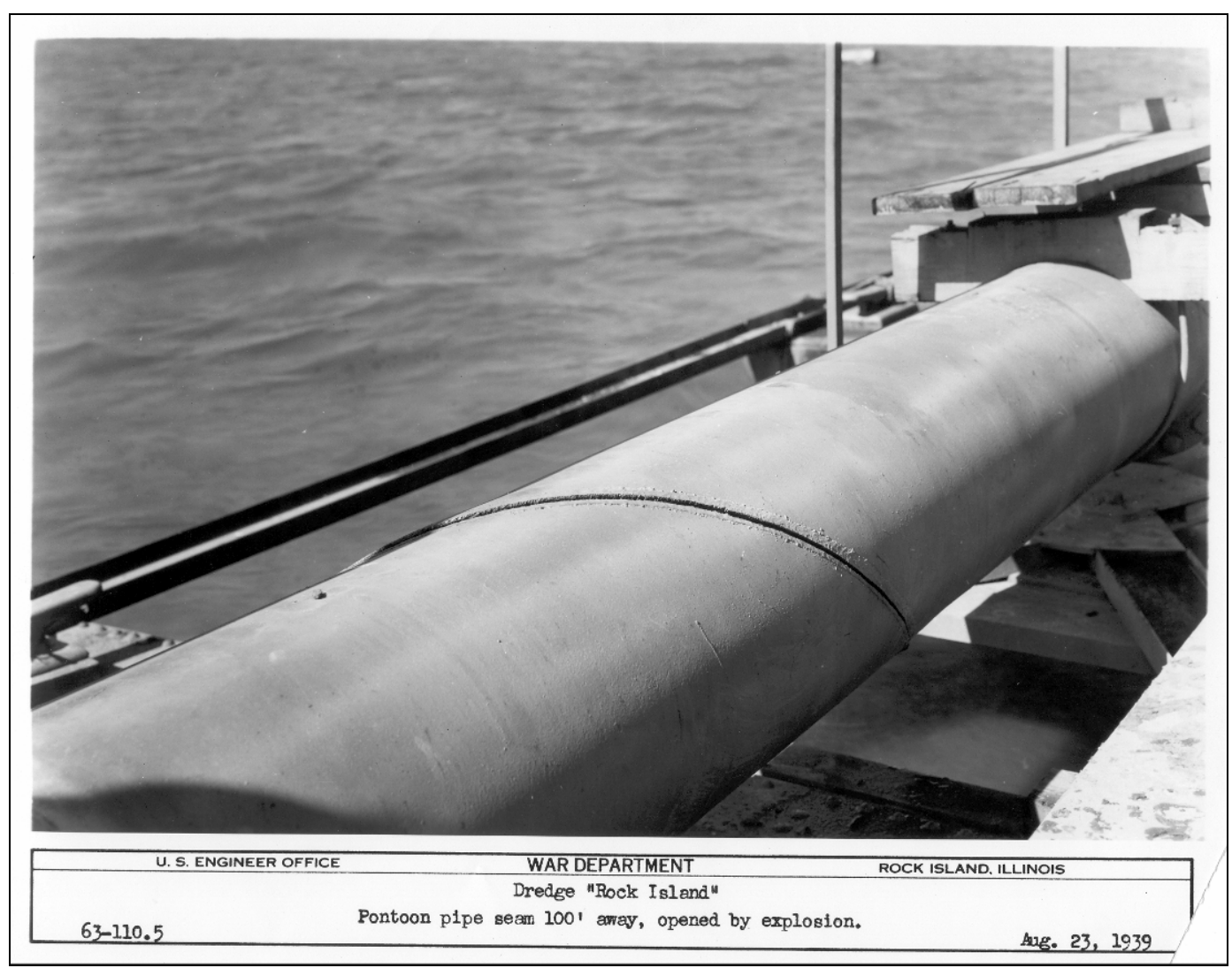

Figure 48. Pontoon pipe seam opened by explosion (courtesy of Rock Island District).

that the Rock Island continued working the project until a piece of ordnance was found at the disposal site and operations were suspended. A barge-mounted dragline was then utilized to complete the project. It is not known whether this dragline was initially onsite to assist the cutterhead in rocky areas, or if it was specifically selected for the task of dredging the area with potential MEC. The dragline side-dumped to a flattop barge, where the deposited load was visually inspected for MEC. This barge, loaded with sediment and rock, is shown in Figure 49. Using this method, the artillery shell shown in Figure 50 was recovered.

This Rock Island District dredging project will be used to examine various MEC dredging aspects in hydraulic pipeline dredges (including dustpan dredges, horizontal auger dredges, etc.) starting from the suction side of the pump (cutterhead or auger, dustpan, etc.), moving through the hydraulic circuit (suction pipeline and pump(s)) to the discharge side of the pump to include the discharge pipeline, all the way through to the discharge point in the placement area. These segments cover applicable portions of the cutterhead dredge and dredging MEC separation alternatives in the MEC/ dredging project planning flow chart (Figure 24). 


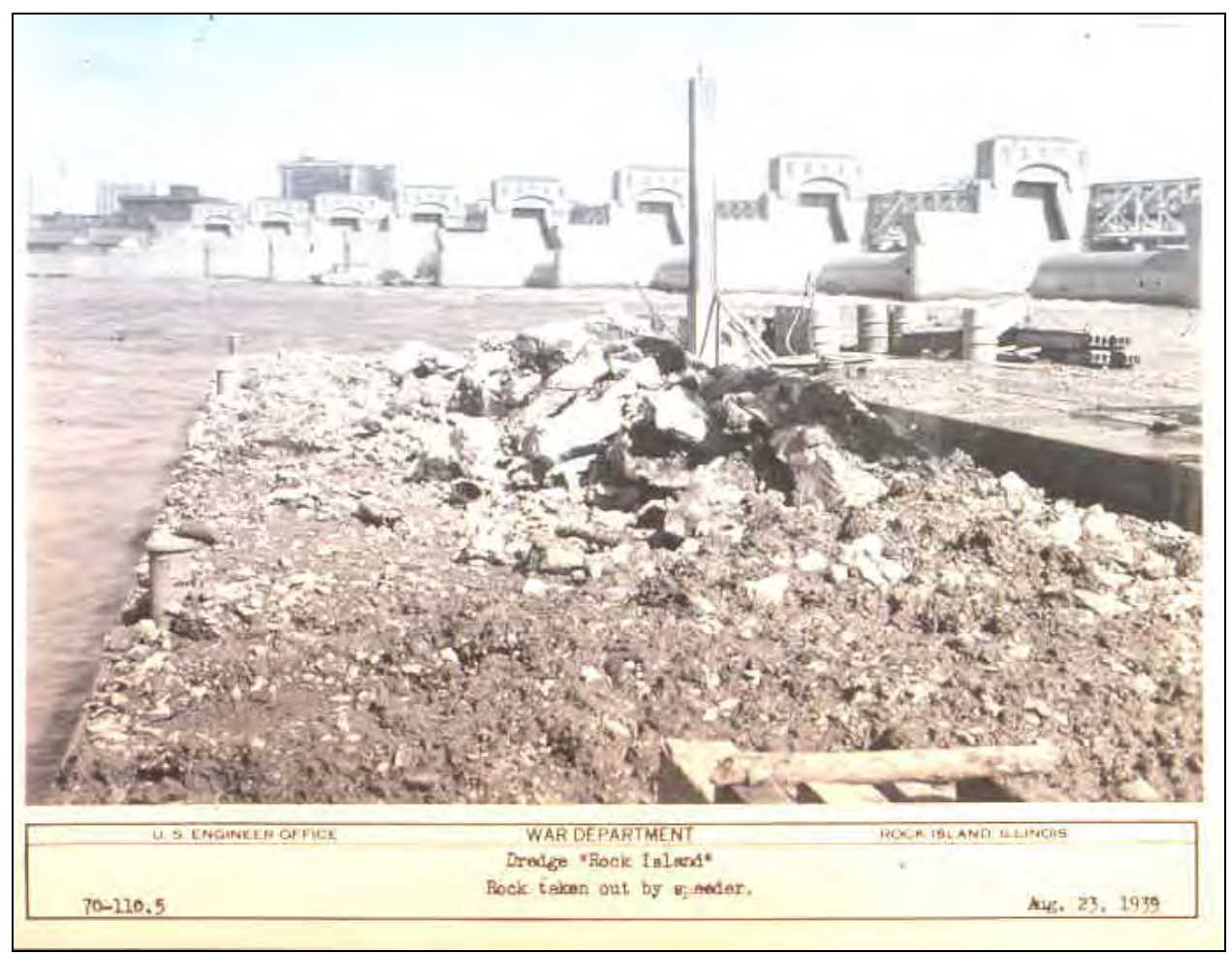

Figure 49. Sediment and rock excavated by barge-mounted dragline (courtesy of Rock Island District).

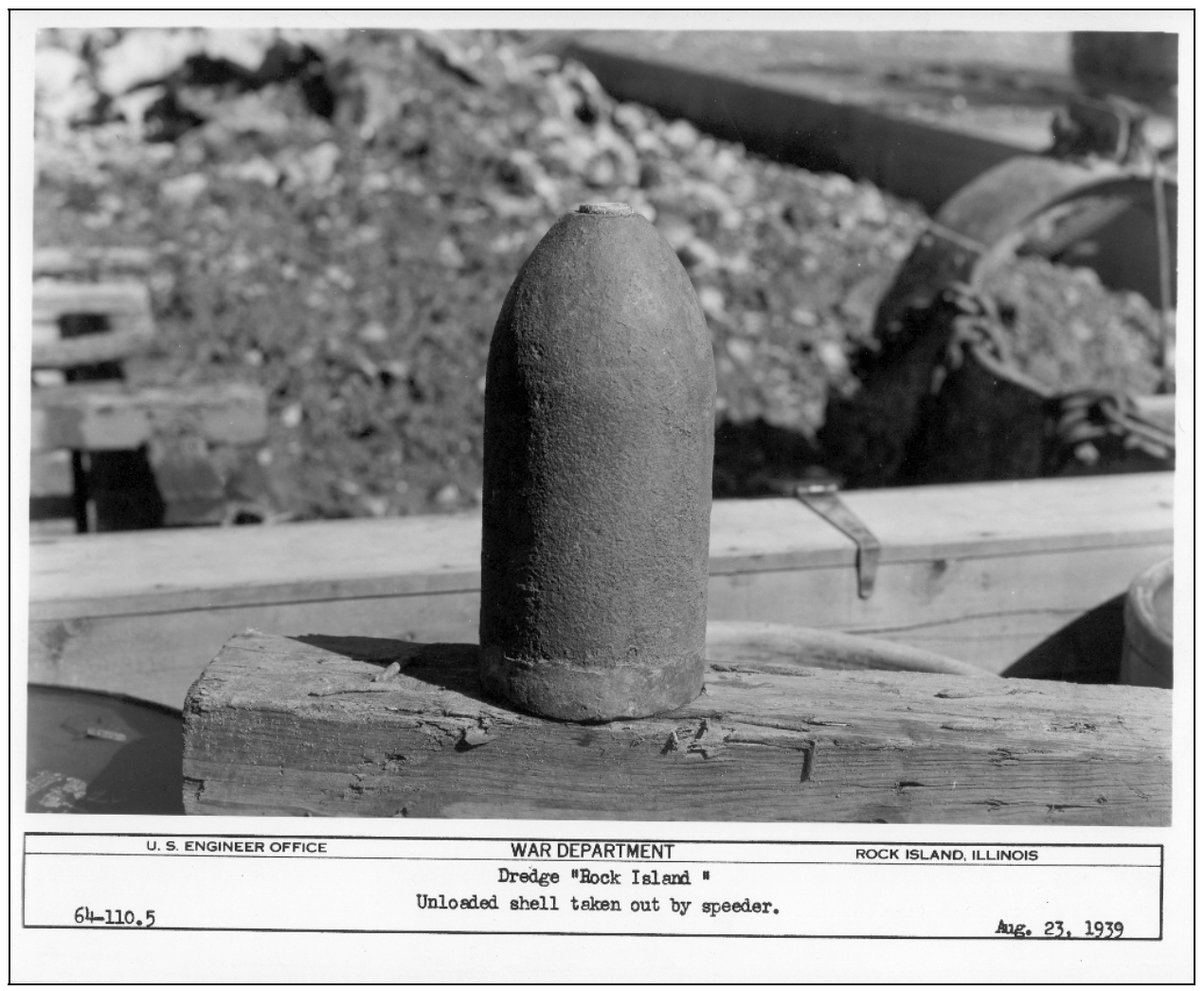

Figure 50. Artillery shell excavated by barge-mounted dragline (courtesy of Rock Island District). 


\section{Cutterhead/suction mouth/suction pipe side of pump}

The initial point of contact between a cutterhead dredge and MEC on the (water body) bottom is at the cutterhead. The MEC in the Rock Island incident was small enough to fit between the cutter blades, flowed through the suction mouth and suction pipe, between the pump vanes, "and through several hundred feet of pipeline before letting go" (much to the surprise of the two fortunate dredge employees).

As presented in Chapter 3, a risk assessment should ask the two primary questions regarding MEC hazards:

1. What points in the dredging process are most likely to cause the MEC to detonate?

2. What are the potential consequences of a detonation at each of these points?

Depending on the project's site-specific conditions (i.e., type of MEC and specific fuze, condition of MEC, relative position and impact surfaces, and forces between MEC and cutterhead, etc.), the rotating cutterhead might be considered a potential detonation point. No documentation regarding potential consequences from detonation of the underwater MEC caused from cutterhead contact was available for hydraulic pipeline dredges. Past MEC dredging projects have involved MEC contact or have considered or actually modified the cutterhead and/ or the suction pipe to exclude MEC from the hydraulic circuit.

\section{Toussaint River}

In 1991 the U.S. Army Engineer District, Buffalo (hereafter Buffalo District), initiated a Civil Works dredging operation at the mouth of the Toussaint River approximately $60 \mathrm{~km}$ (37 mi) east of Toledo, $\mathrm{OH}$. The new-works project consisted of establishing a $46 \mathrm{~m}$ ( $150 \mathrm{ft}$ ) wide federal navigation channel from the mouth of the Toussaint River out into Lake Erie, a reach of approximately $640 \mathrm{~m}$ (2,100 ft). The authorized channel depth was $1.2 \mathrm{~m}$ ( $3.8 \mathrm{ft}$ ) below low water datum. The contract involved a cutterhead dredge and was nearly complete $(38,000 \mathrm{cu}$ m out of $42,000 \mathrm{cu} \mathrm{m}$ [50,000 cu yd out of 55,000 cu yd]) when a $106 \mathrm{~mm}$ artillery projectile was found jammed in the cutterhead and the Buffalo District immediately halted dredging operations. The presence of the $106 \mathrm{~mm}$ round, which later turned out to be inert, could be explained by the fact 
that the Toussaint River is adjacent to the former Erie Army Depot, a previous DoD facility used for testing and proof firing of Army ordnance. Ordnance pattern impact areas included surfaces classified as lake, wet land, and dry land.

\section{Fort Mifflin Philadelphia Naval Yard Reserve Basin}

The U.S. Navy used to anchor a number of reserve fleet ships in the Reserve Basin at the Philadelphia Naval Yard in South Philadelphia at the confluence of the Delaware and Schuykill Rivers. Fort Mifflin, a disposal site owned and operated by the USACE directly across the Schuykill River from the basin entrance, was used by the U.S. Navy as a dredged material placement area for maintenance dredging of the basin (Ogden Beeman \& Associates, Inc. 1994). The southern portion of this basin was being dredged in 1993 by Weeks Dredging Company under contract to the U.S. Navy by a cutterhead dredge that was pumping into the Fort Mifflin disposal area via a submerged pipeline exiting the basin at the bridge and crossing the Schuykill River. On 20 March 1993, while dredging in the vicinity of $\mathrm{B}$ and $\mathrm{C}$ piers, the dredge apparently struck an underwater object which resulted in the following observations:

The hydraulic dredge crew noticed turbulence in the

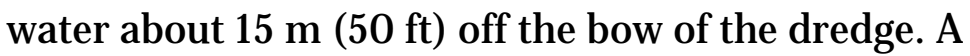
two-foot radius of fire ignited on the surface of the water and burned for approximately 1 minute. Dark colored smoke was produced from the fire. Other smaller pockets of fire ignited on the surface of the water in areas of turbulence. One of the crew members said the air had the smell of burning rubber. The entire incident lasted approximately 2 to 3 minutes. (Memorandum to File, U.S. Navy ROICC Philadelphia.)

During this same time frame, small arms ammunition and $2 \mathrm{~mm}$ and $40 \mathrm{~mm}$ projectiles were reported to have been recovered from the disposal site by people engaged in recreation at Fort Mifflin who discovered that brass was coming out the pipeline and began scavenging the fill area. This public exposure created concern for safety both relating to people scavenging in the spill area, as well as the recovery of the ammunition (Ogden Beeman \& Associates, Inc. 1994). 
Because of this event, the dredging methods were altered and a mechanical (bucket) dredge was brought to the site to place dredged material into bottom dump barges. These barges were hauled to another site for dumping and subsequent rehandling of the dredged material. A grizzly screen with approximately $15 \mathrm{~cm} \times 15 \mathrm{~cm}$ ( $6 \mathrm{in} . \times 6$ in.) apertures was placed on the barges. The dredged material removed by the mechanical dredge within $6 \mathrm{~m}$ ( $20 \mathrm{ft}$ ) of the piers was put through the grizzly. After the cutterhead dredge was switched out with the mechanical dredge, no further MEC was found and the dredging job of the south part of the basin was concluded without incident (Ogden Beeman \&Associates, Inc. 1994).

Because of this incident and the need for subsequent dredging, the Northern Division Naval Facilities Engineering Command directed Moffatt \&Nichol Engineers (who subcontracted out to Ogden Beeman \& Associates, Inc.) to "provide a specification to require the dredging equipment to be modified to allow segregation of all ordnance larger than a $20 \mathrm{~mm}$ round and prevent ordnance from exploding in the pump impellor" (U.S. Navy 1994).

Ogden Beeman \& Associates, Inc. (1994) concluded that, for excluding the small arms ammunition from exploding in the pump impellor:

There are no practical methods for preventing small arms ammunition (20 mm) from entering a dredge pump on a hydraulic dredge or being picked up by a clamshell dredge during the excavation process. There are several methods available to block larger material from entering a pipeline dredge.

A. The most common method is to weld bars or rods between the blades of a standard "basket" type cutter [Figure 51]. This method prevents material over the size of the remaining opening from entering the suction system. Because the cutter continues to rotate, some of the blocked material will drop out of the cutter and remain on the bottom of the dredged area. Commonly the bars are approximately 2 in. diameter and are spaced to leave about a 6 in. opening for the distance between the cutter blades, a distance of several feet depending on the cutter size. 


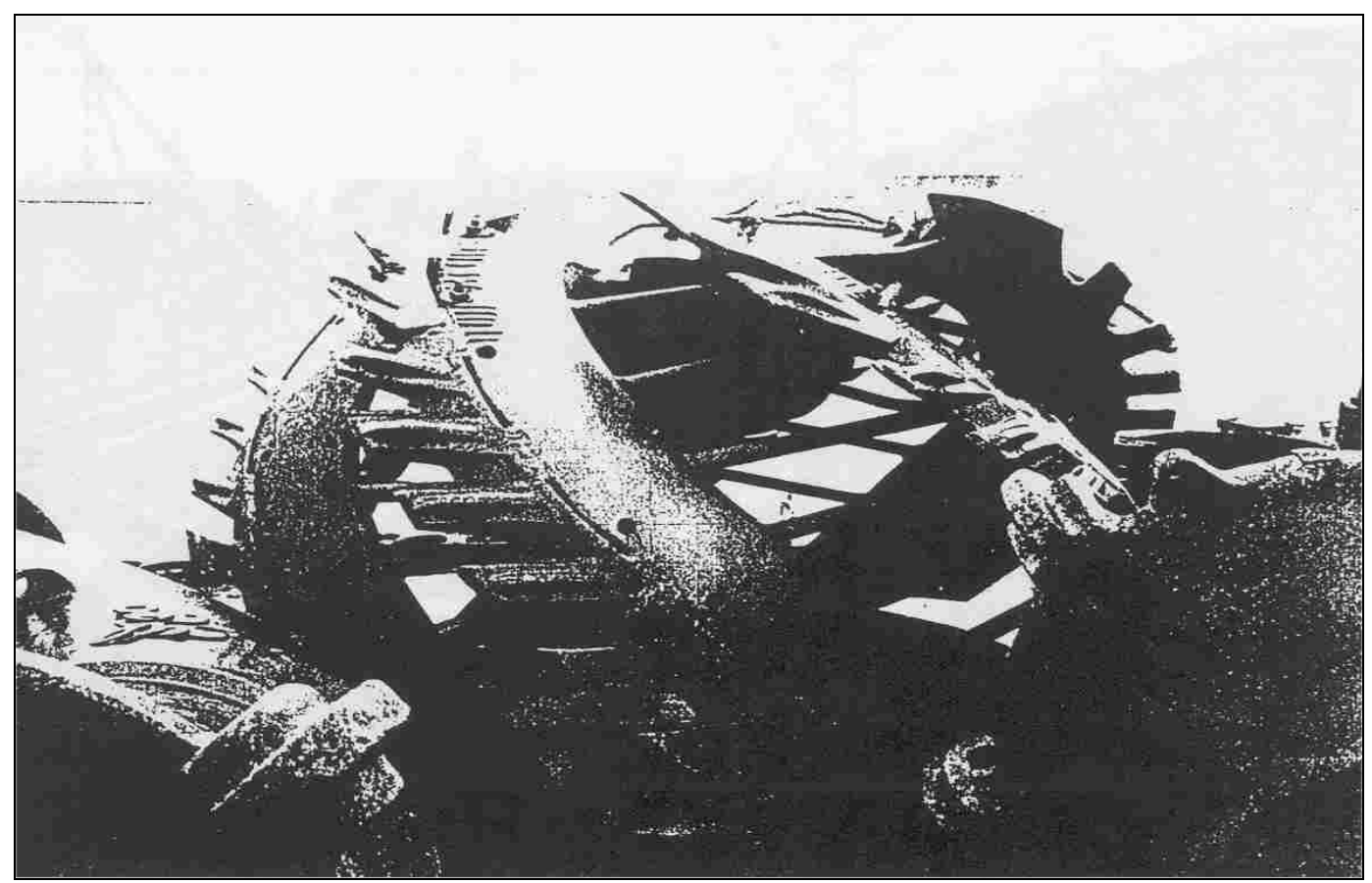

Figure 51. Basket type cutterhead with rods between blades to limit size of opening (source: Odgen Beeman and Associates, Inc. 1994).

The disadvantage to this method is that it can trap and hold material which otherwise would go through the dredge pump thus causing shutdowns and delays for cleaning the cutter.

B. Another common method is to weld a "rock ring" on the inside of the back ring of the dredge cutter. Depending on the configuration of the suction mouth opening, the rock ring will partially block the suction mouth, thus rejecting material which cannot pass between the ring and opening of the mouth. This method is used to block rocks which cannot pass through the pump. It is unlikely that it would block anything smaller than, perhaps, half the suction pipe diameter or say $15^{\prime \prime}$ for a 30 " suction mouth. Therefore, this method is not recommended for application at Philadelphia.

C. A method which the writer has seen used in a hydraulic rehandling barge in China is to have a removable insert in front of the suction side of the dredge. As designed, three or four rods can be 
inserted into the suction line to block larger materials before they reach the pipe. In the Chinese design there is a trash box below the insert into which the blocked material drops. The box is cleaned out when the suction system is shut down. The disadvantage to this system is that it can severely block the suction when there is a great deal of trash. Also, if there is a risk of detonation it would be more like[ly] to cause damage at this point than it would in the pump which is made of heavier steel. Therefore, this method is not recommended for application at Philadelphia.

The most practical and common method would be the use of welded bars or rods crossing the blades of the basket cutter. An opening of around 6" or more would not be considered unusual and probably would have a minimal effect on dredge production since a contractor might choose this method anyway to prevent larger debris from entering the pump. Under any circumstance the contractor can expect down time due to cleaning of the cutterhead and suction mouth."

Odgen Beeman and Associates, Inc. (1994) also concluded that:

Earlier experience at this site and reports from other sites do not suggest that ammunition detonates during the pumping process. However, the likelihood of small ammunition detonating in the dredge pump is beyond the expertise and experience of the writer.

\section{Sea Bright Beach Nourishment Project}

A cutterhead hydraulic pipeline dredge has also been used on the Sea Bright Beach Nourishment Project (for background information on this project see Sea Bright Beach Nourishment Project in Chapter 5).

This cutterhead dredge was the T.L. J ames, a $760 \mathrm{~mm}$ (30 in.) cutterhead of T.L. J ames and Company, Inc. (now out of business), New Orleans, LA. In a memorandum dated 6J une 1995 regarding Contract B, Reach 1 (Sea Bright to Sandy Hook), it was proposed to use this dredge with bars installed on the cutterhead in conjunction with a jetting system and 
hydraulic separator (modified rock or stone box). Round bars of $38 \mathrm{~mm}$ (1-1/2 in.) diameter were proposed to be welded between the cutterhead blades with openings of $90 \mathrm{~mm}$ (3-1/2 in.) between them (Figure 52). The jetting system was proposed to consist of a 1,000 horsepower capacity to deliver $820 \mathrm{~L} / \mathrm{sec}$ (13,000 gal/ min) with pressures up to 10 bars (150 psi).

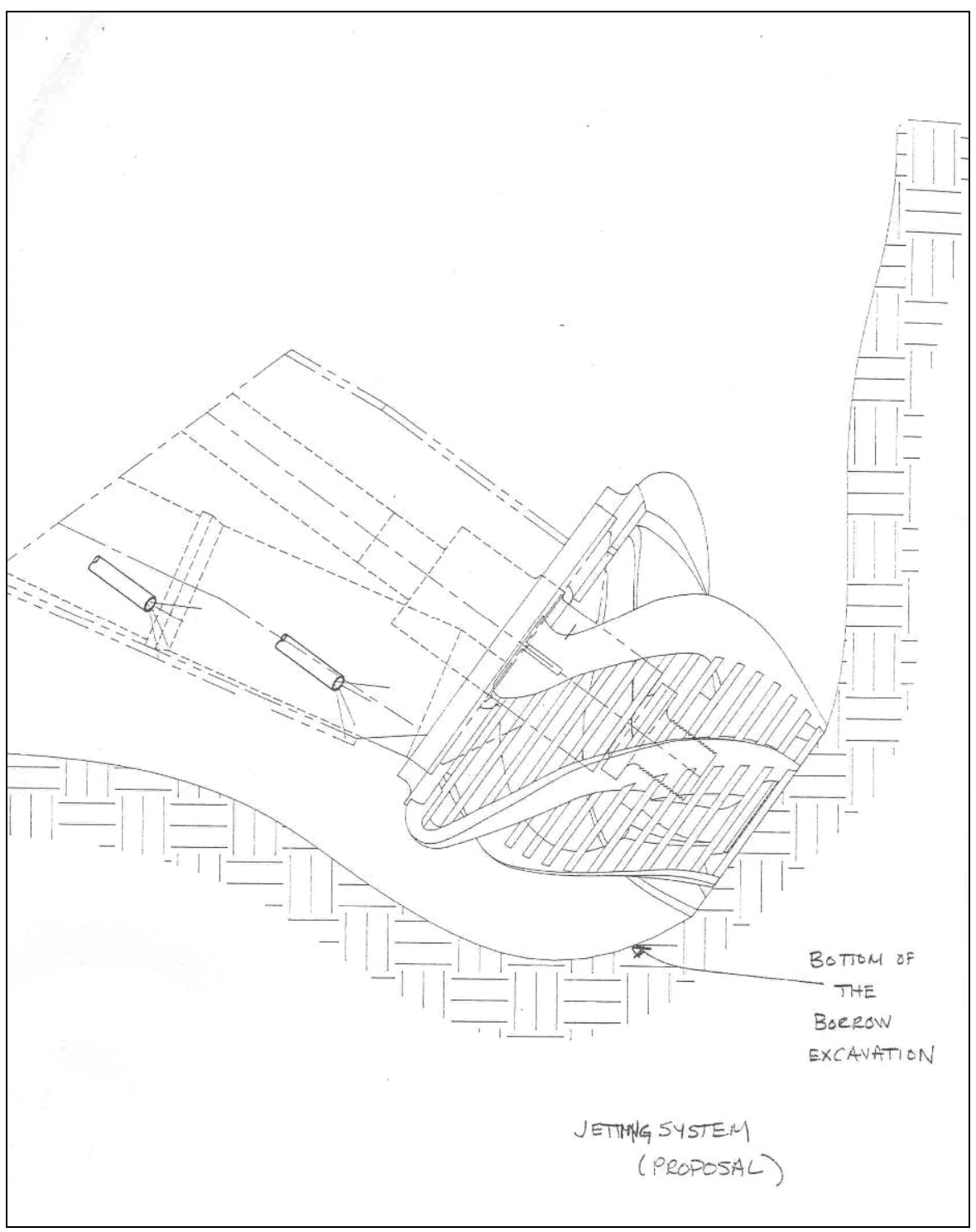

Figure 52. Proposed cutterhead/waterjet configuration (source: T.L. James and Company, Inc. 1995).

The strategy was to mine a $6 \mathrm{~m}$ (20 ft) thick face in one pass from the bottom to allow the undesirable material near the surface (MEC assumed to be near the surface) to "fall behind the excavation operations, or at best, be mixed with the good material below the surface, thereby decreasing the density or rate of occurrence" (T.L. J ames and Company, Inc. 1995). 
Material in the borrow area consisted of fine to coarse sands and gravels and test dredging in $1 \mathrm{~B}$ Borrow Area revealed rock and ordnance having diameters of $76.2 \mathrm{~mm}$ ( $3 \mathrm{in}$.) or larger. The water jets were going to be used to fluidize the sand and allow it to flow into the suction while:

...the heavier rock, rubble, and ordnance materials will settle through the slurry to locations behind and below the cutter and mouth of the suction. Since the total face will be taken as the dredge advances, the density of the ordnance will be much less per cubic yard of sand than if dredged by a draghead, which only cuts a few inches of the surface on each pass. (T.L. J ames and Company, Inc. 1995).

The hydraulic separator (modified rock or stone box) was to be installed behind the cutterhead and in front of the underwater (ladder) pump (Figure 53). The purpose of the hydraulic separator was to extract particles larger than gravel by temporarily reducing slurry velocity. This principal was, in part, based on the design of a rock box. This "box" is located on some dredges in the suction pipe near the pumps entrance for the supposed purpose of trapping large rocks and debris before it can enter the pump (Huston 1986).

The discharge opening of the hydraulic separator was to be fitted with detachable screens with $30 \mathrm{~mm}$ (1-1/4 in.) openings (Figure 54). This screen was to act as a backup device for the hydraulic separator. With less than a cubic meter storage capacity, any material accumulated in the hydraulic separator was going to be returned to the seabed by a remote flushing device (Figure 55). It was anticipated that hourly flushing would be required to prevent noticeable accumulation.

No documentation was available to evaluate how well this equipment and methodology worked on contact $1 \mathrm{~B}$, but in a personal communication with a former T.L. J ames and Company, Inc. employee, Rick Smith, recalled that the hydraulic separator would become blinded with (biological) shell hash so severely that use of the hydraulic separator was ceased almost immediately, and that screens with $38 \mathrm{~mm}$ (1-1/2 in.) apertures instead of $90 \mathrm{~mm}$ (3-1/2 in.) were mounted on the cutterhead basket to meet the New York District's contract requirements. 


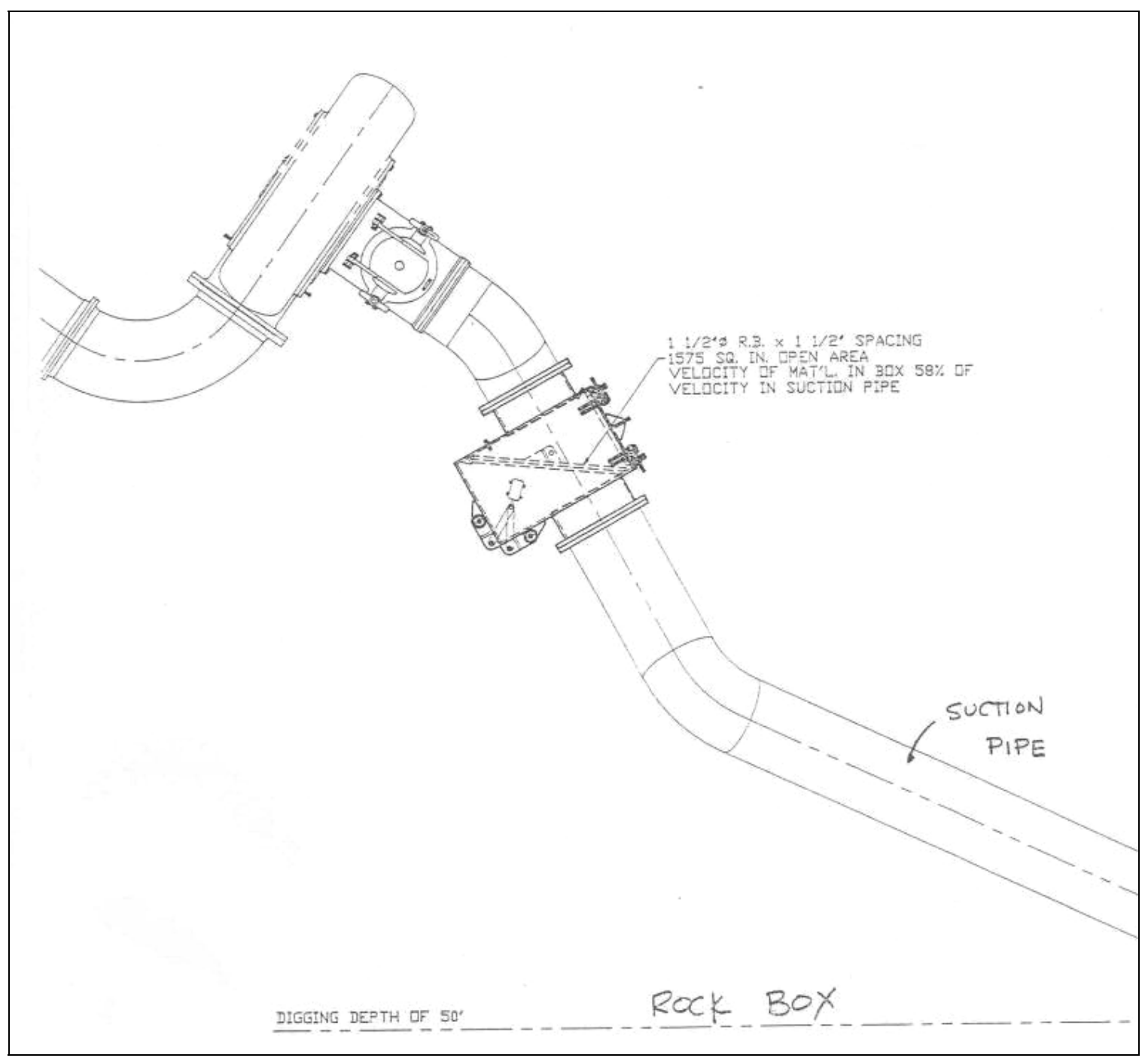

Figure 53. Proposed hydraulic separator configuration (source: T.L. James and Company, Inc. 1995). 


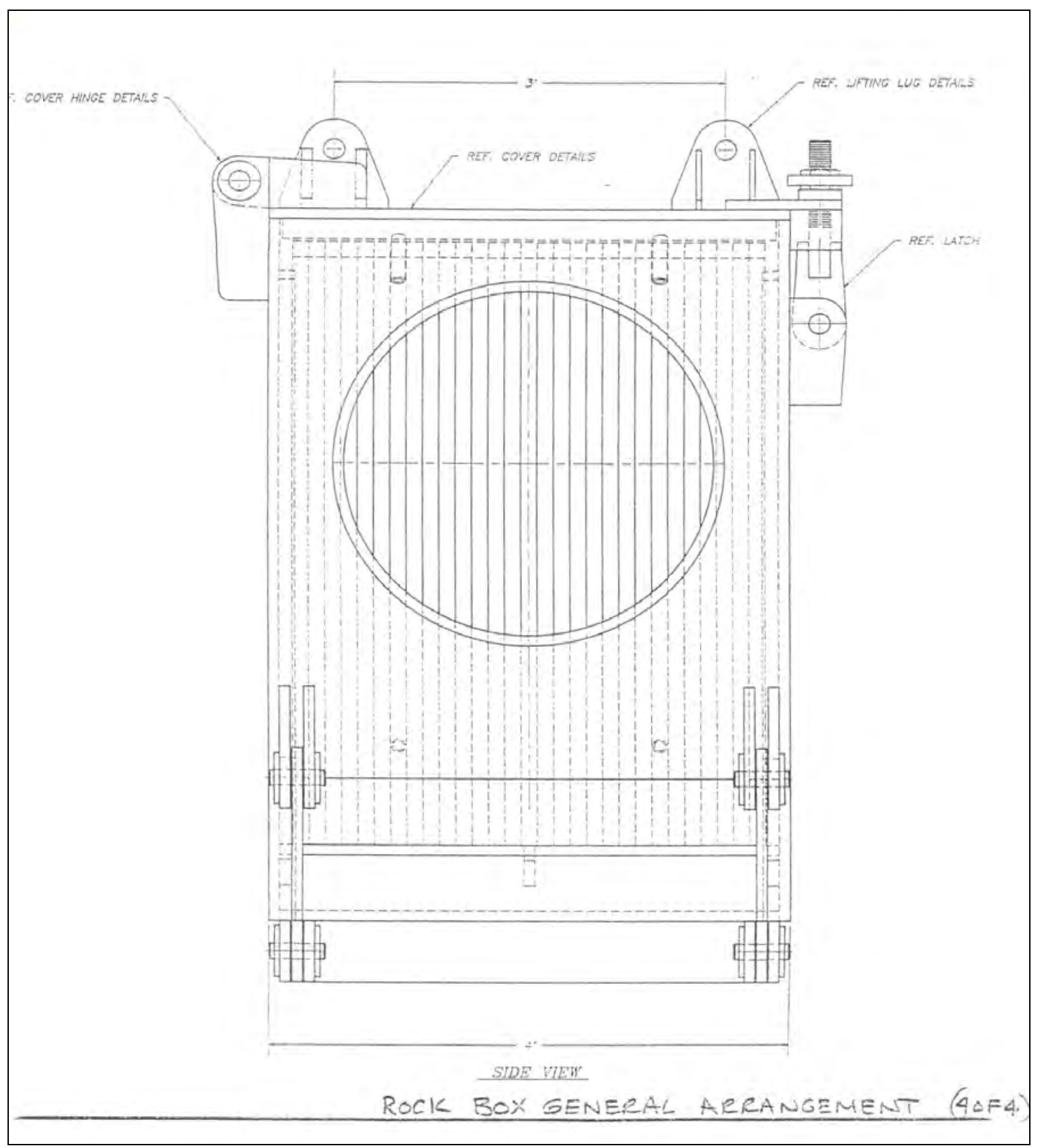

Figure 54. Proposed hydraulic separator screen (source: T.L. James and Company, Inc. 1995). 


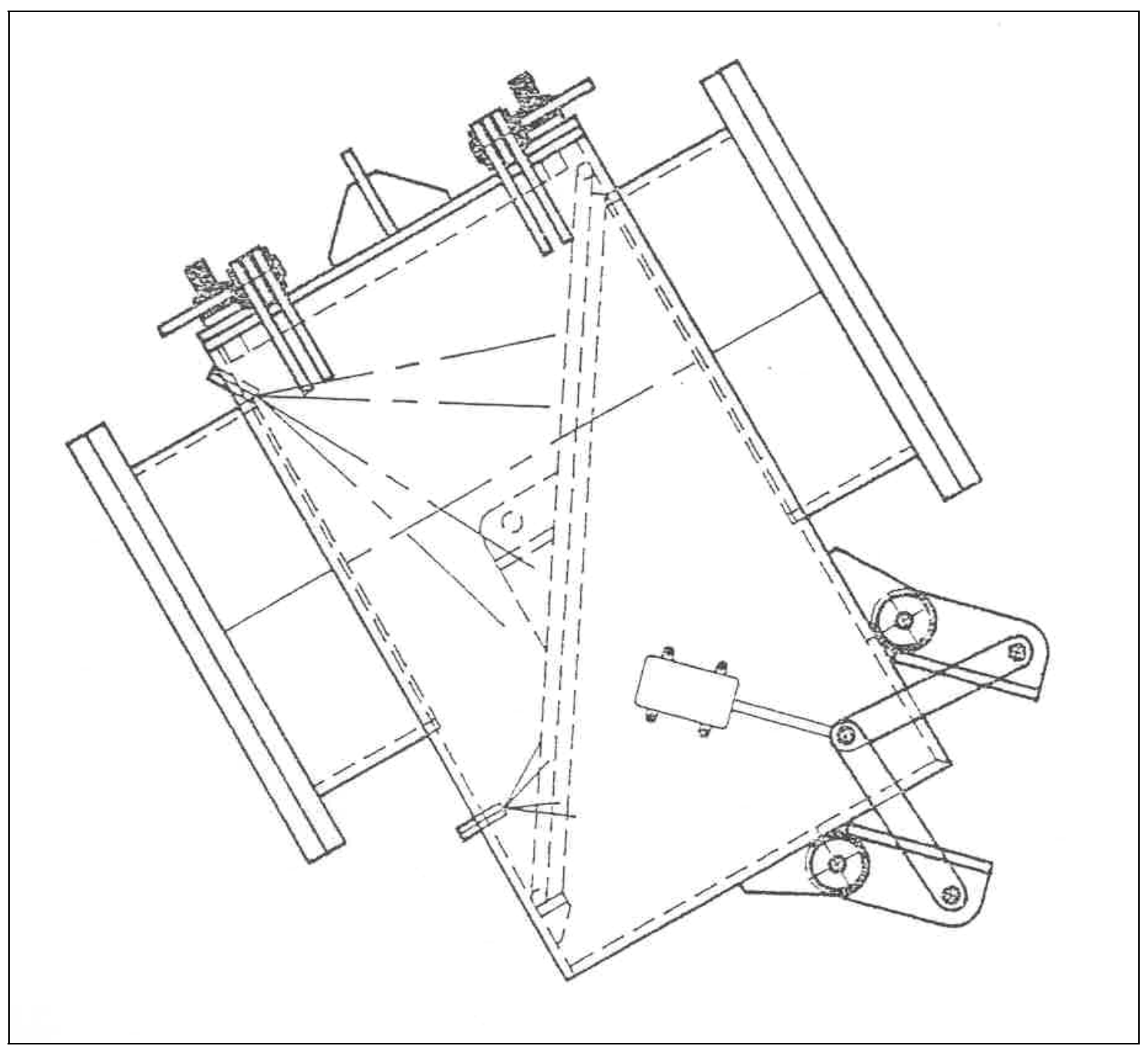

Figure 55. Proposed remote flushing device for hydraulic separator (source: T.L. James and Company, Inc. 1995).

Ordnance reconnaissance study

For background information on the ordnance reconnaissance study conducted by Parsons et al. (1999) see the "Draghead/ suction pipe/ pump" section, $\mathrm{p}$ 76. Design and screening equipment elements common between the suction side of the pump for hopper dredges and cutterhead dredges are also presented in the "Draghead/ suction pipe/ pump" section.

Parsons et al. (1999) presented the following cutterhead dredging modifications for consideration.

Screening Methods. Several methods have been considered to screen ordnance on a cutterhead dredge. 
The first method is to weld bars or rods onto the cutterhead reducing the opening to the design size required for exclusion of ordnance. (This method was used on this project.)

The second method is considered applicable to larger ordnance, for example, up to 3 or $4 \mathrm{in}$. in diam. To exclude the larger ordnance, a "rock ring" can be installed at the back ring of the cutterhead. The rock ring is a steel rod or bar of somewhat lesser diameter than the back ring of the cutterhead. The rock ring turns with the cutterhead and basically blocks the elliptical entrance to the suction line at the bottom of the cutterhead.

Although generally a single rock ring is used to block rocks of up to about one-half the diameter of the suction opening, in theory several rings of different diameters could be installed to achieve whatever maximum opening was indicated by the ordnance size. In general the rock ring concept will reject objects too large to go through the openings although, because of the suction forces, ordnance could become wedged into the opening and need cleaning and removal.

Another method is to screen the suction opening directly. Screen openings can be set to exclude the larger ordnance (as in the rock ring example) or set to exclude all ordnance. The latter approach results in greater blockage of the suction pipe with attendant loss of pumping efficiency as earlier described. Smaller objects, including debris, can collect at the screen resulting in loss of efficiency and the necessity to clean the screen. There are methods of cleaning the screen. The concept is to mount a prong or prongs on the cutterhead. On each sweep of the cutter, the prong would brush across the face of the screen dislodging debris which has accumulated and is held by the suction forces in the opening. 
The rock box concept described for the hopper dredge is equally applicable to the cutterhead dredge. The rock box could be installed on the suction side of the pump or could be installed near or off the stern of the dredge in the discharge pipeline. As in the case of the hopper dredge, the box would require special design considerations to match the hydraulics of the pipeline system with the likely velocity reductions required to drop the ordnance into the box.

In summary, five concepts are deemed worthy of further consideration. They are:

1. Screening the cutterhead to exclude ordnance.

2. Use of rock ring to exclude larger ordnance.

3. Use of screen at the suction entrance.

4. Use of a rock box to segregate ordnance before it reaches the pump.

5. Screening material in the pipeline at the beach, prior to discharge.

Blocking the entrance by means of welding bars on the cutterhead will reduce efficiency in two ways. It will constrict the suction opening and will also be subject to blockage from debris which will further restrict the suction opening. Depending on the design criteria, the blockage provided by the rock rings may not significantly reduce pumping efficiencies. If the blockage was considered significant, the likely solution is to increase the size of the suction ellipse to compensate for the loss of area. This may require a major rebuilding of the suction mouth. The hydraulic losses associated with material hitting the ring should not be significant.

Installation of a screen in the suction entrance will be a more significant problem, depending on the size of the screen openings. The suction ellipse could be increased in area to offset this loss. For cutterhead dredges not equipped with ladder pumps, installation 
of a ladder pump will provide additional suction and should more than offset the screening losses.

The ordnance reconnaissance study produced preliminary cost estimates for these different MEC "capture" methods relative to the Sea Bright projects. Table 3 lists these costs in terms of estimated capital cost, operation and management and other costs, and a total cost in dollars per cubic yard assuming 35 million cu $\mathrm{m}$ ( 45 million cu yd) dredged over the life of the project. Table 3 was intended to provide comparative cost figures and no allowance was made for profit or contingencies. From the comparisons of additional costs for cutterhead dredge modifications, the lowest cost option was a rock box on the beach, but this option entails the most risk because it allows MEC into the dredges hydraulic system and the beach (Parsons et al. 1999).

In discussion of the safety of dredge and crew, the study concluded that:

For the cutterhead dredge, the apparent best solution is to place screens on the suction entrance. The opening size should exclude ordnance of the size deemed to be dangerous to the dredge or crew if allowed into the pumping system. In practice, use of several rock rings should be possible assuming that the minimum size of ordnance to be screened was in the range of 3-4 in. diameter. Use of the rock rings should have a negligible effect on pumping efficiency. An alternative is the use of a screen directly covering the suction ellipse. It is probable that increasing the size of the ellipse, so the overall suction entrance area was not reduced, would offset the potential loss of production.

The New York District Sea Bright nourishment contract specifications requiring screening in the suction side of the pump (New York District 2001) include the same requirements as in the hopper dredge draghead specifications.

\section{Buckroe Beach, Hampton, VA}

The City of Hampton, VA, and the Norfolk District were conducting a beach nourishment project with a cutterhead dredge at Buckroe Beach in 1990 when the operation was shut down shortly after it started because of 
the presence of MEC in the transported sand (Francese et al. 1997). The sand was being pumped to the beach from Horseshoe Shoals, an offshore borrow area approximately $3.22 \mathrm{~km}$ ( $2 \mathrm{mi}$ ) from shore, when MEC consisting primarily of WWI and WWII $70 \mathrm{~mm}$ artillery shells (12 in. long $\times 3$ in. wide) were discovered on the beach. Personnel from the local military bases and CEHNC were brought onsite to dispose of these MEC, and CEHNC conducted magnetometer surveys to locate the MEC that had been covered by sand (Francese et al. 1997). Subsequent magnetic surveys were required periodically on previously placed beach material as MEC became exposed to the surface after storms.

The following description of the 1996 beach nourishment project conducted at Buckroe Beach is summarized from Francese et al. (1997). A primary goal of the 1996 project was to safely replenish the beach with high quality beach sand located in Horseshoe Shoals. The MEC issue was "critically evaluated throughout each stage of the planning, design, and regulatory processes" (Francese et al. 1997). The authors describe how three basic lines of defense were developed as a best approach to protect the dredging contractors, safety officials, and general public from MEC exposure risk.

The first line of defense was to minimize MEC contact by surveying the borrow area to locate smaller ferromagnetic items and then redesigning the borrow area boundaries to avoid the locations where anomalies were identified. For the magnetic survey, tests were conducted to identify optimum operating conditions and the specific magnetic signature for the 76- $\mathrm{mm}$ projectiles. Targets identified during the survey allowed the borrow area to be redesigned to completely avoid the more heavily populated (grouped) locations, and minimize contact with individual targets.

Another line of defense was a public safety outreach program and a detailed safety plan to address any MEC that made its way to the beach. The last line of defense was to exclude MEC from the suction mouth by screening it out (the suction mouth is the opening into the suction line within the cutterhead basket). These specifications were based on screening contract specifications provided by the New York District from the previous Sea Bright project.

The predominant MEC recovered in the 1990 project were $76 \mathrm{~mm}$ (3 in.) projectiles. In order to prevent these items from entering the pump, a 
screen with $50 \mathrm{~mm}$ (2 in.) wide apertures was initially specified. During final contract negotiations with Cottrell Contracting Corporation, this screen opening size was increased to $7 \mathrm{~cm}$ ( $2.75 \mathrm{in}$.) wide apertures to reduce the cost of dredging. "The reasoning was that this design would satisfy the intent by stopping the 76- $\mathrm{mm}$ projectiles from entering the pump, however, there was the possibility that smaller types of ordnance could pass through the bars" (Francese et al. 1997).

Initially, this screen reduced dredging production by nearly 50 percent as oyster shells, ballast stones, and an occasional MEC item blinded it after 20 to $30 \mathrm{~min}$ of dredging, then another $30 \mathrm{~min}$ or so was required to clear the screen. The screen was subsequently removed and bars were welded on the cutterhead basket (between the blades) to construct a screen with $70 \mathrm{~mm}$ ( $2.75 \mathrm{in}$.) wide apertures. "This design would supposedly scatter the debris (including ordnance) away from the cutterhead and allow only small objects to pass through the cutterhead to the intake," (Francese et al. 1997).

This redesigned screen was successful in that it reduced production by only 10 percent. Throughout the entire project, only one $76 \mathrm{~mm}$ projectile came through when one of the screen bars on the cutterhead broke off, and this item was handled by applying the beach response plan.

Francese et al. (1997) noted that a smaller dredge with lower pumping rates was used during the 1996 renourishment effort compared to other dredges that have worked in that area. The dredge Richmond was a $30.5 \mathrm{~cm}$ (12 in.), 2,000 hp hydraulic cutterhead accompanied by the dredge, Shenandoah, as a booster pump. At a slow pumping rate in 1996, it was possible to track the larger items at the discharge. The slurry only

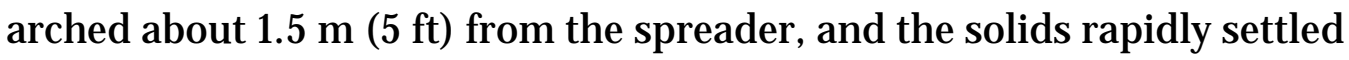
from the fluid. When the original project was executed in 1990 with the use of a larger dredge, the pumping rate exceeded $385 \mathrm{cu} \mathrm{m} / \mathrm{hr}$ ( $500 \mathrm{cu} \mathrm{yd} / \mathrm{hr}$ ) and the slurry arched more than $9 \mathrm{~m}$ (30 ft) from the outfall pipe. As a result, it was difficult to distinguish MEC from large debris from the sand slurry.

In 1990 the dredging and project construction costs were estimated to be between $\$ 3.00$ and $\$ 4.00 / \mathrm{cu}$ yd to pump 224,000 cu yd of sand to the beach. The 1996 project pay volume was 52,000 cu yd at a cost (including 
mob, demob, and pumping unit costs) of $\$ 6.15 / \mathrm{cu}$ yd. Francese et al. (1997) state that:

Although a direct unit cost comparison is not necessarily applicable between the 1990 and 1996 project as a result of the reduced volume and the regulatory and safety constraints associated with the most recent project; it is important to note that the unit cost per yard (including only mob/ demob, and pumping rate) increased 60 percent of that of the previous project. This higher cost more than likely represents a trend for increased costs from borrowing from Horseshoe Shoals.

The most recent dredging project at Buckroe Beach was conducted in 2005 by the Norfolk District. A public Buckroe Beach "Fact Sheet" was distributed by the Norfolk District. Similar to the previous project, safety for the dredging contractors, safety officials, and general public was a primary goal. In the contract specifications (Norfolk District 2004), contractor management requirements included:

The Contractor shall take a pro-active, responsible role in the management of dredging and dredged material placement operations to prevent UXO from being dredged and placed on the beach. The Contractor shall be responsible for implementation of any special programs or work methods to protect the public, workers, and the environment from encounters with UXO to the extent required by federal, state, and local regulations."

Screening to exclude MEC was required as follows (Norfolk District 2004):

Special UXO Screening Requirements.

The Contractor shall utilize screening devices placed on the dredge cutterhead, in pipeline sections prior to reaching the dredge pump, at the discharge end of the pipeline, or by other approved procedures that effectively prevents UXO 2 in. and greater in any 
dimension from entering the dredged material to be placed on the beach. This screening must be of rugged steel or composite material, one-piece or welded members, and constructed to cover the entire area where installed. Dredge cutterhead screening shall be a device similar to that as provided by Dredging Supply Company, contact information and example is shown at the end of this SECTION, or may be of the Contractor's own configuration.

Screening devices in pipeline sections and at the dredge discharge pipeline shall be of the Contractor's own configuration. The screening devices utilized must be demonstrated on site by the Contractor to meet all requirements as specified and are subject to approval of the Contracting Officer. The devices utilized shall allow a production rate that meets or exceeds the contract construction time in relation to the cubic yardage required to be dredged on an average daily basis, and shall be removable for easy replacement if damaged. The Contractor shall be required to maintain adequate replacement parts or additional devices on site to insure production for the work does not stop.

The information concerning MEC exclusion was required as a preconstruction submittal (Norfolk District 2004):

Prior to commencement of dredging, submit a plan for sequence of dredging, dredging methods and plant utilized, pipeline location and material placement requirements, protection of structures, equipment, and land features. The Plan in particular shall include the equipment and methods to be employed by the Contractor for cutterhead suction screening to prevent UXO from being deposited in the beach placement area. 
The borrow material to be dredged was described as:

Predominantly sand; however, the Contractor may encounter unsatisfactory clay materials and unexploded ordnance and exploded ordnance, inert ordnance, and ordnance fragments and similar debris material within the dredging prism of the Designated Dredged Material Borrow Site" (Norfolk District 2004).

The contractor, GLDD, was awarded the contract that used a $760 \mathrm{~mm}$ (30 in.) cutterhead dredge, the Illinois (total installed power of 11,300 hp). The contractor initially installed bars between the cutterhead blades to also produce a screening aperture size of $50 \mathrm{~mm}$ ( $2 \mathrm{in}$.), but production was severely impacted by rapid blinding by debris after a couple of swings. Next, GLDD removed the cutterhead basket bars and installed bars on the suction mouth screen to produce a screening aperture size of $50 \mathrm{~mm}$ ( 2 in.), but this configuration also resulted in reduced production rates similar to that of the cutterhead basket screening configuration. GLDD next fabricated a "rock ring" on the inside of the back ring of the dredge cutter (previously described in the Fort Mifflin Philadelphia Naval Yard Reserve Basin) with a screening aperture size of $50 \mathrm{~mm}$ (2 in.). Actual photographs of this screen are not presented as GLDD deemed this equipment proprietary in nature, but to give the reader an approximate idea of what a rock ring looks like and how it works, the following figures of the Dredging Supply Company, Inc. (DSC) suction screen, known as the Gatling Gun, are presented as examples (Figures 56- 59).

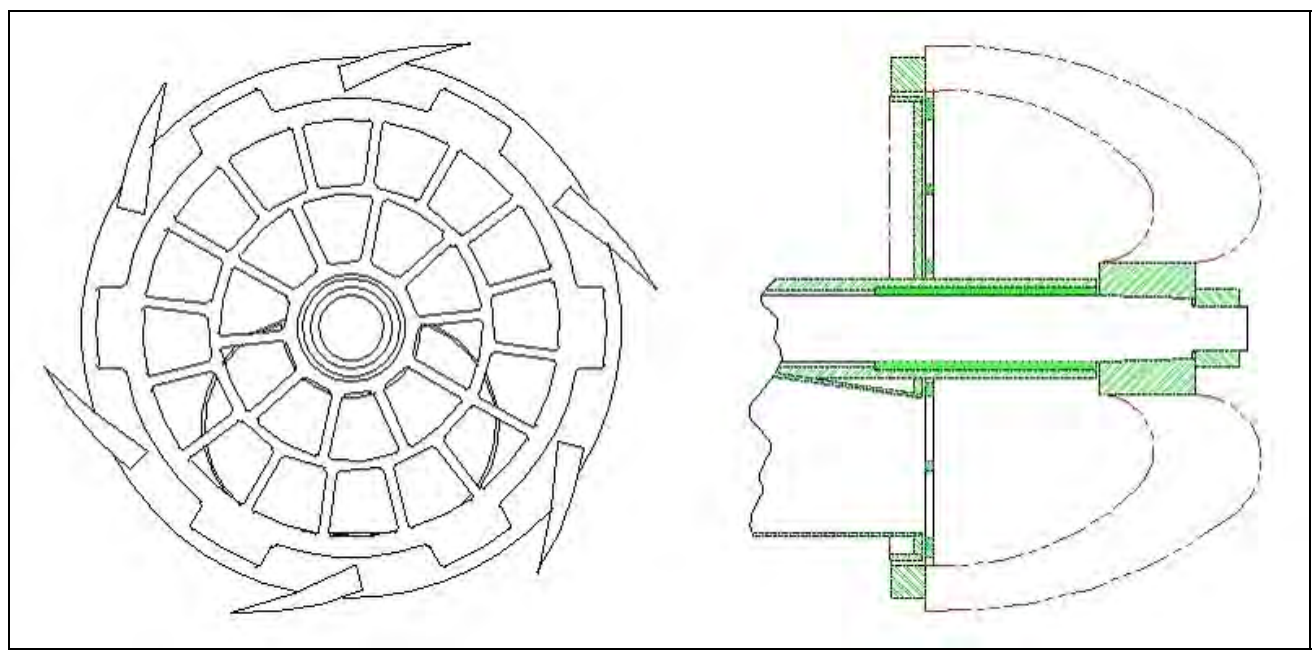

Figure 56. Schematic of Gatling Gun (source: DSC). 


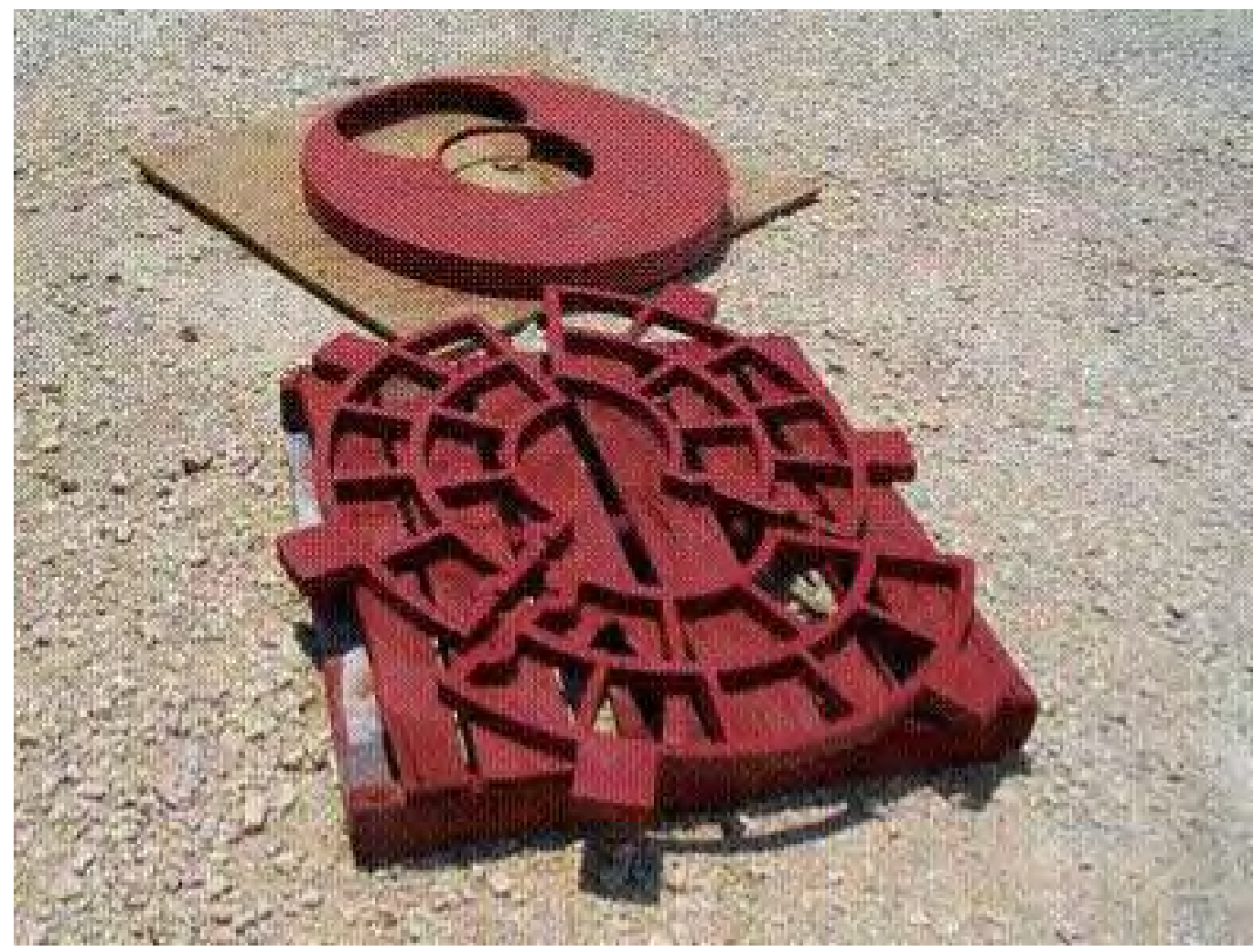

Figure 57. Gatling Gun suction screen (source: DSC).

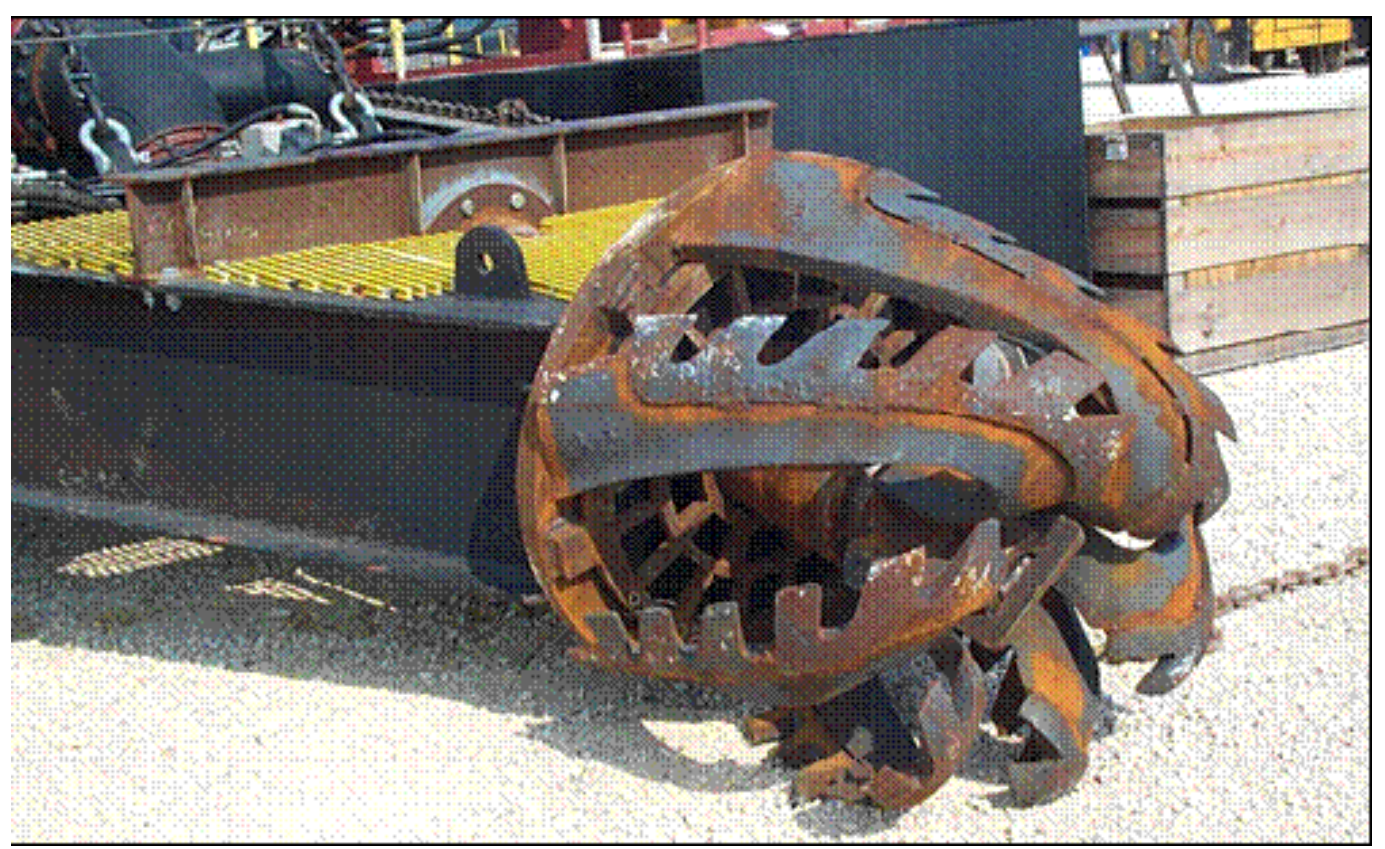

Figure 58. Gatling Gun suction screen installed on cutterhead (source: DSC). 


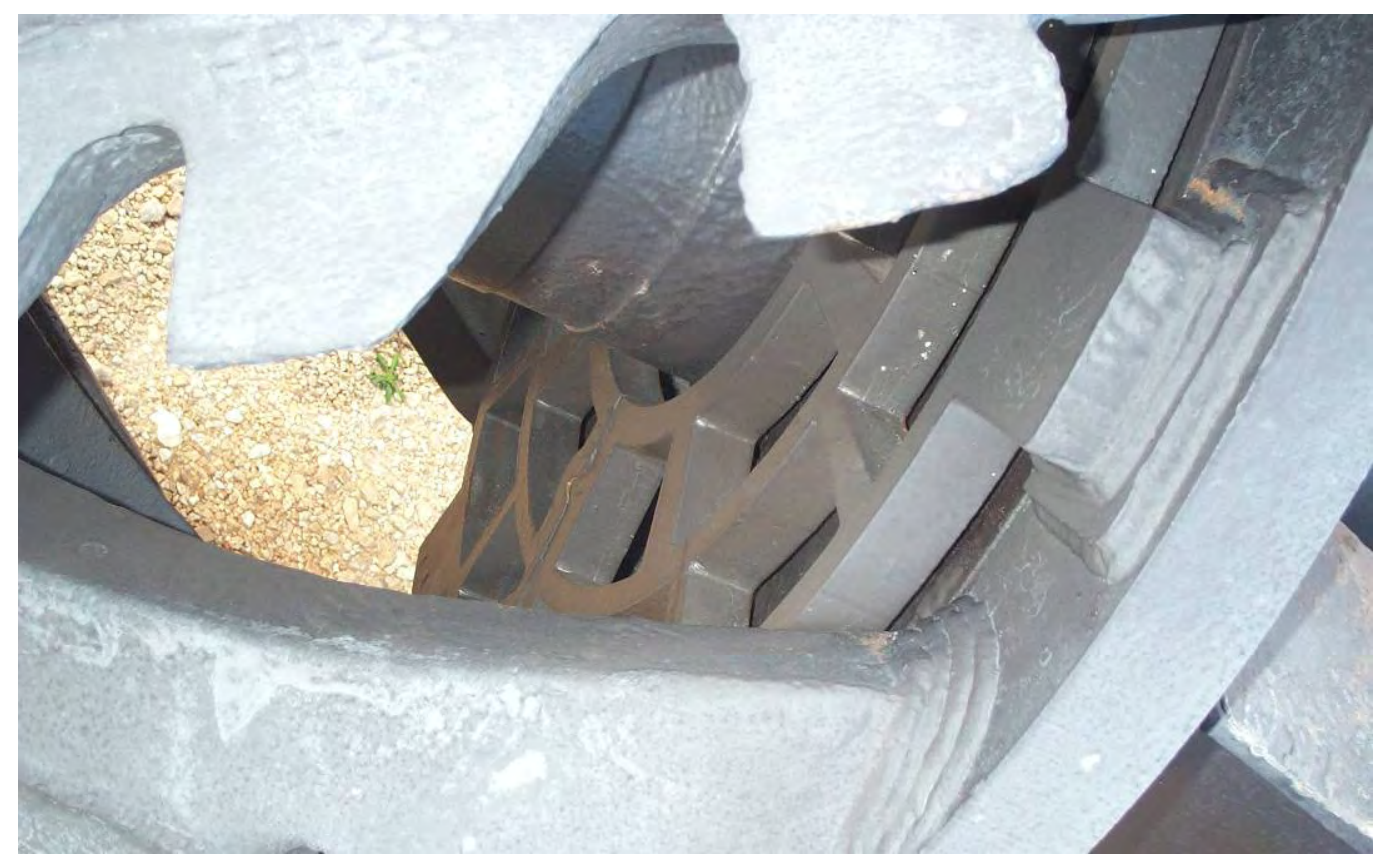

Figure 59. Closeup view of Gatling Gun suction screen (source: DSC).

DSC describes the Gatling Gun as:

A sizing screen that attaches inside the cutter basket near the suction mouth. Until recently, only barring the cutter basket could keep oversized material from being sucked into the suction mouth. Barring the cutterhead greatly reduces the excavating and feeding efficiency; additionally, material that gets through the bars and trapped inside the basket rapidly wears the cutter drive tube. This device (the Gatling Gun) effectively screens out the oversized material while greatly reducing the wear caused. As the suction screen passes by the suction mouth, oversized material is held against the screen by vacuum created by the dredge pump. As the rotation of the suction screen moves the oversized particle away and to the side off the suction mouth, the loss of vacuum allows the particle to fall away and subsequently behind the cutterhead. The screen can be custom tailored to any dredge pump or plant requirement. ${ }^{1}$

1 Personal communication, Charles Johnson, Dredging Supply Company, Inc., 2005. 
The GLDD fabricated rock ring improved production to an acceptable level. Inspections of the cutterhead were required every $8 \mathrm{hr}$ or when debris larger than 2 in. appeared on the beach.

Port of Umm Qasr, Iraq

GLDD also dredged in MEC-contaminated sediment in the Port of Umm Qasr, Iraq. Similar suction mouth and cutterhead basket screen configurations were evaluated. The final replacement-screening method consisting of welding bars on the cutterhead itself to construct a screen with 7.5-cm $\times 7.5$ - $\mathrm{cm}$ (3-in. $\times 3$-in.) apertures that allowed the dredge to operate several hours before cleaning was required (Halkola et al 2006).

Eagle River Flats (ERF), AK, dredging demonstration

Investigations have proven that annual waterfowl dieoff at ERF is due to ingestion of white phosphorous (WP) particles introduced into shallow pond sediments by WP munitions training (Racine et al. 1992, 1993). The U.S. Army Cold Regions Research and Engineering Laboratory (CRREL) was actively involved in these investigations and later conducted a demonstration to investigate the feasibility of remediating WP-contaminated sediment. The demonstration involved using a horizontal auger hydraulic pipeline dredge to excavate the sediment and transport it to a CDF. The treatment process at the $\mathrm{CDF}$ consisted of atmospheric drying and natural attenuation.

The ERF impact area at Fort Richardson, AK, is north of Anchorage where the mouth of the Eagle River flows into the Knik Arm of the Upper Cook Inlet. ERF is an estuarine salt marsh covering 1,000 ha with vegetated and unvegetated mud flats laced with permanent and semi-permanent ponds that are waterfowl feeding areas. The predominant vegetation in the general vicinity where the dredging was conducted is tall coarse sedge and bulrush. The sediment consists of silts and clays with high organic content (Racine et al. 1993). Figure 60 is a photograph of a portion of the ERF general dredging area. Distribution of WP in the wetland sediment was determined by a survey based on hand sampling and sediment core techniques. The maximum depth at which WP was found in a sediment core was $20 \mathrm{~cm}$ (8 in.) (Racine et al. 1993). 


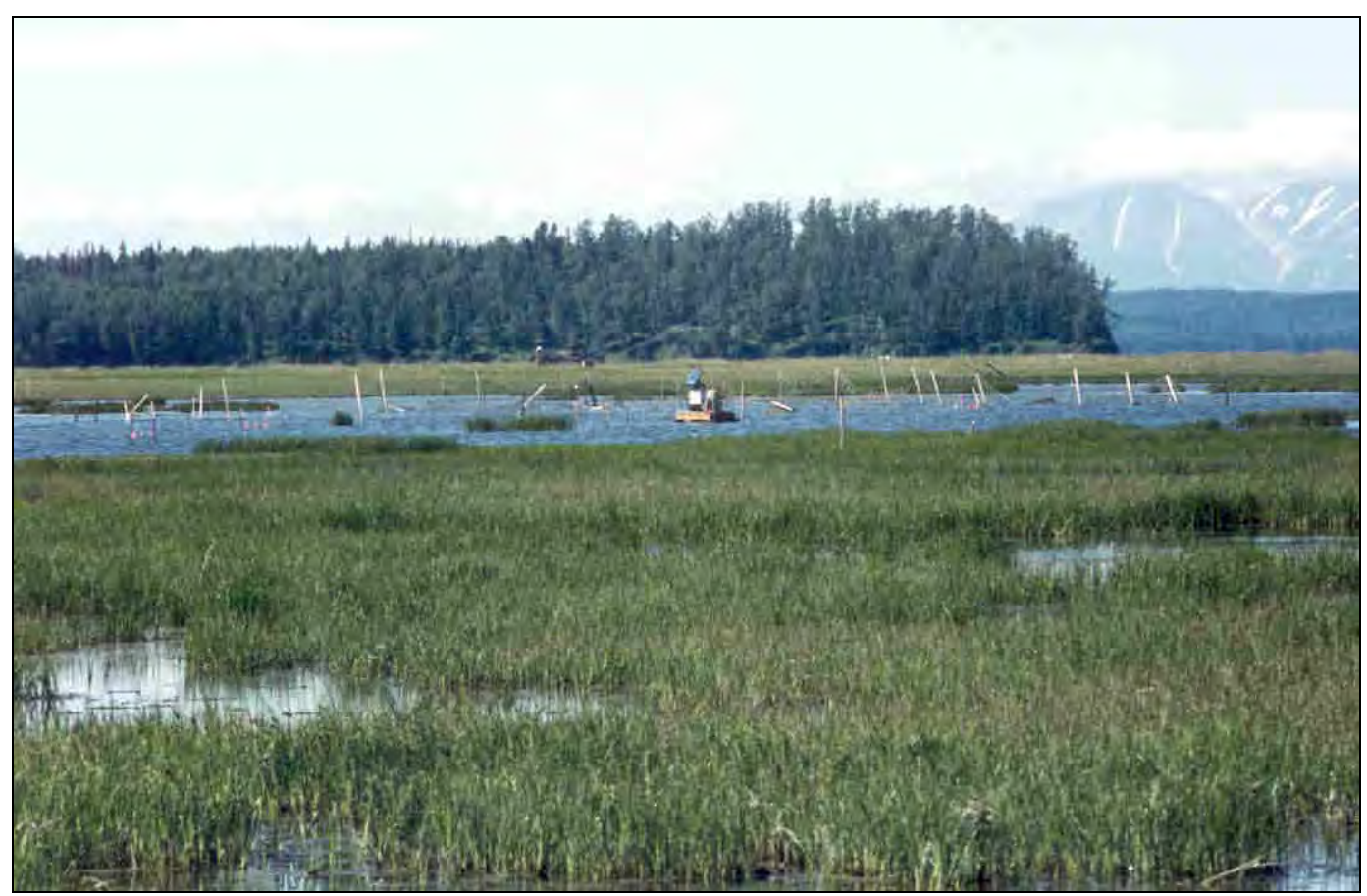

Figure 60. Portion of ERF general dredging area.

A number of WP remediation processes (removal and in situ) were underway at ERF (Walsh et al. 1994). One option for permanently ponded areas consisted of dredging contaminated sediment and depositing it in a CDF to undergo natural drying via atmospheric exposure (and subsequent WPsublimation).

Constraints affecting dredge feasibility, selection, and design studies included the following. Adverse impacts to the wetlands had to be minimized. The water depth at the project site (in ponds with surface areas of 2 ha or less) varied between 2.5 and $50 \mathrm{~cm}$ (1 and 20 in.) with elevation fluctuations occurring only with extreme high tides and river stages. Both WP and MEC contamination were present in the sediment. This contamination required the dredging system to provide worker safety precautions and equipment survivability (or replacement) to counter the potential detonation of MEC (e.g., $100 \mathrm{~kg}$ (500 lb) bombs, WP munitions, or $155 \mathrm{~mm}$ high-explosive projectiles) (Walsh et al. 1996).

The project used the PITHOG, a remotely controlled $150 \mathrm{~mm}$ (6 in.) (discharge) horizontal auger hydraulic dredge equipped with a shrouded, center-feeding auger head. It was manufactured by Liquid Waste Technology of Somerset, WI, and designed primarily for lagoon pumping 
with a submerged pump/ boom auger suction (Figure 61). The dredge was equipped with a $150 \mathrm{~mm}$ (6 in.) centrifugal dredge pump and $2.5 \mathrm{~m}$ (8 ft) auger, both driven by a hydraulic piston pump coupled to a $37 \mathrm{kw}$ (50 hp) electric motor. Biodegradable and nontoxic hydraulic oil was used in the hydraulic system in case of spills or UXO detonation.

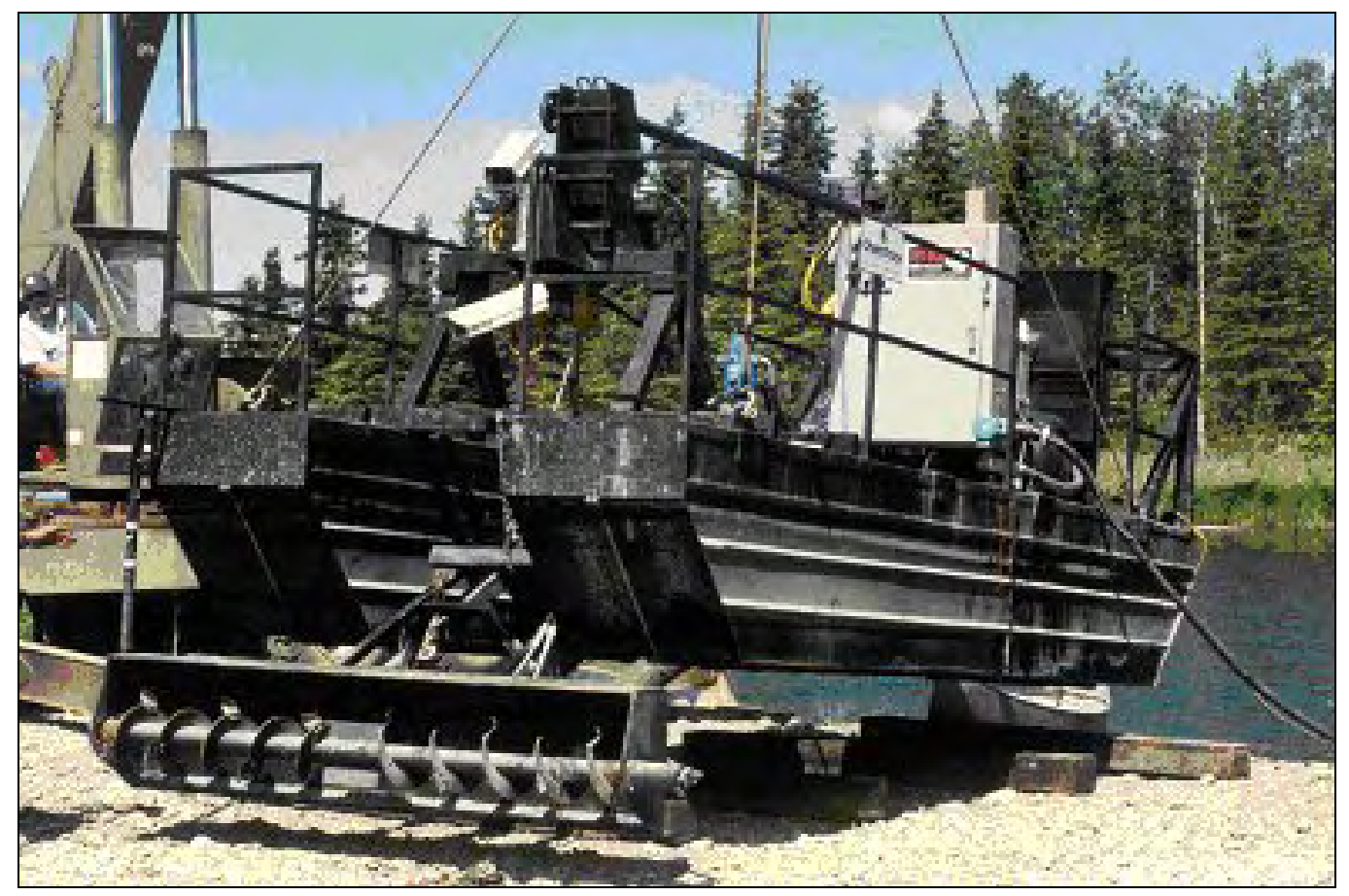

Figure 61. The PITHOG electric remote control lagoon pumper.

The small size and mass (weight) 5,443 kg (12,000 lb) of the dredge facilitated overland transportation to the remote site. The shrouded auger head was selected to minimize sediment/WP resuspension. Lateral and longitudinal movement was provided by an electric motor-driven winching assembly that traversed a cable anchored at both endpoints (Figure 62). The endpoint anchors consisted of concrete blocks (weight) set by helicopter to minimize intrusive operations (i.e., setting spuds) into the substrate contaminated with MEC.

The dredge was modular in design to facilitate repairs in case of MEC detonation, and pump and control systems were located as far away from the auger head as possible to minimize potential detonation damage. In case of a catastrophic detonation, spare parts (including an extra auger head) and a complete second dredge were held in reserve on-site. 


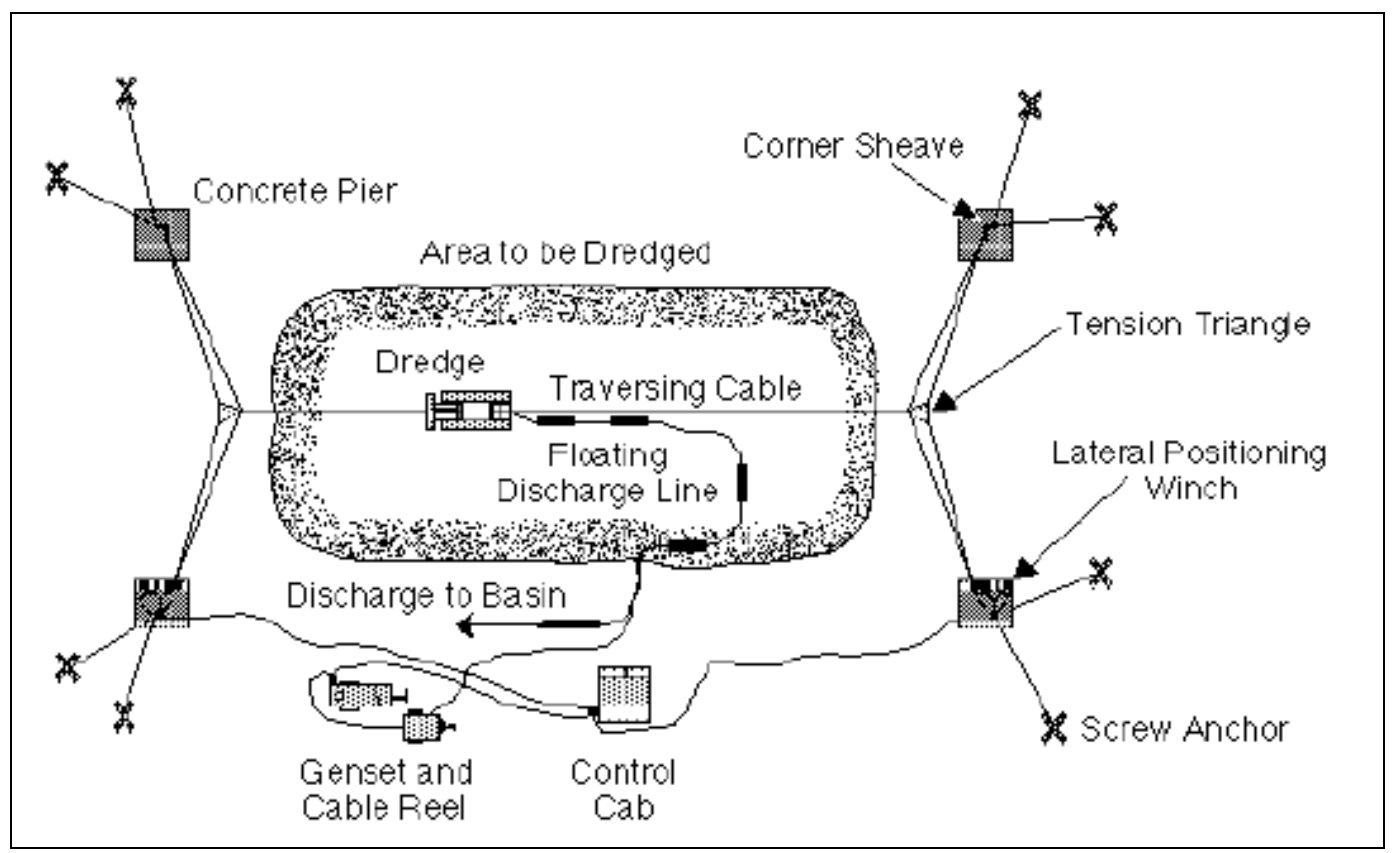

Figure 62. ERF dredging layout (source: Walsh and Collins 1998).

The ability to operate the dredge remotely allowed separation distance to be maintained between the operating dredge and personnel (Walsh et al. 1996). The operator could activate, monitor, adjust, and deactivate certain dredge operations by means of touch-screen technology. These touchscreen controls included pump on/ off, speed, and direction; auger on/ off, speed, and direction; hoist raise and lower; and travel on/ off, speed, and direction. Speed was controlled by digitally entering a percentage of total power (0 to 100 percent). The dredge's hydraulic functions for the pump and hoist were controlled by solenoids. Monitoring information included suction vacuum and discharge pressure.

CRREL modified the factory-supplied remote-control capability to facilitate MEC operations. These modifications included remote surveillance capabilities. The dredge operator could view either the position of the auger (depth) or dredge advance on a video screen. Two charged-coupled device monochrome professional video surveillance cameras enclosed in environmental housings provided these television images. The video signals were telemetered by a wireless video transmission system to the shore control station. 
Electrical power was supplied by the mobile 110/480 volt diesel motor generator set shown in Figure 63. The $5 \mathrm{~cm}$ ( 2 in.) diameter (480 volts) main power cable and $20 \mathrm{~cm}$ (8 in.) flexible high-pressure urethane discharge hose were stored on mobile spool stands equipped with power take-off winding capabilities (Figure 64). The remote control and power cable ran from the shore station to the dredge on a floathose that consisted of an $20 \mathrm{~cm}$ (8 in.) flexible hose nestled between double-ganged float sections of $15 \mathrm{~cm}$ (6 in.) polyethylene pipe heat-sealed at both ends.

The dredge's operation was controlled from a shore station enclosed in a protective enclosure (Figure 65), and a minimum separation distance of $40 \mathrm{~m}$ (130 ft) was required to be maintained between it and the dredge. This "cab" was constructed of $127 \mathrm{~mm}$ ( $0.5 \mathrm{in}$.) thick welded steel with a $317 \mathrm{~mm}$ (1.25 in.) thick ballistic polycarbonate viewport. This structure was blast-tested in two separate trials by detonating a $105 \mathrm{~mm}$ high explosive round (supported on wooden crates approximately $60 \mathrm{~cm}$ (2 ft) from ground surface and oriented with the base of the round facing the $\mathrm{cab})$ at a distance of about $37 \mathrm{~m}$ (120 ft). Only minor damage due to shell fragmentation was incurred by the cab (Walsh et al. 1994).

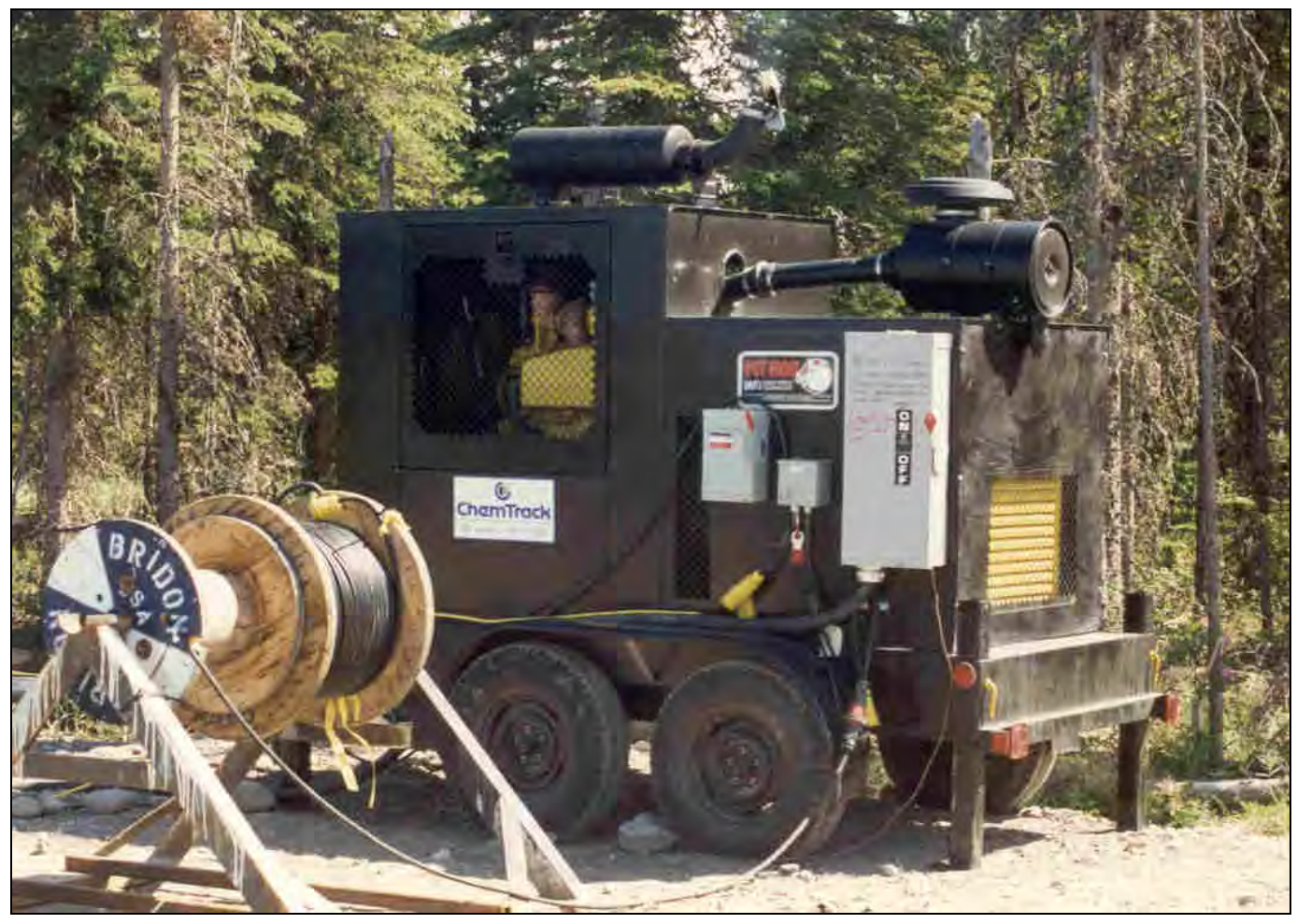

Figure 63. Diesel motor generator. 


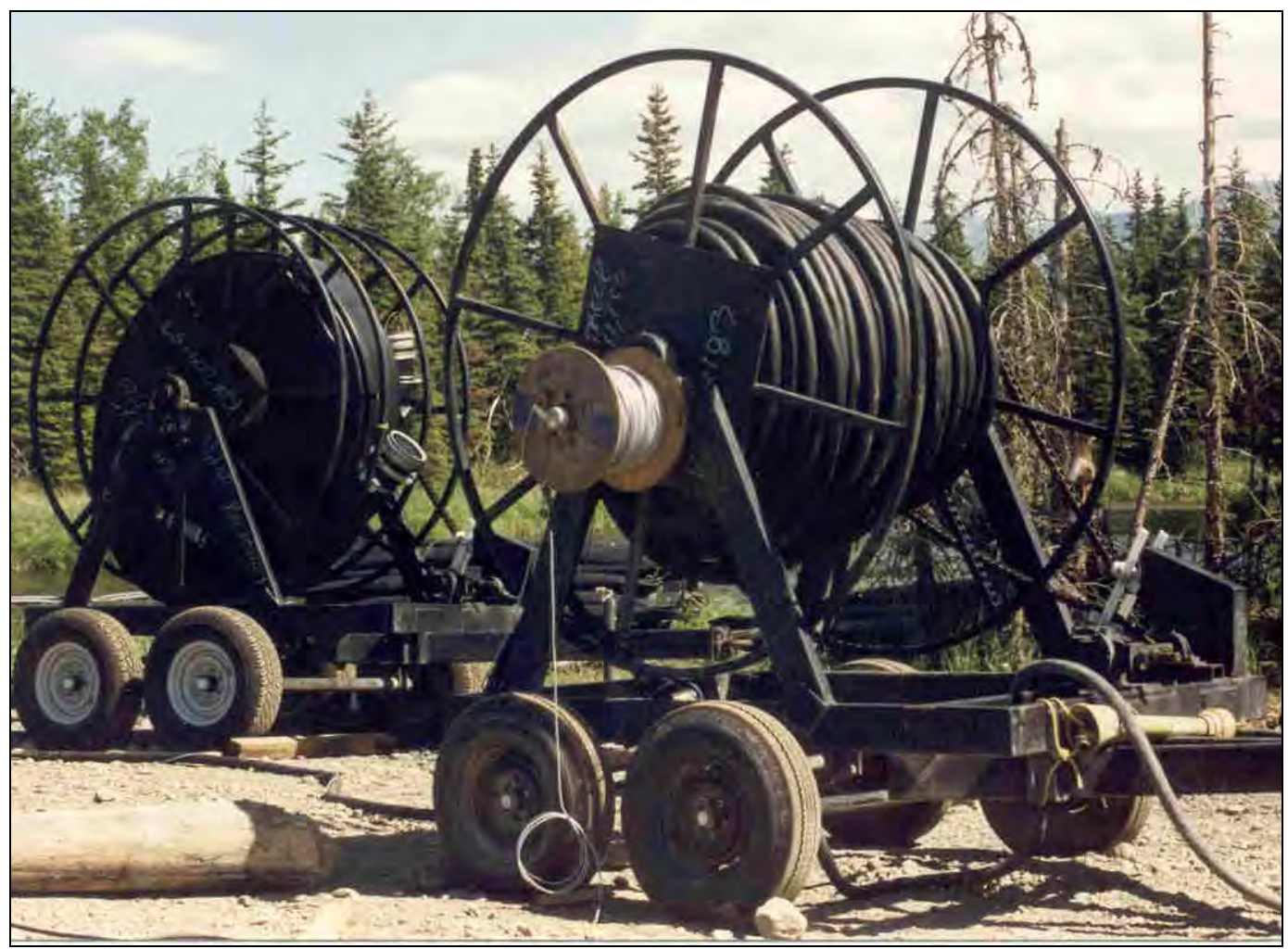

Figure 64. Flexible discharge hose and power cable on mobile spools.

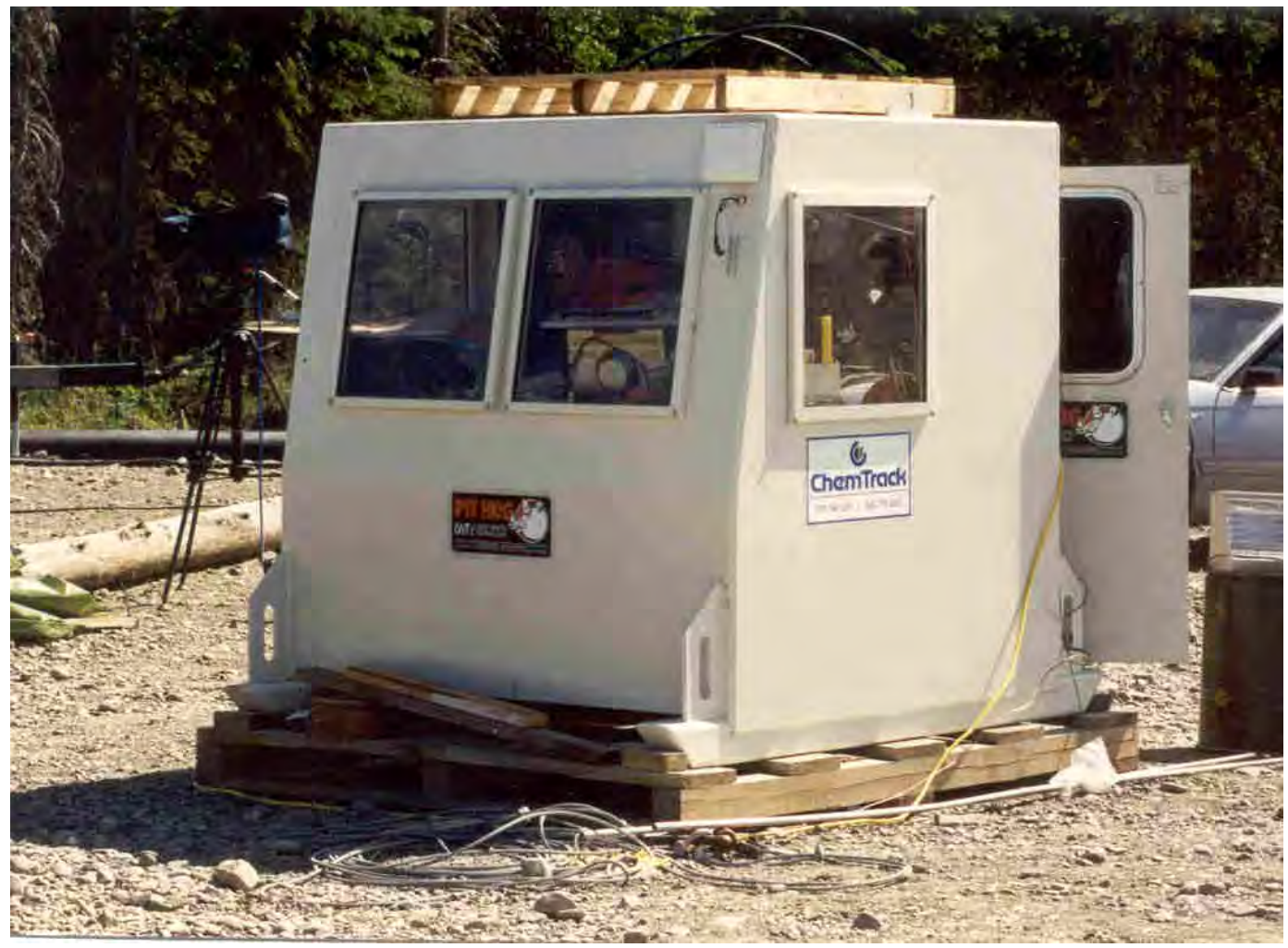

Figure 65. Remote operator protective enclosure. 
The CDF was constructed upon the EOD pad. Containment dikes $2 \mathrm{~m}$ (6.5 ft) high were built upon a consolidated gravel base, and a liner of peaty-silt material was installed to reduce the hydraulic conductivity to below $10-5 \mathrm{~cm} / \mathrm{sec}$. The 0.8 ha CDF was located $305 \mathrm{~m}$ (1,000 ft) from the dredge site with a vertical lift of $4.6 \mathrm{~m}$ ( $15 \mathrm{ft}$ ). Two concrete splash pads were installed to prevent erosion by the slurry influent, and effluent exited via a drop-inlet structure and weir. The splash pads were fenced in to restrict dispersal of any small MEC that passed through the dredge's hydraulic circuit (Walsh 1996). As the sediment underwent treatment, soil parameters (in-situ sediment moisture, temperature, and water level information) were monitored and recorded by four instrumentation towers located throughout the $\mathrm{CDF}$.

A project Health and Safety Plan was required by the Fort Richardson Safety Office (Walsh et al. 1994). The plan included restrictions/ guidance concerning emergency response, communications requirements, access/ egress procedures, safety equipment, required manning levels (e.g., buddy teams required at all times), etc. All dredging personnel were required to be certified under OSHA training requirements of 29 CFR 1910.120 for hazardous waste site workers. They also attended an EOD Briefing, a Range Control Safety Briefing, and conducted familiarization drives to several emergency medical facilities.

A truck-mounted crane with a rated capacity of 22 tonne ( 25 ton) was used to lift the dredge into and out of the water. This crane provided a "dry dock" capability that proved very useful during the various MEC-exclusion trials because it allowed the dredge to be lifted from the water and placed on the EOD pad for handy access when modifying equipment.

During this project various MEC separation methods were tried. An initial UXO exclusion device was an enlarged rock box (Figure 66), called the "boom box," that was installed immediately forward of the pump suction port. This device was designed to retain MEC by reducing the suction line velocity to settle the heavier MEC out of suspension. 


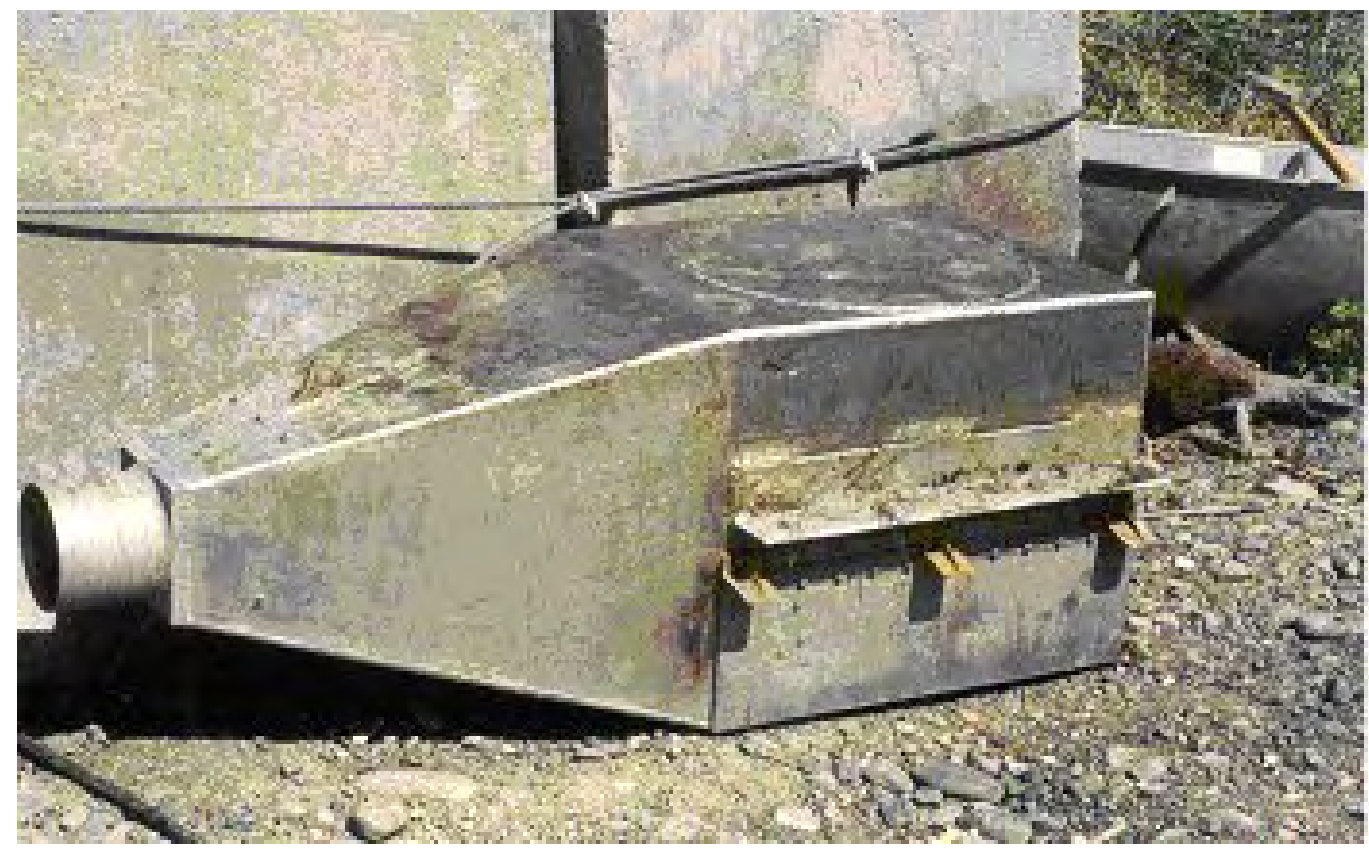

Figure 66. ERF expander (boom) box.

Walsh and Collins (1998) describe the system's performance as follows:

Although the dredge system is designed to process vegetation, the presence of boardwalk and other woody debris was problematic for the pump. Chunks of wood became lodged in the eye of the pump during dredging operations, and the blockage quickly accumulated other debris in a process called "beaverdamming." Evidence of this phenomenon first surfaced during pumping tests, with cyclic surging, the period of which was related to impeller speed. The surging was caused by cavitation due to inlet starvation and the backflow of water into the pump. When pump blockage was suspected, the dredge was pulled from the water and the pump eye examined. It was found to be clogged with debris. The instigators in all occurrences were waterlogged sections of boardwalk approximately $70 \mathrm{~mm} \times 20 \mathrm{~mm} \times 150$ to $200 \mathrm{~mm}$ long. Because the wood was of near-neutral buoyancy, it did not drop out in the expansion (boom) box located ahead of the pump. We also found that aluminum objects did not always drop out. Although the boom box was effective in keeping out the heavier 
steel debris, it was not functioning when confronted with lighter materials. A coarse screen system was installed in the boom box, but that quickly plugged, crippling the dredge within a matter of minutes. A new approach was needed that would exclude debris from the pump but not become clogged with the ubiquitous vegetation.

Another exclusion technology was tried by the installation of a screen over the auger suction mouth to exclude the larger sized MEC (Figure 67). The screen consisted of steel rod laid out in $2.5 \mathrm{~cm}$ ( 1 in.) square mesh. During testing this device excluded larger pieces of UXO, but became clogged with debris, e.g., wood, grasses, and shrapnel (Figure 68).

After completion of initial pumping tests, active dredging commenced on 15 October 1994 and concluded 16 October 1994 due to the onset of winter. Over the 2-day dredging period, actual pumping time was a total of $3 \mathrm{hr}$ due to problems with the flexible hose connections and loss of suction due to dredge modifications (boom box) (Walsh et al. 1996).

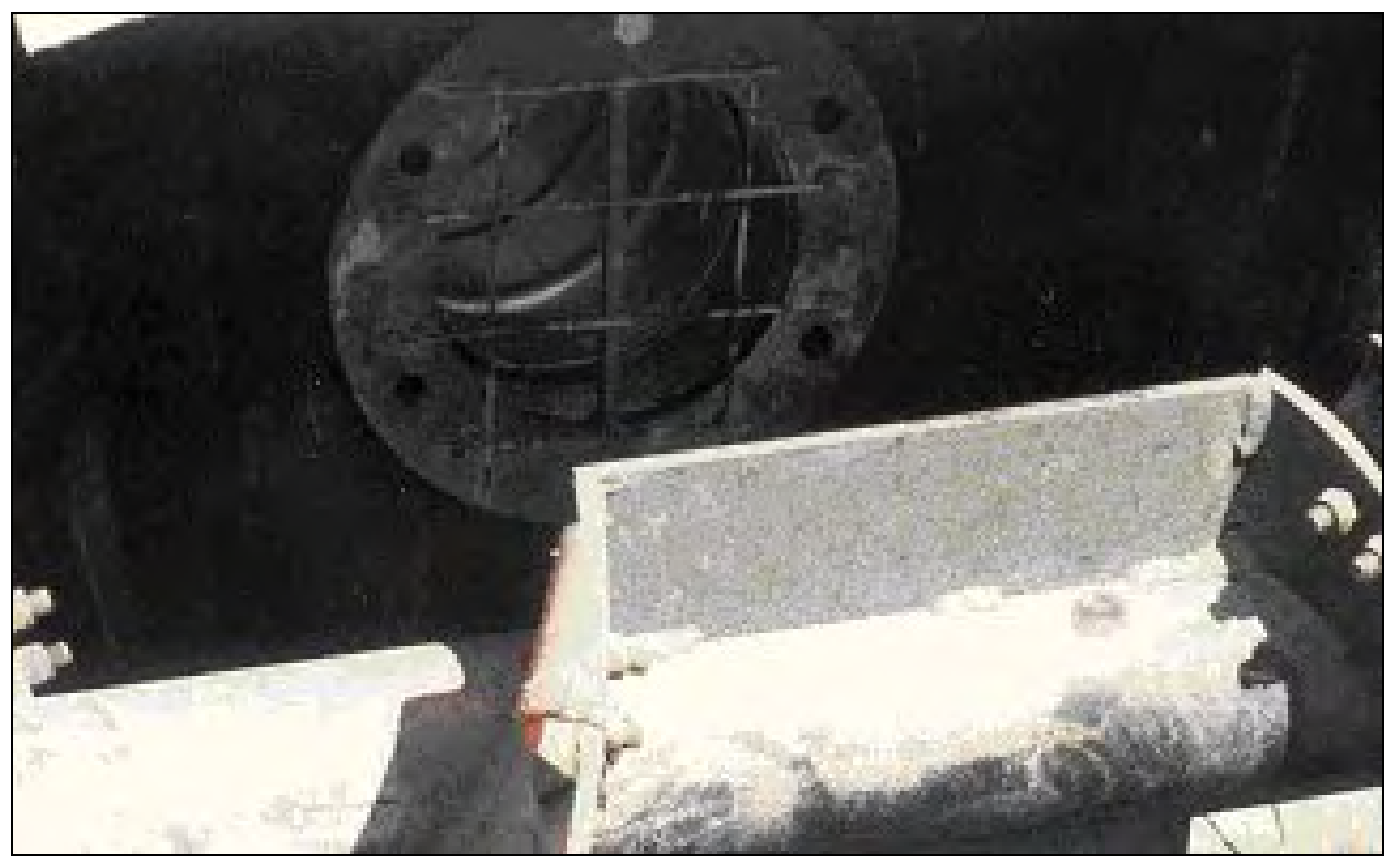

Figure 67. Screen over auger-head suction mouth. 


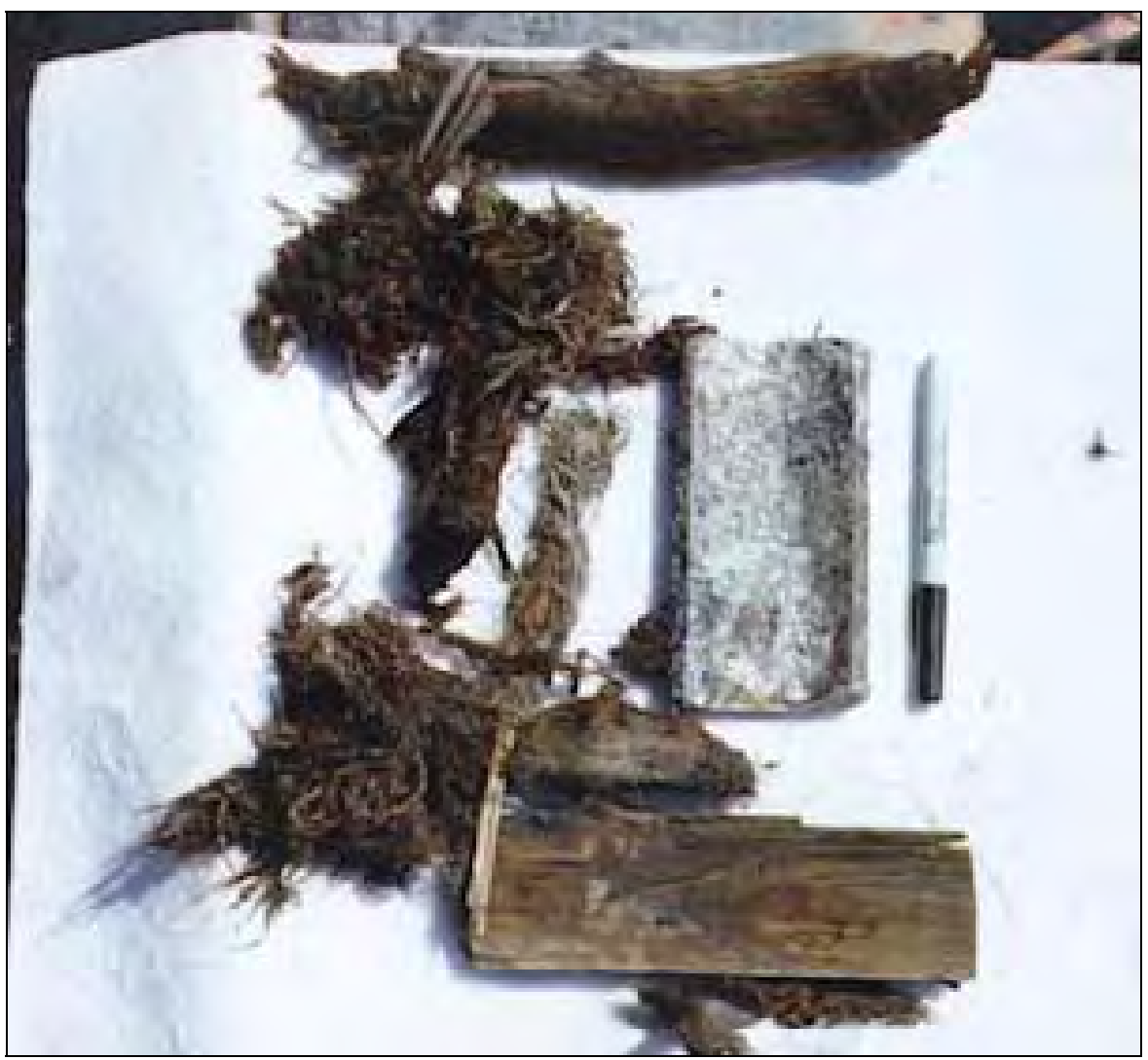

Figure 68. Extracted debris (note aluminum illumination round fragment) (source: Walsh and Collins 1998).

Dredging during 1995 used an improved MEC-exclusion device. Two steel tines were welded on the rotating section of horizontal auger shaft immediately forward of the suction mouth. As the auger rotated, the tines would mechanically "sweep" accumulated debris from a curved exclusion grate (Figures 69 and 70). A tapered transition box immediately "downstream" of the curved grate consisted of a clean-out device that also provided a smooth transitional flow to the system's pump. This exclusion grate/ selfcleaning tines combination was used throughout the remainder of the demonstration and ultimately was patented by Walsh and Lambert (29 J uly 1997, patent number 5651200).

The 1995 demonstration removed an estimated 1,700 cu m (2,200 cu yd) of sediment from approximately 4,047 sq $\mathrm{m}$ ( 1 acre) of wetland at a total cost of $\$ 273,000$. The amount of WP removed was estimated to be enough to kill at least 1,500 ducks. The dredging cost of \$161/ cu m ( $\$ 124 / \mathrm{cu}$ yd) was prohibitive compared to the alternative remediation method of drying in-situ sediment by dewatering the shallow ponds. This dewatering of the 


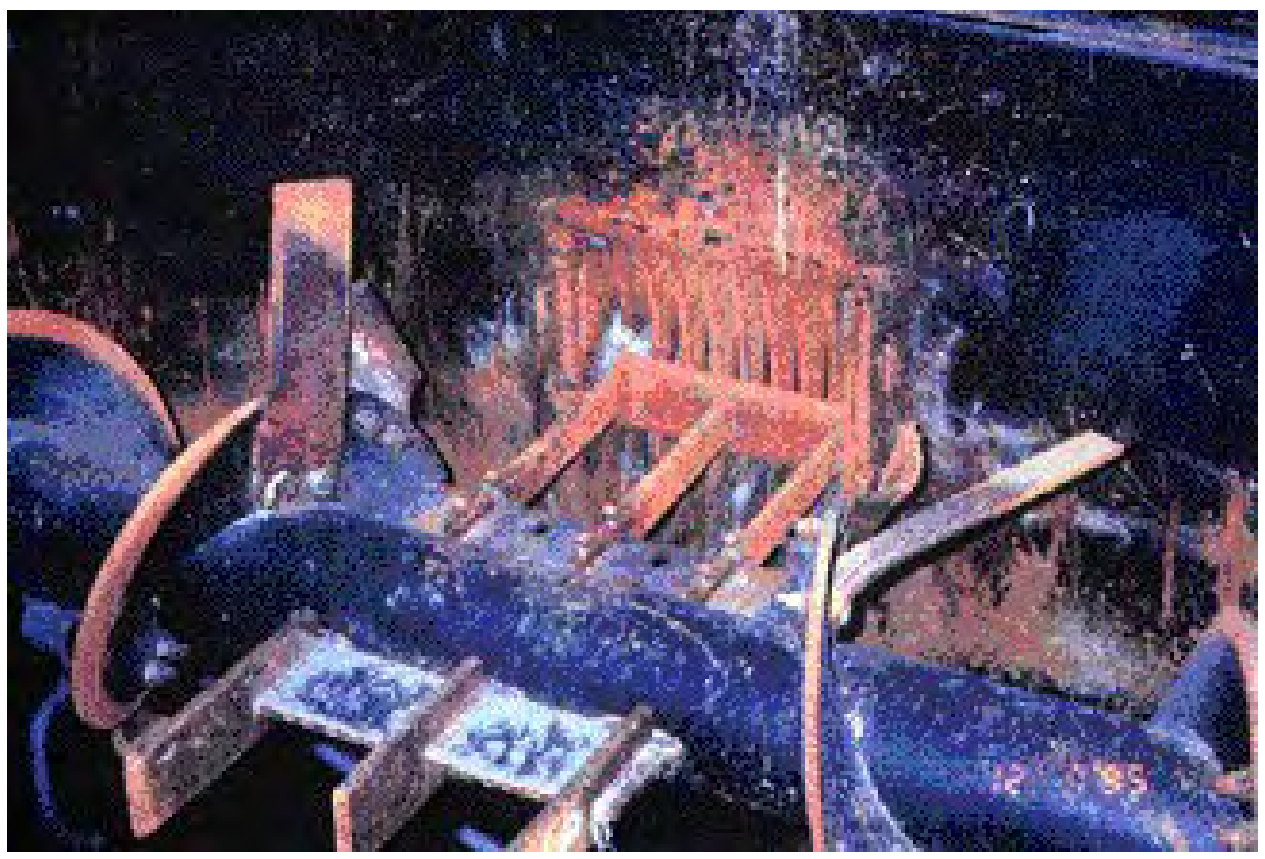

Figure 69. Front view of augerhead suction mouth screen/cutter device (source: Walsh and Collins 1998).

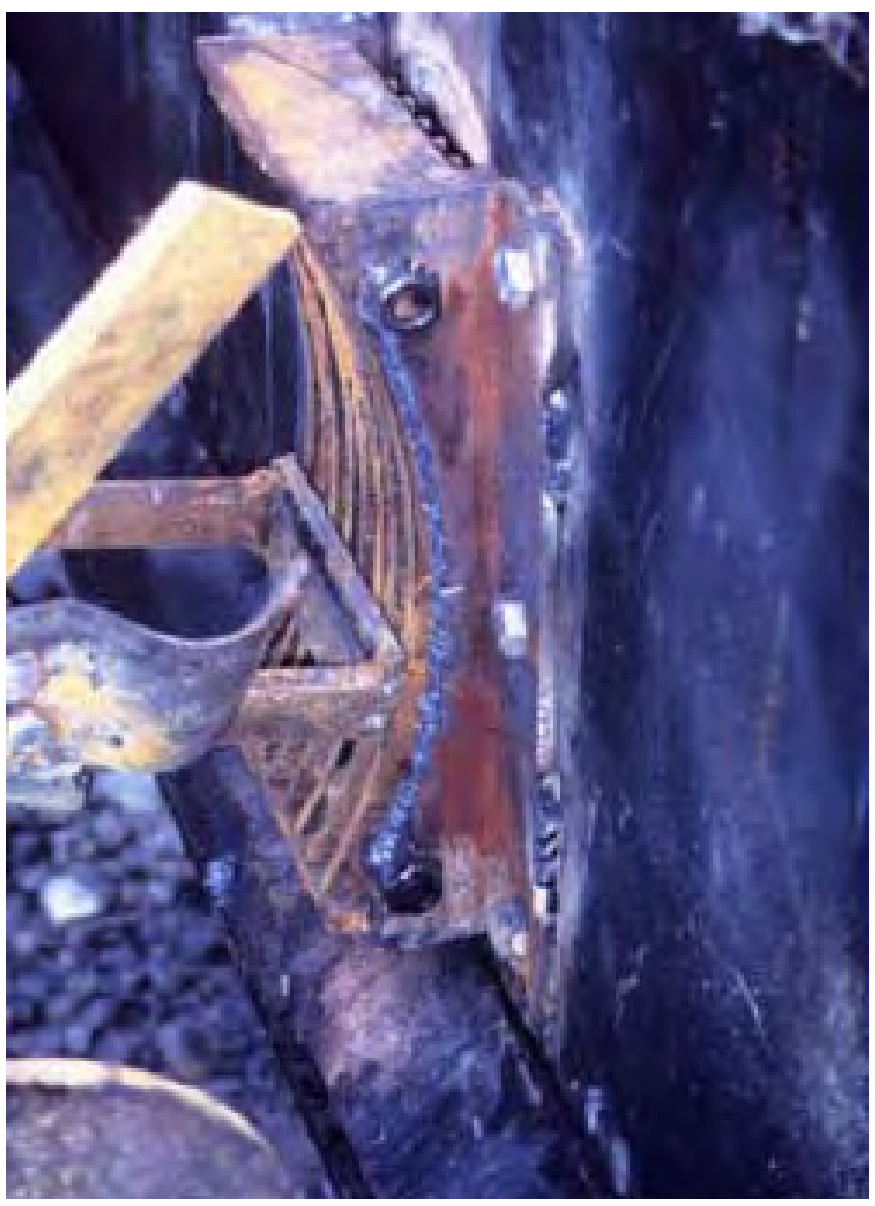

Figure 70. Side view of augerhead suction mouth screen/ cutter device (source: Walsh and Collins 1998). 
ponds was accomplished by draining them into sumps created by detonation of explosives in selected locations. ${ }^{1}$ More detailed information about this project is available in Walsh and Collins (1998) at http://www.crrel.usace.army.mil/techpub/CRREL_Reports/reports/CR98_05.pdf.

\section{Albany Harbor, West Australia}

In the survey conducted by Halkola et al. (2006), a MEC dredging project was identified in Albany Harbor, West Australia (for a detailed description see Halkola et al. 2006). During a new-work dredging project, a $406 \mathrm{~mm}$ (16 in.) cutterhead dredge encountered large quantities of small caliber, $20 \mathrm{~mm}$ (0.78 in.) cannon, and $76.2 \mathrm{~mm}$ (3 in.) Bofor ammunition, in addition to a few 127 and $152 \mathrm{~mm}$ ( 5 and $6 \mathrm{in}$.) naval shells and a $113.4 \mathrm{~kg}$ (250 lb) aerial bomb. MEC items were also discovered at the pipe head and the cutterhead; but the source of this contamination was undetermined.

The cutterhead was fitted with an MEC exclusion screen with $5 \mathrm{~cm}$ (2 in.) apertures and a rock box was installed in the suction line. Blast mats were also installed over the pump and piping in the dredge. None of the MEC items were found to be fuzed, except the $113.4 \mathrm{~kg}$ (250 lb) aerial bomb that was disposed of by Australian EOD personnel, who were required for identification and disposal duties. The small arms that did enter the hydraulic circuit were buried at the dredged material placement site.

The MEC exclusion screen and rock box were viewed as a method to work safely, but they slowed the production rate due to clogging. Halkola et al. (2006) reported that:

The estimate of time lost because of the presence of military munitions was 6 months. Production rates were estimated to be 35 percent of the normal production for similar conditions without military munitions present and averaged $180 \mathrm{cu} \mathrm{m} / \mathrm{hr}(235 \mathrm{cu} \mathrm{yd} / \mathrm{hr})$ for the clay material. Dredging depths were approximately $14.5 \mathrm{~m}$ (48 ft) in the approximate 125,000 sq $\mathrm{m}(13,450 \mathrm{sq} \mathrm{ft})$ dredging area. Recommendations for future maintenance dredging suggested the use of a mechanical dredge to facilitate removal of the military munitions left on the seabed.

1 Personal communication, Michael Walsh, 1997. 


\section{Discharge pipeline}

Sea Bright Beach nourishment project

The New York District Sea Bright nourishment contract specifications requiring screening in the discharge side of the pump (New York District 2001) include the same requirements as in the hopper dredge discharge side specifications.

In the ordnance reconnaissance study by Parsons et al. (1999), it was discussed that:

Design of a rock box in the suction or discharge line is an alternative which will have little or no impact on efficiency or production. Its effectiveness in removing ordnance is not as evident as the positive screening methods. Use of a large box and screen on the beach will have little or no effect on efficiency or production but could be impacted by the requirements to clean the screens at regular intervals. For the cutterhead dredge, the most positive screening device will be a screen along the discharge line on the beach. This will require a suitably designed box and screen. Depending on the line lengths and pressures, it will be logical to place a booster pump to receive slurry which has passed through the screen.

Even though the rock box and the large box and screen were recommended for further study requirements to allow testing of various MEC sizes and configurations through a range of slurry pipeline velocities, the study concluded that:

The best solution for the improvement of dredging techniques is the continuation of screening using the enlarged dragheads. This solution is the safest, least costly, and easiest to implement and maintain. Unlike other solutions discussed, draghead screening is the only technique that excludes ordnance before entering the piping system. Therefore, it is the safest because it provides the greatest separation between dredge personnel and the ordnance. This solution is also the 
least expensive to use and maintain. Enlarging the dragheads has regained the production loss initially encountered from the reduced suction area. This tried and proven method is therefore recommended over other dredge improvements" (Parsons et al. 1999).

San Diego Channel, San Diego, CA

For the San Diego Channel project, the various pumpout screening alternatives previously described for hopper dredges apply to cutterhead discharge pipelines as well, with the addition of screens over material barges, and the use of a modified spider barge fitted with screens. A spider barge is used to transfer slurry from the hydraulic pipeline dredge's discharge and transfer it to barges tied up alongside.

For a given dredge and hydraulic pumping circuit, the primary controlling factors affecting the viability of the screen over material barge and a modified spider barge fitted with screens are (NAVFAC Southwest 1998):

- Size of screen.

- Quantity of material greater than screen size; handling and disposal of that material.

- Physical constraints of barge.

- Location of placement site for oversized dredged material collected on screen.

Discussions with dredging contractors indicated that (for certain protected locations in the San Diego Channel) this alternative may have been viable. The discharge pipeline would have been pumped to flow over an $8 \mathrm{~mm}$ (5/ 16 in.) screen designed to handle the deadload of the screen as well as the dynamic loading from slurry discharge as shown in Figure 71. The sand would flow through the screen and oversized material would, primarily by gravity feed, be collected in a separate oversized material barge tied alongside the regular material barge. The material barge would place the cleaned sand in a nearshore placement site and the oversized barge would dump at an authorized location. 


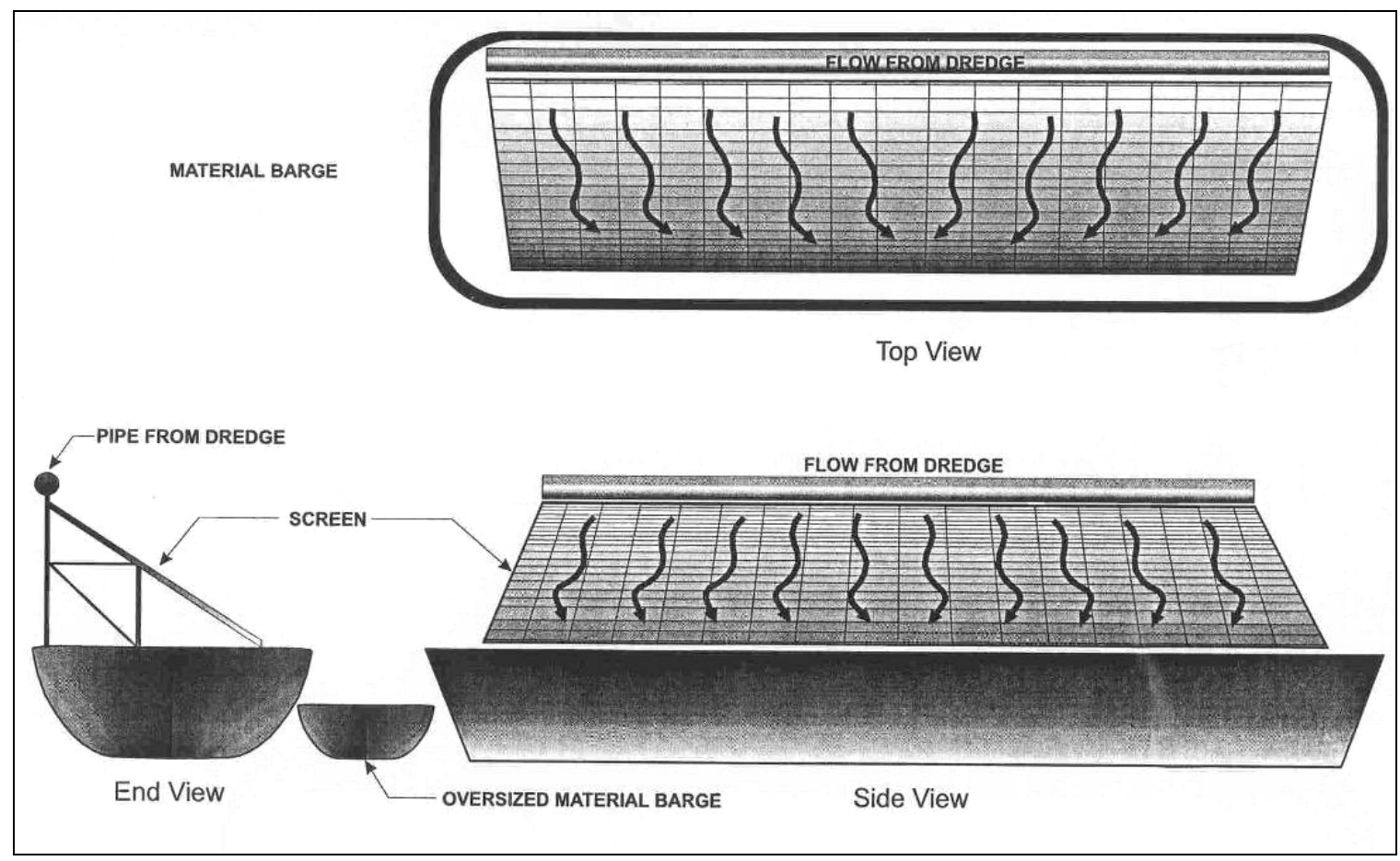

Figure 71. Screen over barge alternative (source: NAVFAC Southwest 1998).

In addition to maintaining the integrity of this screen, it was anticipated that this method would decrease production as it was maintained to stay unclogged during loading. The screen would need to be designed to be moved from barge to barge, and a derrick barge would be required to move it before and after the barge was loaded (NAVFAC Southwest 1998).

A variation of this "screen over barge" concept would be to place the screening operation on a spider barge as shown in Figure 72. Both the screen over barge and screen over spider barge methods were deemed technically viable for providing sand in the nearshore zone, but, in conclusion, Parsons et al. (1999) determined that:

The best solution for the improvement of dredging techniques is the continuation of screening using the enlarged dragheads. This solution is the safest, least costly, and easiest to implement and maintain. Unlike other solutions discussed, draghead screening is the only technique that excludes ordnance before entering the piping system. Therefore, it is the safest because it provides the greatest separation between dredge personnel and the ordnance. This solution is also the 


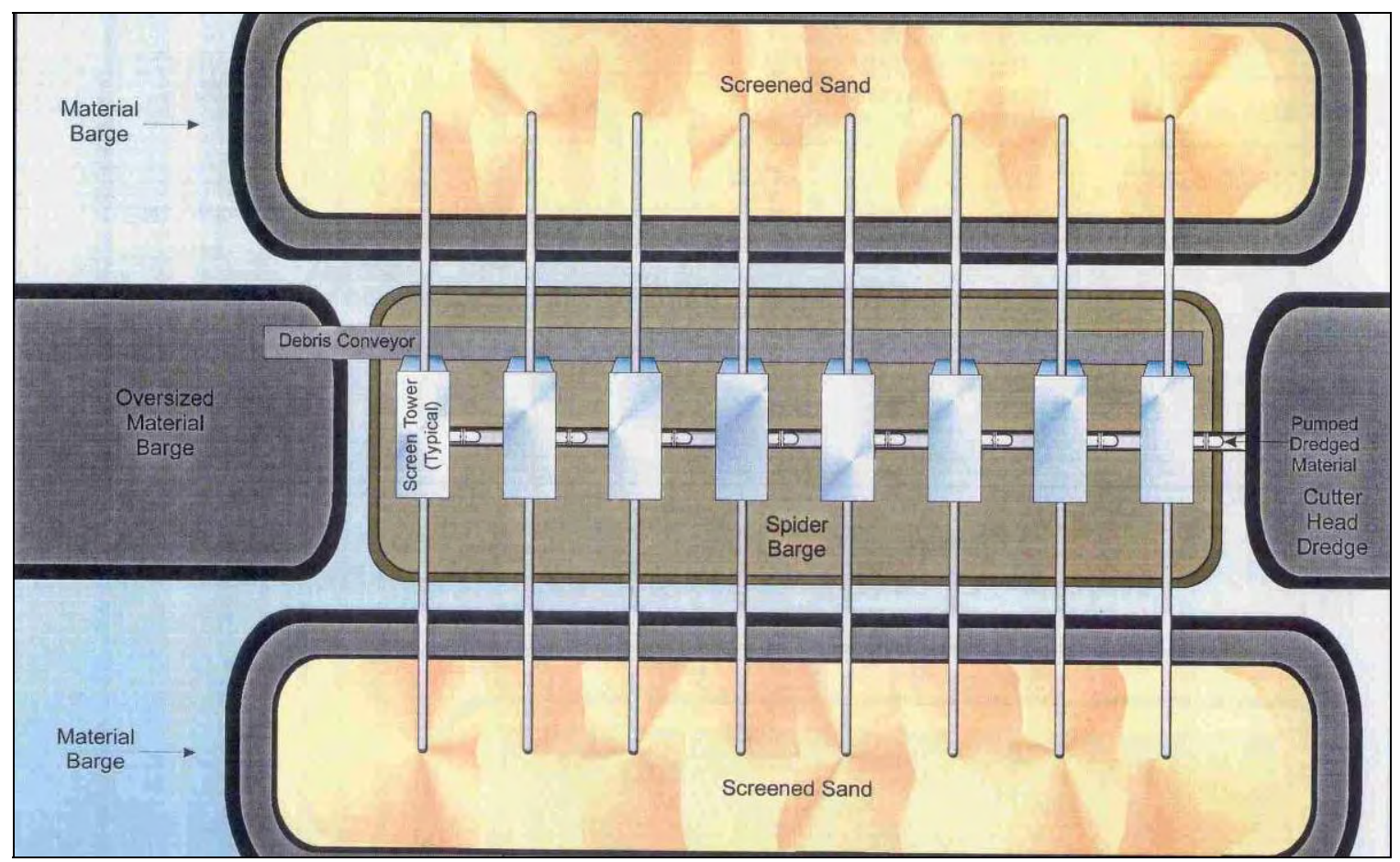

Figure 72. Screen operation on a spider barge (source: NAVFAC Southwest 1998).

least expensive to use and maintain. Enlarging the dragheads has regained the production loss initially encountered from the reduced suction area. This tried and proven method is therefore recommended over other dredge improvements.

\section{Buckroe Beach, Hampton, VA}

The Norfolk District (2004) contract specifications for the suction side of the pump included discharge pipeline as well.

In addition to the modified rock ring with $50 \mathrm{~mm}$ ( 2 in.) apertures, GLDD also constructed screening units for use at the beach called discharge basket screens (Figure 73). Two discharge basket screens were used at the discharge that was split by a Y valve as shown in Figure 74 . This configuration increased flexibility in sand placement and allowed alternative debris cleaning cycles. The discharge basket screen units had an aperture size of $38 \mathrm{~mm}$ (1.5 in.) and were equipped with "trap doors" on the bottom to remove the accumulated oversized material. But, as illustrated in Figure 75, so much oversized material accumulated so quickly that the trap doors were removed and the final operational configuration of the discharge basket screen is shown in Figure 76. 


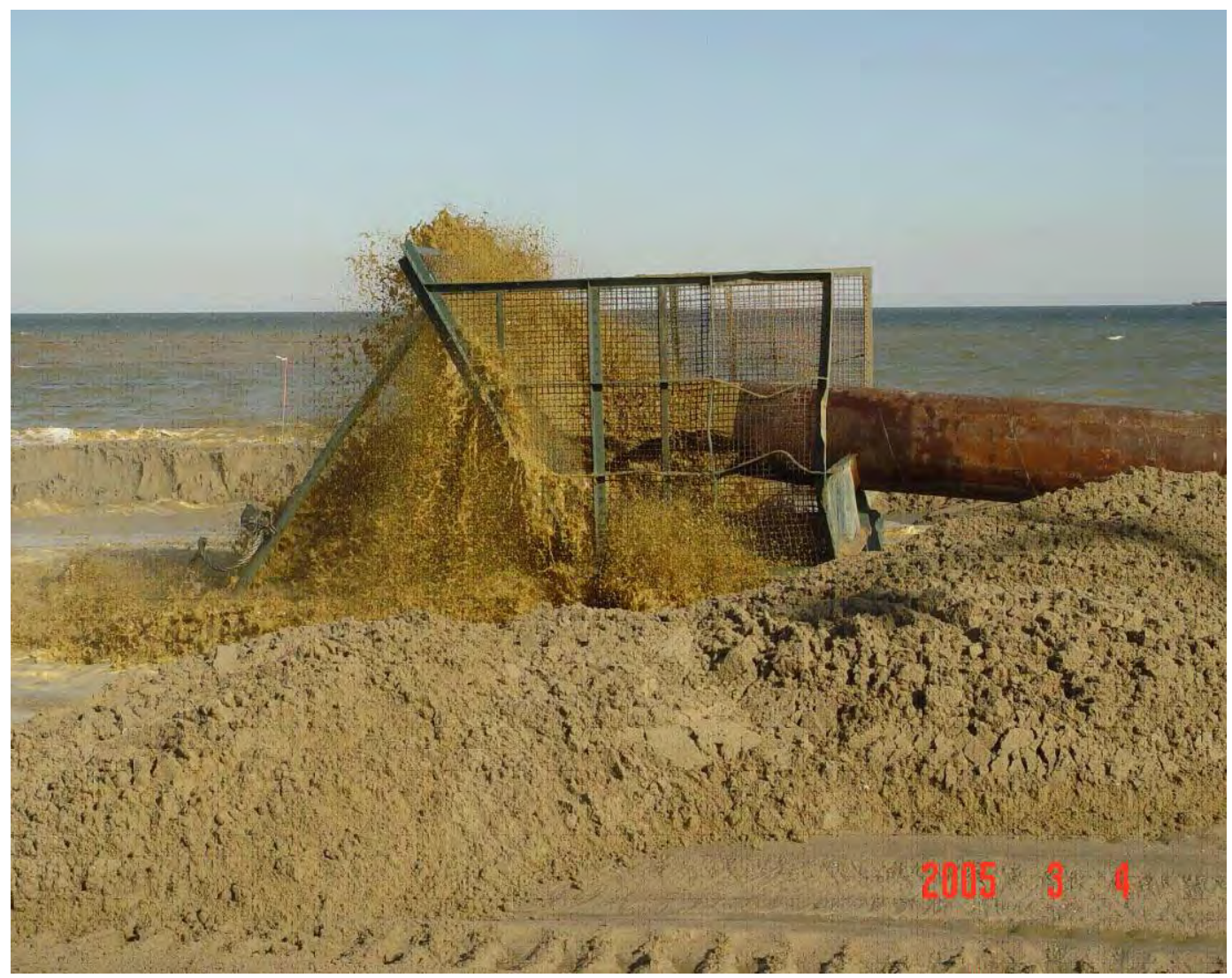

Figure 73. Discharge basket screens at Buckroe Beach.

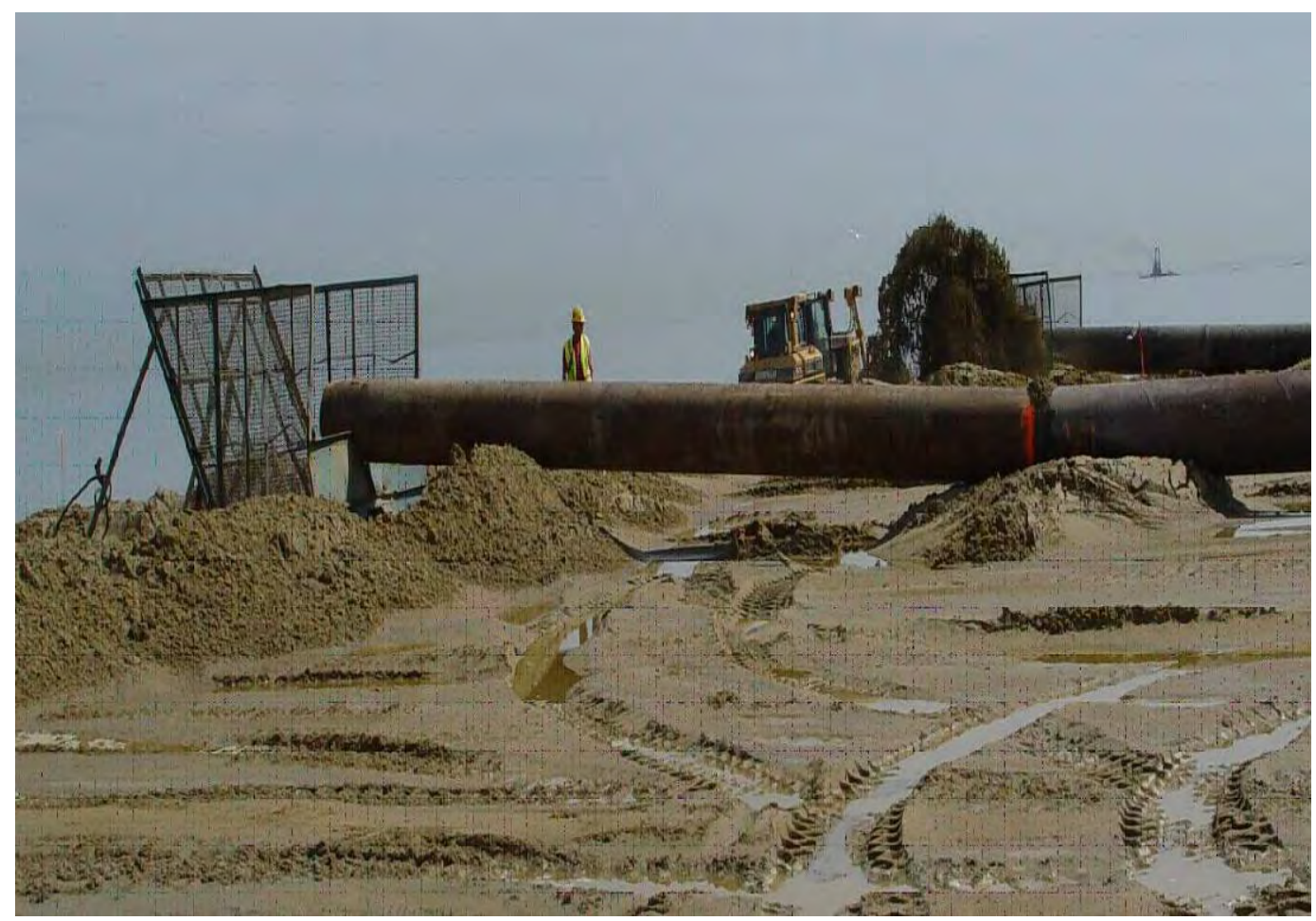

Figure 74. Two discharge basket screens on a bifurcated discharge line. 


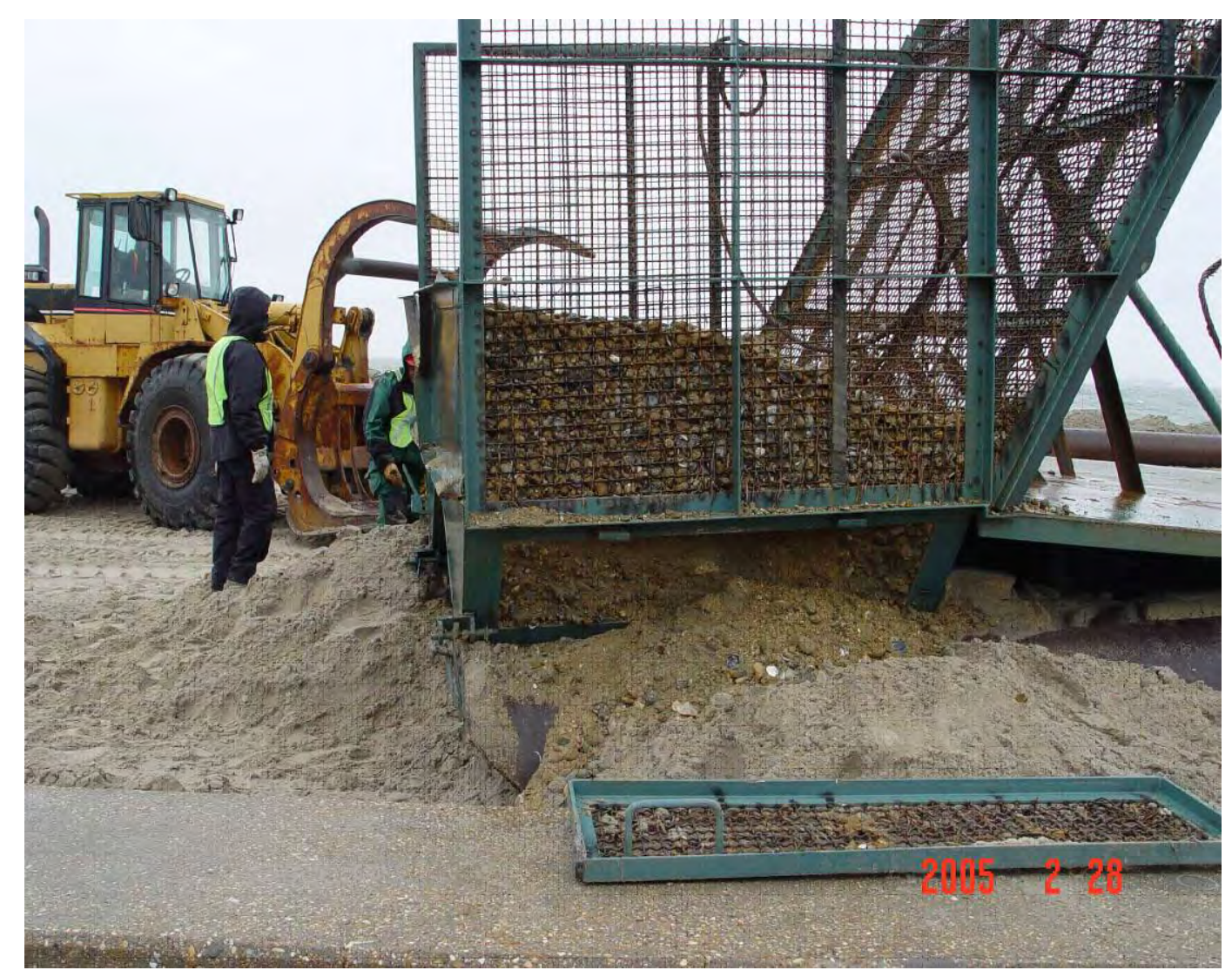

Figure 75. Trap door removed from discharge basket screen.

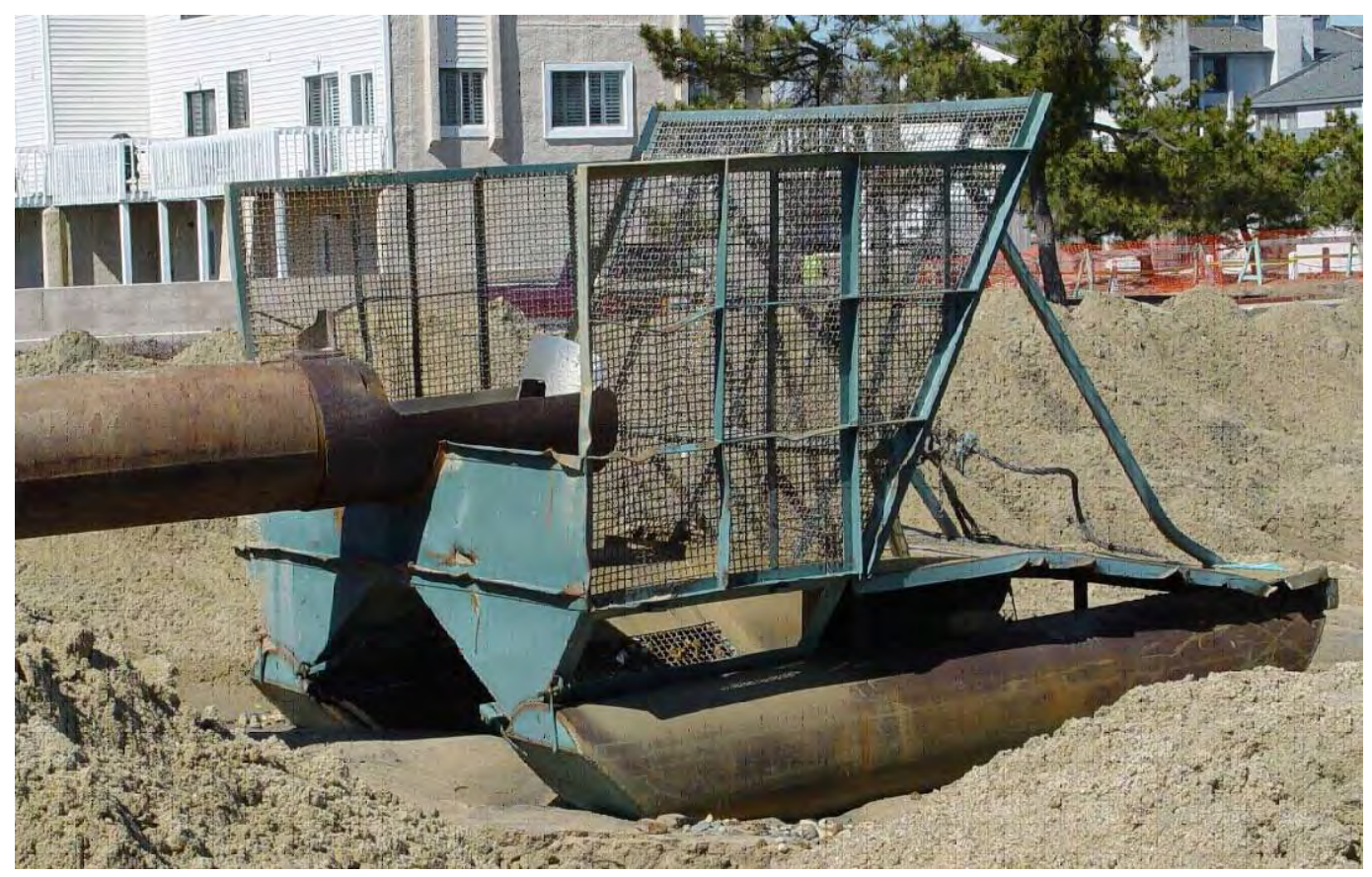

Figure 76. Discharge basket screen ready for next filling cycle. 
The MEC subcontractor was required to have personnel on-site $24 \mathrm{hr}$ a day, 7 days a week. They worked in rotating shifts and were required to inspect all placed material (magnetometer sweeps were required at each discharge basket screen area).

By the end of the project the following ordnance items were recovered from the baskets:

- $37 \mathrm{~mm}$ projectiles

- $40 \mathrm{~mm}$ projectiles

- $75 \mathrm{~mm}$ projectiles

- $76 \mathrm{~mm}$ projectiles

- M1907 powder train time fuze.

\section{Mechanical dredges}

Mechanical dredges (described in Chapter 2) have also been used in dredging projects involving MEC. This section presents various aspects of mechanical dredge operation in past MEC-contaminated projects. As presented in Chapter 3, a risk assessment should ask the two primary questions regarding MEC hazards.

1. What points in the dredging process are most likely to cause the MEC to detonate?

2. What are the potential consequences of a detonation at each of these points?

A mechanical dredge's potential detonation points include contact between the bucket and MEC, and subsequent MEC contact points as the material is placed and transported in barges, trucks, etc., to its intended placement location.

\section{Kokkola Channel Project, Kokkola, Finland}

Halkola et al. (2006) describe a dredging project in the port of Kokkola, Finland, where a hopper dredge was stopped from conducting a new works project due to MEC that were found lodged in the draghead. Subsequent investigation indicated that the area was along a previous transit route for vessels carrying decommissioned MEC from just after WWII to 1974 and an offshore ordnance dumping zone was located $50 \mathrm{~km}$ (31 mi) from the port. The area had also been bombed during WWII causing this area to be 
subsequently assessed as extremely dangerous because of the potential for finding large unexploded aerial bombs.

The Finnish Defense Forces and the "Terramare OY" dredging company developed new dredging methodologies and safety procedures for dredging and handling the MEC-contaminated material. Due to possible exposure to $500-\mathrm{kg}$ aerial bombs a remote-controlled dredging approach with a mechanical dredge was developed. A control vessel was used to remotely control the $5 \mathrm{cu} \mathrm{m}$ ( $6.5 \mathrm{cu}$ yd) clamshell dredge Kahmari by radio command (and cameras) from a distance of up to $500 \mathrm{~m}$ (1,640 ft) away. Two manually operated dredges, the $7 \mathrm{cu}$ m (10 cu yd) bucket backhoe Koura, and the $15 \mathrm{cu} \mathrm{m}$ ( $19.6 \mathrm{cu}$ yd) bucket grab dredge MeriPekka, were used to dredge in channel sections farther away. Personnel on these two dredges were protected with bulletproof glass and steel safety partitions (Halkola et al. 2006).

The dredging area was approximately $3.5 \mathrm{~km}(2.2 \mathrm{mi})$ long and $300 \mathrm{~m}$ (984 ft) wide with an estimated 1.2 million cu m (1.6 million cu yd) of MEC-contaminated clay and silt. Recovered MECidentified on-site included cartridges, artillery, and grenade launcher rounds, fuzes for artillery projectiles (projectiles ranging from 37 to $155 \mathrm{~mm}$ in diameter), and 100 to $500 \mathrm{~kg}$ aerial bombs. Material dredged by the Kahmar was transported to a separate disposal area by $300 \mathrm{cu} \mathrm{m}$ (392 cu yd) remotely controlled split hall barges by tugs at a standoff distance of $300 \mathrm{~m}$ (984 ft).

This disposal area was a confined aquatic disposal (CAD) site (300 m $\times 500 \mathrm{~m}(944 \mathrm{ft} \times 1,640 \mathrm{ft})$ that was specially constructed for the MECcontaminated material. Lateral containment was provided by a gravel berm surrounding the basin with 600,000 cu m (784,800 cu yd) of blasted rock to a depth of $10 \mathrm{~m}$. The CAD was capped with clean material after it was filled with MEC-contaminated material. Halkola et al. (2006) reported that:

The estimated average production cost of the project was 35-Euros/cu m ( $\$ 32.6$ U.S. dollars/ cu yd) for the 1.2 million cu $\mathrm{m}$ (1.6 million cu yd) of material dredged from the channel and placed in the two containment areas. Approximately 42 months were lost because of the discovery of the munitions in this dredging project. The original cost estimate for the 
channel was 25 million Euros (\$30.9 million

U.S. dollars). Delays and alterations to the dredge and dredging procedures, as a result of the discovery of military munitions, caused the channel improvement costs to rise to approximately 62 million Euros (\$76.6 million U.S. dollars)".

For more detailed information on this project refer to Halkola et al. (2006).

\section{Baltimore Harbor, Baltimore, MD}

The U.S. Army Engineers District, Baltimore (hereafter Baltimore District), dredged a new-works project in Baltimore Harbor in 2002 and 2003 that recovered more than 1,300 MEC items from the dredged material. Weeks Marine Inc. dredged 4.6 million cu yd with a mechanical clamshell dredge from Baltimore Harbor Anchorage 3 and 4, and the turning basin at Fort McHenry. This dredged material was transported by barge to the Hart Miller Island (HMI) CDF where it was hydraulically unloaded by submersible pump from the barge and transported via the discharge pipeline. Figure 77 shows a barge load ready to be hydraulically unloaded at HMI. The hydraulic unloading station is shown in Figure 78. Debris that settled to the barge bottom was collected and deposited in a debris barge for later disposal as shown in Figure 79.

An Archive Search Reports and Phase 1Cultural Resources Survey did not indicate MEC and dredging began in March 2002. In April 2002 the first DMM item, a 5 in. brass drill round (Figure 80), was discovered, then 12 other DMM items were discovered by a USACE OE Safety Specialist during debris sorting in J une and J uly 2002 in a sorting yard. Sorting is the process of separating various types of debris (timber, metal, etc.) for various types of disposal (e.g., recycling). These ordnance items were disposed of by the Camden, NJ , Bomb Squad, and Fort Dix EOD. After special training for identifying and avoiding munitions was given to the dredge crew by a USACE OE Specialist, dredging was resumed in September 2002 and a crew member discovered a fuzed and fired $155 \mathrm{~mm}$ projectile on a barge. The Andrews Air Force Base EOD team responded, hand carried the item off the barge, where it was then blown-in-place. The item was determined to have been empty. 


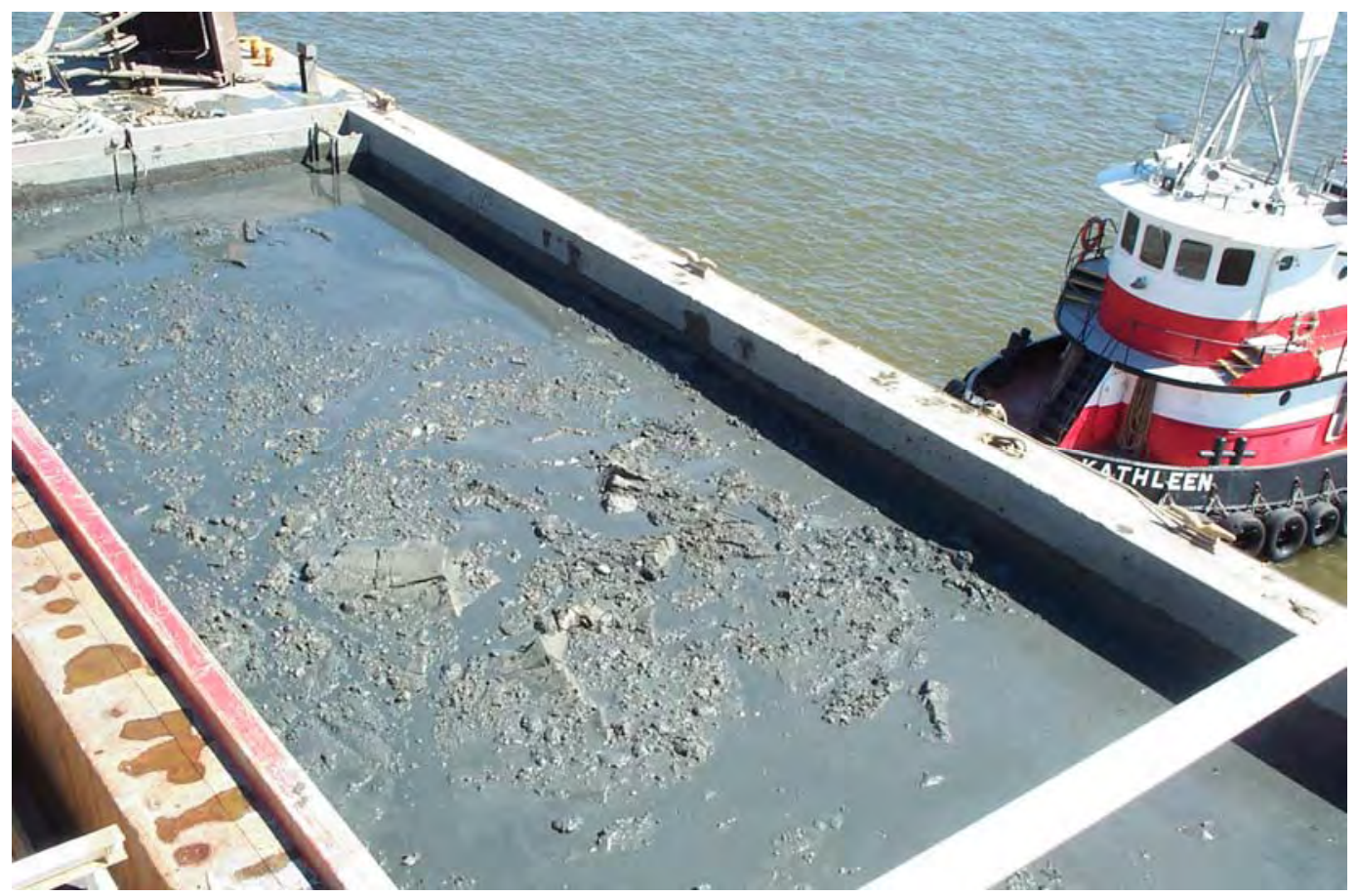

Figure 77 . Barge ready to be hydraulically unloaded at HMI.

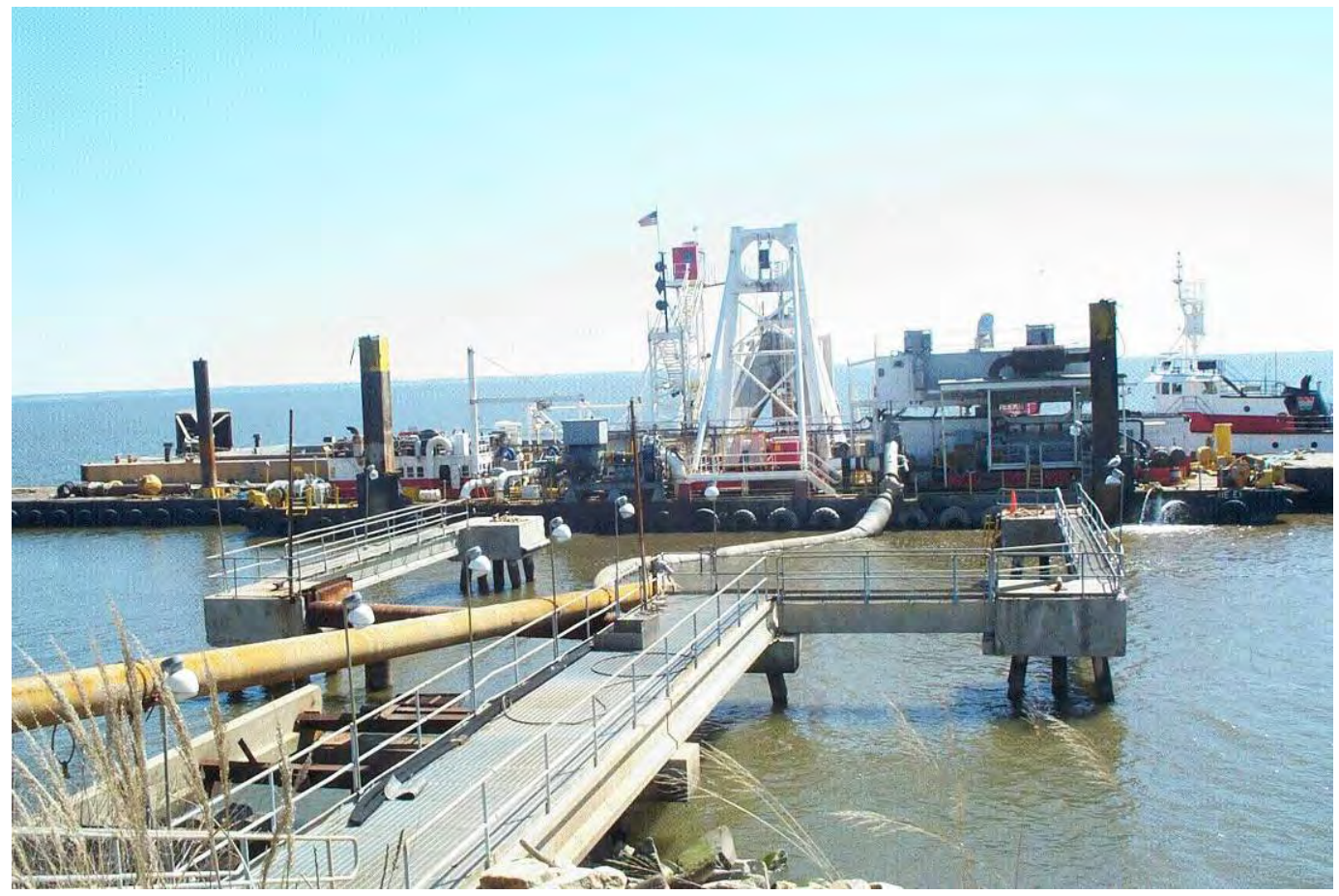

Figure 78. Hydraulically unloading dredged material at HMI. 


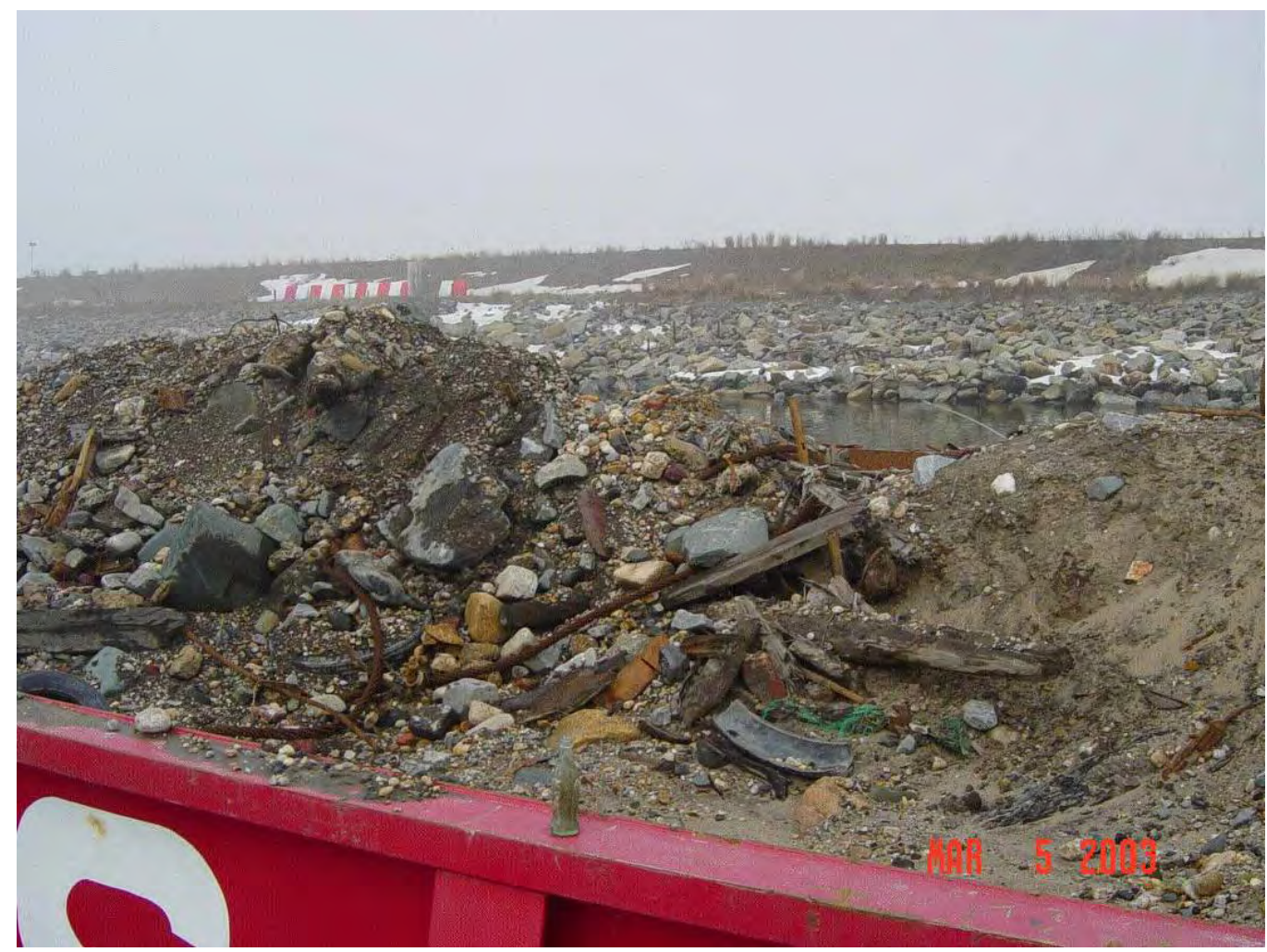

Figure 79. Accumulated dredging debris in a debris barge.

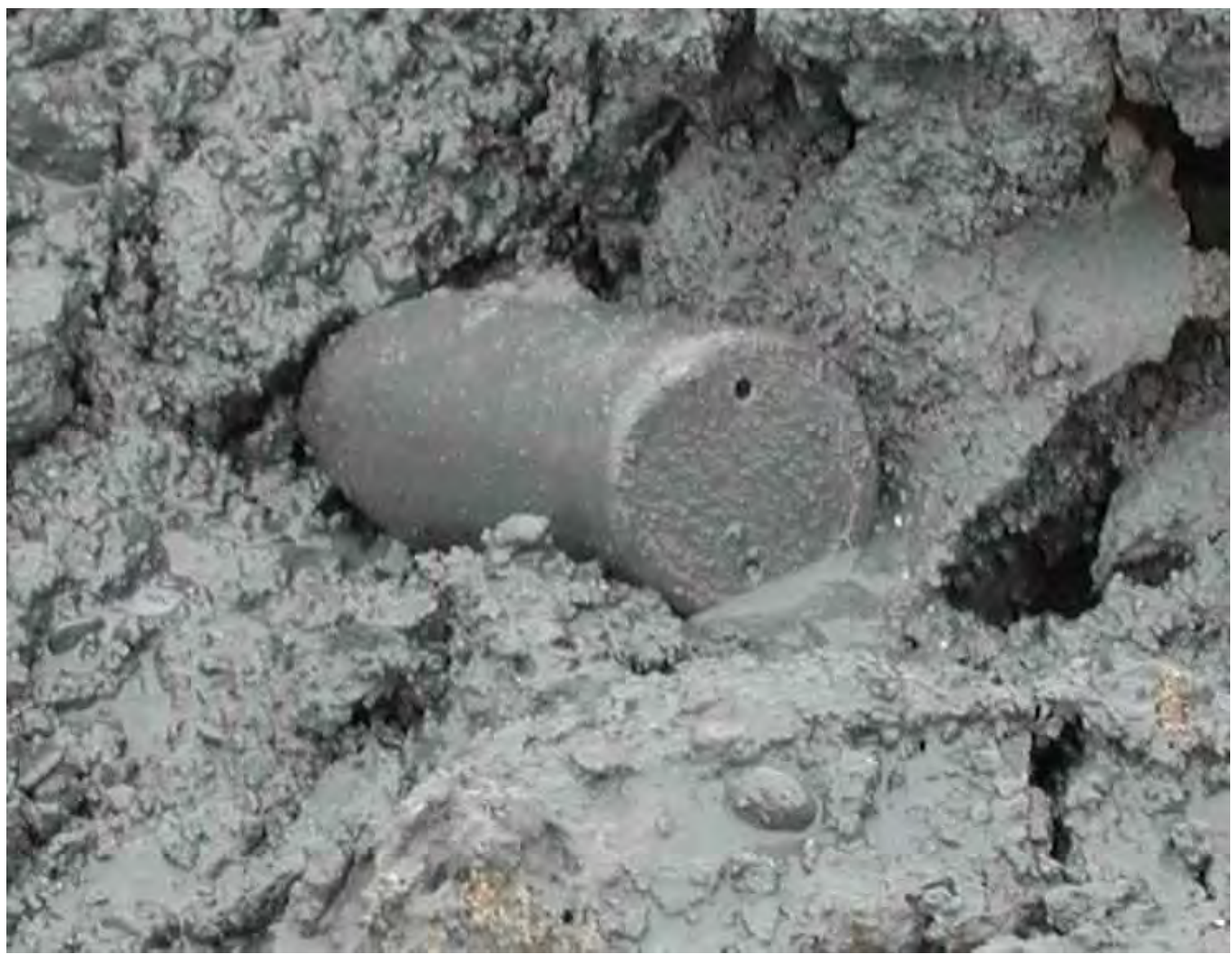

Figure 80. A 5 in. brass training round; first DMM discovered in Baltimore Harbor dredging project. 
From the types of DMM recovered, it was determined that the project was a low-risk site for encountering UXO, but that other DMM would be encountered (including possibly cannonballs) by the dredging operations. It was determined that DMM recovery work would be conducted at HMI with the mud and rocks going into the HMI containment area.

The MEC Contractor developed a Work Plan, Site Specific Health and Safety Plan (SSHP) and ESS, and coordinated activities with the contractors. A $460 \mathrm{~m}$ (1,500 ft) radius waterway restricted zone (Figure 81) was established at the barge/ debris unloading point that required extensive coordination with local fishermen.

The material/ debris sorting was conducted by the dredging and MEC contractors 11 August through 19 December 2003. This sorting was accomplished by unloading the debris from the barge bottom with a clamshell bucket and placing it on trucks for transportation to the screening site (Figure 82). MEC personnel monitored this unloading process (Figure 83), and numerous DMM were recovered at this stage (Figure 84). It was stockpiled there, then subsequently loaded by a front end loader onto a static screen (Figure 85). This screen consisted of woven wire with approximately $25.4 \mathrm{~mm}$ (1 in.) square apertures (Figure 86). Screen throughput was improved by a high pressure water jet system that facilitated gravity feed of undersized material (Figure 87). After DMM was recovered off the screen, remaining material was cleared by inclining the screen with a backhoe (Figure 88).

The dredging contractor was responsible for unloading (by clamshell), transporting, and stockpiling the material/ debris at the screening site. The dredging contractor was also responsible for developing the screening method to separate debris for DMM, and its operation and maintenance.

The MEC contractor was responsible for inspecting the stockpile for visible DMM, inspecting residue on the screen for DMM during and after washdown, placing DMM in the storage magazine, and for proper disposal of the DMM and related scrap. 


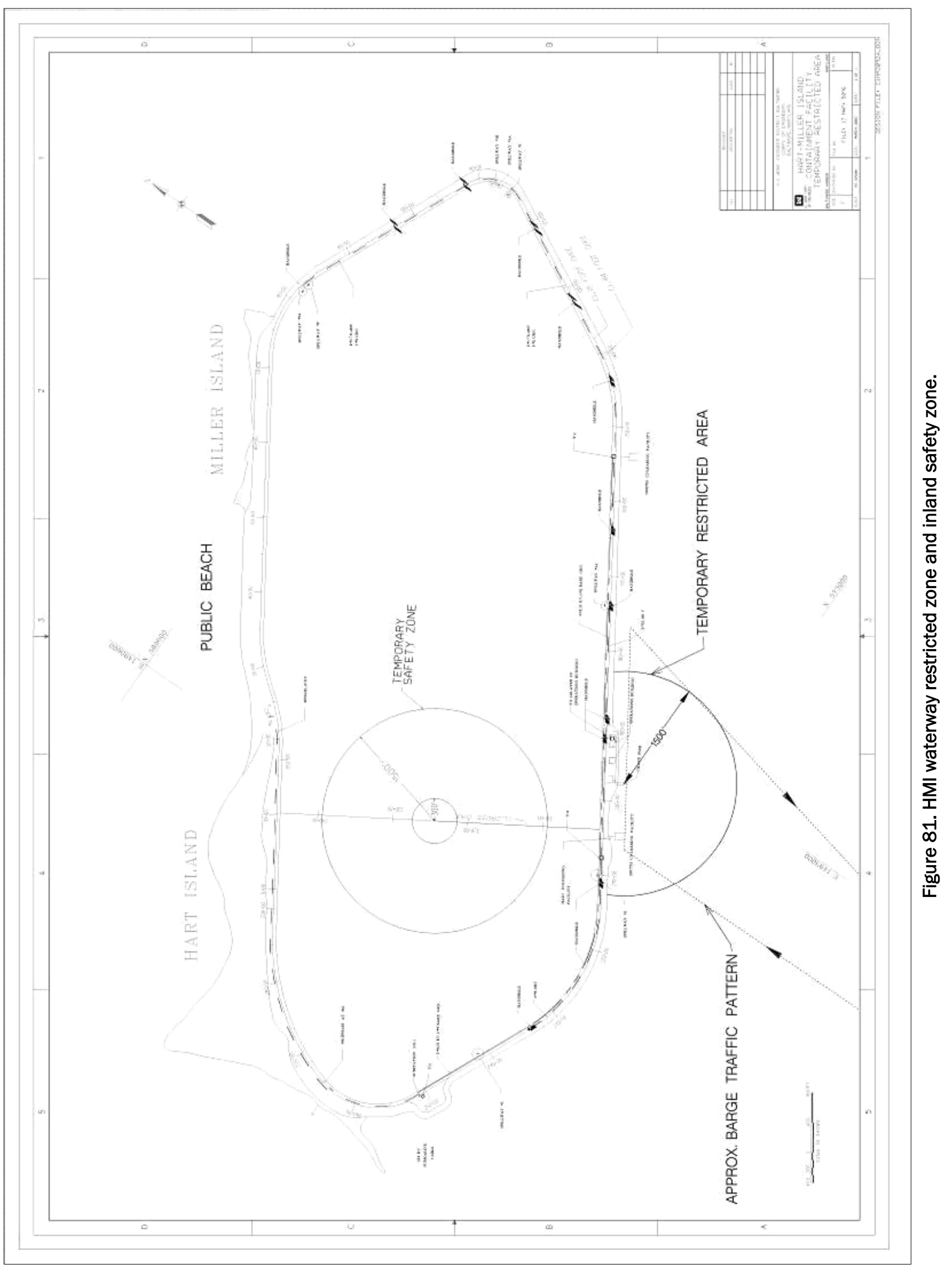




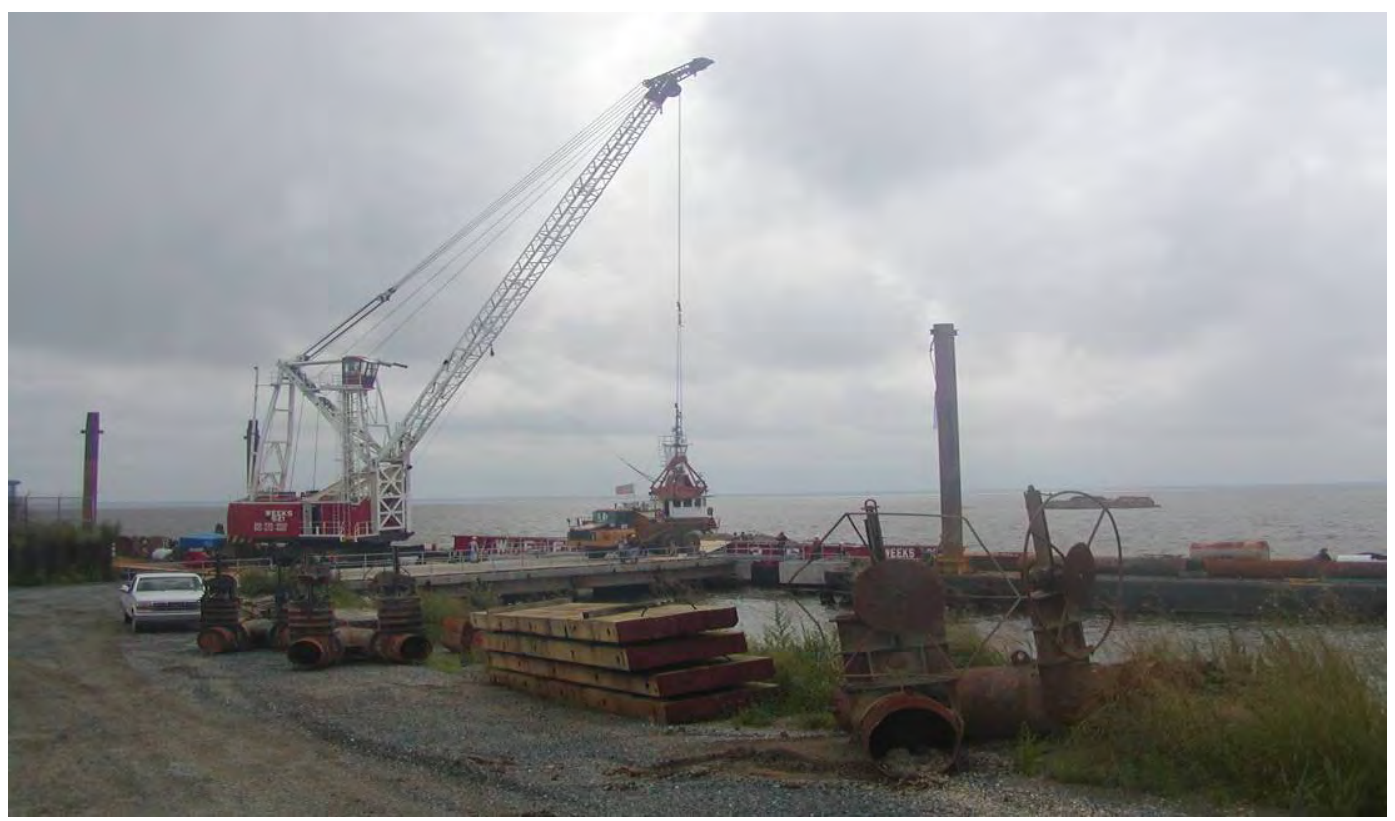

Figure 82. Unloading debris from barge bottom with clamshell bucket.

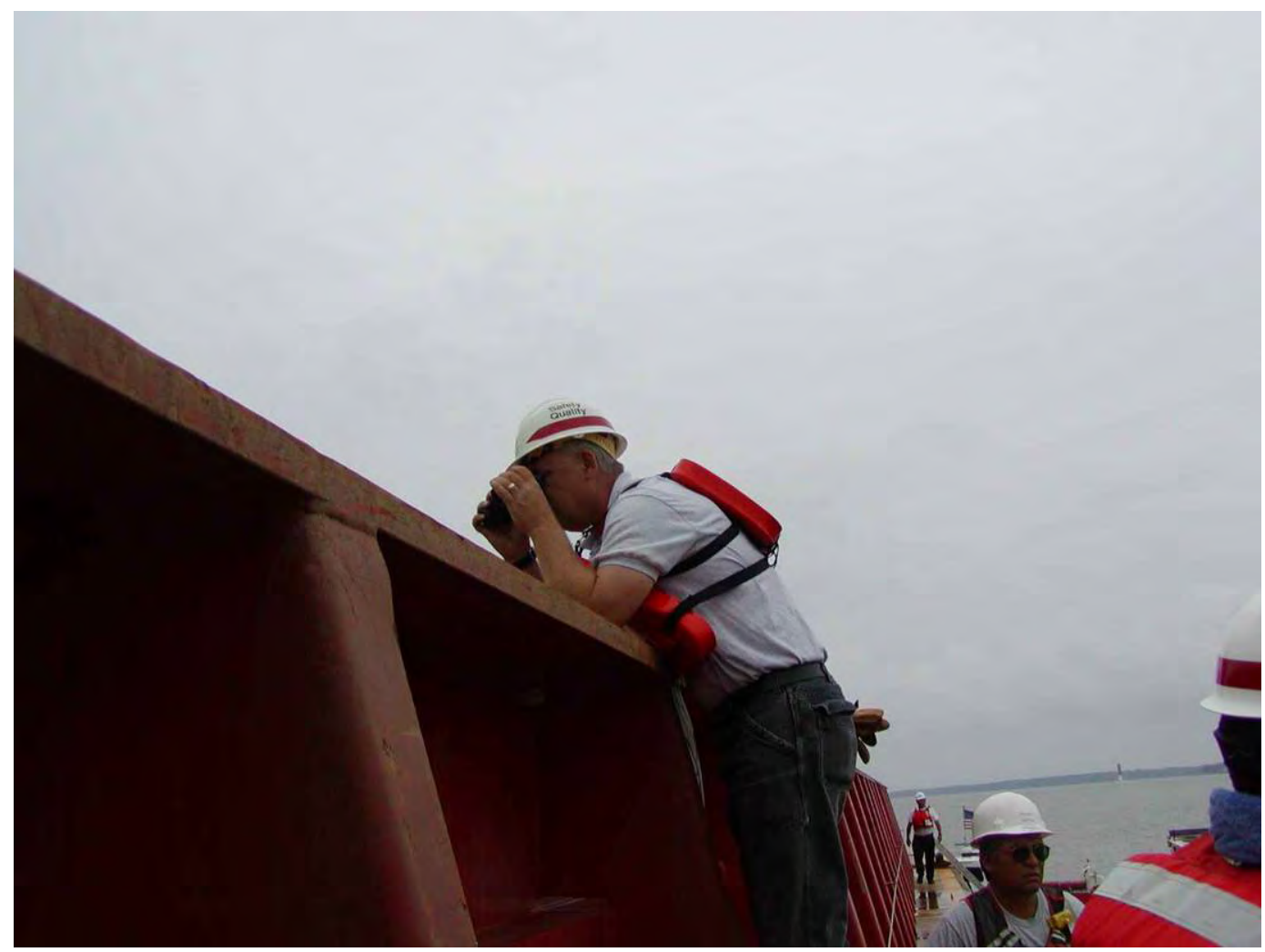

Figure 83. Inspecting debris in barge for DMM. 


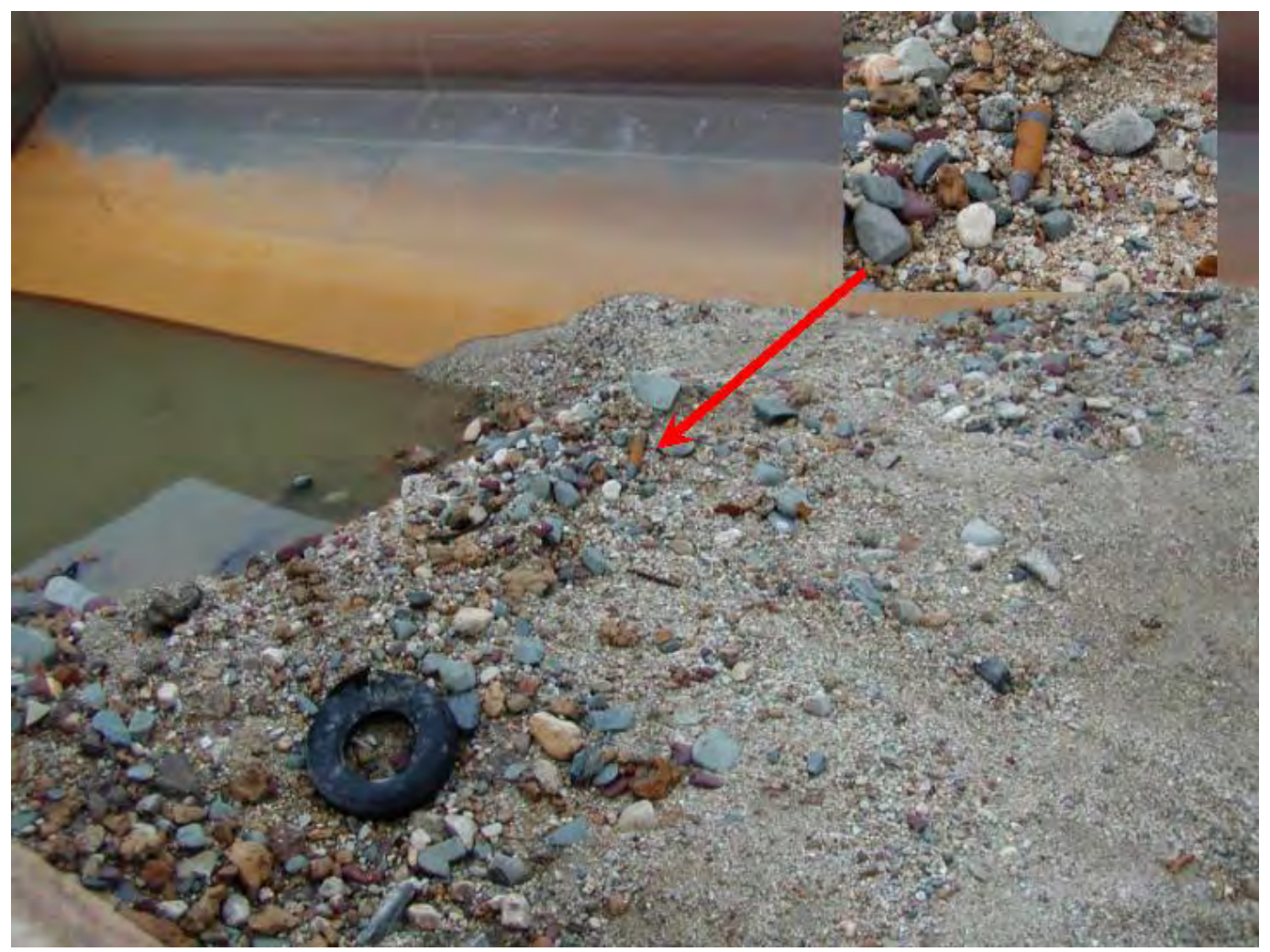

Figure 84. DMM identified and recovered from barge.

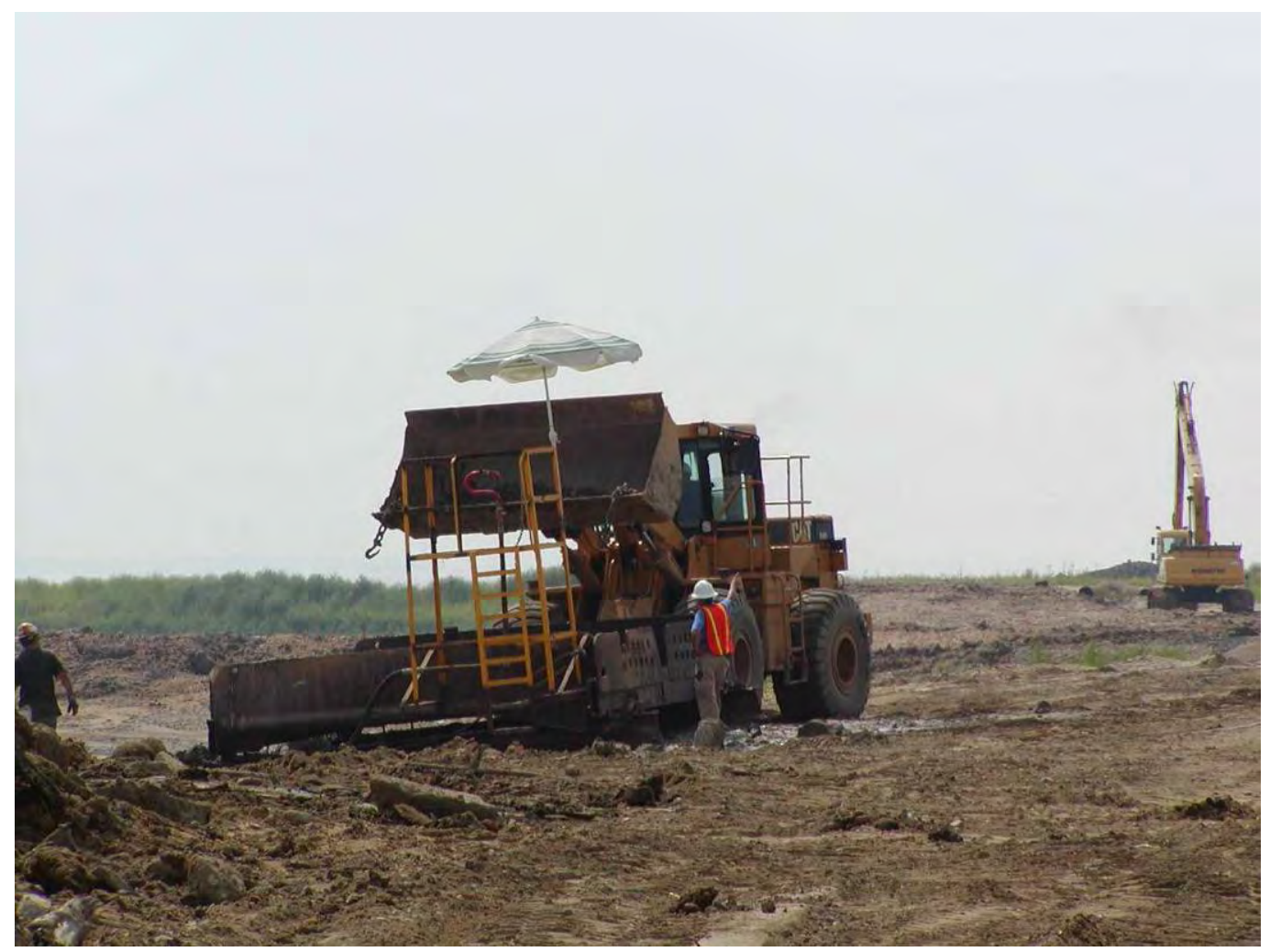

Figure 85. Front-end loader placing debris on HMI static separation screen. 


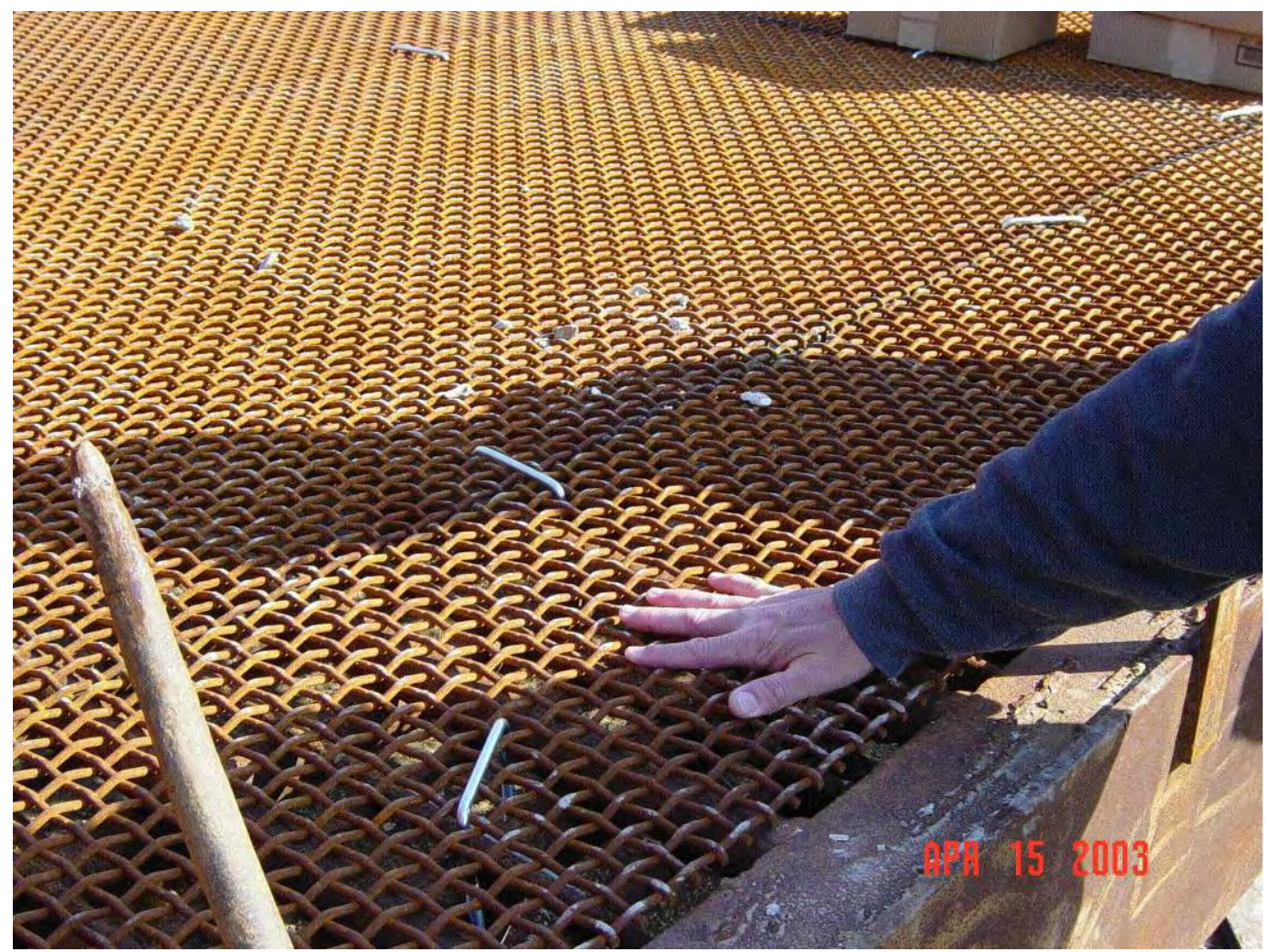

Figure 86. Static screen with approximately $25.4 \mathrm{~mm}(1 \mathrm{in}$.$) square apertures used at HMI.$

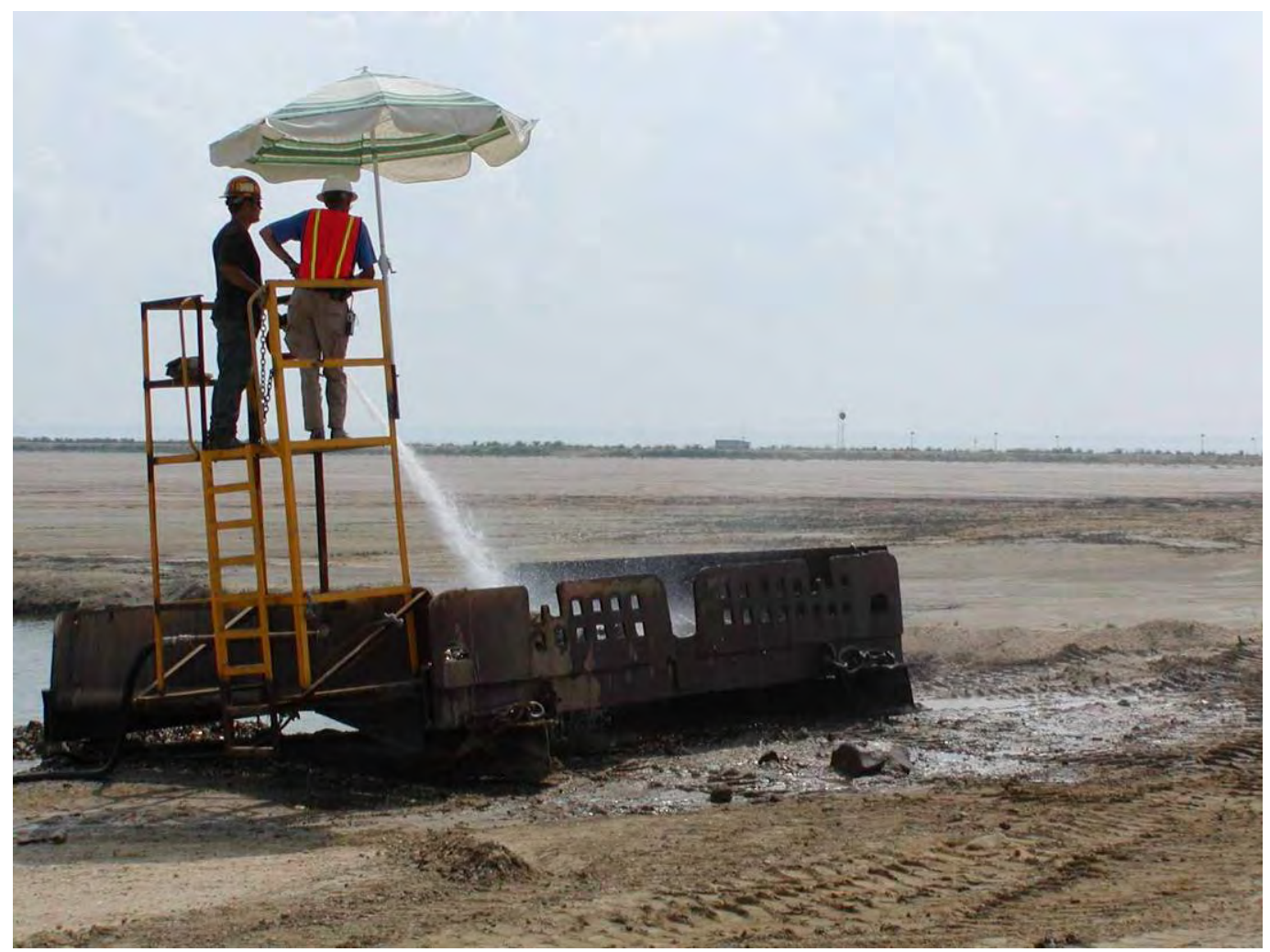

Figure 87. Application of water jet on HMl static screen. 


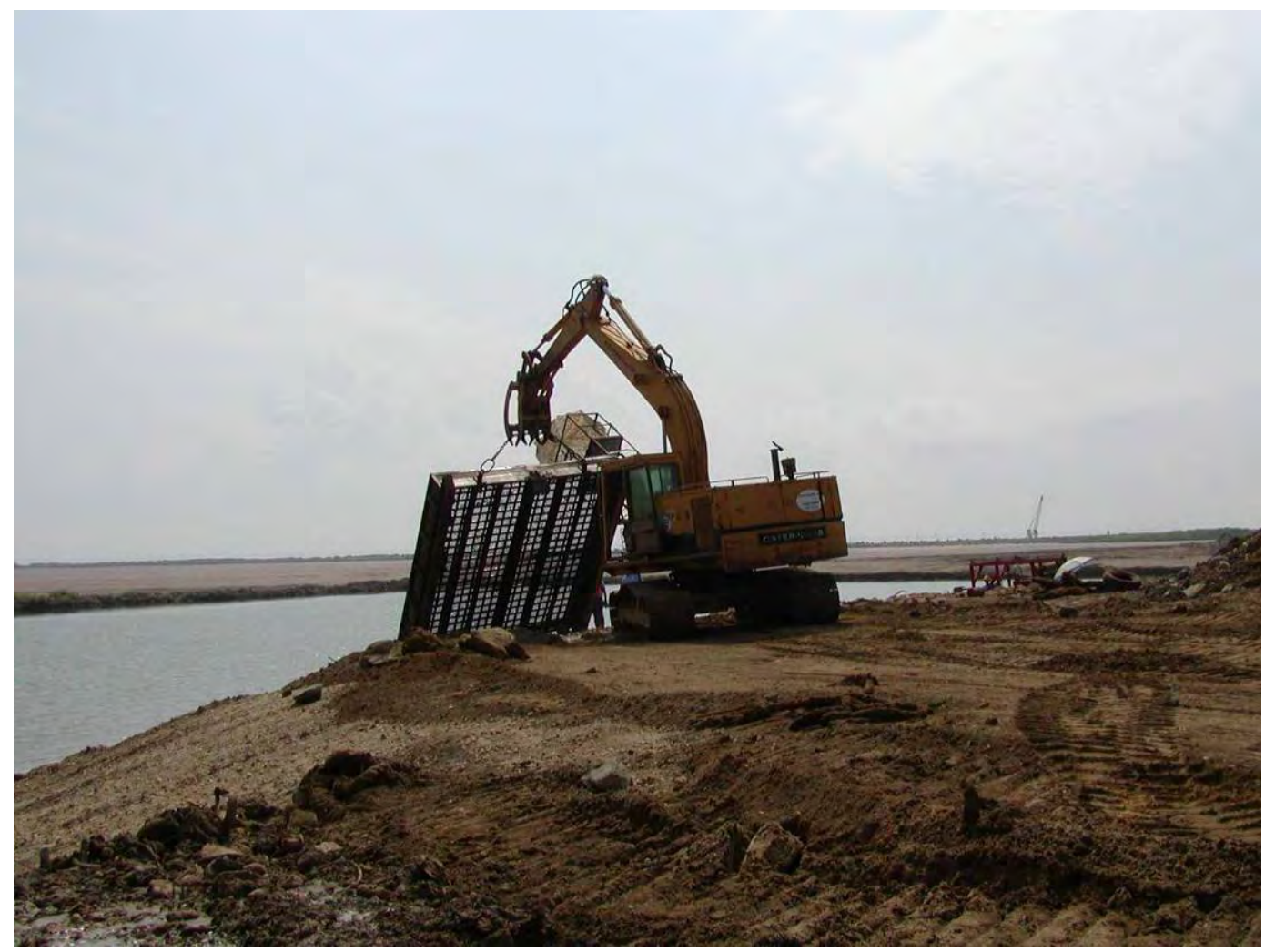

Figure 88. Clearing debris from HMI static screen.

The Baltimore District OE Safety Specialists provided support during the project. Daily MEC and Safety Meetings and Contractor Coordination Meetings were held; work was conducted 7 days a week, $10 \mathrm{hr}$ per day with the worker schedule being 4 days on, 2 days off. Security guards were posted at night to thwart souvenir hunters from trying to recover the historical artifacts, i.e., the cannonballs shown in Figure 89. These types of historical items also generated intense interest by the Maryland State Historical Preservation Office. These items were kept submerged to prevent spalling and 41 items underwent a preservation process. Six civil war era Schenkl rounds did not survive venting. Approximately 5,352 cu m (7,000 cu yd) of debris was screened at an approximate cost of $\$ 250 / \mathrm{cu} \mathrm{m}$ ( $\$ 198 /$ cu yd) to recover more than 1,300 ordnance items. The separation operations were completed in December 2003. 


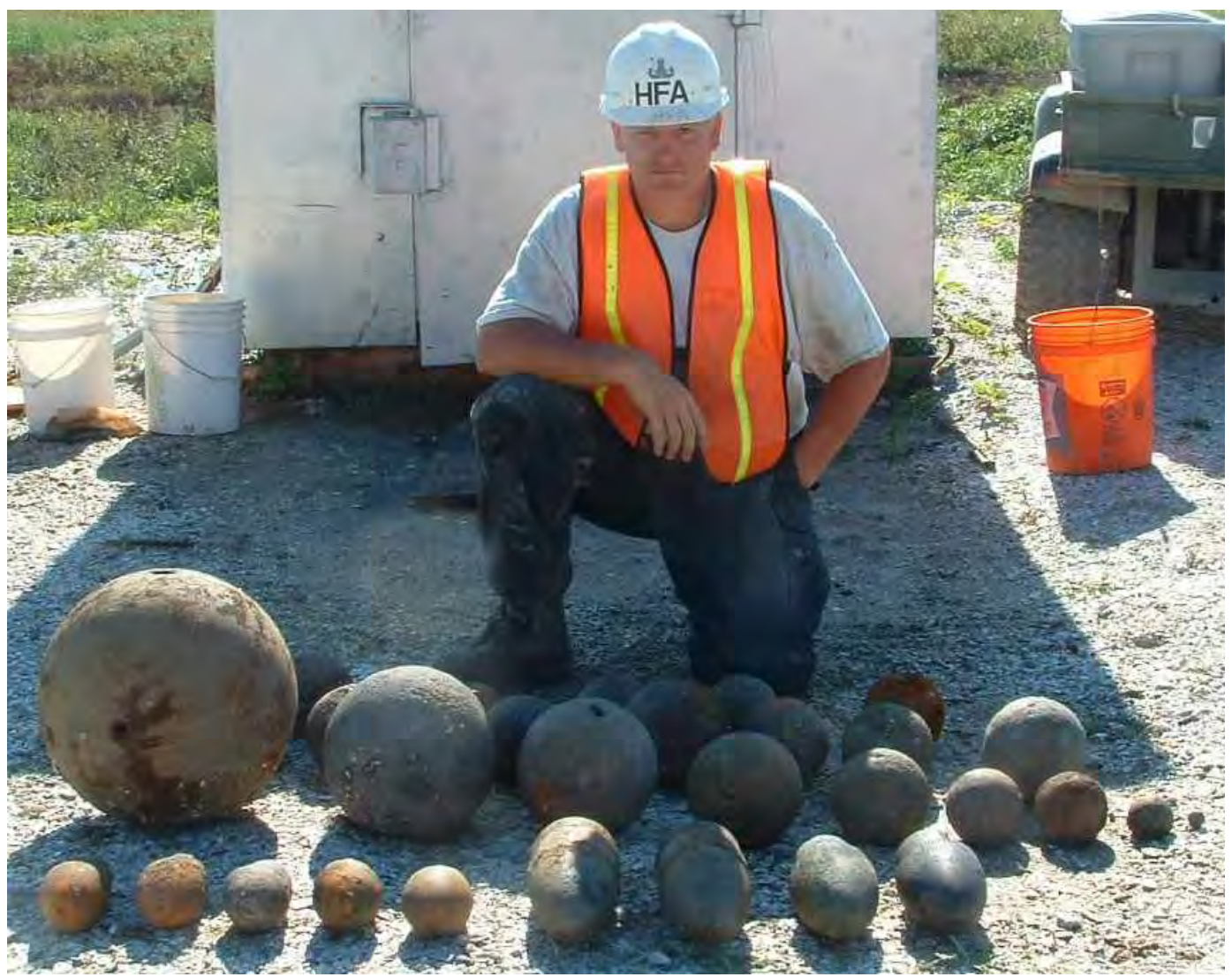

Figure 89. Several cannonballs recovered from debris at HMI.

\section{The Netherlands}

In The Netherlands, MEC investigations are conducted for projects being conducted in areas (i.e., canals) where there is reason to believe that MEC may be encountered. These investigations are conducted to determine the types of MEC that may be encountered, and design appropriate safety measures ${ }^{1}$.

A dredging technique used by The Netherland's dredging contractor Heuvelman Ibis BV, to separate MEC from dredged material involves the use of a conventional backhoe dredge. In this system, called the HeuvelmanUxoMixtureSeparator (HUXOS), a conventional backhoe is used with armor on the operator's cab and a transparent covering over the viewport. No closing buckets or other mechanical 'cutting' devices are used because it may trigger a detonation ${ }^{2}$.

\footnotetext{
1 Personal conversation, Ad van Riel, REASeuro Ltd.

2 Personal conversation, Erik Wildeman, Heuvelman Ibis BV, June 2005.
} 
This armored backhoe dredge excavates material from the water bottom and places it in a hopper modified to separate out MEC (Figures 90 and 91). If required, the backhoe can also place the dredged material onto conventional barges used to transport the load farther away from the excavation site to a screening site where the material is subsequently unloaded by another armored backhoe and placed into a separation hopper.

The separation process inside the hopper is illustrated in Figure 92. A waterjet is directed at the dredged material from behind a vertical screen. The screen opening size depends upon the type of MEC expected, but is normally $2 \mathrm{~cm} \times 5 \mathrm{~cm}$. The sediment is fluidized and, while the larger than aperture-sized material is retained in the same hopper side where the bucket load was placed (i.e., debris and MEC), the fluidized sediment flows through the screen and is drawn into a separate hydraulic circuit that transports the slurry to the placement area.

Figure 93 shows a picture of the fluidization jet being applied to the MEC contaminated sediment (note Aramide blankets on side walls). Examples of recovered MEC by this separation system are shown in Figure 94.

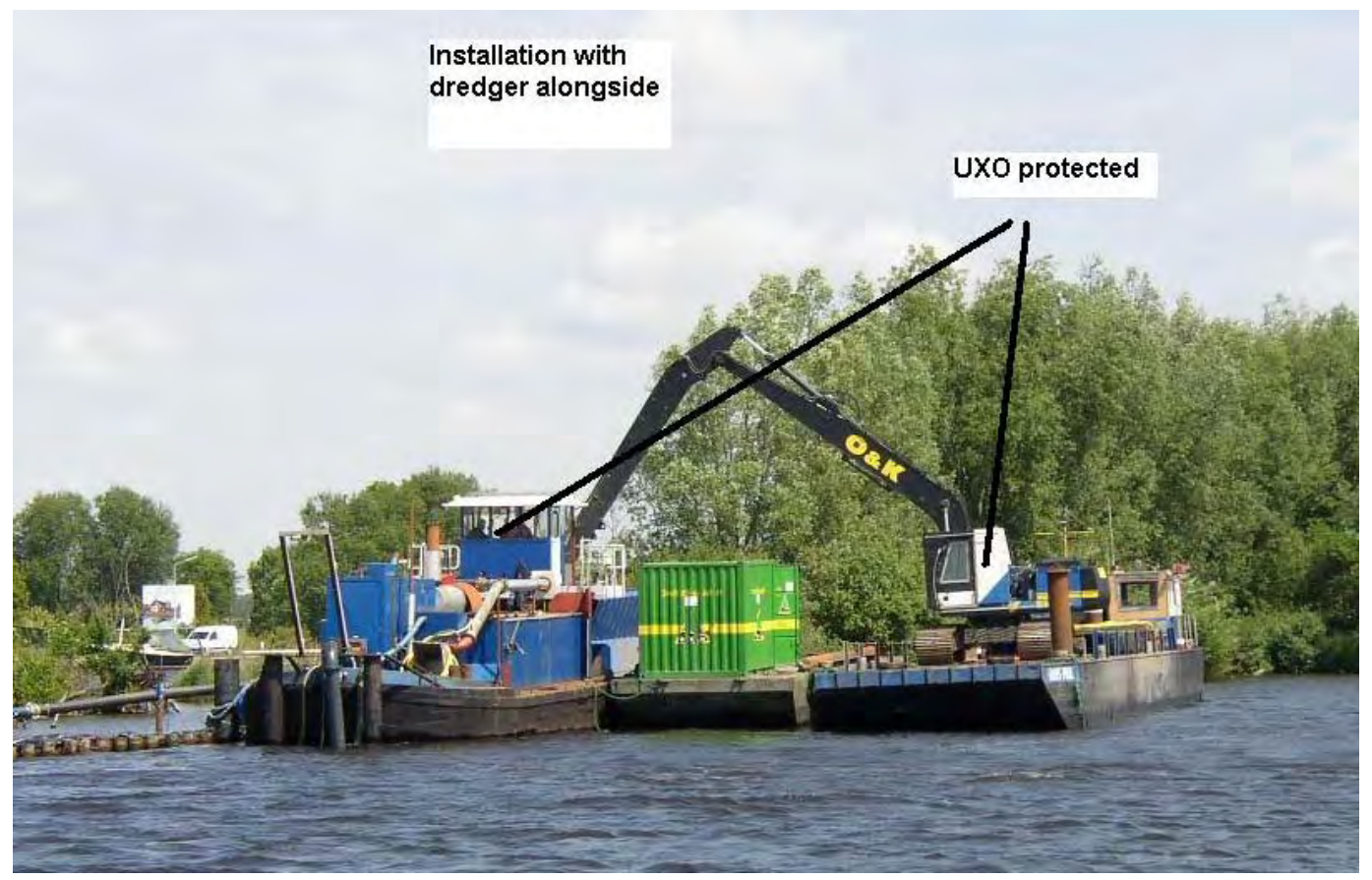

Figure 90. Armored backhoe dredge placing dredged material into separation hopper (courtesy of Heuvelman Ibis BV). 


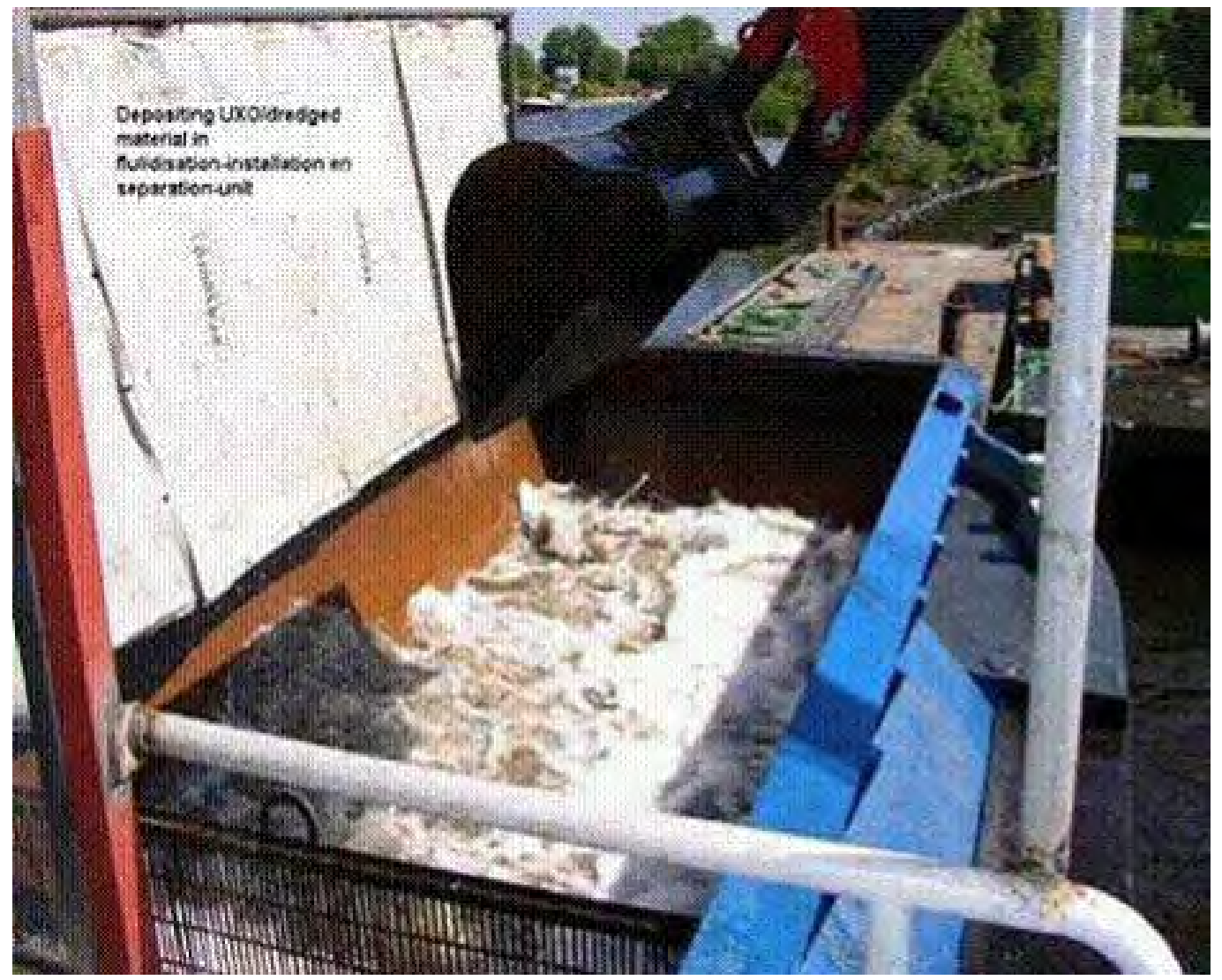

Figure 91. Closeup of bucket placing MEC-contaminated material into separation hopper (courtesy of Heuvelman Ibis BV).

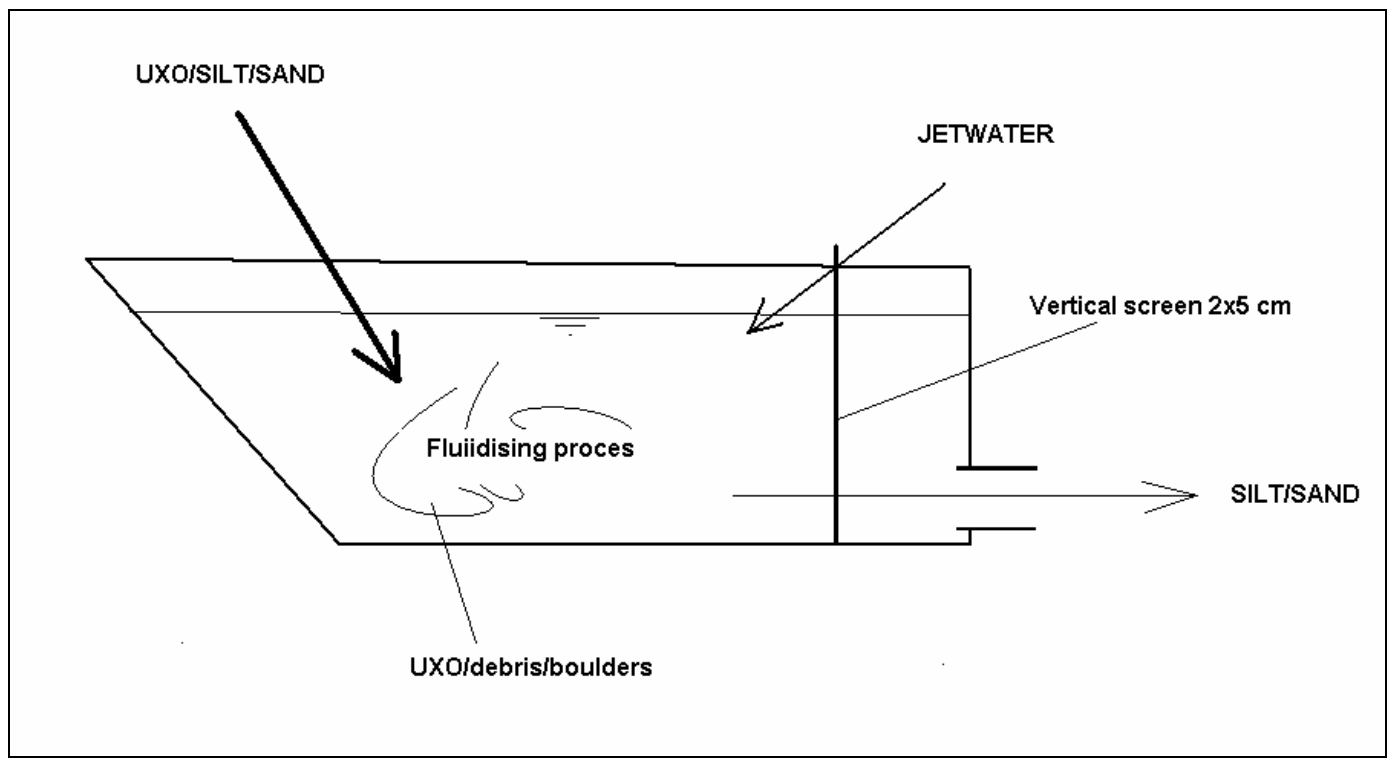

Figure 92. Illustration of HUXOS separation process (courtesy of Heuvelman Ibis BV). 


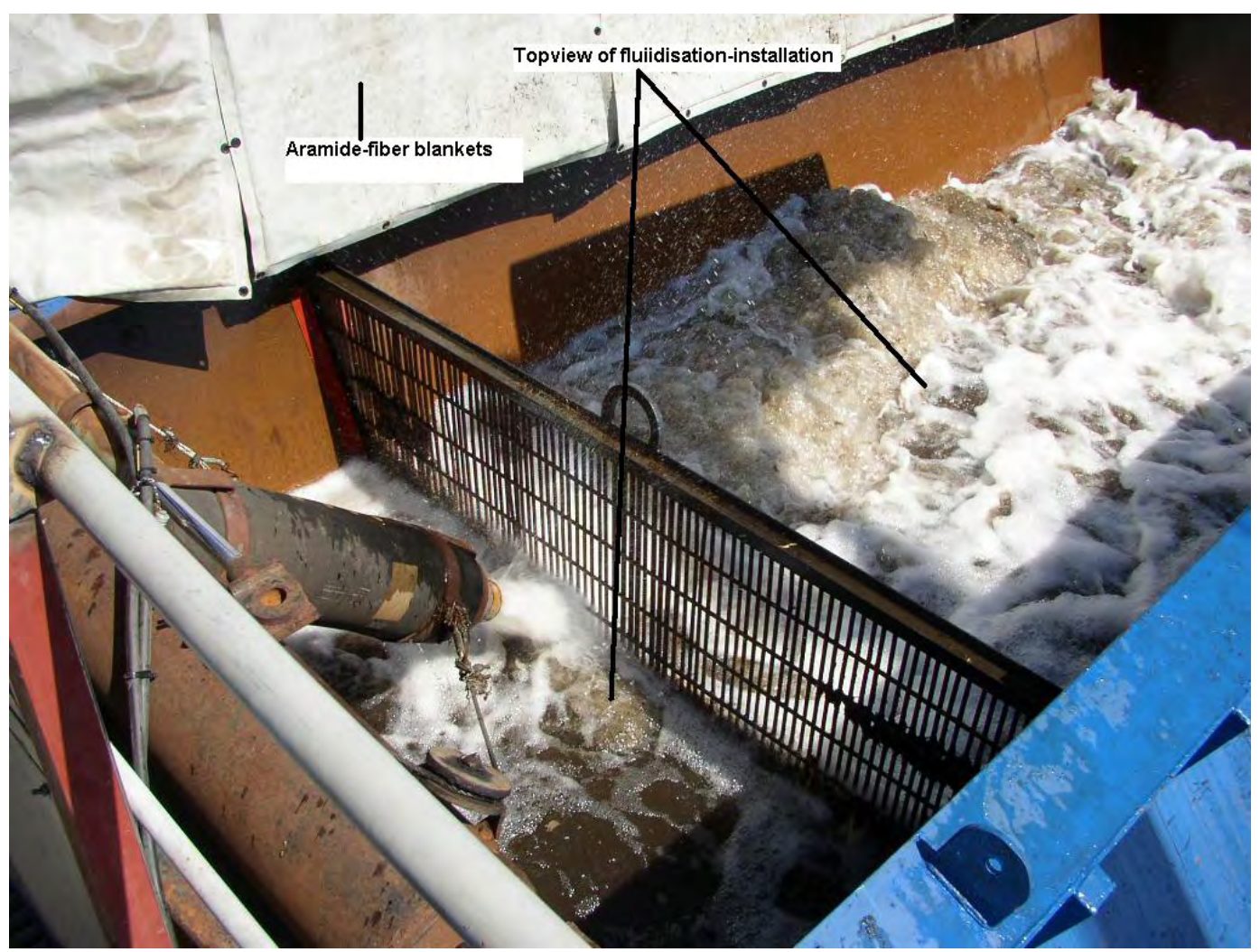

Figure 93. Waterjet applied to MEC-contaminated sediment (courtesy of Heuvelman Ibis BV).

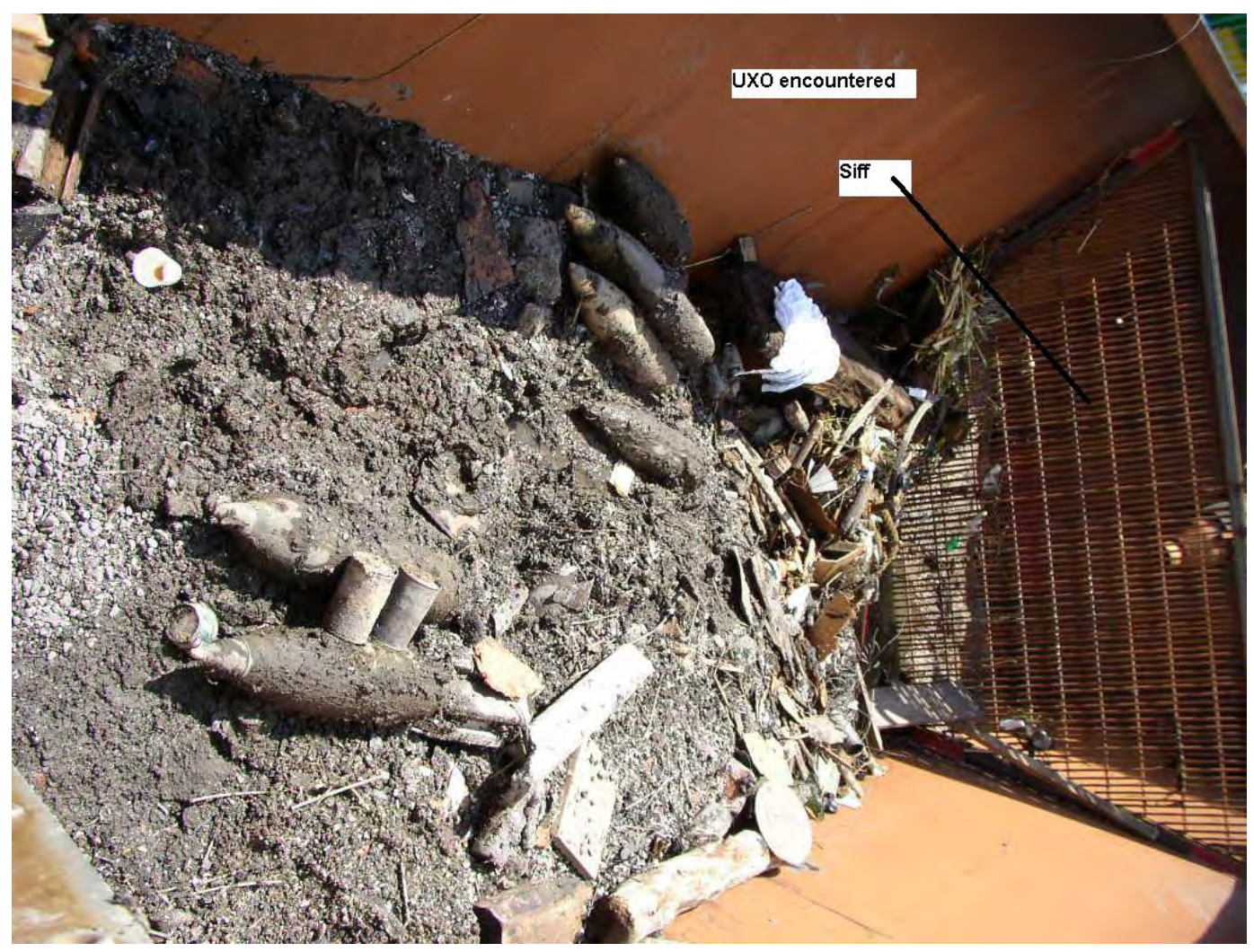

Figure 94. MEC separated from dredged material (courtesy of Heuvelman Ibis BV). 
Aramide blankets used as suppression barriers (shown in Figure 95) are also used to protect workers in the work zone. This system has been in use since 2000, and approximately 50,000 cu m (65,500 cu yd) of dredged material has been safety screened for MEC with an average throughput of $150 \mathrm{cu} \mathrm{m} / \mathrm{hr}(200 \mathrm{cu} \mathrm{yd} / \mathrm{hr})^{1}$.

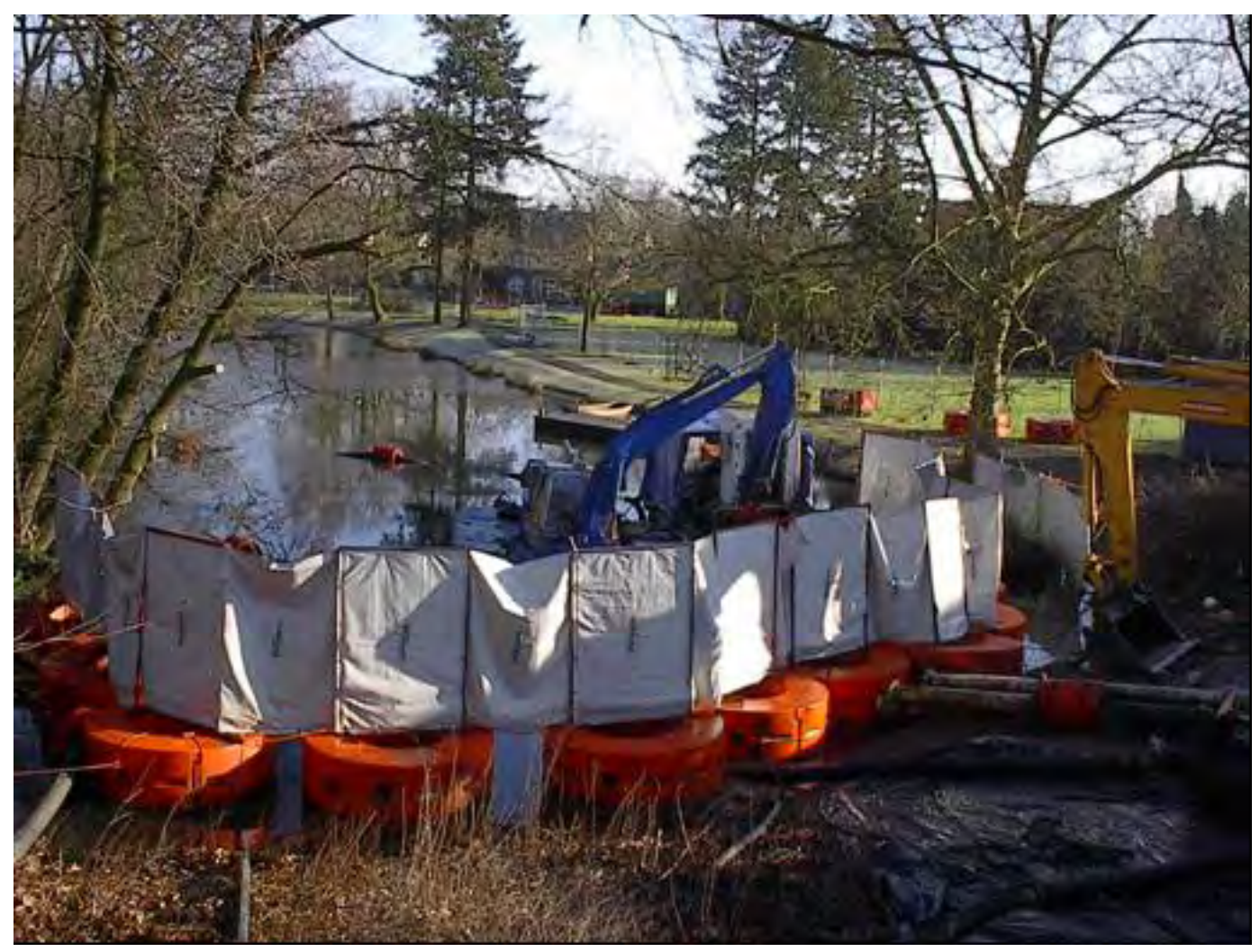

Figure 95. Suppression barriers in work zone (courtesy of Heuvelman Ibis BV).

\section{Toussaint River dredging project}

A significant portion of this project description is adapted from Welp et al. (1998a and 1998b). In 1991 the Buffalo District initiated a Civil Works dredging operation at the mouth of the Toussaint River approximately $60 \mathrm{~km}$ (37 mi) east of Toledo, $\mathrm{OH}$ (Figure 94). The new-works project consisted of establishing a $46 \mathrm{~m}$ ( $150 \mathrm{ft}$ ) wide federal navigation channel from the mouth of the Toussaint River out into Lake Erie, a reach of approximately $640 \mathrm{~m}(2,100 \mathrm{ft})$. The authorized channel depth was $1.2 \mathrm{~m}$ (3.8 ft) below low water datum. The contract involved a cutterhead dredge and was nearly complete (38,000 cu m out of $42,000 \mathrm{cu} \mathrm{m}[50,000 \mathrm{cu}$ yd out of 55,000 cu yd]) when a $106 \mathrm{~mm}$ artillery projectile was found

1 Personal conversation with Erik Wildeman, Heuvelman Ibis BV, June 2005. 
jammed in the cutterhead. The Buffalo District immediately halted dredging operations following this incident. The presence of the $106 \mathrm{~mm}$ round, which later turned out to be inert, can be explained by the fact that the Toussaint River is adjacent to the former Erie Army Depot, which was part of Camp Perry.

Camp Perry was established in 1907 by the state of Ohio for the training of the state's National Guard. In the spring of 1918, part of the camp was used to establish the Erie Army Depot. For almost a half century (19181965), this site was used by the U.S. Department of the Army for testing and proof-firing of artillery and as an ordnance storage and issue center (Rock Island District 1993). Several impact areas in Lake Erie were established by the Army Depot to test fire artillery barrels. The Army Depot was excessed by the General Services Administration in 1966 and closed in 1967. The heavy-caliber lake impact areas, which are currently used by the Army National Guard at Camp Perry, are significantly smaller in size than those documented as being active by Erie Army Depot in the earlier years. Ordnance pattern impact areas included surfaces classified as lake (39,000 ha [96,000 ac] of Lake Erie), wetland (133 ha [329.5 ac] including the beach) (Figure 96). Under the Defense Environmental Restoration Program (DERP), this prior U.S. Army installation and impact area, or FUDS, is subject to federal site cleanup action (Pope et al. 1996a).

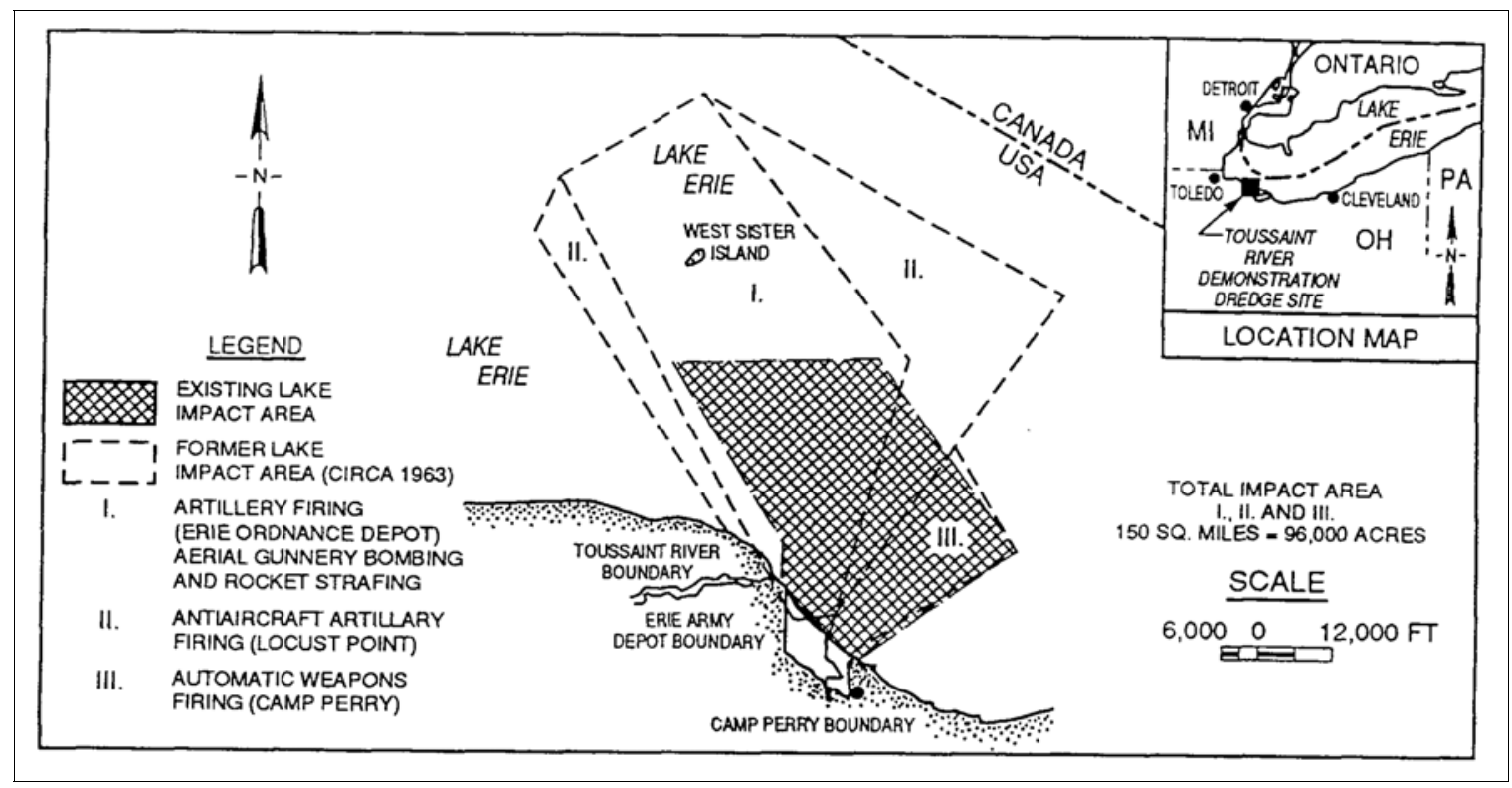

Figure 96. Location of Toussaint Dredging Demonstration and Erie Army Depot and Camp Perry lake impact zones. 
Between 1 September and 9 December 1992, Explosive Ordnance Disposal Technologies, under contract to the U.S. Army Engineer Division, Huntsville (hereafter Huntsville Division), removed or exploded in place all visible MEC as well as MEC within $0.3 \mathrm{~m}$ (1ft) of the Lake Erie beach surface from the still-water surface to $152 \mathrm{~m}$ (500 ft) inland. A total of 5,438 ordnance items, from small-caliber cartridges to large pieces such as $165 \mathrm{~mm}$ projectiles, were identified and removed. The largest populations of MEC were $20 \mathrm{~mm}$ (24 percent), $60 \mathrm{~mm}$ (23 percent), $106 \mathrm{~mm}$ (15 percent), and $105 \mathrm{~mm}$ (14 percent). Approximately 20 percent of the MEC was classified as UXO (Pope et al. 1996a).

During September 1993 the U.S. Army Engineer Waterways Experiment Station (with site assistance from the Huntsville Division, the Buffalo District, and several contractors) conducted a multi-instrumented geophysical and oceanographic field investigation to document site geological conditions and the influences of various coastal processes on ordnance distribution patterns. In particular, the concentrations of suspected ordnance lakeward of the FUDS beach, on the beach, and in the entrance channel of the Toussaint River were documented relative to geomorphic features, sediment type, and the geography of the Erie Army Depot. Ordnance concentrations and site geology were investigated by a variety of methods; land and underwater magnetometers, GPR, SSS, electromagnetics, a remotely operated vehicle, site narratives, and historical information. The results from this study indicate onshore and limited alongshore ordnance migration patterns (Pope et al. 1996a).

The Buffalo District, under the auspices of DERP-FUDS, conducted a demonstration dredging project in the Toussaint River (10 J uly through 26 October 1995) that was specifically designed to address the MEC threat. The purpose of this demonstration project was to evaluate the operational effectiveness of a clamshell bucket dredging process, modified with additional safety precautions and engineering controls, for dredging ordnancecontaminated channel sediment. An important design consideration was to safely recover MEC for proper disposal, as opposed to MEC exclusiontype designs that depend on keeping ordnance "on the bottom."

\section{Dredging system description}

The dredging methodology selected for the demonstration consisted of removing river bottom material with a modified clamshell bucket dredge and depositing it on separation screens placed over the hoppers of bottom 
dump scows. These screens were designed to pass sediment and retain MEC by a combination of gravity flow and water jet fluidization. As dredged material was dumped onto the screen surface, it was visually monitored by a UXO-qualified contractor (under contract with the Huntsville Division) through a remote-controlled camera system to detect MEC as the sediment "sifted" through. When a suspicious object was detected, dredging ceased and the item was positively identified. If determined to be an MEC, it was recovered, transported to shore, and disposed of by a UXO-qualified contractor. After the bottom-dump scow was filled, the sediment and debris remaining on the screen was cleared by a UXO-qualified contractor, and the dredged material was deposited in a nearshore disposal site.

Shoreline Contractors of Lakewood, $\mathrm{OH}$, was awarded the dredging contract, which was based on the maximum number of demonstration dredging hours that could be provided within the allocated $\$ 500,000$ cost constraint. The hourly cost rate included all costs associated with anticipated weather delays, equipment repair, passage of public boaters, transport and disposal of dredged material, and all other items necessary to meet the contract specifications. A $24 \mathrm{~m}$ (80 ft) boomed Bucyrus Erie 61-B tracked crane with a $2.3 \mathrm{cu} \mathrm{m}$ ( $3 \mathrm{cu}$ yd) toothed-clamshell bucket was used for excavating, with an additional $2.3 \mathrm{cu} \mathrm{m}$ ( $3 \mathrm{cu}$ yd) bucket held in reserve in case the first bucket was damaged by UXO detonation. This crane was driven onto the spud barge (Shoreline 785) and temporarily secured. The Shoreline 785, a $24 \mathrm{~m} \times 12 \mathrm{~m} \times 2 \mathrm{~m}(78.5 \mathrm{ft} \times 40 \mathrm{ft} \times 7 \mathrm{ft})$ steel-hulled barge with a hydraulically driven spud system, was specifically designed and built (launched 2 J une 1995) for the project.

Engineering controls to counter health hazards due to potential MEC detonation consisted of enclosing the crane operator's booth with a $6.4 \mathrm{~mm}(0.25 \mathrm{in}$.) thick steel plate protection barrier with a viewport consisting of $64 \mathrm{~mm}$ ( $2.5 \mathrm{in}$.) thick polycarbonate laminate. This viewport provided the equivalent resistance of $6.4 \mathrm{~mm}$ ( $0.25 \mathrm{in}$.) thick mild steel plate (Figure 97). The $24 \mathrm{~m}$ ( $80 \mathrm{ft}$ ) crane was required because it allowed a minimum separation distance of $16 \mathrm{~m}$ ( $52 \mathrm{ft}$ ) between the operator and the clamshell bucket (also a protective barrier). The Huntsville Division designed the appropriate safeguards, including the protective barrier and separation distance based on a $106 \mathrm{~mm}$ antitank round, the maximumsized MEC perceived as a threat. 


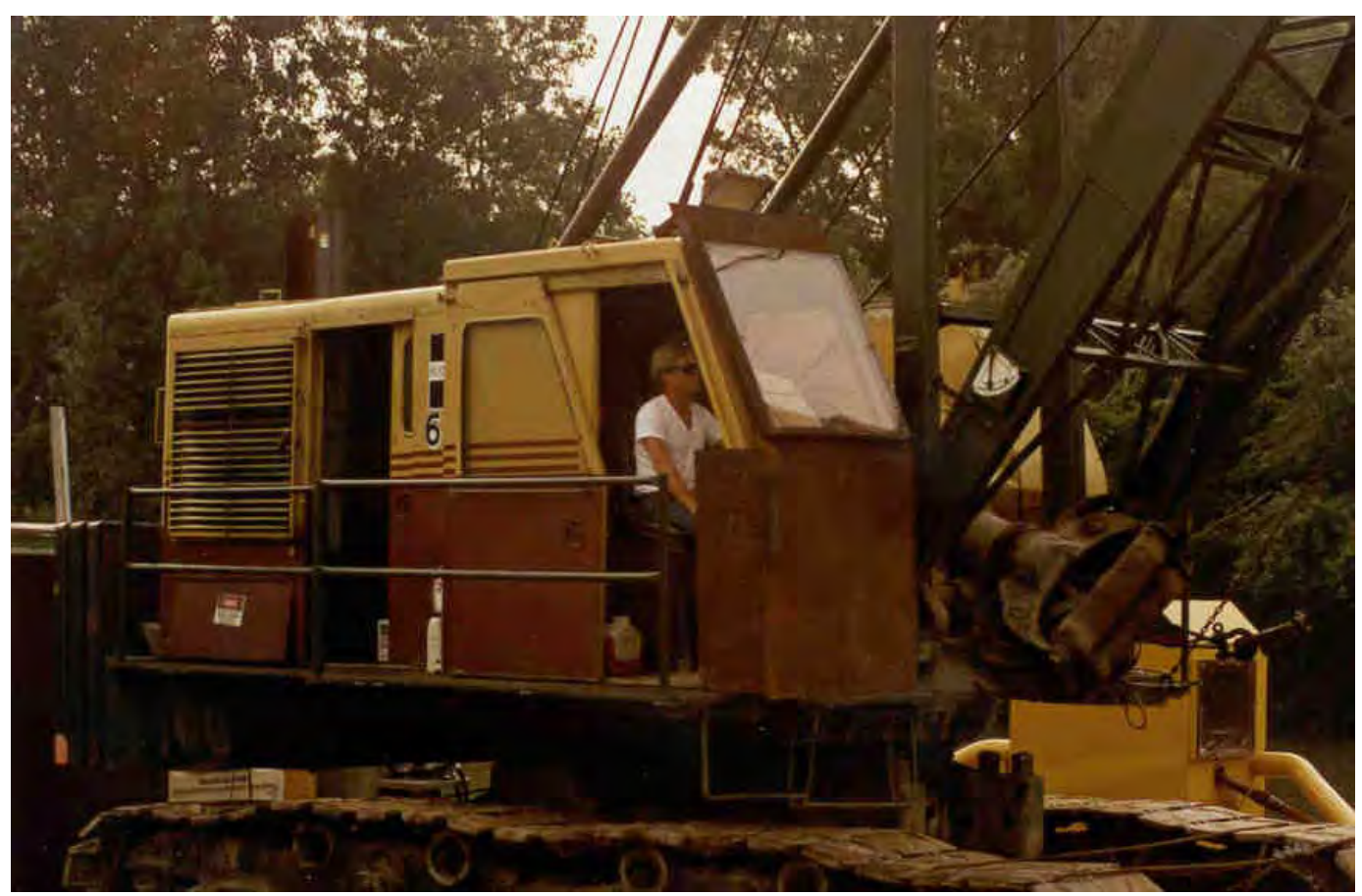

Figure 97. Crane operators protective barrier.

The clamshell excavated medium-sized sand (average $D_{50}$ of $1.2 \mathrm{~mm}$ ) from the navigation channel and dumped onto the scow secured "alongside" as shown in Figure 98. The project used two $65 \mathrm{cu} \mathrm{m}$ (85 cu yd) capacity bottom-dump scows $14 \mathrm{~m} \times 6 \mathrm{~m} \times 2 \mathrm{~m}(45 \mathrm{ft} \times 20 \times$ by $6 \mathrm{ft})$ to transport dredged material to the disposal site. These scows were pushed with the work boat Falcon, an $11 \mathrm{~m} \times 4 \mathrm{~m} \times 0.8 \mathrm{~m}(36 \mathrm{ft} \times 12 \mathrm{ft} \times 2-1 / 2 \mathrm{ft})$ motor vessel equipped with pusher knees and propelled by a $350 \mathrm{hp}$ diesel engine. The shallow drafts of the Shoreline 785, Falcon, and both scows allowed dredging to be conducted in water depths as shallow as $1.2 \mathrm{~m}$ (4 ft).

The separation screen was mounted over each scow on an I-beam support structure welded to the deck and inclined approximately 10 deg from the horizontal plane (Figure 99). In the event of a detonation, the screens were designed and constructed to allow damaged sections to be replaced or repaired. Each screen's $25 \mathrm{sq}$ m ( $272 \mathrm{sq} \mathrm{ft}$ ) total surface area was divided into two equal sections, $5 \mathrm{~m} \times 2.6 \mathrm{~m}(16 \mathrm{ft} \times 8-1 / 2 \mathrm{ft})$ each, that were removable to facilitate repair of detonation-induced damage and also to clean debris by lifting one side with the crane. The contract specifications required that the maximum screen opening dimensions be $19 \mathrm{~mm}$ (0.75 in.) in one direction and $127 \mathrm{~mm}$ (5 in.) in the other direction. 

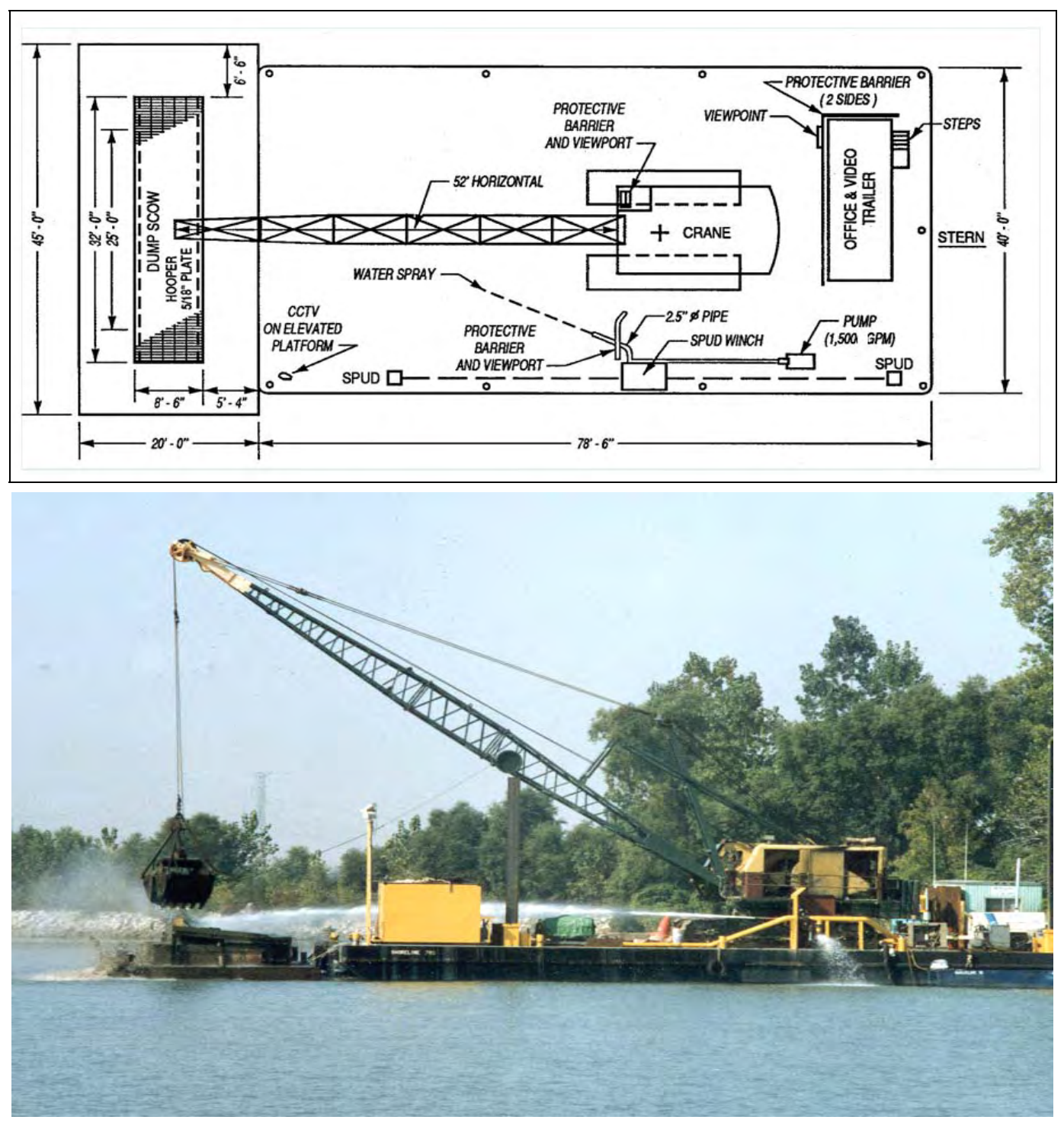

Figure 98. Deck layout and MEC dredging system (courtesy of Shoreline Contractors, Inc.).

These dimensions were based upon the design objective of retaining 20 $\mathrm{mm}$ projectiles. The screens used by the contractor initially consisted of coal-tar epoxy-coated bar grating with $19 \mathrm{~mm} \times 114 \mathrm{~mm}(0.75 \mathrm{in} . \times 4.5 \mathrm{in}$.) openings that were $19 \mathrm{~mm}$ (0.75 in.) deep, but these dimensions were later modified as the project progressed (these changes are discussed later in the paper). Contract specifications required that the screen be constructed such that the maximum allowable opening dimensions were not to be exceeded even when it (the screen) was fully loaded with a design load of $4.6 \mathrm{cu} \mathrm{m}$ ( 6 cu yd) of dredged material (approximately 8 tonnes [9 short tons]). 


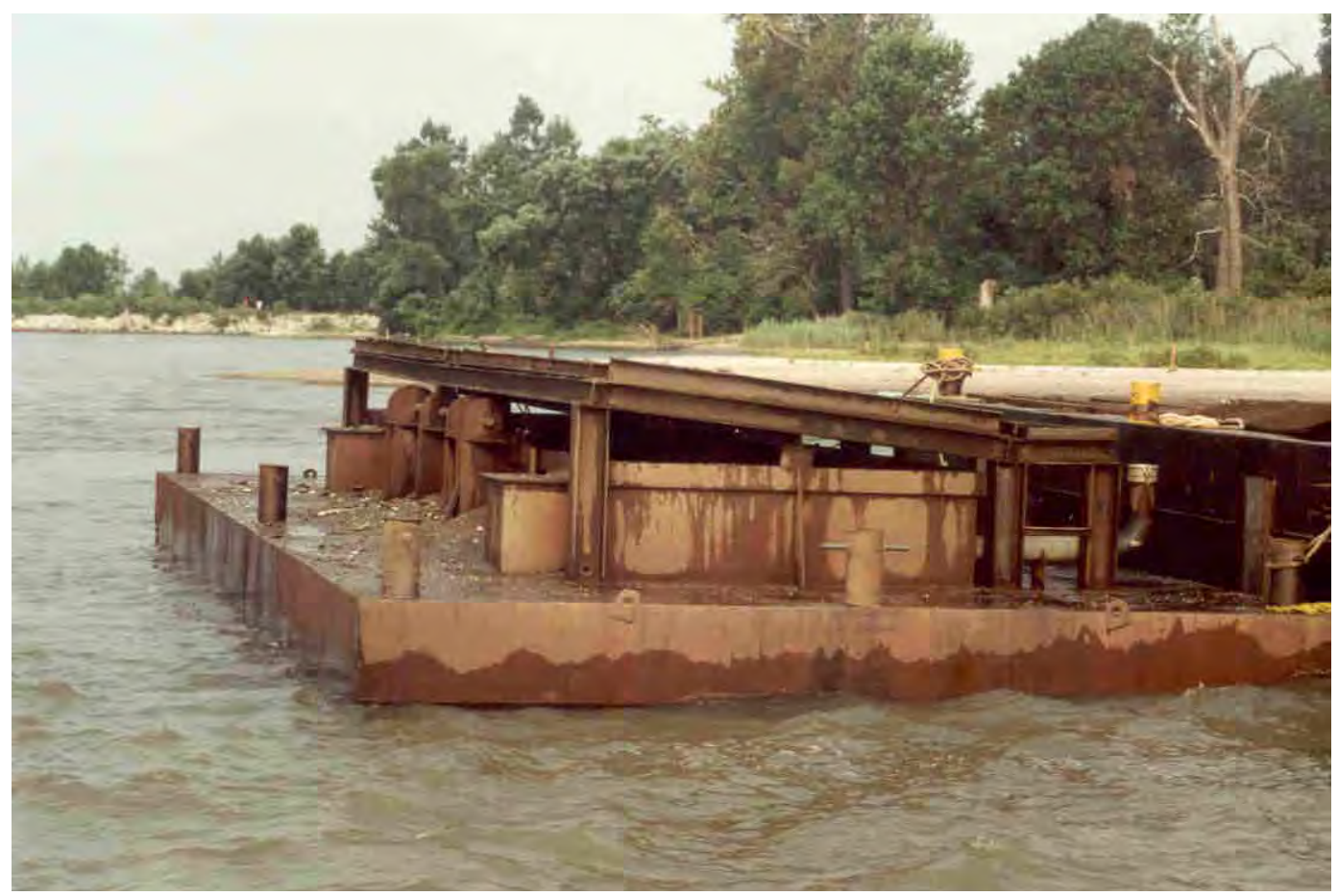

Figure 99. Scow and separation screen.

As the clamshell operator dumped dredged material onto the screen, a jet of water was manually directed into the dredged material from the water cannon station. This water jet facilitated screen throughput by fluidizing sediment and disintegrating the more cohesive clumps. The spraying system used a 100-mm (4-in.) (discharge) fire pump rated for $95 \mathrm{~L} / \mathrm{sec}$ $(1,500 \mathrm{gpm})$ at 24 bars (350 psi). This pump's discharge was coupled to a 152-mm (6-in.) expansion pipe system with three-valve flow control that regulated flow to the water cannon, excess overboard discharge, and the scow's internal spray system (Figure 100).

The water cannon control valve regulated flow through a $64 \mathrm{~mm}$ ( $2.5 \mathrm{in}$.) flexible hose that was connected to a fire-fighting nozzle with a $64 \mathrm{~mm}$ to $25 \mathrm{~mm}$ ( $2.5 \mathrm{in}$. to $1 \mathrm{in}$.) diameter reducer configuration (Figure 101). The water cannon operator was protected from potential MEC detonation by a protective barrier with the same construction materials and thicknesses as the crane operator's enclosure previously described. The nozzle was set in a gimbaled mount located immediately below the viewing port and provided with a $6.4 \mathrm{~mm}$ ( $0.25 \mathrm{in}$.) thick steel rectangular protective barrier to cover the gimbal opening (Figure 101). This mount, comprised of two concentric swivels, provided the water cannon operator with two degrees of freedom to direct the water jet to any location on the entire screen surface. 


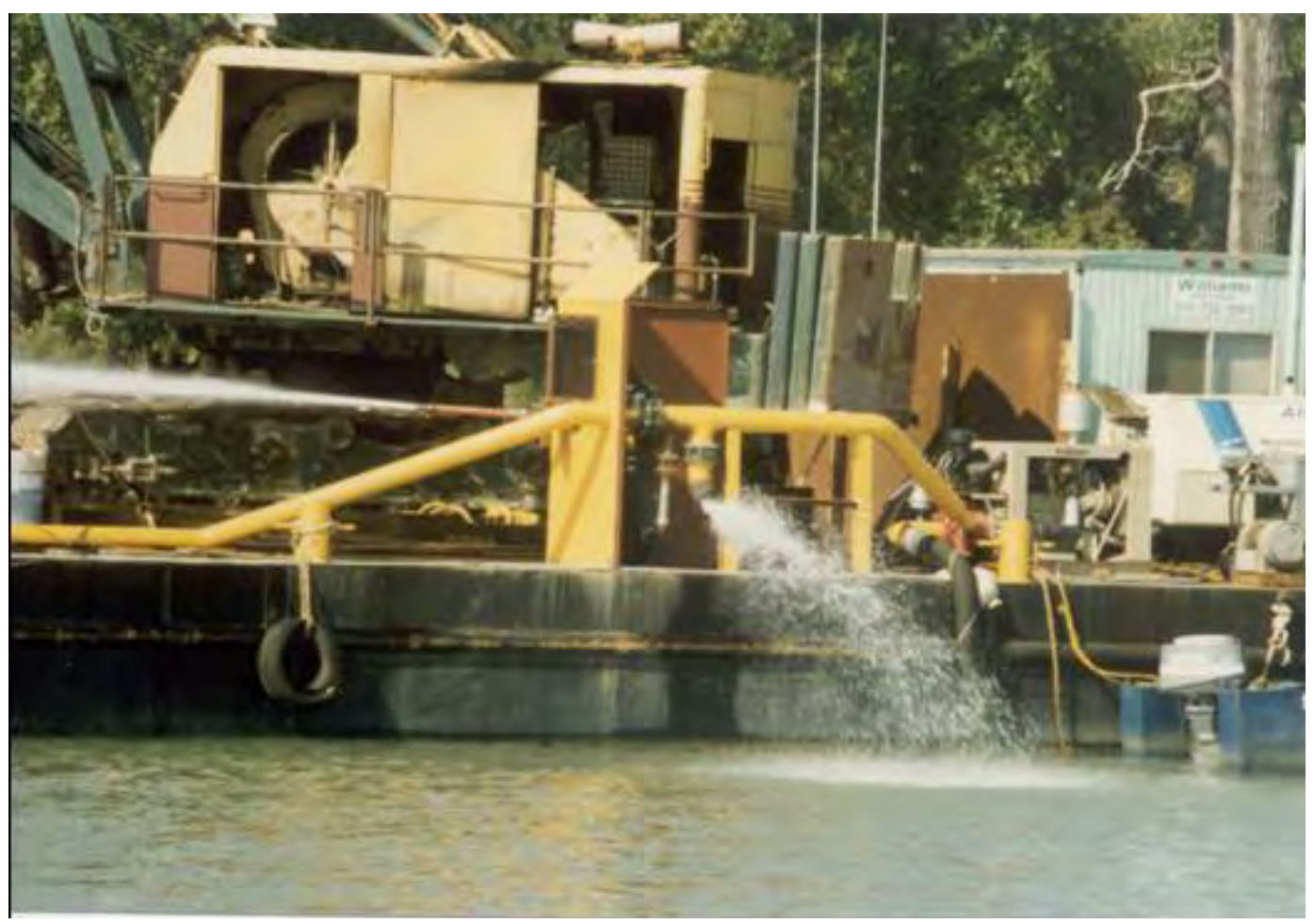

Figure 100. Fluidization valve-control system.

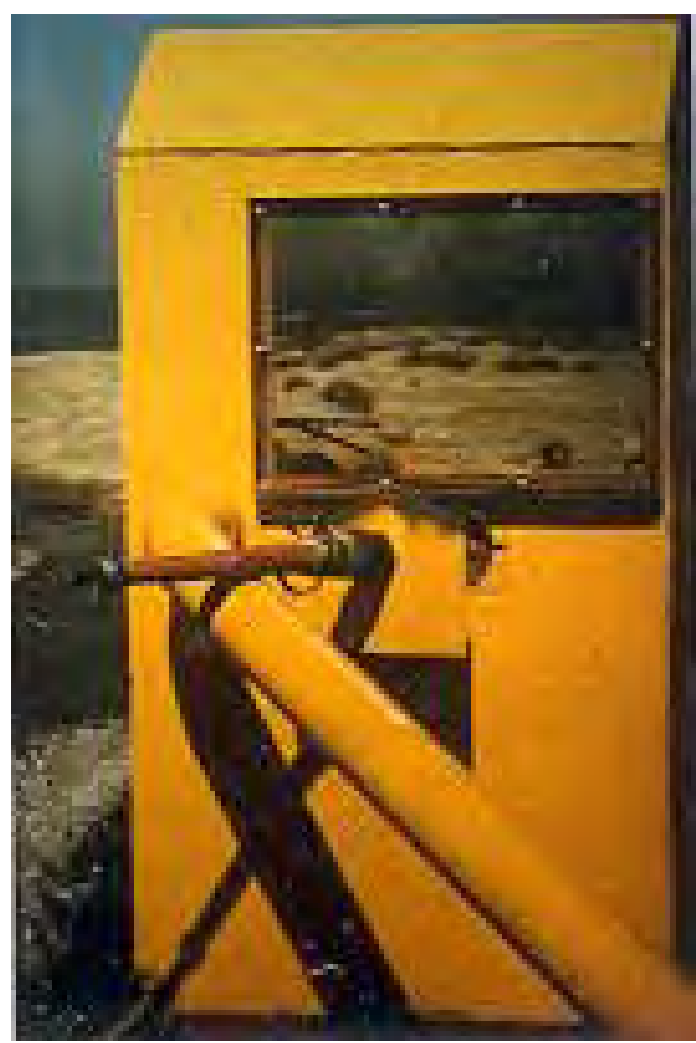

Figure 101. Water cannon operator's station. 
A scow's internal spray system consisted of a perforated-pipe manifold that was mounted on the interior port and starboard sides of the hopper immediately below the separation screen. A $152 \mathrm{~mm}$ (6 in.) water supply pipe ran from the water cannon station and terminated with a section of flexible hose equipped with a quick-disconnect coupling. The flexible hose would be connected to the scow's internal manifold pipe when the scow was brought alongside. The internal manifold consisted of a $100 \mathrm{~mm}$ (4 in.) pipe with $6.4 \mathrm{~mm}$ (0.25 in.) diameter holes [10 holes per meter (3 holes per feet)] oriented such that, when water was pumped to the circuit, water jets were applied in a regularly spaced pattern to the underside of the screen. This system was designed to improve throughput by applying additional fluidization forces to the underside of dredged material placed upon the screen.

The screening process was visually monitored by UXO-qualified personnel in the observation trailer. Human Factors Applications, Incorporated (HFA) of Holicong, PA, provided EOD support during the demonstration in the form of equipment and personnel to locate, identify, recover, transport, and dispose of any MEC encountered. The observation trailer was equipped with a steel protective barrier and polycarbonate viewport on the side facing the screen (Figure 98). During the actual dredging, all personnel except the water cannon and crane operators were stationed inside the observation trailer. A closed-circuit television high-resolution camera lens was mounted on a $4.6 \mathrm{~m}$ (15ft) mast near the screening area. The camera's motorized zoom lens with auto iris was housed in an explosion-proof and waterproof enclosure equipped with remote-controlled pan and tilt capabilities (Figure 102).

An operator in the observation trailer controlled the camera's zoom, pan, and tilt functions. A color video monitor and time-lapse recorder were connected to the camera via a fiber-optic link to provide color-corrected professional quality images (Figure 103).

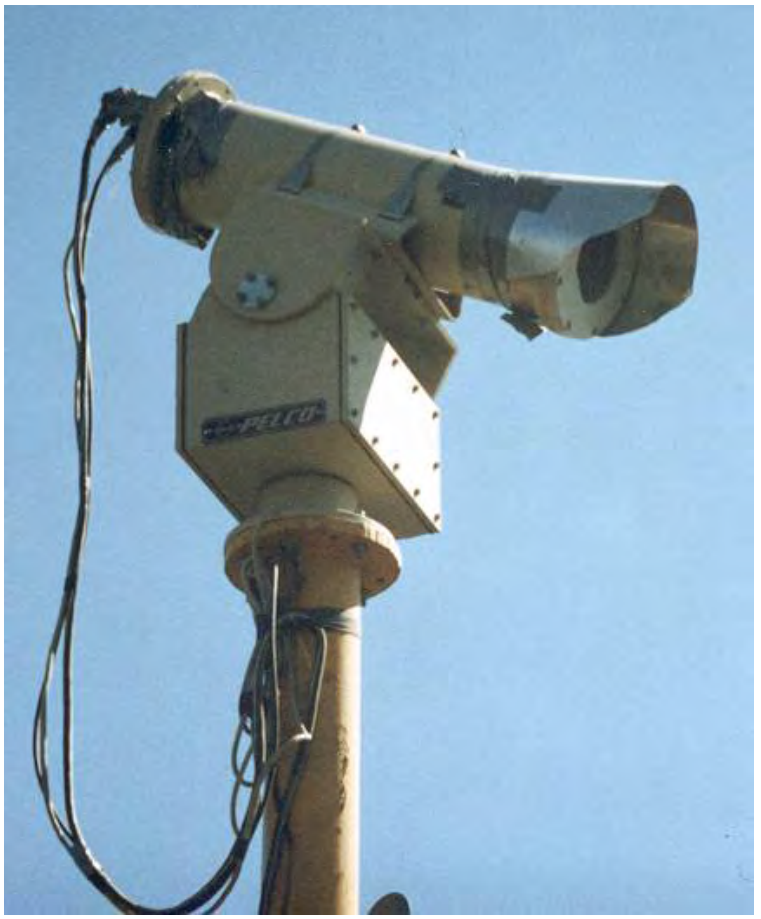

Figure 102. 10X zoom lens with remote-controlled pan and tilt. 


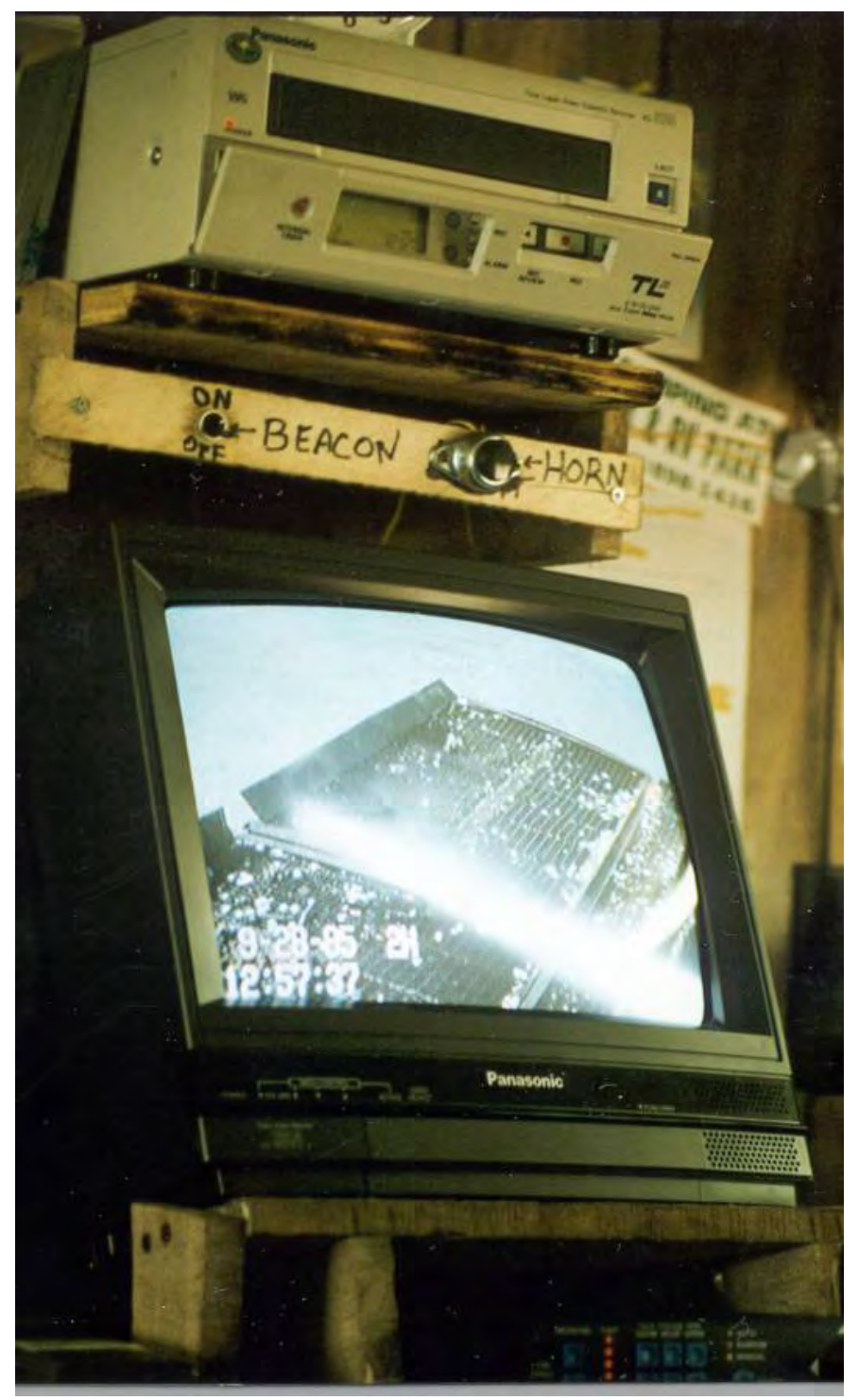

Figure 103. Closed-circuit television control station inside observation trailer (lens zoomed out).

The closed-circuit television field of view provided coverage of the entire screen surface. As a surveillance system backup, one UXO-qualified person monitored the screening process by looking out the view port with binoculars.

\section{Dredging system operation}

After mobilizing from Cleveland, $\mathrm{OH}$, the dredge plant started dredging on

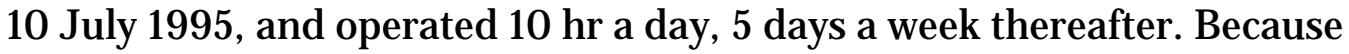
of the shallow vessel drafts, all dredge plant components were able to enter the Toussaint River from Lake Erie and use the river banks as a staging area from the very beginning of the project. EOD mobilization included 
the transportation and establishment of portable explosives magazines (storage for the explosives used to dispose of MEC) in the staging area. The MEC-disposal area was established on the lakeshore $460 \mathrm{~m}$ (1,500 ft) northwest of the dredge site. Prior to the start of actual dredging, crosstraining sessions on dredging operations, MEC disposal operations, and general safety concerns were conducted by the dredging contractor and EOD personnel.

"Tailgate" safety meetings were conducted at the beginning of each day of the demonstration to review general safety issues and address specific concerns as they arose during the project. Due to the nature of safety hazards posed by this project, all contractors were required to prepare and implement effective SSHPs in cooperation with the CEHNC, and all working personnel were required to be certified under OSHA Standard 29 CFR 1910.120 Hazardous Waste/ Site Workers Training.

The dredge plant departed daily from the staging area and took up station while two sentry boats secured public boat traffic at each end of the navigation channel. The sentries were two $5 \mathrm{~m}$ (16 ft) steel-hulled boats with $27 \mathrm{hp}$ diesel outboard engines. The sentry boat operators, equipped with radios, red warning flags, and air horns, would take up relative locations that were determined by the required minimum separation distance of $380 \mathrm{~m}$ (1,250 ft) for public exposure to possible MEC (as per the Huntsville Division). During dredging, which was conducted for 45 min of every hour, public boat traffic in the channel was prohibited. During the remaining $15 \mathrm{~min}$, public vessel traffic (if present), was allowed in the channel. The dredging contractor was paid for each traffic time interval. If no boaters were waiting for access, dredging operations continued without interruption.

Soon after dredging began, it became obvious that, even with the combination of water cannon jet and scow internal spray acting on the sediment, the screen's $19 \mathrm{~mm} \times 114 \mathrm{~mm}(0.75 \mathrm{in} . \times 4.5 \mathrm{in}$.) rectangular openings were becoming excessively clogged (blinded off) by clamshells and rounded coarse gravel (Figure 104). Cleaning the debris that was wedged between the grates proved to be a very time-consuming, labor-intensive job. As the clamshell excavated deeper into the sediment, unexpected amounts of clay (brown-gray with medium high plasticity) and peat were encountered. This clay further decreased production due to the water spraying systems' inability to disintegrate the more cohesive clumps. 


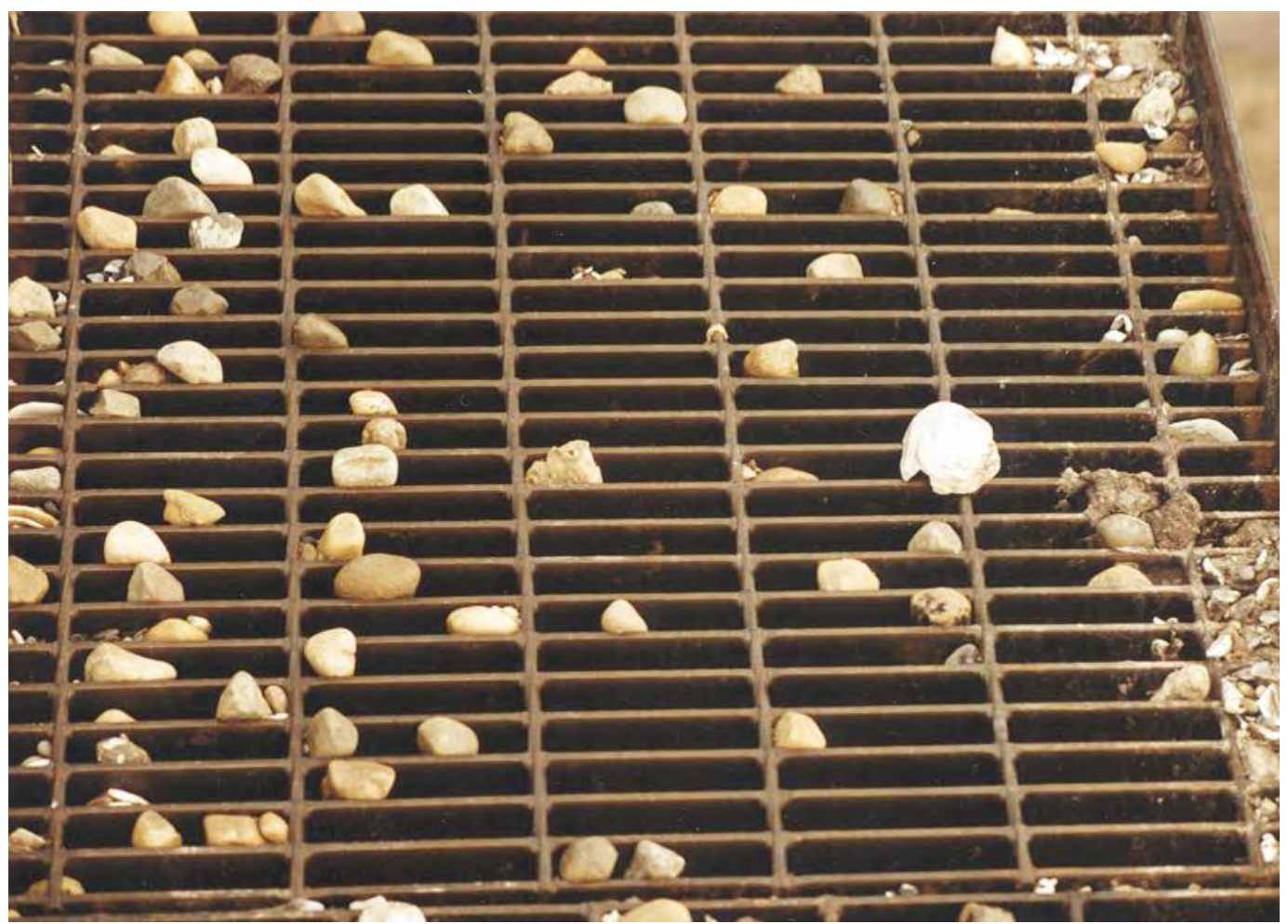

Figure 104. Blinded-off bar grate separation screens.

These increased amounts and types of debris remaining on the screen surface after the scow was filled, would, in turn, increase the time required by EOD personnel to safely inspect and clear. With approval from the Huntsville Division, it was decided to expand the screen opening area by cutting out every other lateral grate bar. Removal of these laterals increased the rectangular dimensions to $38 \mathrm{~mm} \times 114 \mathrm{~mm}(1.5 \mathrm{in} . \times 4.5 \mathrm{in}$.) (Figure 105). This modification dramatically increased screen throughput by allowing more clamshells and coarse gravel to pass through (less blinding), but, when encountered, the more cohesive clumps of clay and peat still remained troublesome.

After expanding the screen openings, experience and production numbers showed that the internal scow spray system did not significantly add to screen throughput, but it did add a significant amount of water to the hopper. The upward-oriented spray also obscured MEC surveillance during dredging. Because of these factors, the scow internal spraying system was not used for the remainder of the demonstration. During loading, if a significant amount of sediment started to accumulate on the screen, the crane operator would dump buckets of water on the sediment to facilitate screen throughput. 


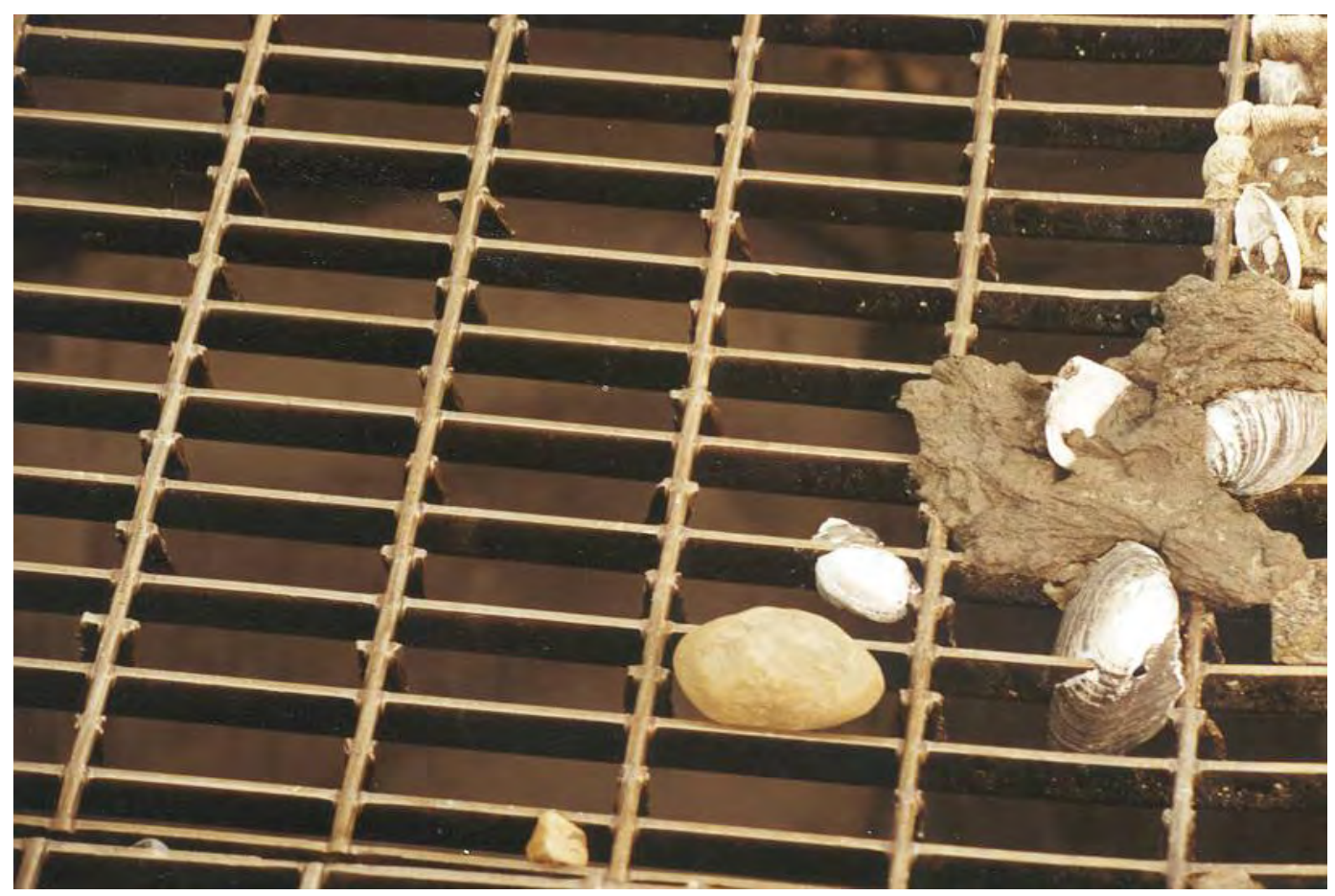

Figure 105. Modified bar grate screens.

Spray from the water cannon was sufficient to fluidize the sand and less cohesive clay clumps, but a significant portion of the water jet's energy, and respective fluidizing capability, was lost overboard because a portion of the spray (and dredged material) was deflected off the screen due to its low angle of trajectory in relation to the plane of the screen. This condition can be observed in Figure 98. A portion of this "lost" energy was recovered when an approximately $200 \mathrm{~mm}$ (8 in.) high, $6.4 \mathrm{~mm}(0.25 \mathrm{in}$.) thick steel plate "splash board" was welded vertically to the screen frame (outboard from the water cannon station) in order to redirect some of the fluidization energy back into the system.

The crane operator would dump as close to the scow screen as possible to reduce screen impact forces and the potential for MEC detonation, but cyclic loading and an occasional piece of dense debris (i.e., quarry stone several feet in diameter) started to excessively deform the bar grating in certain areas. These deformations formed depressions in the plane of the screen between the I-beam cross members. Sediment that accumulated in these "pockets" would increase the percentage of blinded screen area and also reduce the MEC detection ability of the UXO-qualified personnel.

"Space cloth" made from $6.4 \mathrm{~mm}$ ( $0.25 \mathrm{in}$.) diameter round stock with $50 \mathrm{~mm} \times 50 \mathrm{~mm}$ ( 2 in. $\times 2$ in.) square openings was used to replace the 
more damaged grate sections (Figure 106), but the use of this type of screen required welding additional I-beam cross members into the screen frame for support. After this modification, no significant difference in throughput rates was noticed for the space cloth compared to the modified bar grate.

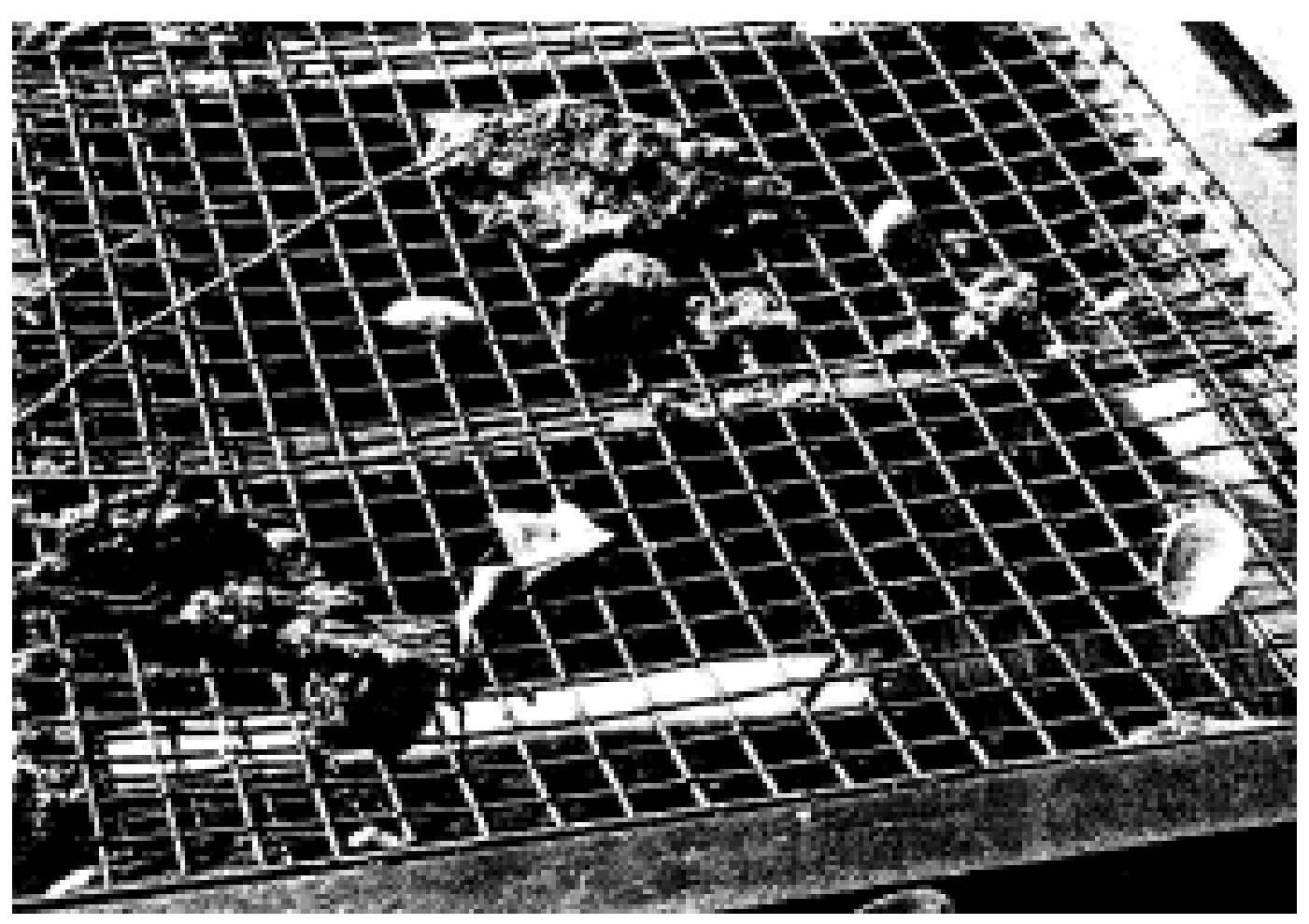

Figure 106. Space cloth separation screen.

As per the operations plan, when possible MEC was detected by UXOqualified personnel, the dredging was to be halted by activating a red flashing beacon on the camera mast. In practice, the first beacon did not always provide sufficient visual stimulus to attract the water cannon and/ or crane operator's attention. This recognition problem was solved by using a larger beacon (more lumens) and supplementing the procedure with an audio signal from an air horn. After dredging ceased the UXOqualified supervisor and one UXO-qualified specialist would leave the observation trailer and investigate. If the item was determined to be nonordnance, dredging was resumed.

If the target was classified MEC, as it was after the 8th day of dredging (a smoke grenade and $106 \mathrm{~mm}$ projectile), a $5 \mathrm{~m}$ ( $16 \mathrm{ft}$ ) diesel-powered (reduced fire hazard) boat piloted by another UXO-qualified specialist would be brought up alongside; the MEC would be sand-bagged and 
transported to shore. At the disposal site, the MEC was laid in a shallow pit and shaped charges were fastened to its casing (Figure 107). A detonation cord was used to initiate the shaped charges and the focused energy of the explosion breached the ordnance's casing. Only after a casing was breached could an item be conclusively classified.

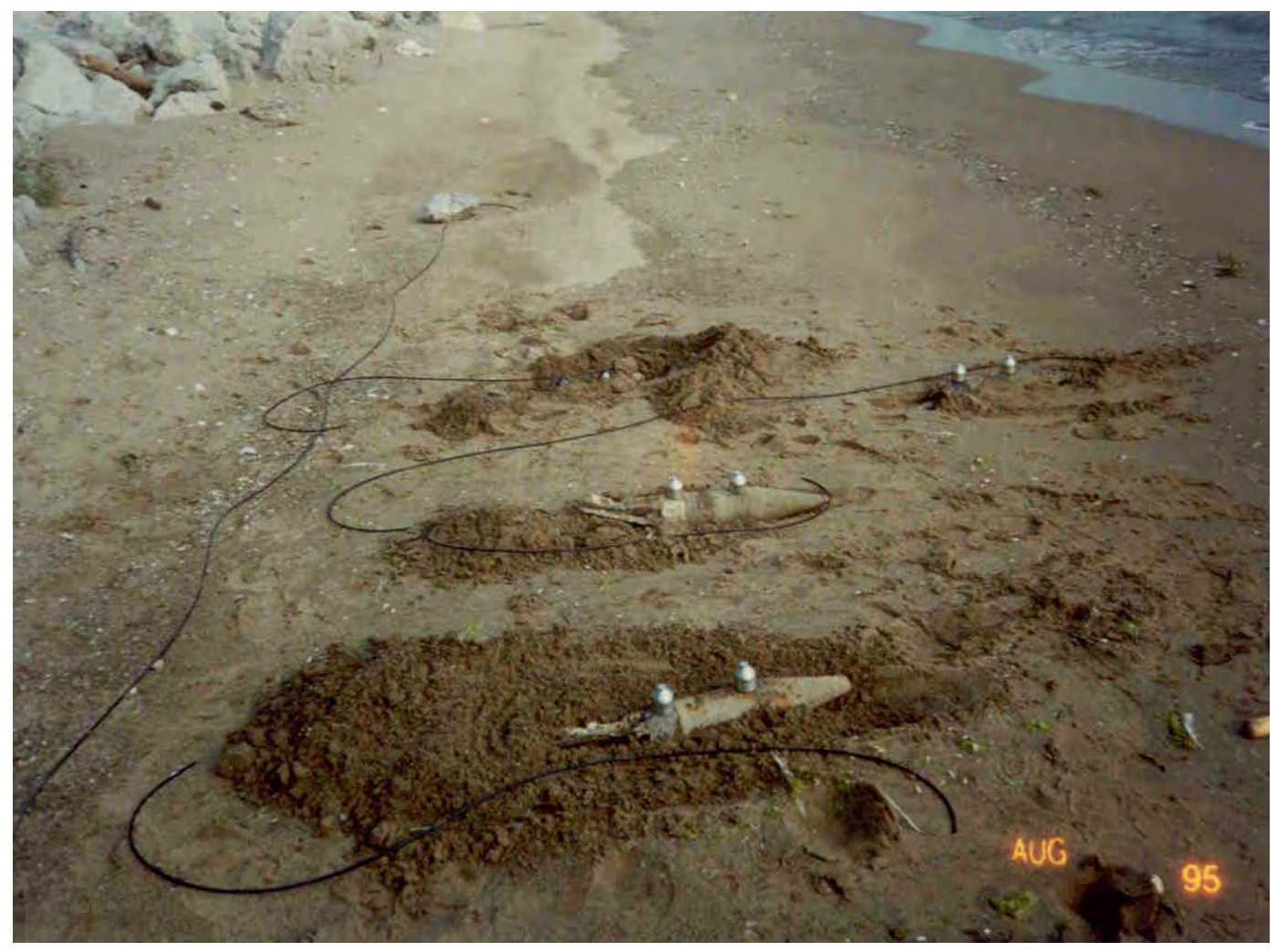

Figure 107. MEC prepared for disposal detonation.

Water depths in the project area required that the $65 \mathrm{cu} \mathrm{m}$ ( $85 \mathrm{cu}$ yd) capacity scows could only be loaded with approximately $46 \mathrm{cu} \mathrm{m}$ (60 cu yd) to maintain an operational draft. After the scows were full, the Falcon pushed them to the nearshore disposal site, located $366 \mathrm{~m}$ $(1,200 \mathrm{ft})$ from the general dredge site, and unloaded the dredged material through the bottom dump doors.

\section{Results and discussion}

During the 79-workday duration of the demonstration project, 14,757 cu m $(19,300 \mathrm{cu} y d)$ of material was removed from the authorized channel limits (as determined by hydrographic survey) during 72 actual days of dredging. The remaining 7 days were spent conducting various tasks such as altering screens, repairing the dredge plant, etc. A total of 37 pieces of military 
munitions were recovered from the separation screens and properly disposed of (resulting in $568 \mathrm{lb}$ of scrap metal). From this total, 31 pieces were classified as inert ordnance, and the remaining 6 as UXO (HFA 1996). In Figure 108, a $106 \mathrm{~mm}$ projectile can be seen in the condition that it was recovered from the screen. Table 6 classifies the total amount of ordnance recovered during the demonstration and Figure 109 shows several different types of ordnance recovered during the demonstration (note condition of $60 \mathrm{~mm}$ mortar in lower right-hand corner after being breached by shaped charge).

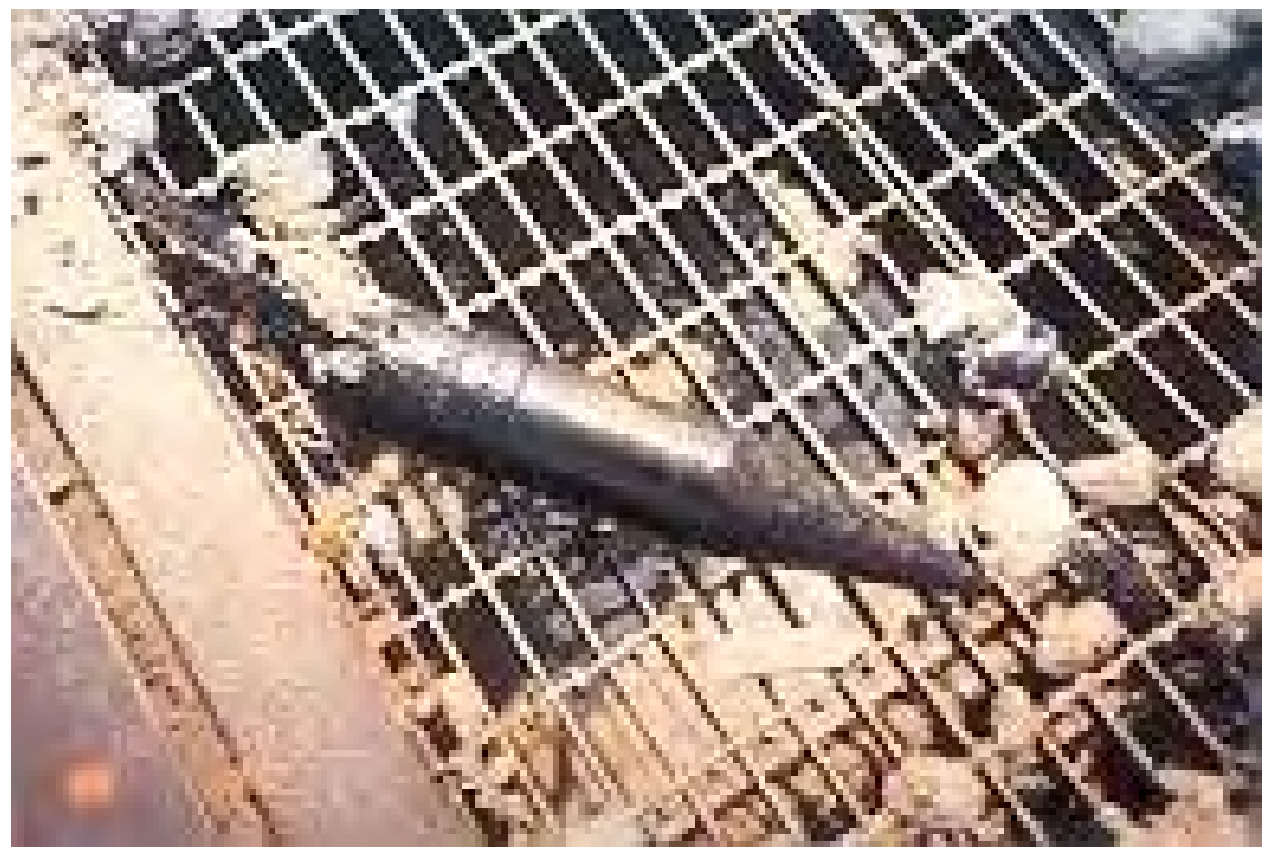

Figure 108. A $106 \mathrm{~mm}$ projectile on separation screen.

Table 6. Total recovered items.

\begin{tabular}{|c|c|}
\hline Ordnance Type & Quantity \\
\hline \multicolumn{2}{|c|}{ UXO } \\
\hline M28 3.5 in. rocket & 4 \\
\hline M49A2 $60 \mathrm{~mm}$ mortar & 2 \\
\hline \multicolumn{2}{|c|}{ Inert Ordnance } \\
\hline M344 106 mm projectile & 22 \\
\hline M52 fuze & 1 \\
\hline M15 smoke grenade & 4 \\
\hline M489 105 mm projectile & 3 \\
\hline M333 90 mm projectile & 1 \\
\hline
\end{tabular}




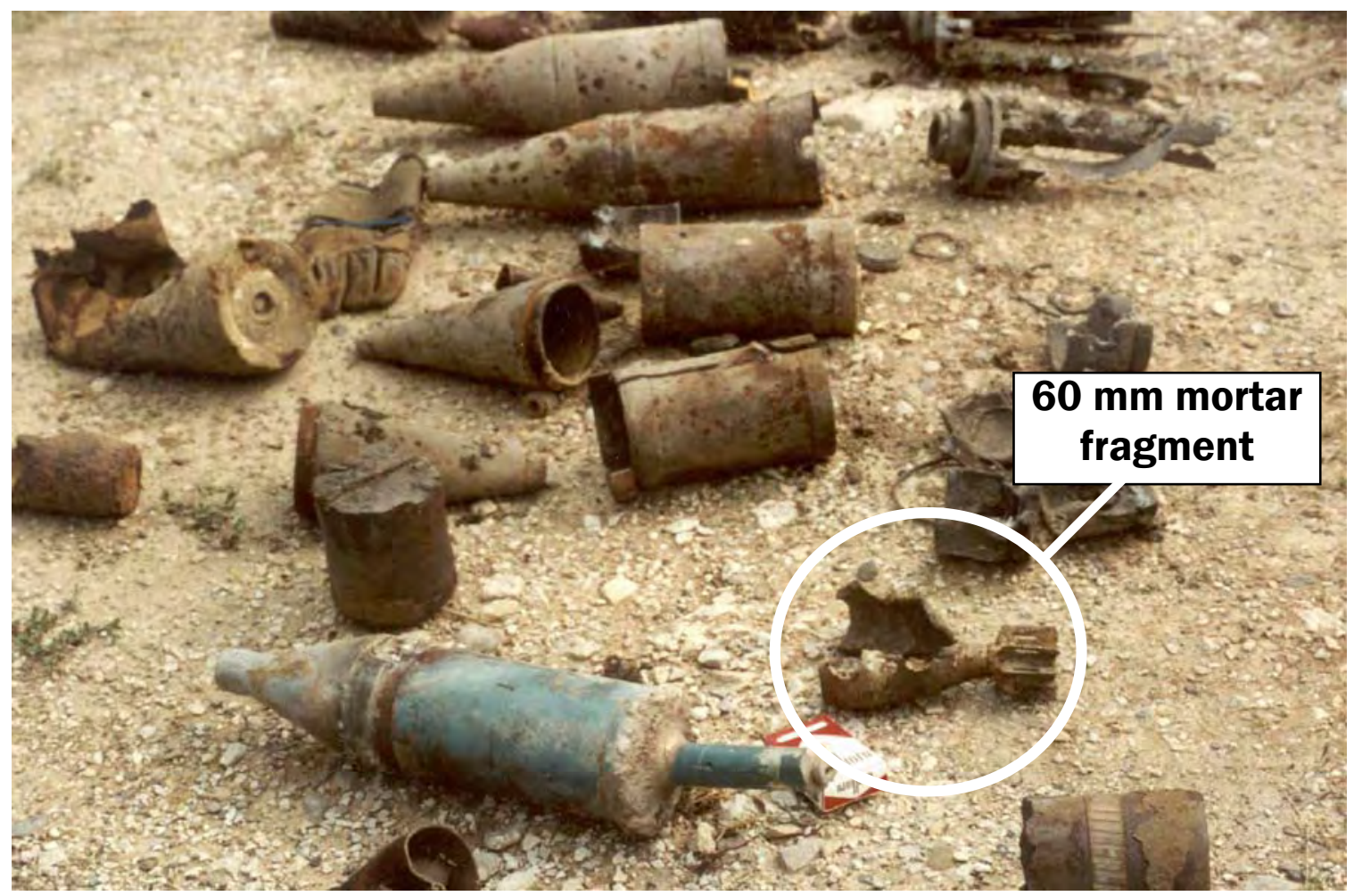

Figure 109. Several examples of recovered ordnance fragments.

An overall production rate of $20.5 \mathrm{cu} \mathrm{m} / \mathrm{hr}$ (26.8 cu yd/hr), or $205 \mathrm{cu} \mathrm{m} /$ day (268 cu yd/day), was attained by the dredge plant at a cost (including equipment fabrication) of approximately $\$ 33.26 / \mathrm{cu} \mathrm{m}$ ( $\$ 25.43 /$ cu yd). EOD personnel support and services incurred an additional cost of $\$ 23.18 / \mathrm{cu} \mathrm{m}$ ( $\$ 17.72 / \mathrm{cu}$ yd). The total demonstration production cost was approximately $\$ 56.44 / \mathrm{cu} \mathrm{m}(\$ 43.15 / \mathrm{cu}$ yd), as compared to an average cost of less than $\$ 6.54 / \mathrm{cu} \mathrm{m}$ ( $\$ 5.00 / \mathrm{cu}$ yd) for conventional dredging in that part of the Great Lakes.

Given the project objectives, the results from this prototype demonstration showed that the dredging technique is a viable method for dredging MECcontaminated sediment, and separating and properly disposing of any MEC encountered. Sediment was successfully dredged and MEC recovered without a single occurrence of MEC detonation (except for MEC being breached at the disposal site) or accidents of any nature. The costs of this project reflect the higher costs normally associated with the application of new techniques to an uncertain set of conditions. Production costs of future projects could be significantly reduced (under the right conditions) by incorporating lessons learned from this project. The overall cost incurred by UXO-qualified support is assumed to remain approximately constant, but dredging costs could be reduced in the following ways: 
1. Optimize sizing and construction of separation screens based on minimum size of MEC to be retained, sediment characteristics, structural integrity, and biological and/ or man-made debris at the dredge site. The separation screen is the "critical choke-point" for this type of dredging system.

2. Optimize the fluidization system design and operation based on sediment/ debris characteristics, and the manner in which the spray is applied to sediment (i.e., water jet configuration (flow rate and pressure) and point(s) of application).

3. Match dredge plant selection (maximum clamshell bucket and scow hopper sizes) with throughput rate of the separation screen/ fluidization system.

The overall, or average, rate of production is influenced by several factors, e.g., MEC recovery delays (less than 10 percent of dredging time for this project), required public boat traffic intervals, etc. Efficient coordination between these delays and scow loading (the instantaneous production rate) and change out time will assist in reducing the cost per cubic meter (cubicyard) dredged.

The 1999 dredging project

The third Toussaint River dredging project was conducted 2 September through 10 October 1999 by a modified clamshell dredge and scows (Figure 110), but this time the scows were not equipped with separation screens (and water spray system) and UXO-qualified personnel were not present at the dredge site. The bid contract was awarded to Lake Michigan Contractors, Inc. The contractor worked $24 \mathrm{hr}$ a day, 7 days a week. If MEC were discovered any time during operations, the contractor was to stop operations in the affected area, mark the location, and notify the contracting officer and the 71st EOD Company, located at Wright Patterson Air Force Base, OH, of the MEC hazard. An EOD Team would then respond to the site to evaluate and dispose of the MECitem discovered.

The contract specifications required that the crane operator be protected by barriers with structural properties equivalent to $2.54 \mathrm{~cm}$ (1.0 in.) thick steel plate protection barrier (as compared to the $0.635 \mathrm{~cm}$ [0.25 in.] thick plate required in 1995) (Figure 111). Protection was also required for the crew on the spud barge (Figure 112) and, unlike the 1995 project, the scow release operator. Protection for the scow operator was similar to the crane operator's and was located at the scow release-mechanism station 


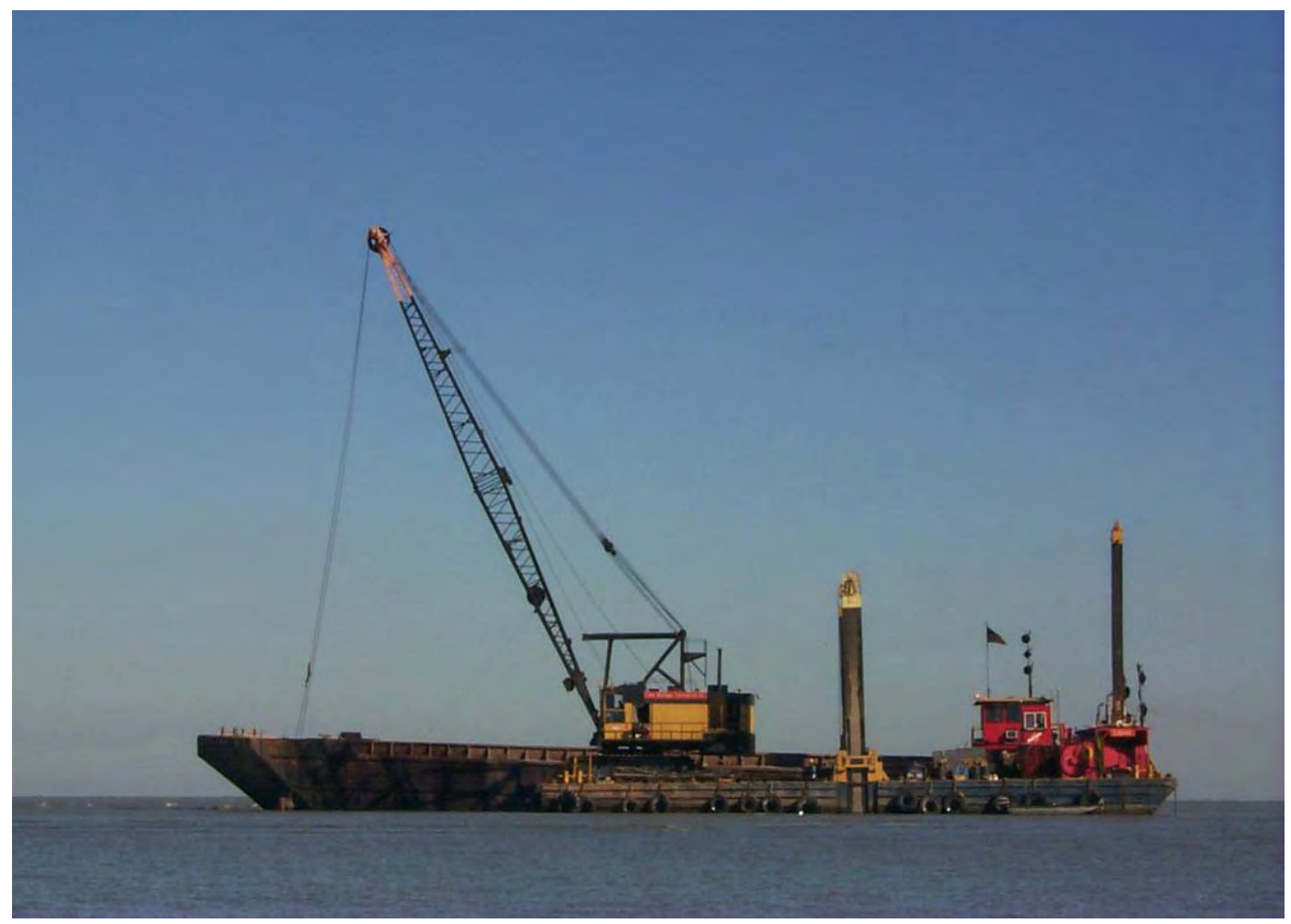

Figure 110. 1999 dredging layout.

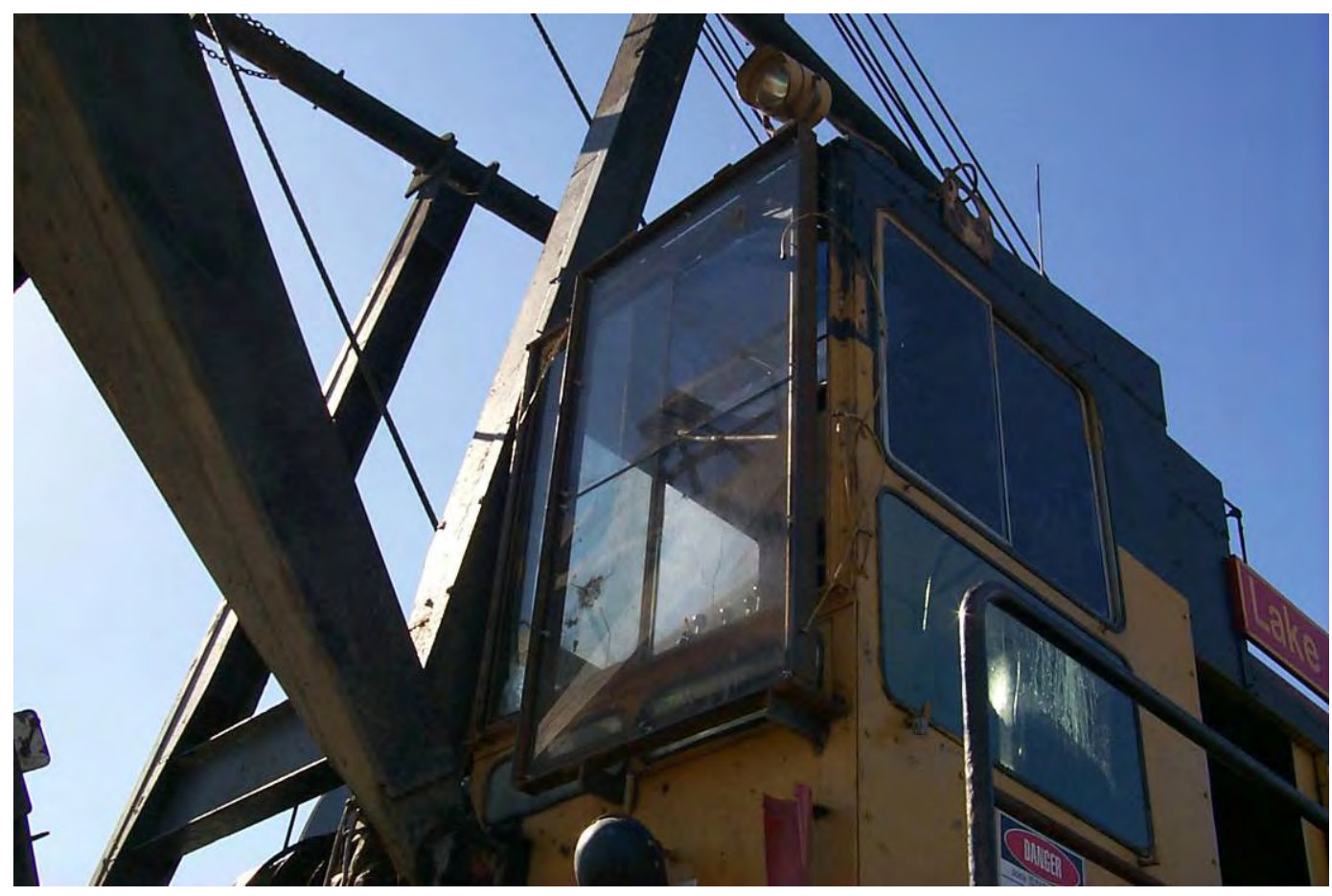

Figure 111. Crane operator's protective barrier. 


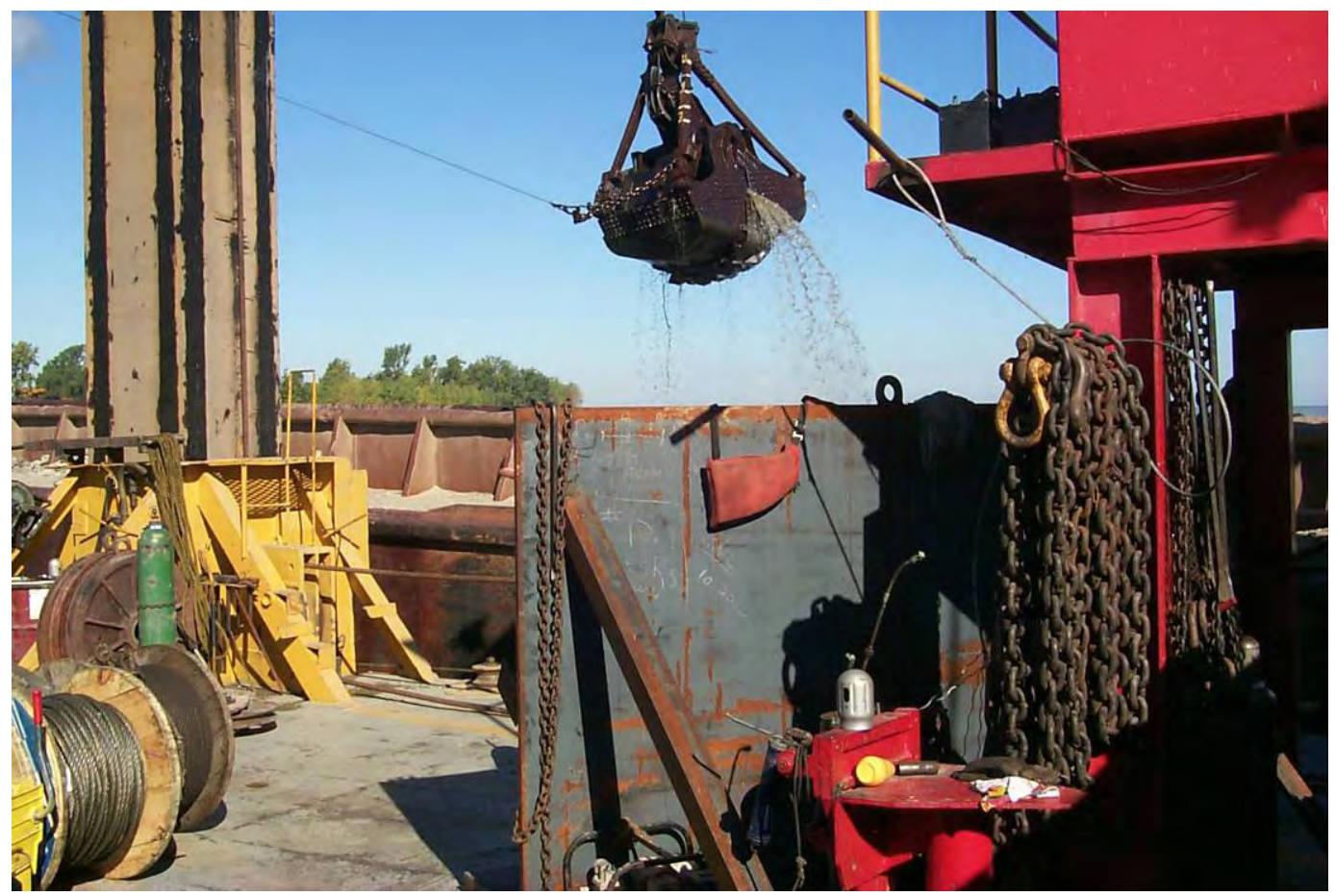

Figure 112. Crew's protective barrier (underneath life jacket).

(Figure 113). A "Public Withdrawal Distance" of 380 m (1,250 ft) between the disposal scow and any other vessel was in effect during disposal operations. No personnel were allowed on the scow during transport operations. Once the scow was in the disposal area, a single workman was transported to the scow to accomplish the unloading procedure. That workman was required to be behind the protection equipment prior to opening any of the scow doors.

A minimum separation distance of $15.85 \mathrm{~m}$ ( $52 \mathrm{ft}$ ) had to be maintained between the crane operator and the clamshell bucket. The crane operator was required to place the dredged material in the scow as close to the scow's bottom as possible to maximize the amount of protective coverage provided by the scow's steel sides. For public safety considerations, the nearby river channel and surrounding areas were closed to marine interests within "Public Withdrawal Distance" of the dredging plant and scows. Marine interests were allowed to use the river channel, within the established "Public Withdrawal Distance" for a maximum of 15 min every dredging hour, and during nondredging periods. If no vessels were waiting to use the channel, the contractor continued the dredging operations. 


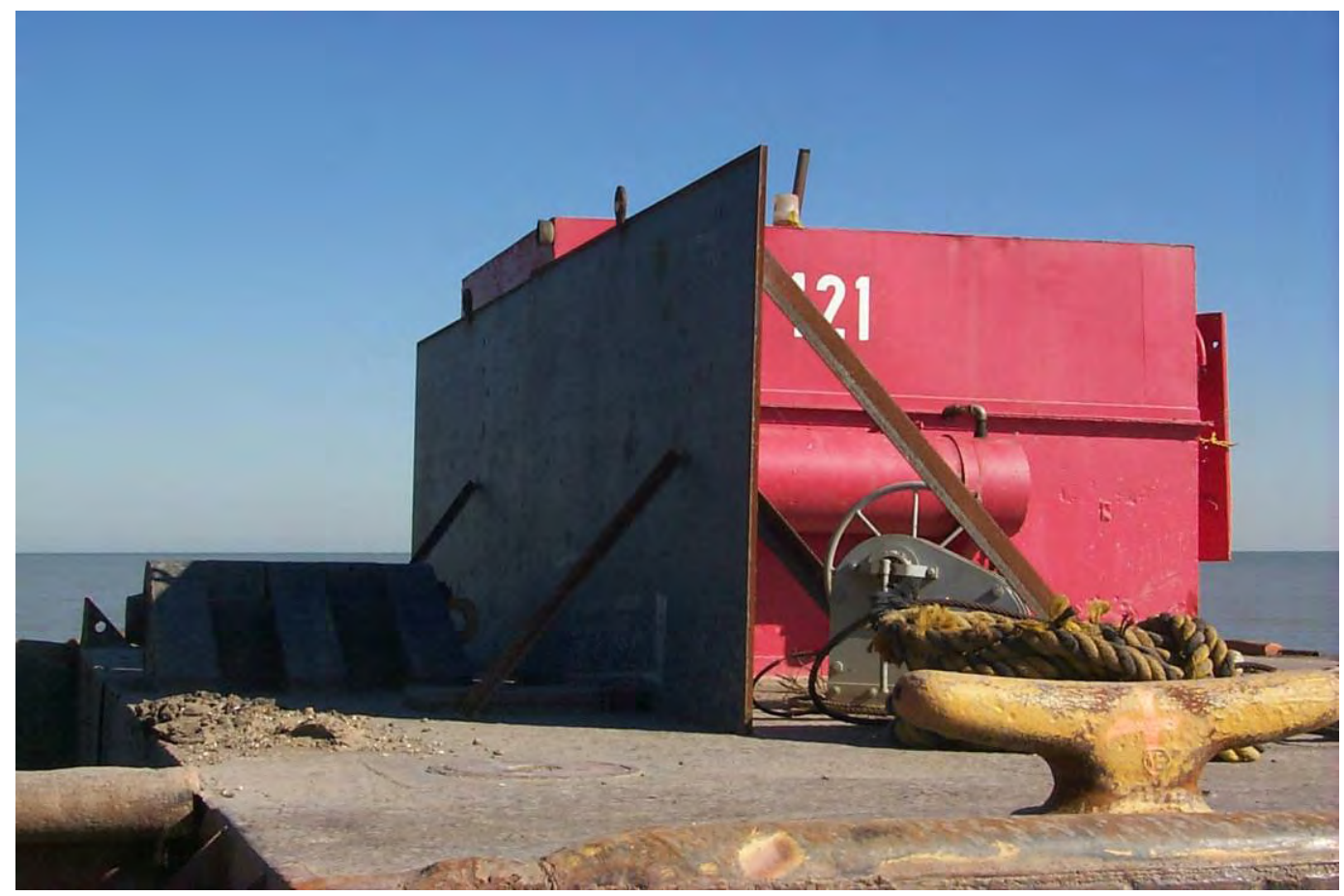

Figure 113. Scow release operator's protective barrier.

All plant equipment, including dredging barges, tug, and power boats, were required to be capable of navigating safely in water depths (initially) as shallow as $1.2 \mathrm{~m}$ ( $4 \mathrm{ft}$ ). Negotiations indicated that the minimum-sized scow was $760 \mathrm{cu} \mathrm{m}$ (1,000 cu yd) and that the clamshell bucket be at least $3.8 \mathrm{cu} \mathrm{m}$ ( $5 \mathrm{cu}$ yd). One additional clamshell bucket was to be on site as a spare. The contractor used a $3.8 \mathrm{cu} \mathrm{m}$ ( $5 \mathrm{cu}$ yd) clamshell bucket on the crane and two $760 \mathrm{cu}$ m (1,000 cu yd) scows. Dredged material was transported about $7 \mathrm{~km}(4.5 \mathrm{mi})$ to an open-lake disposal area in approximately 6- $9 \mathrm{~m}(20-30 \mathrm{ft})$ of water.

During the entire dredging project, no ordnance was encountered (observed) in the authorized federal channel. Because separation screens were not used in this project, the presence or absence of MEC cannot be conclusively determined. Approximately $5 \mathrm{~km}$ ( $3 \mathrm{mi}$ ) of shoreline (and visible nearshore) to the southeast of the Toussaint River was monitored for ordnance during and after the project by beach walkers. The 1999 project's approximate unit price cost was $\$ 13.07 / \mathrm{cu} \mathrm{m}$ ( $\$ 10.00 / \mathrm{cu}$ yd) to dredge roughly 38,000 cu m (50,000 cu yd). 


\section{Summary}

Dredging can be defined as the process of excavating sediments and other materials from underwater locations, and transporting and placing this material for purposes (i.e., constructing new waterways, maintaining existing waterway dimensions, obtaining fill for land reclamation, beach nourishment, dike and levee construction, creating wetlands and marshes, obtaining materials from borrow areas, or other beneficial uses).

The majority of U.S. dredging projects are conducted by hydraulic and mechanical dredges. The following parameters influence the selection of dredging equipment and method(s) used to perform the dredging:

1. Physical characteristics of material to be dredged.

2. Quantities and physical layout of material to be dredged.

3. Dredging depth.

4. Location of both the dredging and placement sites and distance between them.

5. Physical environment of and between the dredging and placement areas.

6. Contamination level of sediments.

7. Method of placement.

8. Production required.

9. Type of dredges available.

10. Presence of MEC.

Past dredging projects have encountered MEC and MD. It has been discovered on the dredges (i.e., in dragheads, cutterheads, rock boxes, or turtle screens) and at the dredged material placement site (i.e., on nourished public beaches or in $\mathrm{CDFs}$ ). Detonations have occurred that have either damaged the dredge plant or, in more severe cases, sunk the dredge. Not all apparent MEC items contain energetic material. Only a qualified EOD or UXO technician can determine which items are considered UXO or DMM and deal with them accordingly. In some cases, it may not be possible to visually determine what the item is due to corrosion or encrustation. Correct usage of the terms MD, DMM, and UXO can critically influence the relative severity of subsequent impacts that the potential risk posed by these items can have on a dredging project. 
The purpose of this report is to provide guidance to personnel involved in $\mathrm{MEC} /$ dredging projects. The guidance presented herein is primarily in the form of compiled information gained from experiences on past MEC dredging projects involving UXO and MD. This information has been compiled and summarized to inform the reader about what has been done in the past to deal with the risk inherent in this potentially dangerous situation where dredge and crew or the public (i.e., in a beach nourishment project) can be exposed to MEC. Information has been presented to illustrate how different site-specific parameters have influenced the outcomes of various past MEC dredging projects and some contract language presented that has been used successfully in past MEC dredging projects.

Considerations related to dredging in sediments containing MEC are presented to guide project personnel ranging from those who have the advantage of planning in advance for dealing with MEC, to those who unexpectedly find it while in the process of dredging. These considerations include:

1. General planning approaches to MEC dredging projects.

2. Archive searches (historical records review).

3. MEC detection, discrimination, and disposal.

4. Dredging operations explosives hazards analysis.

5. Removal of MEC versus leaving MEC underwater.

6. Risk assessment for dredging operations.

7. Impacts to production rate.

8. Costs.

While available documentation of past projects that encountered MEC is sparse, it appears that MEC is more often encountered in new-work projects as opposed to maintenance dredging projects. Past projects (i.e., the CSDRP in Surf City, NJ ) have proven that it is safer and usually more cost effective to address the presence of MEC from the very outset of the dredging project (i.e., in planning stage), as opposed to dealing with it later after the actual dredging has started. In the evolution of a MEC/ dredging situation, the dredging project employer (entity requiring the dredging) is required to coordinate with their respective MEC safety organization (i.e., the Baltimore District Military Munitions Design Center (http://www.nab.usace.army.mil/MilitaryMunitions/mmdc.htm) for USACE projects, and the NOSSA (http://www.nossa.navsea.navy.mil/) for U.S. Navy projects). 
Various technologies have been used to detect, discriminate, and locate underwater MEC in the past in relatively shallow waters ( $<20 \mathrm{~m}[<65 \mathrm{ft}])$, and current research and development is being conducted to improve these capabilities. While the current state-of-practice for recovering underwater MEC is primarily done by the use of EOD divers (except for specialized projects where MEC has been recovered during the dredging project, i.e., Toussaint River, Kokkola Channel Project, Baltimore Harbor, Netherlands, etc.). Research and development of more efficient and safer recovery technologies are also being pursued.

If MEC is encountered unexpectedly on a dredging project onboard the dredge, the subsequent actions of the crew will depend on the circumstances, but some general tips on how to respond if you suspect that you have encountered munitions are the 3Rs presented in the document "Munitions at Sea, A Guide for Commercial Maritime Industries" by the Defense Ammunition Center, U.S. Army Technical Center for Explosives Safety (USATCES) (Appendix C).

The 3Rs consist of:

RECOGNIZE: Recognize when you may have encountered a munition.

RETREAT: If you know or suspect you have encountered a munition, jettison it or secure it and keep the crew out of the immediate area.

REPORT: Immediately notify the U.S. Coast Guard of the vessel's or munition's location and provide a description of the munition.

Emergency contacts:

- In port: Call 911.

- At sea: Use channel 16 (156.800 MHz).

In addition to the usual planning considerations of a conventional dredging project, project planning for operations in an area containing or suspected to contain MEC requires consideration of:

- Removal of the MEC versus leaving it underwater.

- Risk assessment for the dredging operations (risks to people and equipment). 
- Production rate of dredge.

- Equipment cost.

Two primary questions regarding MEC hazards are to be considered in the risk assessment for dredging operations involving MEC:

- What points in the dredging process are most likely to cause the MEC to detonate?

- What are the potential consequences of a detonation at each of these points?

The relative magnitude of some of the effects that MEC can have on dredging projects depends on parameters such as:

- MEC presence (how many, what type, what caliber?).

- Timing of the determination that MEC exists at the site (when was MEC discovered?).

- Type of dredging project being conducted (navigation, beach renourishment, and remediation).

- Relative size of dredging project.

- Feasible alternatives to obtain original dredging goals.

- Contractual issues (i.e., scheduling, payment basis, risk allotment).

- Type(s) of dredges used.

- Potential environmental impacts.

- Social and political considerations.

There are no absolutely safe procedures for dealing with MEC, merely procedures considered to be least dangerous. It is essential that a planned and systematic approach to dealing with such items be established. Plans should be developed to expose the least number of people to the minimum amount of MEC for the shortest amount of time. The safety of personnel (dredge crew and public) must be the primary consideration when dredging in sediments containing MEC. 


\section{References}

AETC Inc. 2005. Marine towed array technology demonstration at the former Naval Duck Target Facility. ESTCP Project No.200324, Washington, DC (http://www.estcp.org/Technology/upload/MM-0324_FR_01.pdf).

Bray, R. N., A. D. Bates, and J. M. Land. 1997. Dredging, a handbook of engineering. New York, NY: Wiley and Sons.

Clark, G. R. 1983. Survey of portable hydraulic dredges. Hydraulics Laboratory Technical Report HL-83-4. Vicksburg, MS: U.S. Army Engineer Waterways Experiment Station.

Clausner, J. E., T. L. Welp, and D. D. Bishop. 1992. Controlled tests of eductors and submersible pumps. Dredging Research Program Technical Note DRP-3-05. Vicksburg, MS: U.S. Army Engineer Waterways Experiment Station.

Clausner, J . E., P. J . Neilans, T. L. Welp, and D. D. Bishop. 1994. Controlled tests of eductors and submersible pumps. Miscellaneous Paper DRP-94-2. Vicksburg, MS: U.S. Army Engineer Waterways Experiment Station.

Concurrent Technologies Corporation. 2006. Safety analyses of equipment for UXO removal from sediment unexploded ordnance (UXO) Task N.0407. Distribution authorized to U.S. Government agencies only. Requests for this document shall be referred to Office of the Assistant Secretary of the Army, Installation and Environment, ASA (I\&E) ESOH, 1235 Clark Street, Crystal Gateway 1, Suite 307, Arlington, VA.

Cullinane, J . M., D. E. Averett, R. A. Shafer, J . W. Male, C. L. Truitt, and M. R. Bradbury. 1986. Guidelines for selecting control and treatment options for contaminated dredged material requiring restrictions. Puget Sound Dredged Disposal Analysis of the U.S. Department of the Army, September 1986. Vicksburg, MS: U.S. Army Engineer Waterways Experiment Station.

Damen Dredging Equipment. 2007. DOP solution for an explosive problem. 18 J anuary (http://www.damendredging.com/html/en/index.htm).

Department of Defense Explosives Safety Board (DDESB). 2007. Methodologies for calculating primary fragment characteristics. Technical Paper TP 16.

Washington, DC.

Francese, R., T. Daniel, and A. D. Clark. 1997. Horseshoe Shoals Borrow Site: A study of sand, ordnance, and biotic integrity. New Insights into Beach Preservation, Proceedings 1997 National Conference on Beach Preservation Technology. St. Petersburg, FL, 246-261.

Funk, R., L., R. J . Feldpausch, and B. Bridge. 2007. An Integrated Marine Gradiometer Array system (MGA) for detection and location of UXO in littoral to deep marine and freshwater environments. Proceedings MTS/ ADCI Underwater Intervention 2007, 30 J anuary to 1 February 2007. 
Halkola, H., W. Wild, T. Welp, C. Pollock, V. Dickerson, L. Helms, L. Brown, and B. Sugiyama. 2006. Dredging equipment modifications for detection and removal of ordnance. ESTCP Project MM-0321. Washington, DC: Environmental Securities Technology Certification Program.

Headquarters, U.S. Army Corps of Engineers. 2007a. Dredging and dredged material management. Engineer Manual 1110-2-5025. Washington, DC, (http://www.usace.army.mil/publications/eng-manuals/em.htm).

Headquarters, U.S. Army Corps of Engineers. 2007b. Safety and health requirements for Munitions and Explosives of Concern (MEC) operations. Engineer Regulation 385-1-95. Washington, DC (http://www.usace.army.mil/publications/eng-regs/er.htm).

Headquarters, U.S. Army Corps of Engineers. 2006. Ordnance and explosives response. Engineer Regulation 1110-1-8153. Washington, DC (http://www.usace.army.mil/publications/eng-regs/er.htm).

Headquarters, U.S. Army Corps of Engineers. 2004. Basic safety concepts and considerations for Munitions and Explosives of Concern (MEC) Response Action Operations. Engineer Pamphlet EP 385-1-95a. Washington, DC (http://www.usace.army.mil/publications/eng-pamphlets/ep385-1-95a/entire.pdf).

Headquarters, U.S. Army Corps of Engineers. 2003. Safety - safety and health requirements. Engineer Manual 385-1-1. Washington, DC (http://www.usace.army.mil/publications/eng-manuals/em.htm).

Herbich, J . B., ed. 2000. Handbook of dredging engineering, 2nd edition. New York, NY: McGraw Hill.

Human Factors Applications, Inc (HFA). 1996. Task Order \#006 Unexploded Ordnance support for the Toussaint River Dredging Project, Ottawa, Ohio - Final Removal Report. Holicong, PA: Human factors Applications, Inc.

Huston, J. 1986. Hydraulic dredging. Corpus Christi, TX: J ohn Huston Inc.

Kerksis, S. C., and T. S. Dickey. 1968. Field artillery projectiles of the Civil War 18611865. Atlanta, GA: Phoenix Press.

Maddrell, R. J . 2001. Dealing with ordnance. Proceedings 16 th $^{\text {th }}$ World Dredging Congress, Volume II, Session 8A. Kuala Lumpur, Malaysia.

McDonald, J . R. 2007. The MTA UXO survey and target recovery on Lake Erie at the Former Erie Army Depot. Demonstration Report to the ESTCP Program Office, J anuary 2007, http://www.estcp.org/Technology/upload/MM-0324-LakeErie.pdf.

Ogden Beeman \&Associates, Inc. 1994. Philadelphia Navy Yard final report, Reserve Basin Dredging Phase 2. Philadelphia, PA.

Parsons, Brinckerhoff, Quade, and Douglas, Inc. 1999. Ordnance reconnaissance study for the Sandy Hook to Barnegat Inlet, New J ersey, beach erosion control project. Draft Report prepared for U.S. Army Engineer District, New York. 
Pederson, A., D. Wardlaw, and J . Noke. 2002. ESTCP cost and performance report, low order underwater detonation. ESTCP, Report UX-0104, http://www.estcp.org/ documents/techdocs/200104.pdf.

Pneuma S.R.L. 2006. http://www.pneuma.it/.

Pope, J ., R. D. Lewis, and T. Welp. 1996a. A beach and underwater occurrences of ordnance at a former defense site: Erie Army Depot, Ohio. Coastal Engineering Research Center Technical Report CERC-96-1. Vicksburg, MS: U.S. Army Engineer Waterways Experiment Station.

Pope, J ., R. D. Lewis, A. Morang, and T. Welp. 1996b. A pilot study to characterize ordnance contamination within the Sea Bright, New J ersey, sand borrow site. Coastal Engineering Research Center Technical Report CERC-96-8. Vicksburg, MS: U.S. Army Engineer Waterways Experiment Station.

Racine, Charles H., Marianne E. Walsh, Charles M. Collins, Darryl J . Calkins, and Bill D. Roebuck. 1992. Waterfowl mortality in Eagle River Flats, Alaska: The role of munition compounds. CRREL Report 92-5. Hanover, NH: Cold Regions Research and Engineering Laboratory.

Racine, Charles H., Marianne E. Walsh, Charles M. Collins, Susan Taylor, and Bill D. Roebuck. 1993. White phosphorus contamination of salt marsh pond sediments at Eagle River Flats, Alaska. CRREL Report 93-17. Hanover, NH: Cold Regions Research and Engineering Laboratory.

NAVFAC Southwest. 1998. Channel dredging-sand screening report-FY'97. MCON Project P-706.

T.L. J ames and Company, Inc. 1995. Memorandum to the New York District, Corps of Engineers. Regarding IFB DACW51-95-B-0040, Contract B, Reach 1, Sea Bright to Sandy Hook.

Turner, T. M. 1984. Fundamentals of hydraulic dredging. Centreville, MD: Cornell Maritime Press.

U.S. Army Engineer District, New York. 2001. Beach erosion control project Atlantic Coast of New J ersey Sandy Hook to Barnegat Inlet renourishment Contract No. 1: Sea Bright to Spring Lake, New J ersey. IFB No. DACW51-01-B-0017. New York, NY: New York District.

U.S. Army Engineer District, Norfolk. 2004. Buckroe Beach Nourishment Contract Specifications. Norfolk, VA: Norfolk District.

U.S. Army Engineer District, Rock Island. 1939. Safe Channel. Rock Island publication. September issue.

U.S. Army Engineer District, St. Louis. 1993. Archives search for Fort Hancock, Sandy Hook, New J ersey: DERP-FUDS Site No. C02NJ 0032. Unpublished report prepared for the U.S. Army Engineer Division, Huntsville. Huntsville, AL: U.S. Army Engineer Division.

U.S. Department of the Army. 1972. Vietnam studies, base development, 1965- 1970. Washington, DC: Department of the Army. 
U.S. Naval School, Explosive Ordnance Disposal. 1972. Civil War explosive ordnance 1861-1865. Indian Head, MD: U.S. Naval Ordnance Station.

U.S. Navy. 1994. Memorandum to File: Subject: Department of the Army Permit NAPOP-R-87-0122-11; Construction Contract No. N62472-92-C-0008, Repair/ Upgrade Berthing Space for Inactive Ships, Naval Reserve Basin, Schuylkill River, Philadelphia Naval Shipyard, U.S. Navy Northern Division. Lester, PA: Naval Facilities Engineering Command.

U.S. Navy. 2003. Military Munition Response Program Oversight. Washington, DC: Office of the Chief of Naval Operations, (http://www.usa-federal-forms.com/usafedforms-dod-opnavinst/dod-opnavinst-8020-15-nonfillable.pdf).

Walsh, M. R. 1996. Dredging at Eagle River Flats: Remediation study of a superfund site in an impact area. UXO Forum 1996. Williamsburg, VA: U.S. Army Environmental Center, 66-76.

Walsh, Michael R., and Charles M. Collins. 1998. Evaluation of dredging as remediation for white phosphorus contamination at Eagle River Flats, Alaska. Cold Regions Research and Engineering Laboratory Report 98-5. Hanover, NH: U.S. Army Engineer Research and Development Center.

Walsh, M. R., E. J . Chamberlain, and D. E. Garfield. 1994. Dredging as a Remediation Strategy for White-Phosphorus-Contaminated Sediments at Eagle River Flats, Alaska. C. H. Racine and D. Cate, eds.

Walsh, M. R., E. J . Chamberlain, and K. S. Henry. 1996. Dredging in an Active Artillery Impact Area Eagle River Flats, Alaska. Cold Regions Research and Engineering Laboratory Report 96-22. Hanover, NH: U.S. Army Engineer Research and Development Center.

Welp, T., J . Clausner, J . Pope, R. Lewis, and R. Pilon. 1994. Unexploded ordnance (UXO) and dredging. Proceedings Second international Conference on Dredging and Dredged Material Placement, Dredging 94. C. McNair, ed., 48- 55.

Welp, T. L., J. E. Clausner, and R. L. Pilon. 1998a. Toussaint River unexploded ordnance (UXO) demonstration dredging project. Coastal and Hydraulics Laboratory Miscellaneous Paper CHL-98-6, August. Vicksburg, MS: U.S. Army Engineer Waterways Experiment Station.

Welp, T., R. Pilon, and L. Bocamazo. 1998b. Dredging in unexploded-ordnance (UXO)contaminated Sediment. Proceedings 15th World Congress. Las Vegas, NV.

Welp, T., Tubman, M., Hamm, A., Redman, K., 2004. Toussaint River, Ohio, ordnance migration study. Coastal and Hydraulics Laboratory Technical Report TR-04-8. Vicksburg, MS: U.S. Army Engineer Research and Development Center, (http://libweb.erdc.usace.army.mil/uhtbin/cgisirsi/WSro26voMV/ERDC_VBG/162480012/52 3/7350).

Wilson, J. V, I. McKissick, W. Daly, S. A. J enkins, A. Devisser, B. M. Sugiyama. 2006. Predicting the mobility and burial of underwater unexploded ordnance (UXO) using the UXO Mobility Model. Interim Field Test Report, (FRF Duck, NC). (ESTCP) 200417. Washington, DC, (http://www.estcp.org/Technology/ upload/MM0417-IR.pdf). 


\section{Appendix A: Munitions Response Terminology}




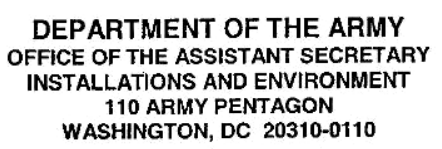

APR 212000

\section{MEMORANDUM FOR THE ASSISTANT CHIEF OF STAFF FOR INSTALLATION MANAGEMENT}

SUBJECT: Munitions Response Terminology

1. This memorandum replaces my October 28,2003 memorandum, subject:

Definitions Related to Munitions Response Terms, and requests your office ensure that the enclosed terms and their definitions (Enclosure 1) are used, when appropriate, in correspondence (e.g., policies, guidance) and briefings concerning the Army's implementations of its Military Munitions Response Program (MMRP), Sustainable Range Management Program (SRMP) and, as appropriate, in other munitions-related matters.

2. In the past three years, the Department of Defense (DoD) has developed policies and guidance to implement its MMRP and SRMP. It has also worked to close a policy gap related to the management of material that may pose explosives hazards to DoD personnel and/or the public. During this period, DoD has been actively engaged, through the Munitions Response Committee (MRC), with the U.S. Environmental Protection Agency, Federal Land Managers, states, and with American Indians and Alaska Natives, to address issues related to the cleanup of munitions response sites.

3. To provide clarity and consistency in these efforts and in internal and external discussions, DoD has been working to establish and use common terms and definitions. The consistent use of accurate, descriptive terms, the definitions of which are commonly understood, is important to our dialogue with environmental regulators and safety officials, stakeholders, and the public.

4. Many of the terms that DoD has adopted for use in addressing munitions-related issues are now codified in Federal statute. On December 14, 2004, the Department of Defense Explosives Safety Board approved revisions to DoD 6055.9-STD, Ammunition and Explosives Safety Standards, using the enclosed terms.

5. The U.S. Army Technical Center for Explosives Safety, in coordination with other agencies, developed the enclosed matrix (Enclosure 2) to help the communities (e.g., operational, explosives safety, logistical, and cleanup) involved in addressing munitions-related operations to better understand how some of the new terms apply to actions they conduct.

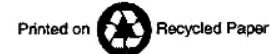


$-2-$

6. Use of this terminology does not imply any specific funding authority, nor does it alter the DERP Management Guidance's program eligibility criteria.

7. My staff point of contact is J. C. King at (703) 697-5564 or jc.king@us.army.mil.

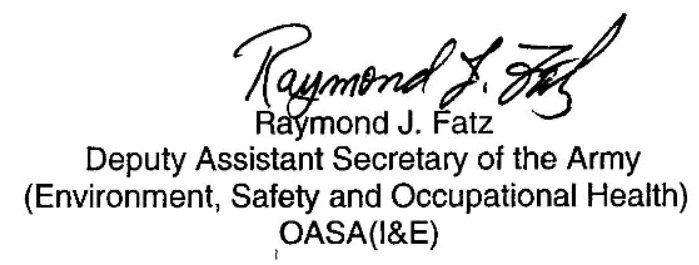

Enclosures

cf:

G-3

G-4

DAIM-BD

SFIM-OP

SAGC

OTJAG-ELD

NGB

CEMP-R

USACE

AEC 


\section{Enclosure 1: Military Munitions-Related Terms and Definitions}

\begin{tabular}{|c|}
\hline Consolidated Definitions \\
\hline $\begin{array}{l}\text { Anomaly Avoidance. Techniques employed on property known or suspected to contain UXO, other munitions that } \\
\text { may have experienced abnormal environments (e.g., DMM), munitions constituents in high enough concentrations } \\
\text { to pose an explosive hazard, or CA, regardless of configuration, to avoid contact with potential surface or subsurface } \\
\text { explosive or CA hazards, to allow entry to the area for the performance of required operations. }\end{array}$ \\
\hline $\begin{array}{l}\text { Chain of Custody. The activities and procedures taken throughout the inspection, re-inspection and documentation } \\
\text { process to maintain positive control of } \mathrm{MPPEH} \text { to ensure the veracity of the process used to determine the status of } \\
\text { material as to its explosive hazard. This includes all such activities from the time of collection through final } \\
\text { disposition. }\end{array}$ \\
\hline $\begin{array}{l}\text { Chemical Agent (CA). A chemical compound (to include experimental compounds) that, through its chemical } \\
\text { properties produces lethal or other damaging effects on human beings, is intended for use in military operations to } \\
\text { kill, seriously injure, or incapacitate persons through its physiological effects. Excluded are research, development, } \\
\text { testing and evaluation (RDTE) solutions; riot control agents; chemical defoliants and herbicides; smoke and other } \\
\text { obscuration materials; flame and incendiary materials; and industrial chemicals. }\end{array}$ \\
\hline $\begin{array}{l}\text { Chemical Agent (CA) Hazard. A condition where danger exists because CA is present in a concentration high } \\
\text { enough to present potential unacceptable effects (e.g., death, injury, damage) to people, operational capability, or the } \\
\text { environment. }\end{array}$ \\
\hline $\begin{array}{l}\text { Chemical Agent (CA) Safety. A condition where operational capability and readiness, people, property, and the } \\
\text { environment are protected from the unacceptable effects or risks of a mishap involving chemical warfare material } \\
\text { (CWM) and CA in other than munitions configurations. }\end{array}$ \\
\hline $\begin{array}{l}\text { Chemical Warfare Material (CWM). Items generally configured as a munition containing a chemical compound } \\
\text { that is intended to kill, seriously injure, or incapacitate a person through its physiological effects. CWM includes V- } \\
\text { and G-series nerve agents or H-series (mustard) and L-series (lewisite) blister agents in other-than-munition } \\
\text { configurations; and certain industrial chemicals (e.g., hydrogen cyanide (AC), cyanogen chloride (CK), or carbonyl } \\
\text { dichloride (called phosgene or CG)) configured as a military munition. Due to their hazards, prevalence, and } \\
\text { military-unique application, chemical agent identification sets (CAIS) are also considered CWM. CWM does not } \\
\text { include: riot control devices; chemical defoliants and herbicides; industrial chemicals (e.g., AC, CK, or CG) not } \\
\text { configured as a munition; smoke and other obscuration producing items; flame and incendiary producing items; or } \\
\text { soil, water, debris or other media contaminated with low concentrations of chemical agents where no CA hazards } \\
\text { exist. }\end{array}$ \\
\hline $\begin{array}{l}\text { Chemical Warfare Material (CWM) Response. Munitions responses and other responses to address the chemical } \\
\text { safety; explosives safety, when applicable; human health; or environmental risks presented by CA-filled munitions } \\
\text { and CA in other than munitions configurations. (See munitions response.) }\end{array}$ \\
\hline $\begin{array}{l}\text { Construction Support. Assistance provided by DoD EOD or UXO-qualified personnel and/or by personnel trained } \\
\text { and qualified for operations involving CA, regardless of configuration, during intrusive construction activities on } \\
\text { property known or suspected to contain UXO, other munitions that may have experienced abnormal environments } \\
\text { (e.g., DMM), munitions constituents in high enough concentrations to pose an explosive hazard, or CA, regardless } \\
\text { of configuration, to ensure the safety of personnel or resources from any potential explosive or CA hazards. }\end{array}$ \\
\hline $\begin{array}{l}\text { Cultural Debris. Debris found on operational ranges or munitions response sites, which may be removed to } \\
\text { facilitate a range clearance or munitions response, that is not related to munitions or range operations. Such debris } \\
\text { includes, but is not limited to: rebar, household items (refrigerators, washing machines, etc.), automobile parts and } \\
\text { automobiles that were not associated with range targets, fence posts, and fence wire. }\end{array}$ \\
\hline $\begin{array}{l}\text { Defense Sites. Locations that are or were owned by, leased to, or otherwise possessed or used by the Department of } \\
\text { Defense. The term does not include any operational range, operating storage or manufacturing facility, or facility } \\
\text { that is used for or was permitted for the treatment or disposal of military munitions. (10 U.S.C. } 2710(\mathrm{e})(1))\end{array}$ \\
\hline $\begin{array}{l}\text { Discarded Military Munitions (DMM). Military munitions that have been abandoned without proper disposal or } \\
\text { removed from storage in a military magazine or other storage area for the purpose of disposal. The term does not } \\
\text { include unexploded ordnance, military munitions that are being held for future use or planned disposal, or military } \\
\text { munitions that have been properly disposed of, consistent with applicable environmental laws and regulations. } \\
\text { (10 U.S.C. } 2710(\mathrm{e})(2) \text { ) }\end{array}$ \\
\hline Disposal. End of life tasks or actions for residual materials resulting from demilitarization or disposition operations. \\
\hline $\begin{array}{l}\text { Disposition. The process of reusing, recycling, converting, redistributing, transferring, donating, selling, } \\
\text { demilitarizing, treating, destroying, or fulfilling other life-cycle guidance, for DoD property. }\end{array}$ \\
\hline
\end{tabular}




\section{Enclosure 1: Military Munitions-Related Terms and Definitions}

Documentation of the Explosives Safety Status of Material. Documentation attesting that material:

(1) does not present an explosive hazard and is consequently safe for unrestricted transfer within or release from DoD control, or (2) is MPPEH, with the known or suspected explosive hazards stated, that is only transferable or releasable to a qualified receiver. This documentation must be signed by a technically qualified individual with direct knowledge of: (1) the results of both the material's 100 percent inspection and 100 percent re-inspection or of the approved process used and the appropriate level of re-inspection, and (2) the veracity of the chain-of-custody for the material. This signature is followed by the signature of another technically qualified individual who inspects the material on a sampling basis (sampling procedures are determined by DoD entity that is inspecting the material). Environmental Regulators and Safety Officials. Include, but may not be limited to environmental regulators, environmental coordinators or hazardous material coordinators, law enforcement officers, and safety personnel of the U.S. Environmental Protection Agency (USEPA), American Indians and Alaska Natives, other Federal Land Managers, and/or the States. When appropriate, public health officials of various agencies may also be involved. Explosive Hazard. A condition where danger exists because explosives are present that may react (e.g., detonate, deflagrate) in a mishap with potential unacceptable effects (e.g., death, injury, damage) to people, property, operational capability, or the environment.

Explosive Ordnance Disposal (EOD). The detection, identification, on-site evaluation, rendering safe, recovery, and final disposal of unexploded ordnance and of other munitions that have become an imposing danger, for example, by damage or deterioration.

Explosive Ordnance Disposal (EOD) Personnel. Military personnel who have graduated from the Naval School, Explosive Ordnance Disposal; are assigned to a military unit with a Service-defined EOD mission; and meet Service and assigned unit requirements to perform EOD duties. EOD personnel have received specialized training to address explosive and certain CA hazards during both peacetime and wartime. EOD personnel are trained and equipped to perform Render Safe Procedures (RSP) on nuclear, biological, chemical, and conventional munitions, and on improvised explosive devices.

Explosive Ordnance Disposal (EOD) Unit. A military organization constituted by proper authority; manned with EOD personnel; outfitted with equipment required to perform EOD functions; and assigned an EOD mission.

Explosives or Munitions Emergency Response. All immediate response activities by an explosives and munitions emergency response specialist to control, mitigate, or eliminate the actual or potential threat encountered during an explosives or munitions emergency. An explosives or munitions emergency response may include in-place rendersafe procedures, treatment or destruction of the explosives or munitions, and/or transporting those items to another location to be rendered safe, treated, or destroyed. Any reasonable delay in the completion of an explosives or munitions emergency response caused by a necessary, unforeseen, or uncontrollable circumstance will not terminate the explosives or munitions emergency. Explosives and munitions emergency responses can occur on either public or private lands and are not limited to responses at RCRA facilities. (Military Munitions Rule, 40 CFR 260.10) Explosives Safety. A condition where operational capability and readiness, people, property, and the environment are protected from the unacceptable effects or risks of potential mishaps involving military munitions. Interim Holding Facility (IHF). A temporary storage facility designed to hold recovered chemical warfare material (RCWM).

Land Use Controls (LUC). LUC are physical, legal, or administrative mechanisms that restrict the use of, or limit access to, real property, to manage risks to human health and the environment. Physical mechanisms encompass a variety of engineered remedies to contain or reduce contamination and/or physical barriers to limit access to real property, such as fences or signs.

Long-Term Management (LTMgt). The period of site management (including maintenance, monitoring, record keeping, 5-year reviews, etc.) initiated after response (removal or remedial) objectives have been met (i.e., after Response Complete).

Material Potentially Presenting an Explosive Hazard (MPPEH). Material potentially containing explosives or munitions (e.g., munitions containers and packaging material; munitions debris remaining after munitions use, demilitarization, or disposal; and range-related debris); or material potentially containing a high enough concentration of explosives such that the material presents an explosive hazard (e.g., equipment, drainage systems, holding tanks, piping, or ventilation ducts that were associated with munitions production, demilitarization or disposal operations). Excluded from MPPEH are munitions within DoD's established munitions management system and other hazardous items that may present explosion hazarods (e.g., gasoline cans, compressed gas cylinders) that are not munitions and are not intended for use as munitions. 
Enclosure 1: Military Munitions-Related Terms and Definitions

Military Munitions. Military munitions means all ammunition products and components produced for or used by the armed forces for national defense and security, including ammunition products or components under the control of the Department of Defense, the Coast Guard, the Department of Energy, and the National Guard. The term includes confined gaseous, liquid, and solid propellants; explosives, pyrotechnics, chemical and riot control agents, smokes, and incendiaries, including bulk explosives, and chemical warfare agents; chemical munitions, rockets, guided and ballistic missiles, bombs, warheads, mortar rounds, artillery ammunition, small arms ammunition, grenades, mines, torpedoes, depth charges, cluster munitions and dispensers, demolition charges; and devices and components thereof.

The term does not include wholly inert items; improvised explosive devices; and nuclear weapons, nuclear devices, and nuclear components, other than nonnuclear components of nuclear devices that are managed under the nuclear weapons program of the Department of Energy after all required sanitization operations under the Atomic Energy Act of 1954 (42 U.S.C. 2011 et seq.) have been completed. (10 U.S.C. 101(e)(4)(A) through (C)) Military Munitions Burial Site. A site, regardless of location, where military munitions or CA, regardless of configuration, were intentionally buried, with the intent to abandon or discard. This term includes burial sites used to dispose of military munitions or CA, regardless of configuration, in a manner consistent with applicable environmental laws and regulations or the national practice at the time of burial. It does not include sites where munitions were intentionally covered with earth during authorized destruction by detonation, or where in-situ capping is implemented as an engineered remedy under an authorized response action.

Minimum Separation Distance (MSD). MSD is the distance at which personnel in the open must be from an intentional or unintentional detonation.

Munition with the Greatest Fragmentation Distance (MGFD). The munition with the greatest fragment distance that is reasonably expected (based on research or characterization) to be encountered in any particular area.

Munitions and Explosives of Concern (MEC). This term, which distinguishes specific categories of military munitions that may pose unique explosives safety risks means: (A) Unexploded ordnance (UXO), as defined in 10 U.S.C. 101(e)(5); (B) Discarded military munitions (DMM), as defined in 10 U.S.C. 2710(e)(2); or (C) Munitions constituents (e.g., TNT, RDX), as defined in 10 U.S.C. $2710(\mathrm{e})(3)$, present in high enough concentrations to pose an explosive hazard.

Munitions Constituents (MC). Any materials originating from unexploded ordnance (UXO), discarded military munitions (DMM), or other military munitions, including explosive and non-explosive materials, and emission, degradation, or breakdown elements of such ordnance or munitions. (10 U.S.C. $2710(\mathrm{e})(3)$ ).

Munitions Debris. Remnants of munitions (e.g., fragments, penetrators, projectiles, shell casings, links, fins) remaining after munitions use, demilitarization, or disposal.

Munitions Response. Response actions, including investigation, removal actions and remedial actions to address the explosives safety, human health, or environmental risks presented by unexploded ordnance (UXO), discarded military munitions (DMM), or munitions constituents (MC), or to support a determination that no removal or remedial action is required.

Munitions Response Area (MRA). Any area on a defense site that is known or suspected to contain UXO, DMM, or MC. Examples include former ranges and munitions burial areas. A munitions response area is comprised of one or more munitions response sites.

Munitions Response Site (MRS). A discrete location within an MRA that is known to require a munitions response.

Mutual Agreement. A meeting of the minds on a specific subject, and a manifestation of intent of the parties to do or refrain from doing some specific act or acts. Inherent in any mutual agreement or collaborative process are the acknowledgement of each member's role in the process and their differing views of their authorities. The mutual agreement process will provide a means of resolving differences without denying the parties an opportunity to exercise their respective authorities should mutual agreement fail to be achieved.

One Percent Lethality Distance. A distance calculated from a given CA Maximum Credible Event (MCE) and meteorological conditions (temperature, wind speed, Pasquill stability factor) and established as the distance at which dosage from that MCE agent release would be $150 \mathrm{mg}-\mathrm{min} / \mathrm{m}^{3}$ for $\mathrm{H}$ and $\mathrm{HD}$ agents, $75 \mathrm{mg}-\mathrm{min} / \mathrm{m}^{3}$ for $\mathrm{HT}$ agent, $150 \mathrm{mg}-\mathrm{min} / \mathrm{m}^{3}$ for Lewisite, $10 \mathrm{mg}-\mathrm{min} / \mathrm{m}^{3}$ for GB agent, $4.3 \mathrm{mg}-\mathrm{min} / \mathrm{m}^{3}$ for VX vapor, and $0.1 \mathrm{mg}-\mathrm{min} / \mathrm{m}^{3}$ for inhalation and deposition of liquid VX. 


\section{Enclosure 1: Military Munitions-Related Terms and Definitions}

On-call Construction Support. Construction support provided, on an as needed basis, where the probability of encountering UXO, other munitions that may have experienced abnormal environments (e.g., DMM), munitions constituents in high enough concentrations to pose an explosive hazard, or CA, regardless of configuration, has been determined to be low. This support can respond from off-site when called, or be on-site and available to provide required construction support.

On-site Construction Support. Dedicated construction support, where the probability of encountering UXO, other munitions that may have experienced abnormal environments (e.g., DMM), munitions constituents in high enough concentrations to pose an explosive hazard, or CA, regardless of configuration, has been determined to be moderate to high.

On-the-Surface. A situation in which UXO, DMM or CA, regardless of configuration, are: (A) entirely or partially exposed above the ground surface (i.e., the top of the soil layer); or (B) entirely or partially exposed above the surface of a water body (e.g., because of tidal activity).

Open Burn (OB). An open-air combustion process by which excess, unserviceable, or obsolete munitions are destroyed to eliminate their inherent explosive hazards.

Open Detonation (OD). An open-air process used for the treatment of excess, unserviceable or obsolete munitions whereby an explosive donor charge initiates the munitions being treated.

Operational Range. A range that is under the jurisdiction, custody, or control of the Secretary of Defense and that is used for range activities; or although not currently being used for range activities, that is still considered by the Secretary to be a range and has not been put to a new use that is incompatible with range activities. (10 U.S.C. $101(\mathrm{e})(3)(\mathrm{A})$ and $(\mathrm{B}))$. Also includes "military range," "active range," and "inactive range" as those terms are defined in 40 CFR $\$ 266.201$.

Primary Explosives. Primary explosives are highly sensitive compounds that are typically used in detonators and primers. A reaction is easily triggered by heat, spark, impact or friction. Examples of primary explosives are lead azide and mercury fulminate.

Public Access Exclusion Distance (PAED). The PAED is defined as longest distance of the hazardous fragment distance, inhabited building distance (IBD) for overpressure, or the One Percent Lethality Distance. For siting purposes, the PAED is analogous to the IBD for explosives; therefore, personnel not directly associated with the chemical operations are not to be allowed within the PAED.

Qualified Receiver. Entities that have personnel who are, or individuals who are, trained and experienced in the identification and safe handling of used and unused military munitions, and any known or potential explosive hazards that may be associated with the MPPEH they receive; and are licensed and permitted or otherwise qualified to receive, manage, and process MPPEH.

Range. A designated land or water area that is set aside, managed, and used for range activities of the Department of Defense. The term includes firing lines and positions, maneuver areas, firing lanes, test pads, detonation pads, impact areas, electronic scoring sites, buffer zones with restricted access, and exclusionary areas. The term also includes airspace areas designated for military use in accordance with regulations and procedures prescribed by the Administrator of the Federal Aviation Administration. (10 U.S.C. 101(e)(1)(A) and (B))

Range activities. Research, development, testing, and evaluation of military munitions, other ordnance, and weapons systems; and the training of members of the armed forces in the use and handling of military munitions, other ordnance, and weapons systems. (10 U.S.C. 101(e)(2)(A) and (B))

Range Clearance. The destruction, or removal and proper disposition of used military munitions (e.g., unexploded ordnance (UXO) and munitions debris) and other range-related debris (e.g., target debris, military munitions packaging and crating material) to maintain or enhance operational range safety or prevent the accumulation of such material from impairing or preventing operational range use. "Range clearance" does not include removal, treatment, or remediation of chemical residues or munitions constituents from environmental media, nor actions to address discarded military munitions (e.g., burial pits) on operational ranges.

Range-Related Debris. Debris, other than munitions debris, collected from operational ranges or from former ranges (e.g., target debris, military munitions packaging and crating material).

Recovered Chemical Warfare Material (RCWM). CWM used for its intended purpose or previously disposed of as waste, which has been discovered during a CWM response or by chance (e.g., accidental discovery by a member of the public), that DoD has either secured in place or placed under DoD control, normally in a DDESB-approved storage location or interim holding facility, pending final disposition. 


\section{Enclosure 1: Military Munitions-Related Terms and Definitions}

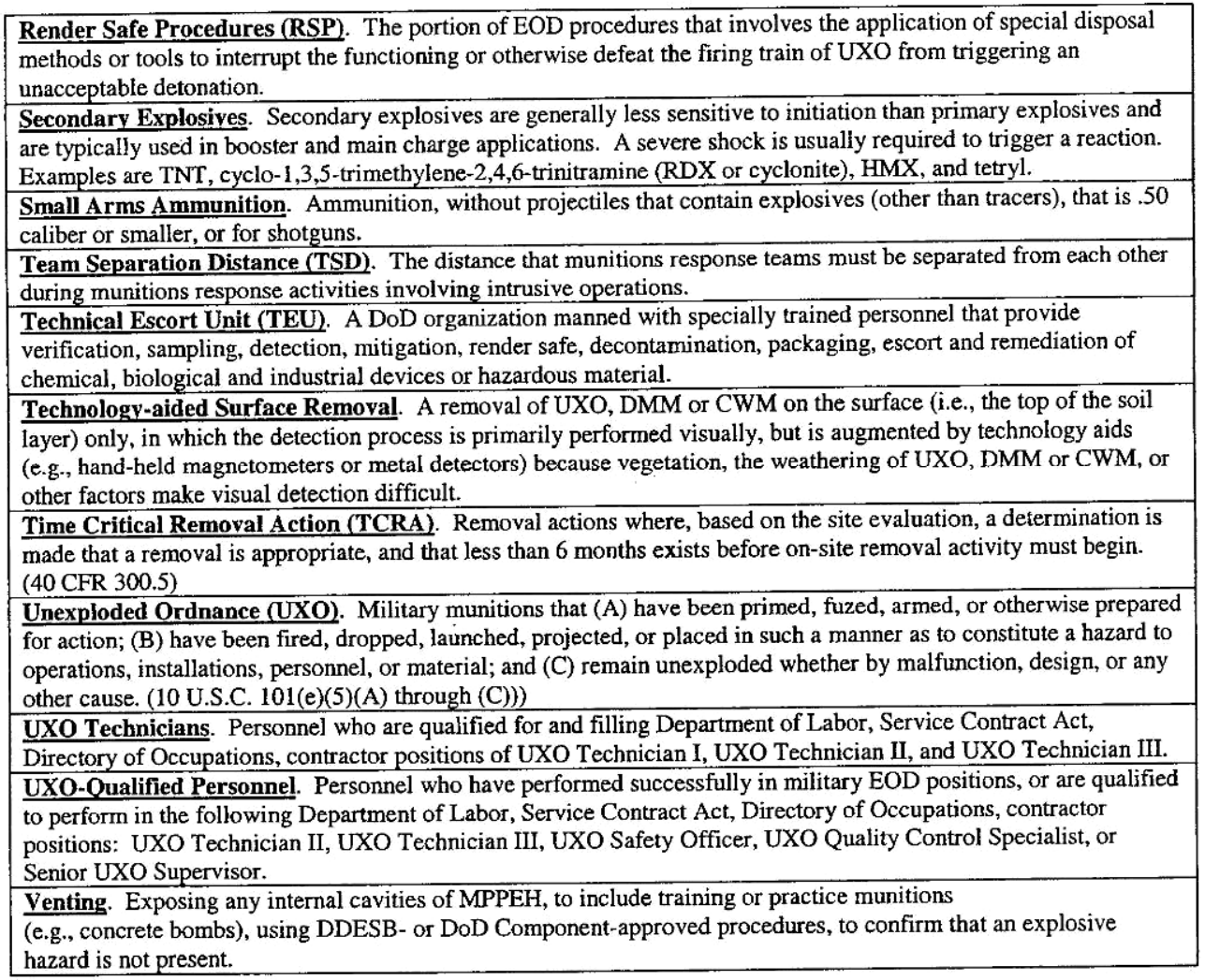




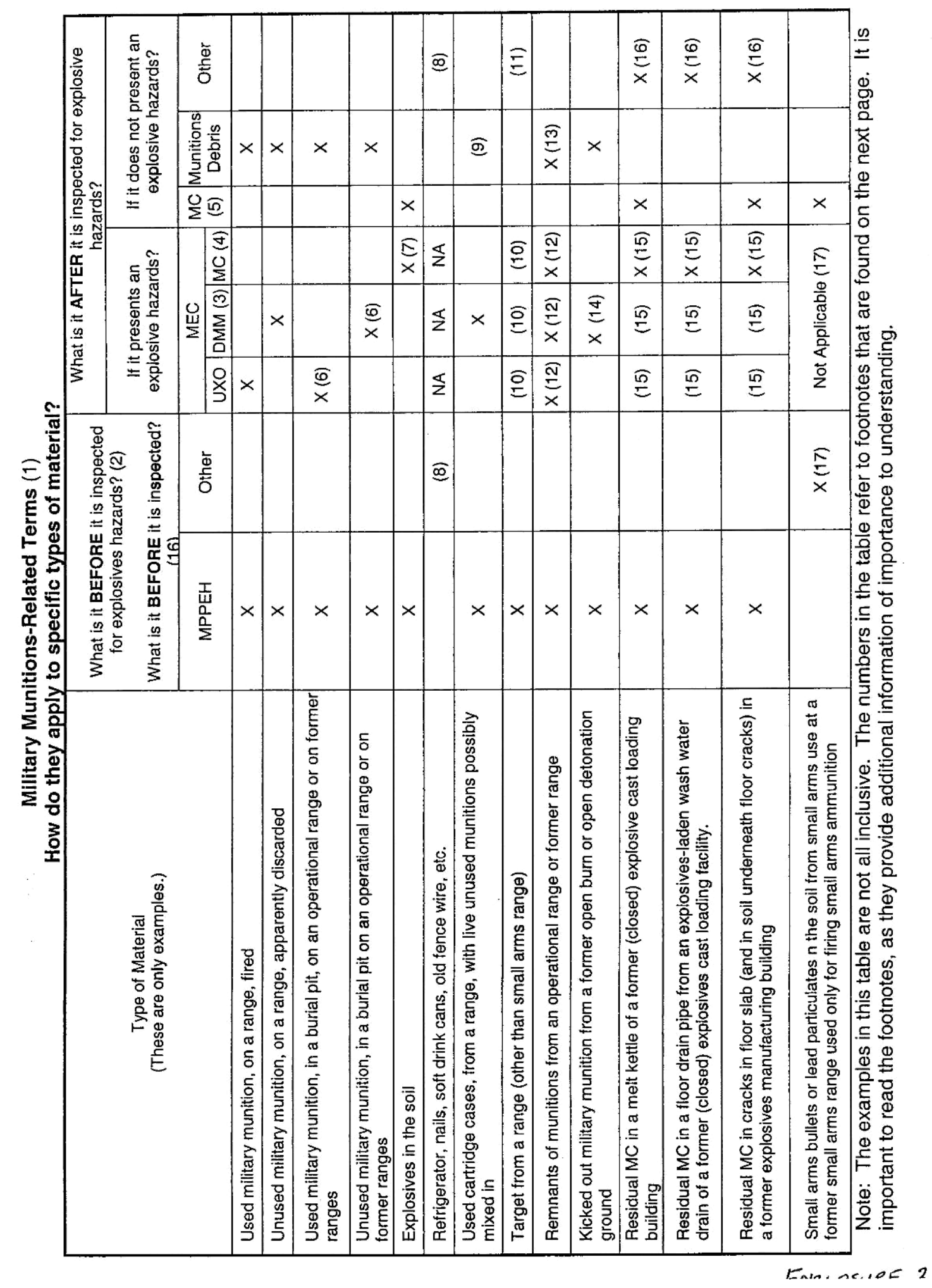




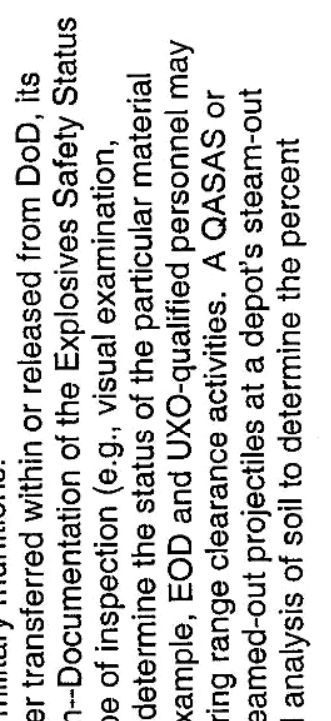

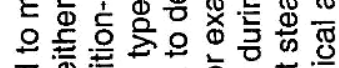

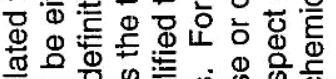

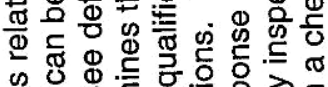

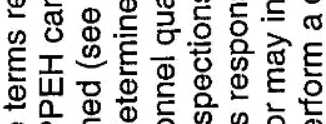

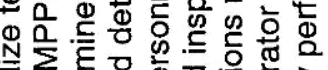

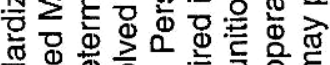

要 密

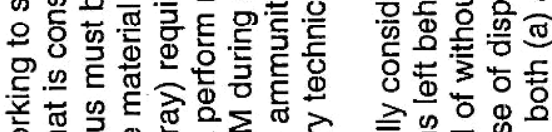

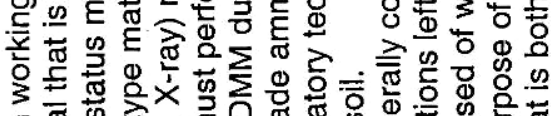

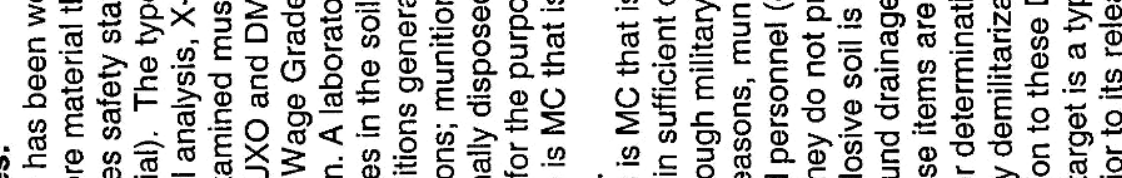

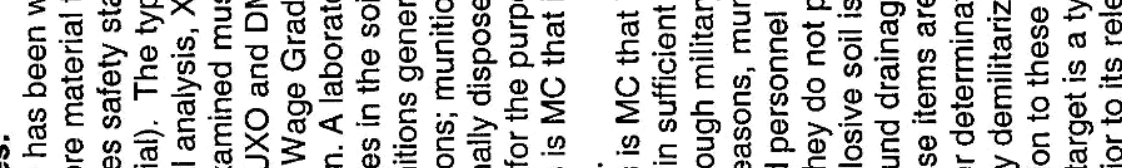

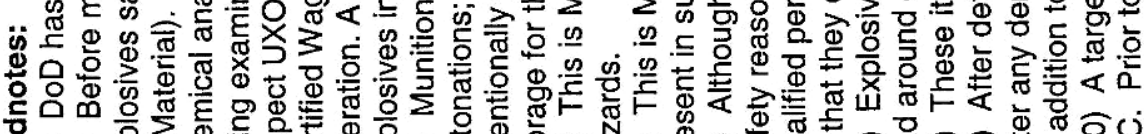

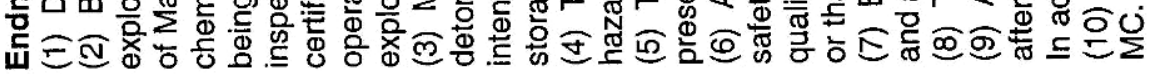




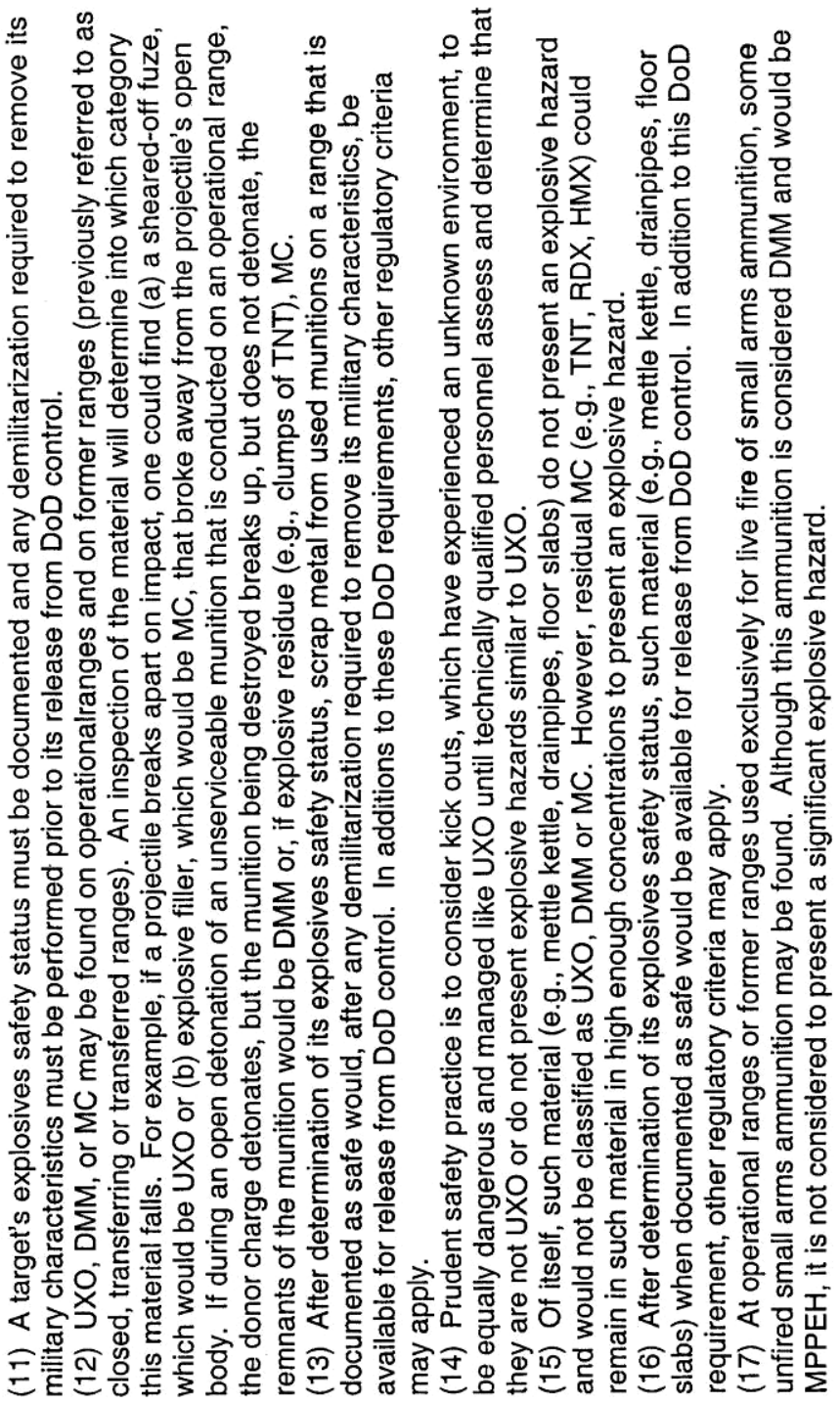




\section{Appendix B: MEC/Dredging Project Planning \\ Flow Chart}




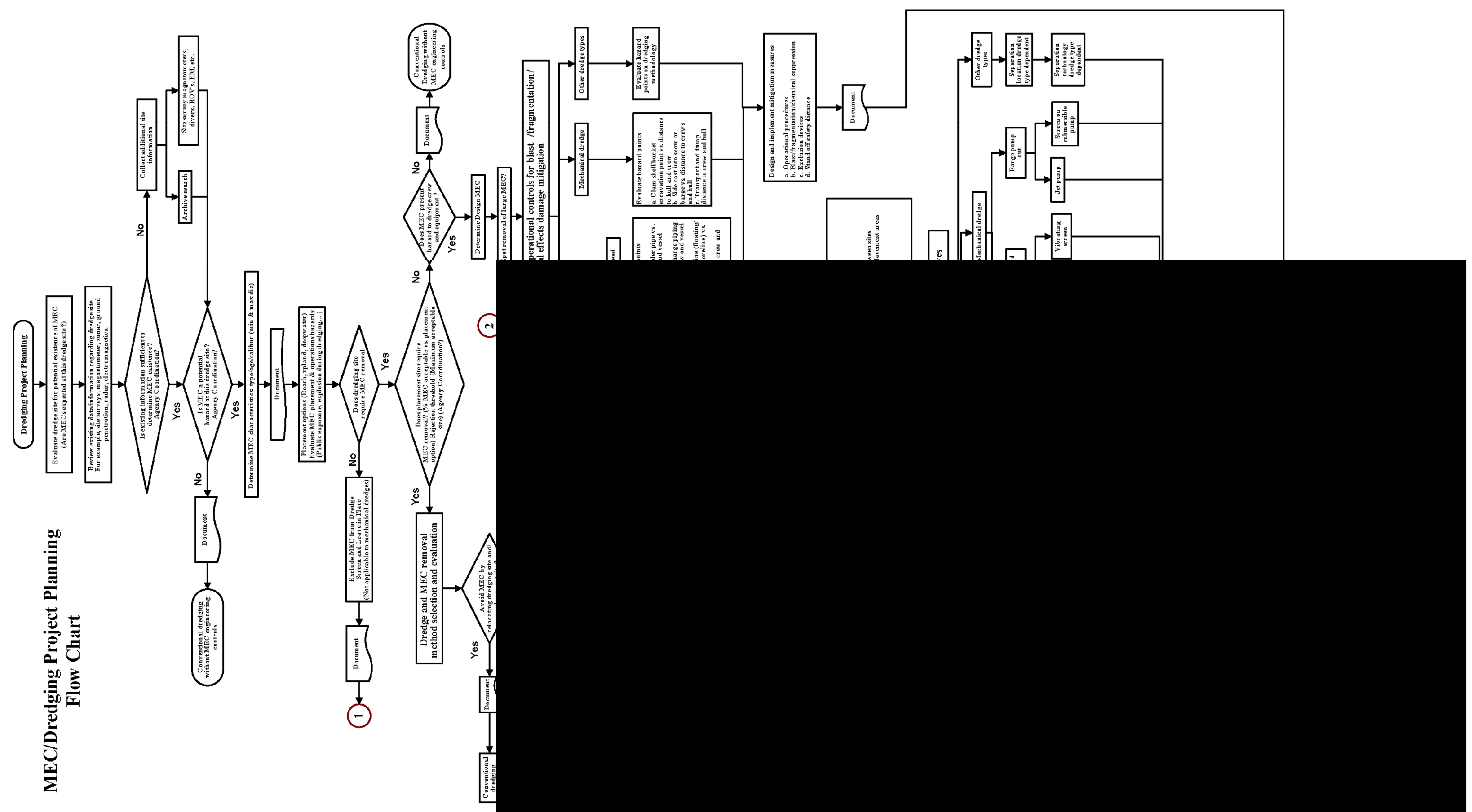




\section{Appendix C: Guide for Commercial Maritime Industries}




\section{Munitions At Sea}

A Guide for Commercial

Maritime Industries

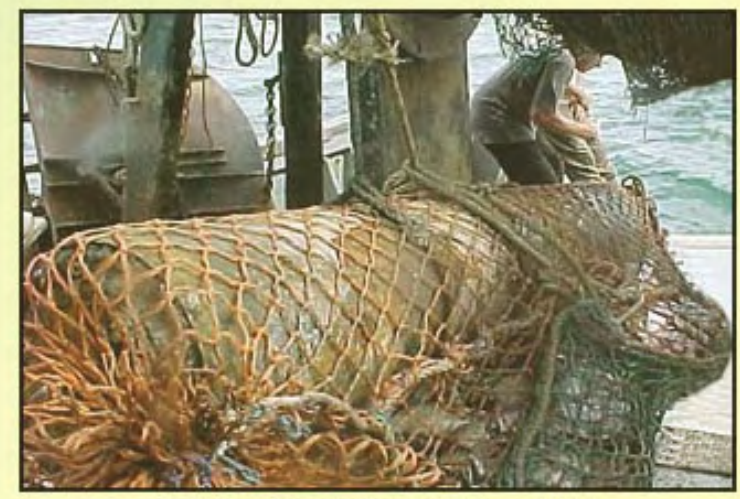

A Munition Caught in a Net

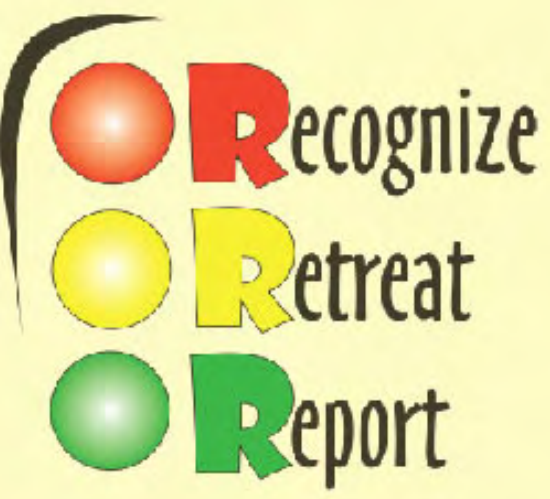


Drring commercialfishing,clamming, or itedging operations, nets, bottomtending gear, and diedges mxy catch or dre dge u mintions from the oce an. The se minitions should be consilered as preserting a serious danger to a vessel and its arew.

Mary ve sse 1 arews tell se a stories about catching suspicious items in the in nets or dre dging gear.

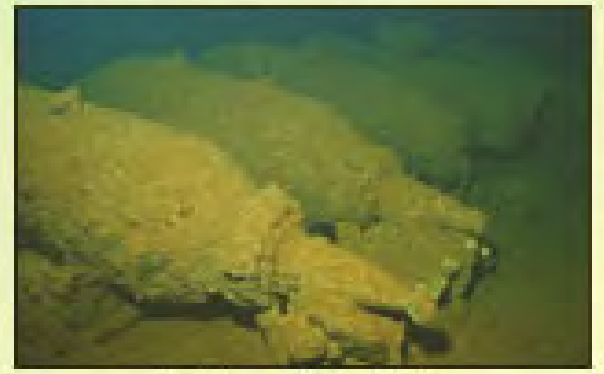

Bombs on thes eobed

The bucky arews live to spin their own tales, while others become the subject. of tragic sea stories.

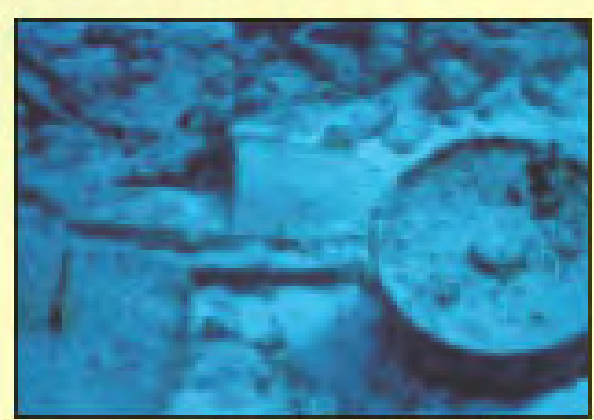

Deth Che rgeon thes obbed'

In July 1965, such a trage dy took place aboard the fishing wessel shoopy. The Shoopy was trawling for scallops off the cost of North Carolina when it caught a large cylinder-shaped tem in its net A witness said he could cle arly see a long round object swaying in the net smidships over the Shoopy.

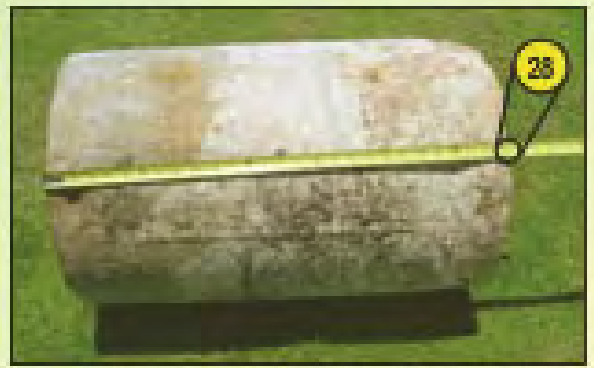

Focovered 'WWII Deth Cha res'

What happene d next is unclear; but an explosion oc curred that $c$ ansed the loss of the Shoopy and eight members of the वew.

What wert wrong? Whs it prevertable? Could something have been done to save the crew? While all the se questions were scked, no one but the crew aboard the Snoopy knows what actually happered that day. However, the tale of the Shoopy is mearingfill if others leam from this trigedy.

(Note: Divers, both commer cial and sport, should also be aware of the harards munitions presert).

Here are some tips on how to respond if you suppect you have encourtered mumitions at sea. Remember the $3 \mathrm{Rs}$ (Re cogrine, Retre at, Report).

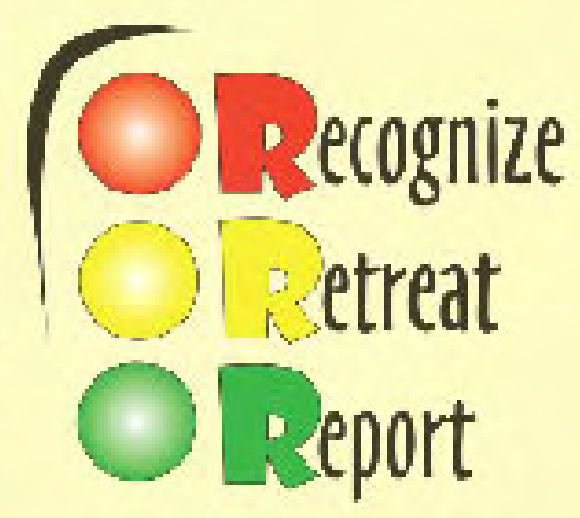




\section{Recognize}

The military has conducted training and combat operations at sea for centuries. Prior to 1970 , the military also sea disposed of excess, obsolete or unserviceable munitions en route to port or as part of planned disposals. In the 1970 s, our military stopped sea disposal of munitions and now only allows it in an emergency. Mariners are cautioned they could encounter munitions anywhere during commercial operations, such as fishing or dredging. Using common sense and basic knowledge, you can spin your own story rather than becoming a character in a tragic sea tale.

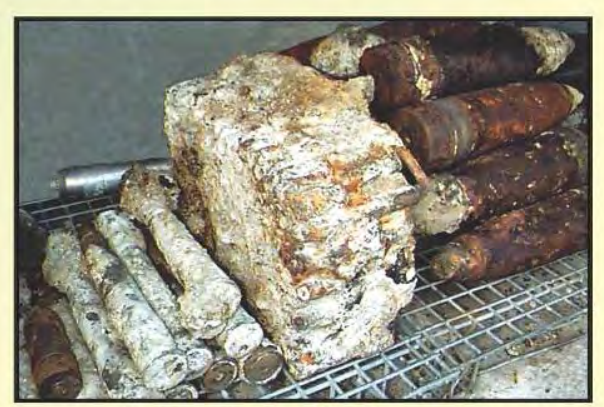

Various Projectiles Recovered from the Water

Munitions can be encountered anywhere, not just in charted hazard areas, at sea. Munitions that crews may encounter include mines, torpedoes, depth charges, artillery shells, bombs and missiles. These munitions can contain high explosives or chemical agents that present a serious danger to a vessel and its crew.

- Munitions, to include those that have been lying dormant in sea or fresh water for many years, are extremely DANGEROUS.
In some cases, munitions that have been in water for long periods may be more sensitive. It is best to avoid handling any suspected or actual munitions recovered from the sea.

- Often, munitions that are discovered on land or recovered from the sea are referred to as "duds" or "UXO" (unexploded ordnance), and such munitions can explode when handled.

- Munitions submerged in sea or fresh water for any length of time may be:

o Like new and easy to identify;

o Heavily encrusted with sea growth and difficult to identify.

\section{MUNITIONS ARE DESIGNED TO BE DANGEROUS}

Munitions are designed to injure, maim, or kill people, or to destroy a vessel or other equipment. The best protection from the hazards associated with munitions is to heed the warnings on nautical charts, avoid known disposal areas and learn the 3Rs (Recognize, Retreat, Report).

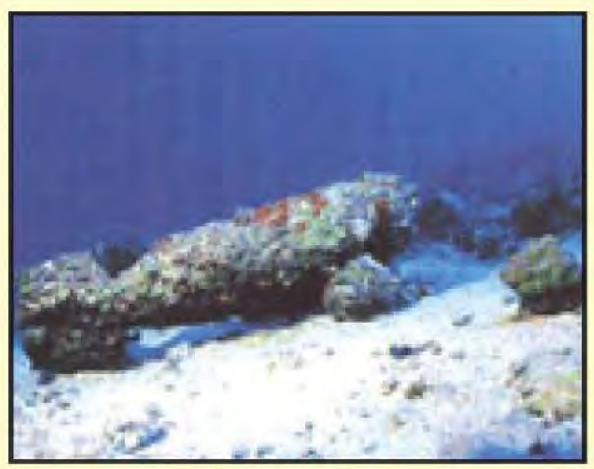

Aerial Bomb on Seabed 
This guide includes drawings representative of various munitions that may be encountered. Drawings may help people recognize suspect munitions.

\section{CHEMICAL MUNITIONS AND CHEMICAL AGENTS}

Beginning in World War I, the Department of Defense (then, the Department of War) designed chemical agents to kill, seriously injure, or incapacitate an enemy. In the past, the United States and other countries sea-dumped both munitions with chemical agent fills and chemical agents in bulk, such as 55 -gallon drums filled with chemical agents. As a result, some munitions or drums recovered from the sea may contain chemical agents.

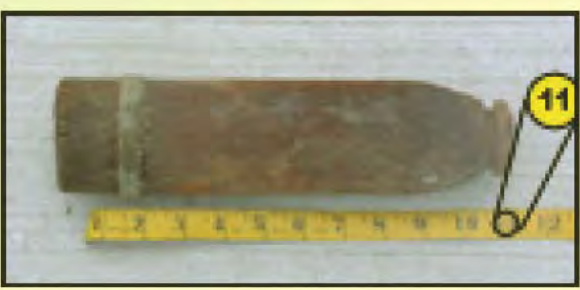

Recovered Chemical Projectile

\section{CHEMICALAGENTS PRESENT A SERIOUS DANGER TO A VESSEL AND ITS CREW}

Vessel crews should be alert for abnormal conditions that may indicate the presence of chemical agents:

- Unusual smells to tackle or fish;

- A stinging sensation in the eyes or burning, irritated skin;

- Corroded containers or suspicious clay-like lumps.

If chemical agents are suspected, immediate action is necessary to protect the crew and vessel.
- Close all doors and hatches;

- Shut down all ventilation systems;

- Steam into the wind to carry contaminants away from the crew;

- Move all crewmembers up wind;

- Contact the US Coast Guard for assistance.

In case of contact with chemical agents, immediately rinse with large amounts of water (if possible, warm soapy water), even if no effects are felt. Crewmembers should not work in a contaminated area and every effort should be made to prevent the spreading of contaminants.

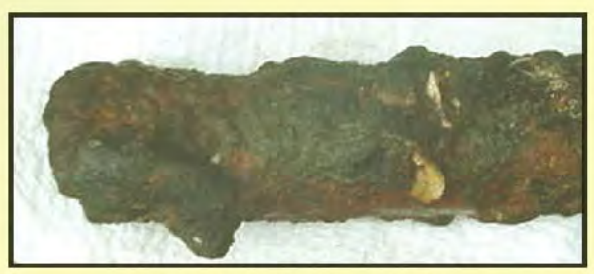

Chemical Filled Projectile Recovered from Clam Beds

Fishing vessels that have come into contact with chemical agents must not bring their catch ashore until it has been checked and released by the appropriate state's Department of Environmental Health. Sea life contaminated by chemical agents is unsuitable for human or animal consumption.

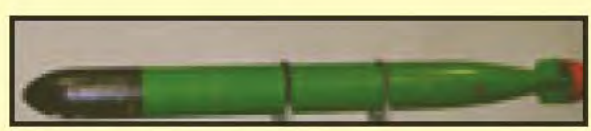

A clean torpedo (top) and a recovered torpedo (bottom)

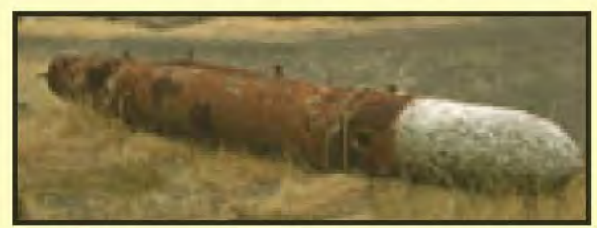




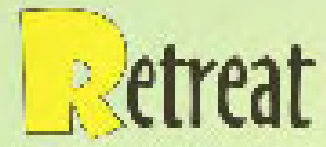

The specific action requied will de pend on the circunstances. However, if possible, arews should aroid bringing munitions (or suppect mmitions) onbosrd. If a munition is foumd, a decision mut be made whether to retre it by car efully jettisoning the munition, outting awry the geir, if necessary or, is a last resort, securing the mmition onboard and moving the aew awry. Great care should be taken to aroid bumping the munition; e ach action carries risk.

\section{NEVER BRING AC TUAL OR SUSPEC T MUNITONS INTOA PORT}

\section{MUNITINS NOT ONB OARD}

If an actual or suspect mmition is recovered:

- Inmediately stop all qerations;

- Do not bring the mintion or gear containing it onboard, if possibl;

- Do not allow the mmition to come or remain along side the vessel where wave action may cause contact with the houll;

- If a manuition is in the gear and has not been brought onbosrd, try to safe ly lower it back into the water and, as indicated be low, note the position and report it to the U.S. Cosit Guard.

- If in shallow water (less than 130 feet), lower the mmition to the bottom, buoy off the net or tre dge re covery lines (remain in the inme diate are a).
- If in deep water, stream the murition as fir aft as possble and maintain ste erageway as necessary. Remain in the area while anditing assistance .

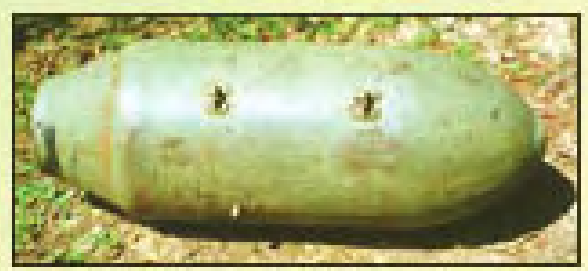

Adeon Aoris I Bomb (top) Q reovored herial Bomb (bottom)

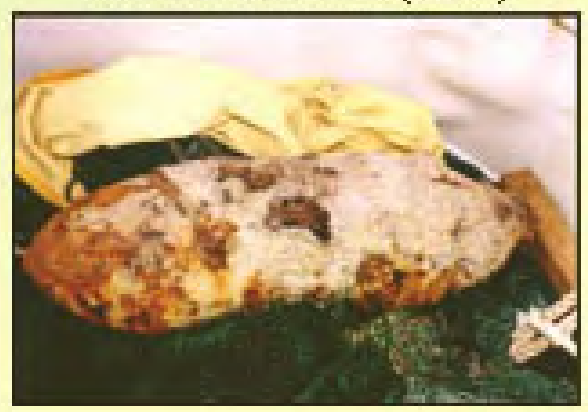

\section{MUNITIONS ONB OARD}

If an actual or suspected muntion in the gear is brought ower the deck, but remains supended and can continue to be safely susperded in place or ne arby, inmme diately:

- Secure the munition with guy lines to prevent further movemert;

- Keep the crew away from that area.

If a suspect manition is brought anboard:

- Keep uncee ded aew members as far awayasposstle.

- Decide whe ther to do one of the followirg:

- Carefully jettison $\mathbf{t}$, or

- Rutain i auboard

- If jettioned, note postian and report it 
- If retained onboard:

- Limit handling and anoid hilting or berding ary part of the manition;

- Stow the mantion on deck as far away as possible from heat sources, vitration and the an, but limithandling;

- Finnly chock and hast the munitian to preserent mosement;

- Cover andior wet to minimize the potertialfa:

- Deterioration of metalparts andrels ase of ant fill;

- Explosires to dy out and become serstise to shock.

- Ke cp cew away from item.

- Request assistarce. (Chammel $16-156.800 \mathrm{MHz})$

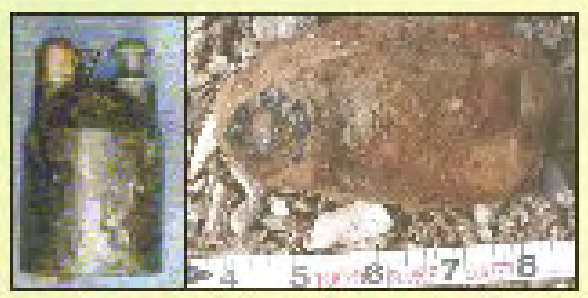

Fran ch Fillo Gronod on good cond tion (bt) and o rooverod gren ads (right)

If within 2 or 3 hours of land, the safest measure is to notify the US Cosst Guard and move to a rende zwous are a offshore.

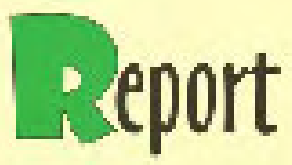

Carefulobservation is necessary prior to reporting, so that proper instructions and assistance can be provided. The inf onmation youprovide may also be comb ine d wifl other reports to produce new wamings to mariners and udate nautic al charts.
When actual or suppect mmitions are encountered at sea, the vessel's captain should ensure the US Cost Guard is notified and proviled the be low information, as soon as possible. (Note: If a munition is encountered while in port [e g., during off losding or processing] call 911.)

- The vessel's position (use World Geodetic System 1984 [WGS-84] for reporting).

- If the exact position is unkrown, give approximate coordinates, or a range and be aring from a charted fe atine.

- The activity being conducted when the minition was encountered (e.g., fishing, dredging).

- A general desciption of the mmition's key features (sine, shape, fins, props, mark ings) and condition (Never attempt to cle an the munition for idertific stion punposes, open it, or tamper with it in any way).

- The action taken (e.g. stowed or jettisoned).

- If jettisoned, also provide:

- The position of the re lease, water depth, and buoys or markings used;

- Adesaption of aryertangl. mert (e g.ret, dredge) or ather datals.

- Ary mrossual odors, if noticed.

- Whether the mmition was jettisoned:

- Ir or near a charted mmitions dump;

- Hear (within 1 p00 yards of) any sufface or sub-sirface structures. 

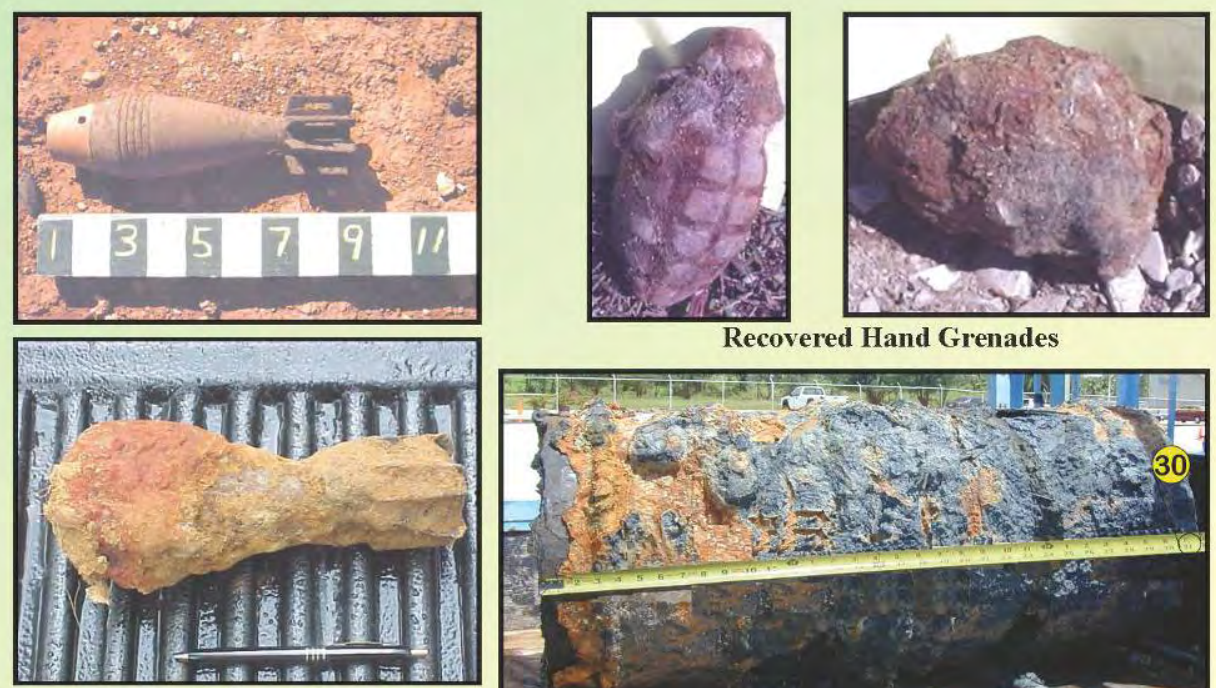

Recovered $60 \mathrm{~mm}$ Mortars

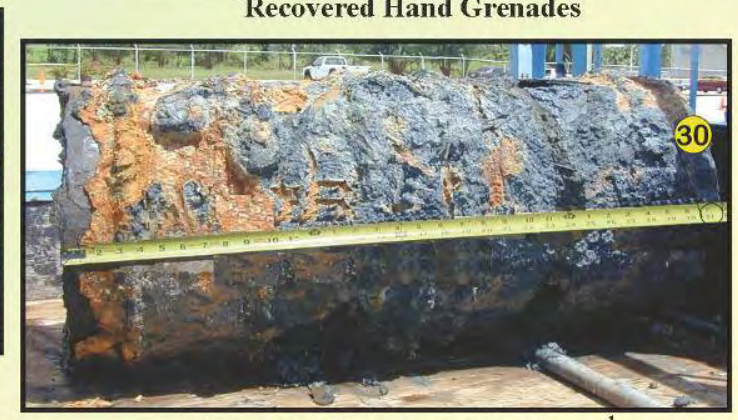

Recovered Fragmentation Bomb ${ }^{1}$

THE US COAST GUARD WILL NOTIFY THE APPROPRIATE MILITARY EXPLOSIVE ORDNANCE DISPOSAL UNIT TO ARRANGE FOR REQUIRED SUPPORT
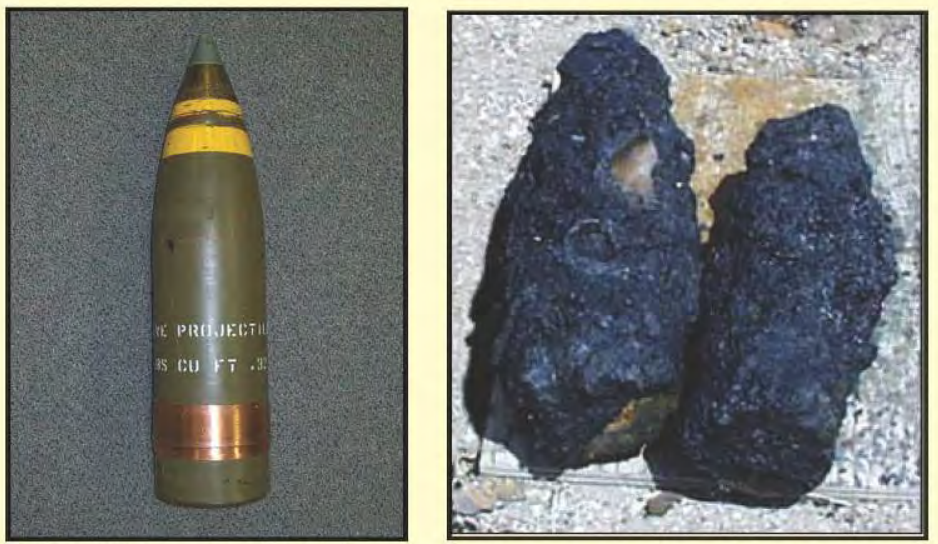

A clean 5-inch 38 Caliber Projectile (Left) and recovered 5-inch 38 Caliber Projectiles (Right)

${ }^{1}$ Photographs Courtesy of AMPRO Consultants.

${ }^{2}$ A Fisherman's Guide to Explosive Ordnance, UNC Sea Grant College Publication UNC-SG-81-05, May 1981. 

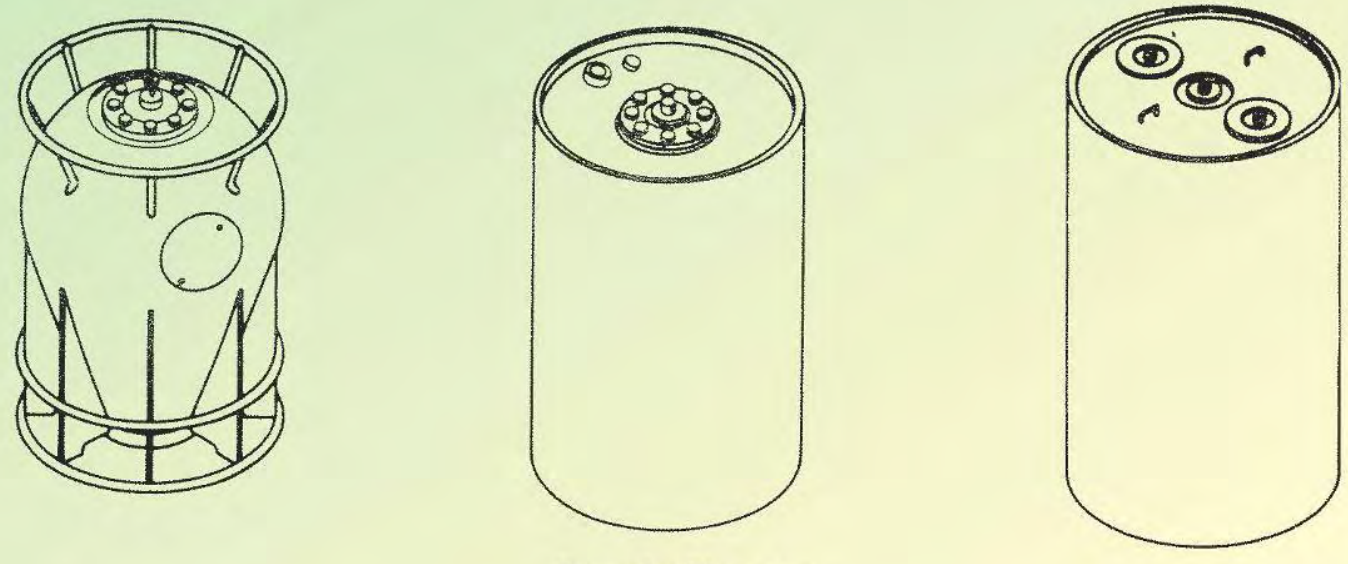

Depth Charges Length 28 "

Diameter 18 " to 25 "

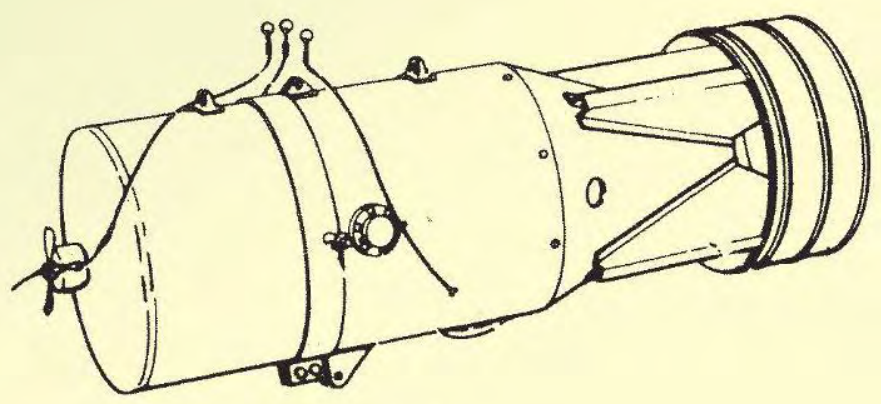

Depth Bomb

Length 50 "to 59 "

Diameter 15 " to 18 "

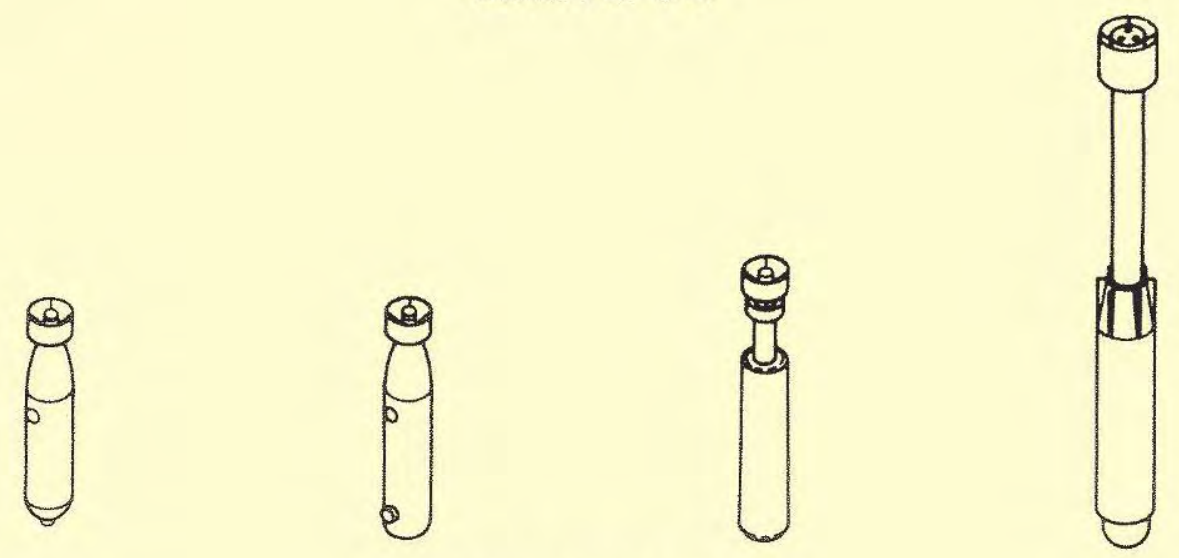

\section{Practice Depth Charges}




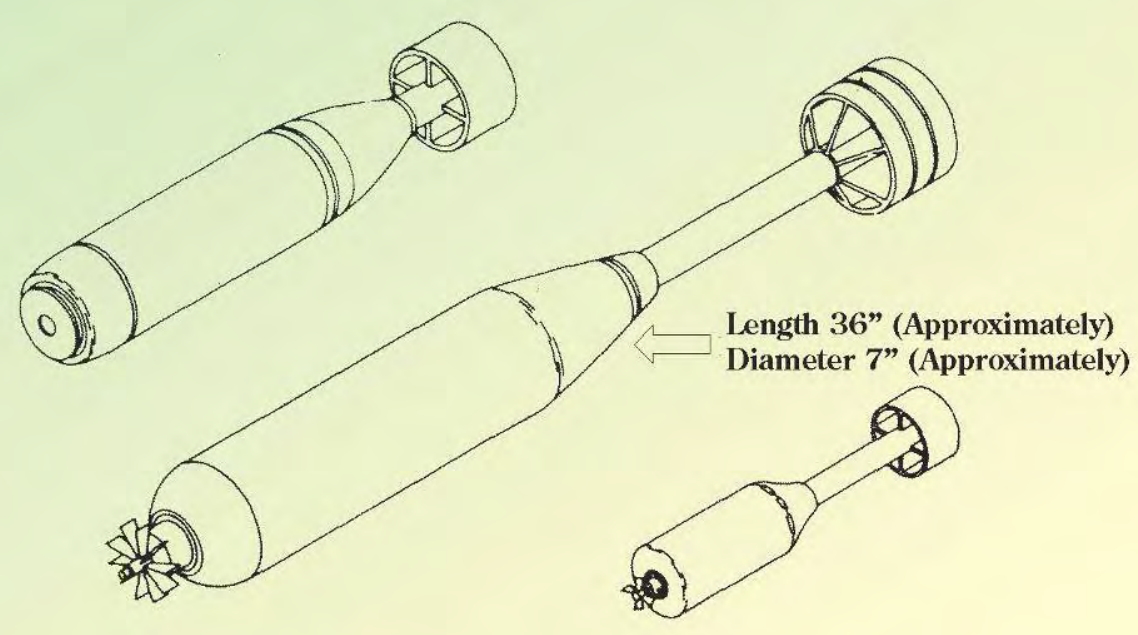

Projected Anti-Submarine-Warfare Weapons

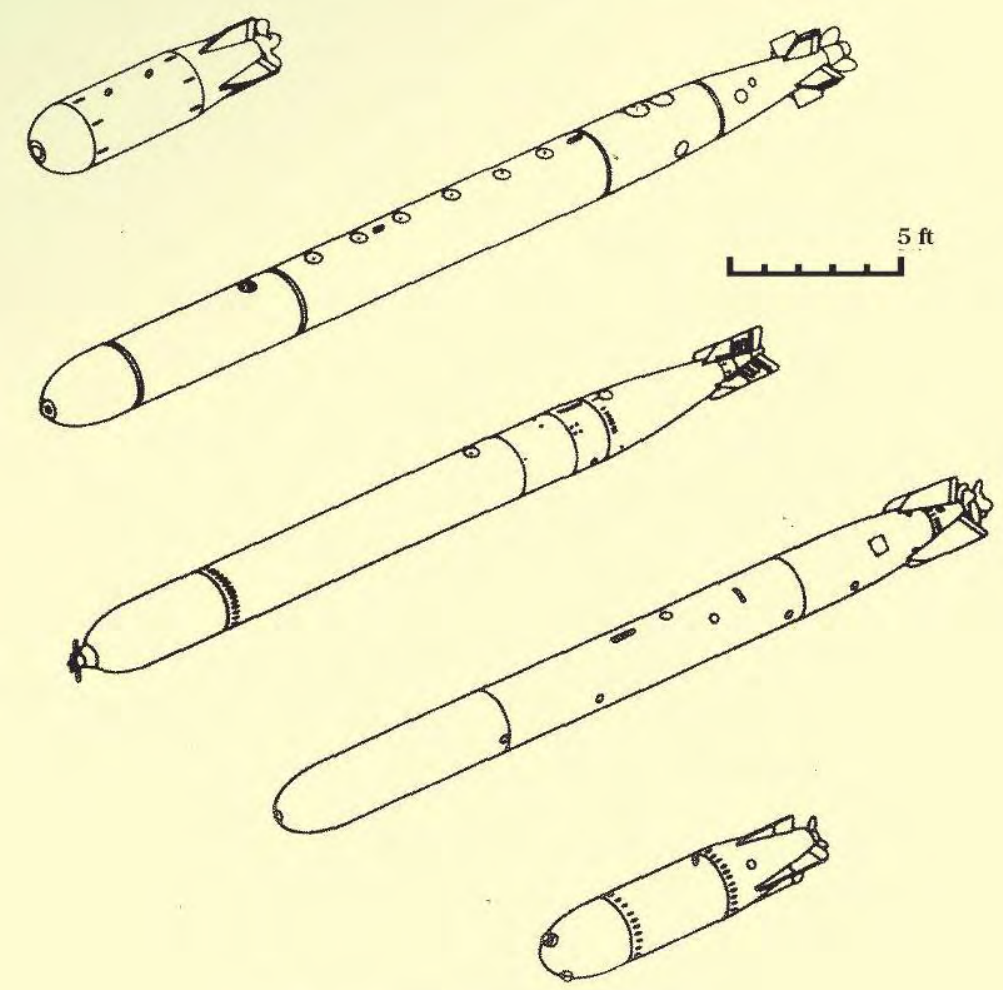

Representative Torpedoes 

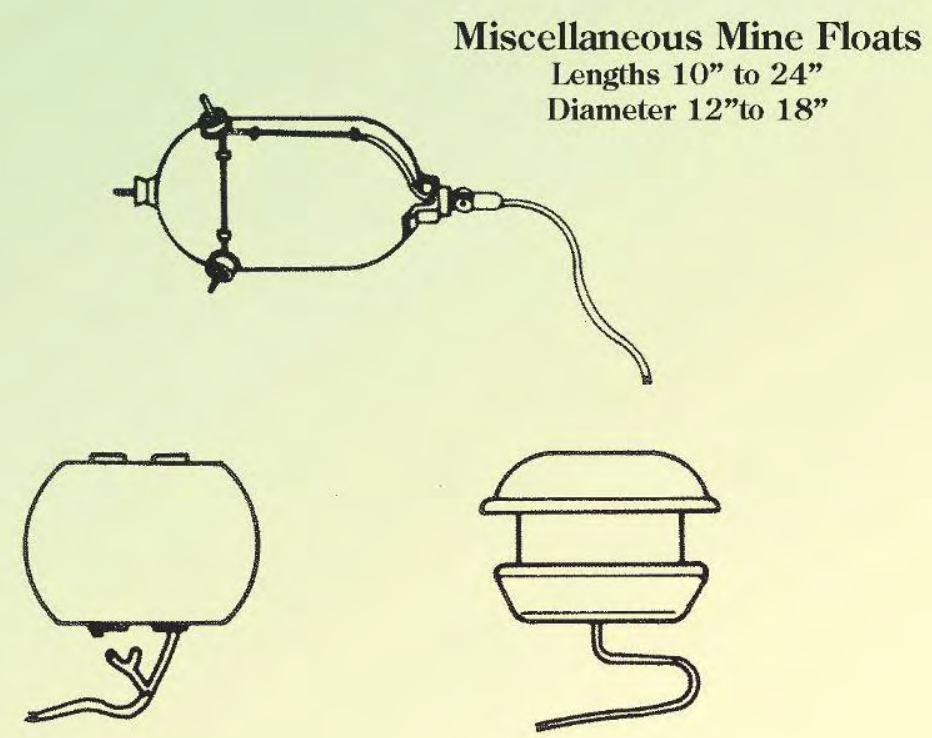

Miscellaneous Mine Floats

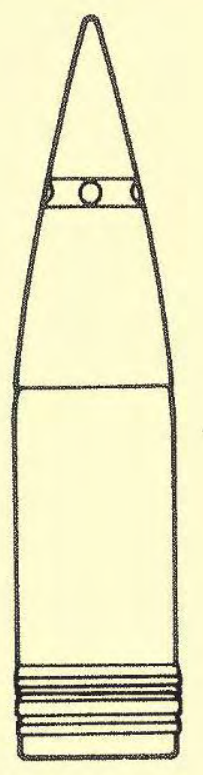

Projectiles

Diameter $20 \mathrm{~mm}$ to 16 "

(Normally 3 " to 5 " in Diameter)
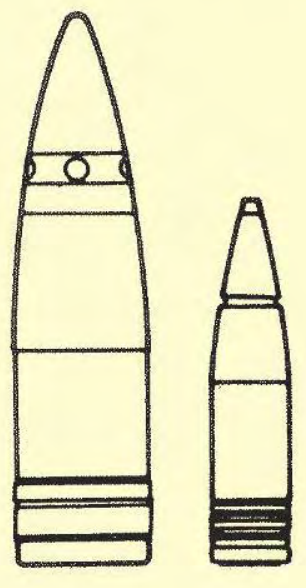

Projectiles 


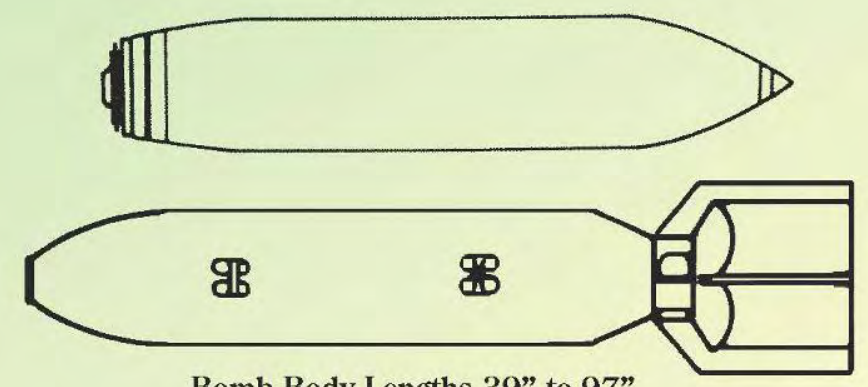

Bomb Body Lengths 39" to 97" Diameter 7" to 19 "

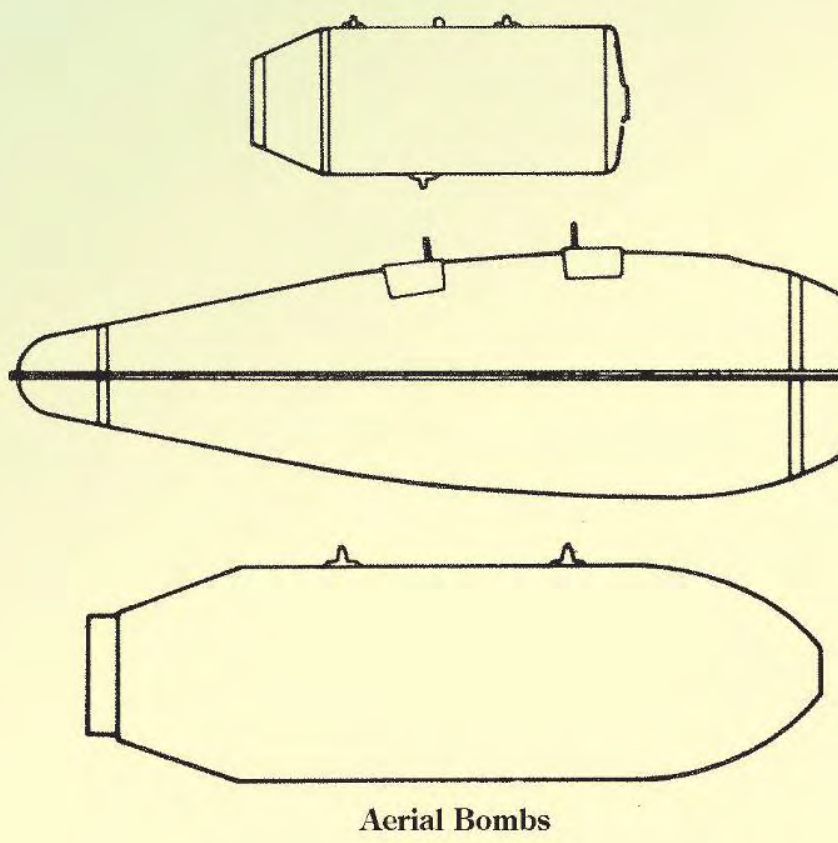

8

Markers and Signals Lengths 10" to 18" (Approximately) Diameter 2" to 5" (Approximately)
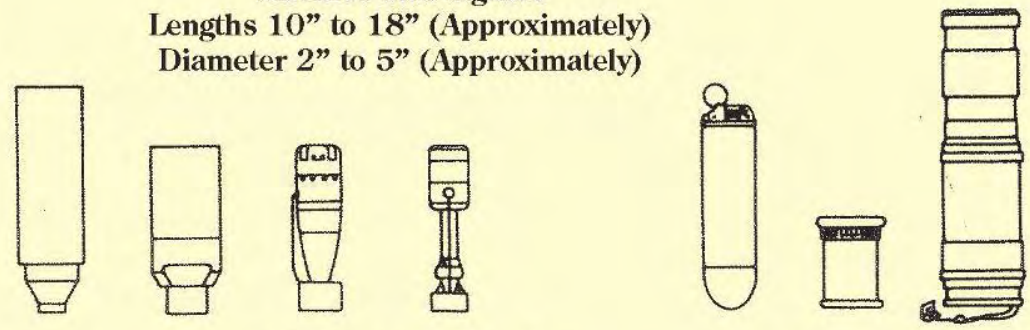

Markers and Signals 


\section{DON'T FORGET}

Munitions are dangerous, and may not be easily recognizable!

Avoid known explosives disposal areas!

Do not bring munitions on-board!

Avoid physical contact, if possible, but minimize handling to that needed to protect the vessel and crew!

Never bring a munition into port, unless directed to do so by USCG!

\section{REMEMBER THE 3Rs}

RECOGNIZE: Recognize when you may have encountered a munition.

RETREAT: If you know or suspect you have encountered a munition, jettison it or secure it and keep the crew out of the immediate area.

REPORT: Immediately notify the US Coast Guard of the vessel's or munition's location and provide a description of the munition. Emergency contacts:

- In Port: Call 911

- At sea: Use Channel 16 (156.800 MHz)

For additional information on this and related issues see the USArmy's UXO Safety Education Website www.denix.osd.mil/UXOSafety

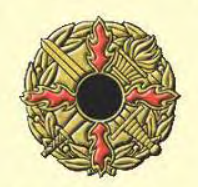

Prepared by the Defense Ammunition Center

U.S. Army Technical Center for Explosives Safety (USATCES)

(918) 420-8919 


\section{Appendix D: List of Acronyms}

\begin{tabular}{|c|c|}
\hline AETC & Arete Engineering Technologies Corporation \\
\hline ARAMS & Army Risk Assessment Modeling System \\
\hline BIP & Blow-in-place \\
\hline CAD & Confined aquatic disposal \\
\hline CDF & Confined disposal facility \\
\hline CEHNC & U.S. Army Engineering and Support Center, Huntsville \\
\hline CFR & Code of Federal Regulations \\
\hline $\mathrm{COG}$ & Course over ground \\
\hline CRREL & U.S. Army Cold Regions Research and Engineering Laboratory \\
\hline CSDRP & Coastal Storm Damage Reduction Project \\
\hline DDESB & Department of Defense Explosives Safety Board \\
\hline DENIX & Defense Environmental Network and Information Exchange \\
\hline DERP & Defense Environmental Restoration Program \\
\hline DGPS & Deferential Global Positioning System \\
\hline DMM & Discarded military munitions \\
\hline DoD & Department of Defense \\
\hline DOER & Dredging Operations and Environmental Research \\
\hline DSC & Dredging Supply Company, Inc. \\
\hline $\mathrm{EE} / \mathrm{CA}$ & Engineering evaluation/Cost analysis \\
\hline EM & Electromagnetics \\
\hline EM & Engineer Manual \\
\hline EMI & Electromagnetic Induction \\
\hline EOD & Explosive ordnance disposal \\
\hline EP & Engineer Pamphlet \\
\hline ER & Engineer Regulation \\
\hline ERDC & U.S. Army Engineer Research and Development Center \\
\hline ERF & Eagle River Flats \\
\hline ESS & Explosive Safety Submission \\
\hline ESTCP & Environmental Security Technology Certification Program \\
\hline fsw & Feet of seawater \\
\hline FUDS & Formerly Used Defense Site \\
\hline G\&A & General and Administrative \\
\hline GIS & Geographic Information System \\
\hline
\end{tabular}




\begin{tabular}{|c|c|}
\hline GLDD & Great Lakes Dredge and Docks \\
\hline GPR & Ground penetrating radar \\
\hline GPS & Global Positioning System \\
\hline GUI & Graphical User Interface \\
\hline HFA & Human Factors Applications, Inc. \\
\hline $\mathrm{HMI}$ & Hart Miller Island \\
\hline HUXOS & HeuvelmanUxoMixtureSeparator \\
\hline MD & Munitions debris \\
\hline MEC & Munitions and explosives of concern \\
\hline MGA & Marine Gradiometer Array \\
\hline MGFD & Greatest fragment distance \\
\hline MMDC & Military Munitions Design Center \\
\hline MMTC & Marine Mineral Technology Center \\
\hline MMRP & Military Munitions Response Program \\
\hline MPPEH & Material Potentially Presenting a Explosive Hazard \\
\hline MTA & Marine Towed Array \\
\hline MTADS & Multi-Sensor Towed Array Detection System \\
\hline NAVFAC & Naval Facilities Engineering Command \\
\hline NAVSTA & Naval Station \\
\hline nT & nanoTeslas \\
\hline NOSSA & Naval Ordnance Safety and Security Activity \\
\hline OE & Ordnance and explosives \\
\hline OEW & Ordnance and explosive waste \\
\hline OSHA & Occupational Safety and Health Administration \\
\hline OTU & Ordnance test unit \\
\hline QC & Quality control \\
\hline RDX & Cyclotrimethylenetrinitramine \\
\hline ROICC & Resident Officer in Charge of Construction \\
\hline ROV & Remotely operated vehicle \\
\hline RTK & Real Time Kinematic \\
\hline SAG & Speed over ground \\
\hline SMEC & Simulated MEC \\
\hline SONAR & Sound Navigation and Ranging \\
\hline SERDP & Strategic Environmental Research and Development Program \\
\hline SSHP & Site Specific Health and Safety Plan \\
\hline SSS & Side-scan sonar \\
\hline
\end{tabular}




\begin{tabular}{|l|l|}
\hline TNT & trinitrotoluene \\
\hline USACE & U.S. Army Corps of Engineers \\
\hline USATCES & U.S. Army Technical Center for Explosives Safety \\
\hline USEMS & Underwater Simultaneous Electromagnetic Magnetometer System \\
\hline UXO & Unexploded ordnance \\
\hline WP & White phosphorous \\
\hline WW & World War (I or II) \\
\hline
\end{tabular}




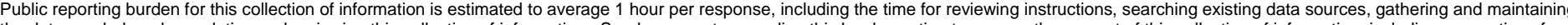

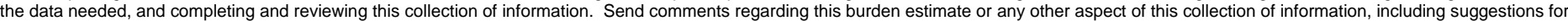

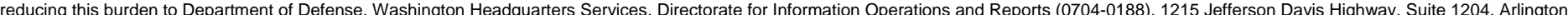

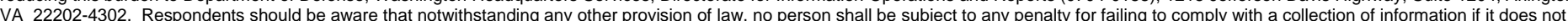
display a currently valid OMB control number. PLEASE DO NOT RETURN YOUR FORM TO THE ABOVE ADDRESS.

\section{REPORT DATE (DD-MM-YYYY) August 2008}

\section{TITLE AND SUBTITLE}

Dredging in Sediments Containing Munitions and Explosives of Concern (MEC)

\section{AUTHOR(S)}

Timothy Welp, George Follett, Michelle Crull, and Cheryl Pollock
3. DATES COVERED (From - To)

5a. CONTRACT NUMBER

5b. GRANT NUMBER

5c. PROGRAM ELEMENT NUMBER

5d. PROJECT NUMBER

200321

5e. TASK NUMBER

5f. WORK UNIT NUMBER

8. PERFORMING ORGANIZATION REPORT NUMBER

ERDC/CHL TR-08-12

See reverse.

10. SPONSOR/MONITOR'S ACRONYM(S)

ERDC, ESTCP, DOER

Environmental Security Technology Certification Program

901 North Stuart Street, Suite 303

Arlington, VA 22203

11. SPONSOR/MONITOR'S REPORT NUMBER(S)

\section{DISTRIBUTION I AVAILABILITY STATEMENT}

Approved for public release; distribution is unlimited.

\section{SUPPLEMENTARY NOTES}

\section{ABSTRACT}

This document provides guidance to personnel (e.g., planners, cost estimators, specification writers, engineers, managers, and dredging contractors) involved in dredging projects with sediment containing Munitions and Explosives of Concern (MEC). The guidance is primarily in the form of compiled information gained from experiences on past dredging projects involving MEC and was compiled from a variety of sources. This report describes the different types of dredges and dredging projects that can encounter MEC, describes how these dredges’ operational methodologies can be impacted by MEC, and summarizes past project methodology modifications that have been used to deal with MEC. Technical aspects of past MEC/dredging projects are presented with regard to engineering controls to mitigate detonation hazards, underwater MEC detection and discrimination technologies, contracting, public awareness, safety requirements, and MEC separation techniques and (where available) subsequent impacts on production rates and costs.

\begin{tabular}{|ll|}
\hline 15. SUBJECT TERMS & Hopper dredge \\
Cutterhead dredge & Mechanical dredge \\
Dredging & Military munitions \\
\hline
\end{tabular}

16. SECURITY CLASSIFICATION OF:

\begin{tabular}{|l|l|l|}
\hline $\begin{array}{l}\text { a. REPORT } \\
\text { UNCLASSIFIED }\end{array}$ & $\begin{array}{l}\text { b. ABSTRACT } \\
\text { UNCLASSIFIED }\end{array}$ & $\begin{array}{l}\text { c. THIS PAGE } \\
\text { UNCLASSIFIED }\end{array}$ \\
\hline
\end{tabular}

Munitions and Explosives of Concern (MEC)

Unexploded ordnance (UXO)

\begin{tabular}{|l|} 
17. LIMITATION \\
OF ABSTRACT
\end{tabular}

\begin{tabular}{|c|c|}
$\begin{array}{c}\text { 18. NUMBER } \\
\text { OF PAGES }\end{array}$ & $\begin{array}{c}\text { 19a. NAME OF RESPONSIBLE } \\
\text { PERSON }\end{array}$ \\
\cline { 2 - 2 } 240 & $\begin{array}{c}\text { 19b. TELEPHONE NUMBER } \\
\text { (include area code) }\end{array}$ \\
&
\end{tabular}


7. PERFORMING ORGANIZATION NAME(S) AND ADDRESS(ES) (Concluded)

U.S. Army Engineer Research and Development Center, Coastal and Hydraulics Laboratory

3909 Halls Ferry Road, Vicksburg, MS 39180-6199;

U.S. Army Corps Engineer District, Baltimore,

City Crescent Building

10 South Howard Street, Room 11000

Baltimore, MD 21201-2555MD;

U.S. Army Engineering and Support Center, Huntsville 4820 University Square

Huntsville, AL 35807-4301 